\title{
A TAXONOMIC REVISION OF THE ORIENTAL WATER STRIDER GENUS VENTIDIUS DISTANT (HEMIPTERA, GERROMORPHA, GERRIDAE)
}

Chen, P. P. \& H. Zettel, 1999. A taxonomic revision of the oriental water strider genus Ventidius Distant (Hemiptera, Gerromorpha, Gerridae). - Tijdschrift voor Entomologie 141 [1998]: 137-208, figs. 1-266, maps 1-6, tables 1-3. [ISsN 0040-7496]. Published 1 March 1999. The Oriental water strider genus Ventidius Distant is redescribed and revised. The morphological characters of Ventidiopsis Miyamoto and Esakia Lundblad and their relationships with Ventidius are discussed. Ventidiopsis Miyamoto is ranked as a subgenus of Ventidius (stat. n.). Six species are described as new: Ventidius (s. str.) longitarsus sp. n. from Viet Nam, $V$. (s. str.) pilosus sp. n. from Indonesia (Nusa Tenggara Timur, Nusa Tenggara Barat), V. (s. str.) polhemorum sp. n. from Malaysia (Sabah, Sarawak), V. (Ventidioides) heissi sp. n. from Malaysia (Sarawak), V. (Ventidioides) nieseri sp. n. from Brunei, Malaysia (Sarawak) and Indonesia (Kalimantan), and $V$. (Ventidiopsis) yangae sp. n. from Malaysia (Sabah). The following species are redescribed: Ventidius (s. str.) aquarius Distant, $V$. (s. str.) usingeri Hungerford \& Matsuda, $V$. (s. str.) harrisoni Cheng, $V$. (s. str.) malayensis Hungerford \& Matsuda, $V$. (s. str.) henryi Esaki, $V$. (s. str.) hungerfordi Cheng, $V$. (s. str.) werneri Hungerford \& Matsuda, $V$. (s. str.) modulatus Lundblad, V. (Ventidioides) kuiterti Hungerford \& Matsuda, V. (Ventidioides) karen Lansbury, V. (Ventidioides) pulai Cheng, V. (Ventidioides) lundbladi Miyamoto, V. (Ventidioides) xiphibion Chen \& Nieser, V. (Ventidioides) xyele Chen \& Nieser. V. (Ventidioides) kurtokalami Chen $\&$ Nieser, and $V$. (Ventidiopsis) imadatei Miyamoto. Type specimens of most species were re-examined, except those of $V$. (s. str.) distanti Paiva, $V$. (s. str.) sushmae Gupta, and $V$. lundbladi, which were unavailable. The following taxa are considered as synonyms (junior synonyms in brackets): Ventidius (s. str.) hungerfordi Cheng (= Ventidius wallacei Lansbury, syn. n.), $V$. (s. str.) modulatus Lundblad (=V. pubescens Cheng, syn. n., = V. chinai Hungerford \& Matsuda, syn. n.). V. sushmae Gupta is regarded as a nomen inquirendum. One new combination is established: Ventidius (Ventidiopsis) imadatei Miyamoto, comb. n. The identity of $V$. dis tanti is discussed. A lectotype of $V$. modulatus Lundblad is designated.

The species are arranged in three subgenera and five species groups: Ventidius (s. str.): V. aquarius-group, V. modulatus-group; Ventidius (Ventidioides): V. kuiterti-group, V. xiphibion-group; Ventidius (Ventidiopsis): V. imadatei-group. Descriptive notes and illustrations of pertinent characters are presented for all species. Tables of measurements and an identification key for apterous males of all described species are presented.

Correspondence: Pingping Chen, c/o Naturhistorisches Museum Wien, Zweite Zoologische Abteilung, A-1014 Wien, Austria.

Key words. - Gerridae; Ventidius; revision; new species; distribution; identification key; Oriental region.

\section{Contents}

Introduction . . . . . . . . . . . . . . . . 137

Notes on relationships . . . . . . . . . . . . . . . . . . . . . . . . . . . . . . . . . .

Checklist . . . . . . . . . . . . . . . . . . . 139

Material and methods . . . . . . . . . . . . 140

List of depositories . . . . . . . . . . . . . . . . . . . . . . . . . . . . . . . . . . .

Acknowledgements . . . . . . . . . . . . 141

Taxonomy . . . . . . . . . . . . . . . . . 141

Genus Ventidius Distant. . . . . . . . . . . . . . . 141

Key to the subgenera of Ventidius. . . . . . . . . . . 144
Subgenus Ventidius Distant . . . . . . . . . . . . . . . . . 144

The Ventidius aquarius-group. . . . . . . . . . . . . 148

The Ventidius modulatus-group . . . . . . . . . . 157

Subgenus Ventidius (Ventidioides) Hungerford \&

Matsuda... . . . . . . . . . . . . . . . . 176

The Ventidius kuiterti-group. . . . . . . . . . . . . . . . . . . 178

The Ventidius xiphibion-group . . . . . . . . . . 188

Subgenus Ventidius (Ventidiopsis) Miyamoto . . . 199

The Ventidius imadatei-group . . . . . . . . . . . 199

References ... . . . . . . . . . . . . . . . . . 204

Tables ... . . . . . . . . . . . . . . . . . . 206 


\section{INTRODUCTION}

This revision deals with the species of the Oriental water strider genus Ventidius Distant, 1910, which was last revised by Hungerford \& Matsuda (1960). Ventidius was established by Distant for a Halobatine gerrid from 'Travancore, India', which he named Ventidius aquarius (Distant 1910a: 150). In the same year, Distant (1910b: 157) figured both macropterous and apterous specimens of the same species.

Bergroth (1911) considered Ventidius a synonym of Metrocoris Mayr, which was corrected by Esaki (1929). Paiva (1918) described $V$. distanti from 'Yawnghwe State' (today belonging to Myanmar), a species which was misinterpreted several times by the following authors: Dover (1929), Esaki (1930), Hungerford \& Matsuda (1960). Esaki (1928) and Lundblad (1933) described two further species, $V$. henryi Esaki from Sri Lanka and $V$. modulatus Lundblad from Java.

Hungerford \& Matsuda (1960) revised the genus, recognizing nine species, including five new species from Myanmar (Burma), Malaysia, and the Philippines. Beside giving excellent pictures of the dorsal view of all the nine species, they also presented figures for characters of the new species ( $V$. malayensis, $V$. usingeri, $V$. werneri, $V$. chinai, and $V$. kuiterti). They also divided the genus into two subgenera: Ventidius (s. str.) and Ventidioides Hungerford \& Matsuda, 1960 (type species: $V$. kuiterti) according to four characters: shape of posterolateral angle of metacetabula bilobate or transverse; fore femur with or without a tubercle; mesosternum with or without a tubercle; and parameres large or small and asymmetrical or symmetrical. Matsuda (1960) gave an extensive morphological description for the genus and set it close to the Madagassian genus Eurymetropsielloides Poisson 1956, and the Oriental genus Esakia Lundblad 1933, and within the newly established tribe Metrocorini Matsuda 1960. Cheng (1965) reviewed the Ventidius species of Malaysia and Singapore and described four species as new from this area: Ventidius pulai, $V$. harrisoni, $V$. hungerfordi, and $V$. pubescens.

Since that time, only smaller notes on Ventidius and sporadic descriptions of new species have appeared. Miyamoto (1967) added V. lundbladi as a new species from Thailand, and Ventidius sushmae was described by Gupta (1981) from India (here regarded as a nomen inquirendum). Andersen (1982) figured the distribution of Metrocorini, indicating that its range in the Malay archipelago is limited by the Wallace's Line. Later on, several species of Ventidius and Metrocoris were described from Sulawesi. Lansbury (1990) described $V$. (Ventidioides) karen from Thailand, and $V$. (s. str.) wallacei from Malaysia, the latter a synonym of $V$. hungerfordi (syn. n.). Three new species of the sub- genus Ventidioides, V. kurtokalami (from Sabah), V. xiphibion, and $V$. xyele (both from Sulawesi), were described by Chen \& Nieser (1992), increasing the number of species to 20. Kovac \& Yang (1989) and Yang \& Kovac (1995) reported new records of $V$. malayensis, $V$. harrisoni, $V$. hungerfordi, $V$. pulai and $V$. modulatus from the Malaysian Provinces of Pahang and Perak, respectively. Finally, Thirumalai (1996) reported $V$. (Ventidioides) kuiterti as a new record from NE India.

The genus Ventidiopsis was erected by Miyamoto (1967) for the single species Ventidiopsis imadatei Miyamoto 1967, from Borneo. Because of close relationship between Ventidiopsis and Ventidioides, both taxa are regarded as subgenera of Ventidius in the present study.

Since the genus Esakia, which here is regarded as the genus most closely related to Ventidius, was described by Lundblad (1933), six species were described from Myanmar (Burma), Malaysia, Borneo (Brunei), and the Philippines (Luzon) (Cheng 1966, Hungerford \& Matsuda 1958, Miyamoto 1967). Further new species are known to the authors from Viet Nam, Borneo, and the Philippines (Palawan). In the present study, Esakia ventidioides Lundblad 1933, from Sumatra (Lundblad 1933) was checked.

The Madagassian genus Eurymetropsielloides, which is according to Matsuda (1960) the sister taxon of Ventidius+Esakia, differs from both of these genera by the metacetabula having strongly downcurved posterolateral corners (plesiomorphic character) and an unusual colour pattern (apomorphic character) (see also Matsuda 1960).

In the present taxonomic revision we recognize 24 species of Ventidius, including six new species described from Viet Nam, Borneo and Indonesia (Sumba, Sumbawa). They are arranged in three subgenera and five species-groups (see following check-list).

Ventidius species are small, black and green (turns to yellowish after death) water striders which are typical inhabitants of slow-flowing forest streams in South and Southeast Asia. Their preferred habitats are-as far as we know for a few species-lotic areas of brooks, streams and rivers, where they stroke and glide across the surface. Because of their preference for the slowflowing streamlets, Ventidius are mainly encountered in hilly and lowland areas. The life history of Ventidius species is unknown. Murphy (1990) described the habitat in Singapore of $V$. (s. str.) hungerfordi Cheng as follows: 'The outflow stream of the Nee Soon swamp forest is small but fairly recent alluvia, and is deeply shaded. Here the open water is populated by Ventidius harrisoni and Rheumatogonus intermedius, sandbanks by Amemboa riparia and Tenagogonus quiquemaculata and under the overhanging root mats the tiny haloveliinae Strongilovelia occurs. [...] Farther upstream a network of shallow channels on peat but 
still with moving water is populated by Metrocoris tenuicornis, stiller water with leaf beds by Tenagogonus insularis. Throughout the whole system, leafy banks carry large numbers of Rhagovelia femorata. Elsewhere in the swamp forest of Nee Soon are larger but now inaccessible rivers where Ventidius hungerfordi, Esakia fernanndoi and Cylindrostethus costalis were collected.'

\section{Notes on relationships}

In this paragraph, relationships between the taxa Ventidius, Ventidioides, Ventidiopsis and Esakia are discussed.

The subgenus Ventidius s. str. consists of two rather different species-groups of closely related species which are both widely distributed in the Oriental region. Although both of these groups are clearly defined by several apomorphic characters, the only synapomorphy of both groups may be the reduction of paramere size. It is not proved, if the subgenus Ventidius s. str. is a monophyletic taxon or a paraphyletic group at the base of the genus Ventidius. In the latter case, the species of the $V$. aquarius-group belong to Ventidiuss. str., and the V. modulatus-group should be raised to a presently unnamed subgenus.

Ventidioides forms a rather nonhomogeneous accumulation of species which are divided here into two established species-groups; all characters discussed by Hungerford \& Matsuda (1960), Matsuda (1960), Cheng (1965), and Lansbury (1990) refer to species of the V. kuiterti-group, which inhabits the Southeast Asian mainland. The V. xiphibion-group contains five species from Borneo and Sulawesi. The only synapomorphy for all Ventidioides species is the presence of special structures on mesosternum of males (tubercle with setae or row of setae). All other 'apomorphic' characters mentioned by Hungerford \& Matsuda (1960) and Matsuda (1960) are either not developed in all species (tubercle of fore femur lacking in the $V$. xiphibion-group) or are also developed in Ventidiopsis. If Ventidioides proves to be polyphyletic, then the $V$. xiphibion-group should be raised to a presently unnamed subgenus.

When Miyamoto (1967) described Ventidiopsis imadatei, only the female was known, which has striking characters, and therefore this species was placed in a new genus different from Ventidius. After studying the male of $V$. imadatei, we found some reasons to include Ventidiopsis as a subgenus within Ventidius and to treat it within this revision. At least two striking characters are regarded as synapomorphies of the subgenera Ventidioides and Ventidiopsis stat. n., i.e. the bilobate posterolateral angle of metacetabula and the asymmetrical parameres.

The species of Esakia form a homogeneous group with several synapomorphic characters, e.g. the dilat- ed third antennal segment of male, the reduced fore wing venation, and a flatter, anteriorly more widened body (see also Matsuda [1960]). But the complete absence of an anterolateral separation of the metanotum (which is present in Esakia by a longitudinal elevation) is the only character which we found useful as synapomorphy of the proposed monophylum Ventidius+[Ventidioides+Ventidiopsis].

The monophyletic status of Ventidius+Esakia is supported by several characters, e.g. short pronotum, larger eyes, and rather strongly flattened metacetabula (Matsuda 1960), which is confirmed by this study. This provisional arrangement of genera and subgenera should be proven in a subsequent cladistic analysis.

An analysis of the present distribution of Ventidius suggests that Malaysia has the richest biodiversity.

\section{Checklist}

Ventidius Distant 1910

Subgenus Ventidiuss. str.

Ventidius aquarius-group

1. aquarius Distant 1910

2. usingeri Hungerford \& Matsuda, 1960

3. harrisoni Cheng, 1965

4. malayensis Hungerford \& Matsuda, 1960

5. longitarsus sp. $\mathbf{n}$.

Ventidius modulatus-group

6. henryi Esaki, 1928

7. hungerfordi Cheng, 1965

= wallacei Lansbury, 1990

8. werneri Hungerford \& Matsuda, 1960

9. polhemorum sp. $\mathbf{n}$.

10. pilosus sp. $\mathbf{n}$.

11. modulatus Lundblad, 1933

= china $i$ Hungerford \& Matsuda, 1960

= pubescens Cheng, 1965

12. ? distanti Paiva, 1918

13. ? sushmae Gupta, 1981

Subgenus Ventidioides Hungerford \& Matsuda, 1960 Ventidius kuiterti-group

14. kuiterti Hungerford \& Matsuda, 1960

15. karen Lansbury, 1990

16. pulai Cheng, 1965

17. lundbladi Miyamoto, 1967

Ventidius xiphibion-group

18. xiphibion Chen \& Nieser, 1992

19. xyele Chen \& Nieser, 1992

20. kurtokalami Chen \& Nieser, 1992

21. nieserisp. $\mathbf{n}$.

22. heissi sp. $\mathbf{n}$.

Subgenus Ventidiopsis Miyamoto, 1967

Ventidius imadatei-group

23. imadatei Miyamoto, 1967

24. yangae sp. $\mathbf{n}$. 


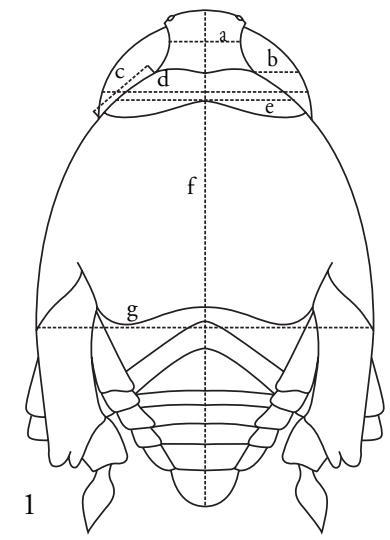

$21 \mathrm{~s}$

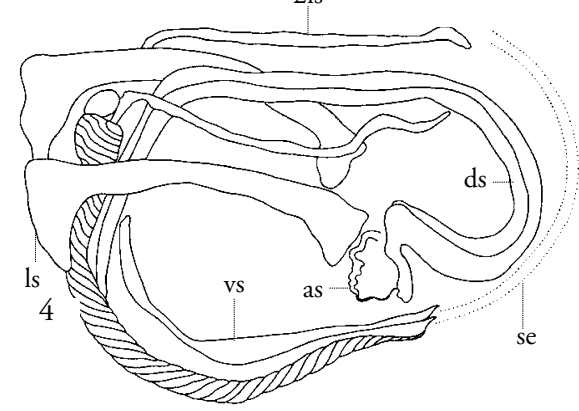

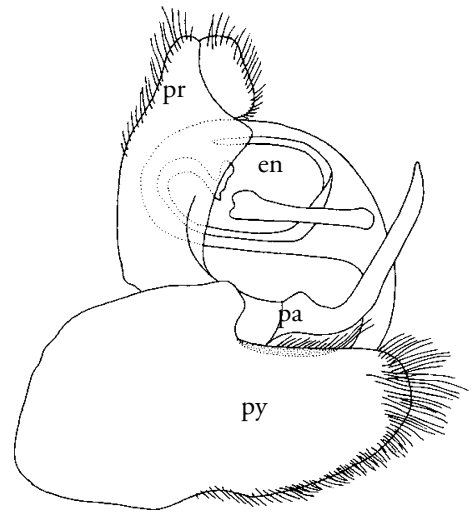

3
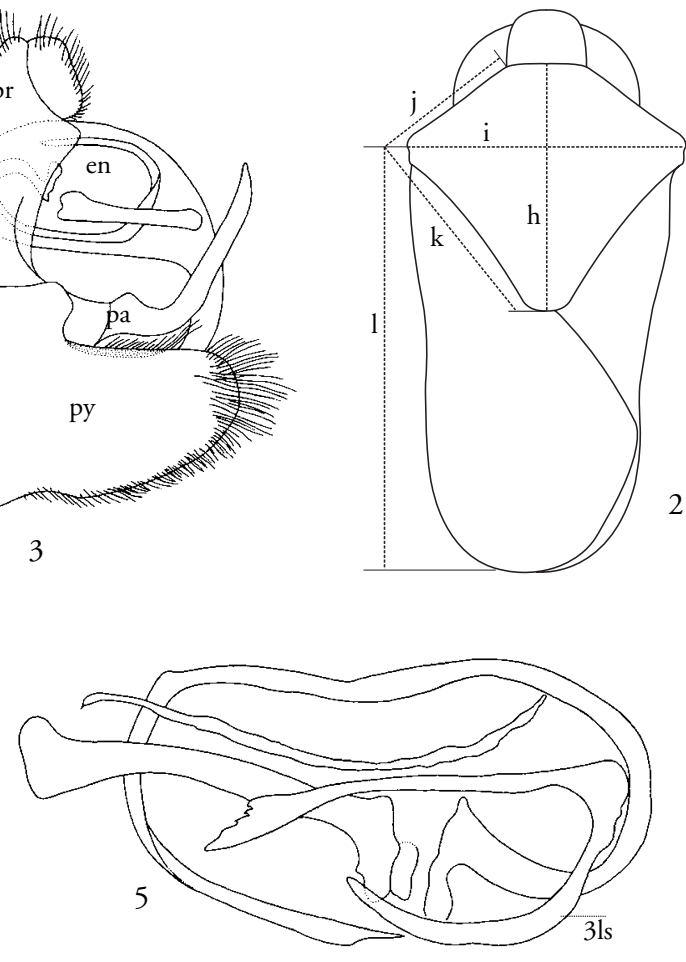

Figs. 1-5. Diagrams of Ventidius sp. with lines indicating measurements. - 1, apterous male (appendages removed) in dorsal view (a, interocular width; b, eye width; c, posterior eye width; $d$, head width; e, pronotum width; $f$, median length of body; g, body width across acetabula); 2, macropterous form (appendages removed) in dorsal view (h, median length of pronotum; $i$, humeral width of pronotum; $j$, length of lateral margin from anterior angle to humerus of pronotum; $k$, length of lateral margin from humerus to apex of pronotum; 1, length of fore wing from humerus to apex); 3, lateral view of genital segments (py, pygophore; pr, proctiger; pa, paramere; en, endosoma); 4, dorsolateral view of endosoma (as, apical sclerites; ds, dorsal sclerites; ls, lateral sclerites; 2ls, second lateral sclerites; se, ductus seminis; vs, ventral sclerites); 5, lateral view of endosoma (31s, third lateral sclerites).

\section{Material AND METHOdS}

The revision is chiefly based on material borrowed from various museums and private collections (listed as depositories below). Parts of the material were recently collected by the authors in Eastern Malaysia, Thailand, and the Philippines. The holotypes of all new species are deposited in major institutions and museums as indicated in the taxonomic section.

Olympia optics, including a Camera Lucida, were used in studying and drawing the specimens. Examination of the male terminalia is essential for a safe identification of most species of Ventidius. The male genital segments were detached from the specimens. Before dissection, the segments were cleared in 10\% potassium hydroxide for 12-24 hours at room temperature, or till the endosoma became clearly visible. For studies of thoracic hair layers in species of the $V$. modulatus-group a Wild binocular optic with magni- fication up to $1000 \times$ was used.

All measurements in the descriptions are in millimetres. The tables of measurements (table 1-3) give the means of measurements of six specimens for each species or, if less than six specimens were available, of all specimens studied. Interocular width is the shortest distance between eyes (fig. 2, a); eye width is the greatest width of the eye measured perpendicular to the longitudinal axis of the head (fig. 2, b); head width is the greatest width of head measured across eyes (fig. 2, d). Width of pronotum in the apterous form and pronotal measurements in the macropterous form as illustrated in figs. 1 and 2, respectively. When measuring the antennal segments, the small internodal piece between segments 2 and 3 was included into the length of segment 3 . Terms of male genitalia see figs. 4-5. 


\section{List of depositories}

AMNH American Museum of Natural History, New York, U.S.A.

BIMC B.P. Bishop Museum, Honolulu, U.S.A.

BMNH The Natural History Museum, London, U.K. (= former British Museum [Natural History]).

CNHM Chicago Natural History Museum, Chicago, U.S.A.

FMHF Finnish Museum of Natural History, Helsinki, Finland.

FMnH Field Museum of Natural History, Chicago, U.S.A.

GClB Gupta Collection, Los Banos, Philippines.

JTPC Colorado Entomological Museum, Englewood, Colorado, U.S.A. (= formerly J. T. Polhemus Collection).

KKUA Khon Kaen University, Faculty of Agriculture, Department of Entomology, Khon Kaen, Thailand.

NCTN Nieser Collection, Tiel, The Netherlands.

NHMw Naturhistorisches Museum Wien, Vienna, Austria.

oumc Hope Department, Oxford University Museum, Oxford, U.K.

PPCC P. P. Chen Collection, Beijing, China.

RMNH Nationaal Natuurhistorisch Museum Naturalis (formerly Rijksmuseum van Natuurlijke Historie), Leiden, The Netherlands.

sccu W. D. Shepard Collection, California State University, Sacramento, U.S.A.

SEMC Francis Huntington Snow Entomological Museum, University of Kansas, Lawrence, Kansas, U.S.A.

SMNH Swedish Museum of Natural History, Stockholm, Sweden.

sPCM Sabah Parks Collection, Kota Kinabalu, Malaysia.

TMBC Magyar Termeszettudomanyi Museum (= Hungarian Natural Science Museum), Budapest, Hungary.

UmSM Universiti Malaysia Sabah, Kota Kinabalu, Malaysia.

uplb University of the Philippines, Los Banos, Natural History Museum, Philippines.

zCMG G. Zimmermann Collection, Marburg, Germany.

zcwa H. Zettel Collection, Vienna, Austria.

ZMAC Instituut voor Systematiek en Populatiebiologie (= formerly Zoologisch Museum), University van Amsterdam, Amsterdam, The Netherlands.

zMUC Zoological Museum, University of Copenhagen, Copenhagen, Denmark.

ZRCS Zoological Reference Collection, Singapore.

\section{ACKNOWLEDGEMENTS}

We are indebted to the following persons who made types and/or other material for this revision available: N. M. Andersen (zMuc), R. W. Brooks (SEMc), J. Duffels (zMAC), E. Heiss (Innsbruck), I. Lansbury (oumc), P. Lindskog (sMNH), J. Margerison-Knight (вMNH), N. Nieser (NCTN), S. Oygur (Amnh), P. P. Parillo (fmnh), D. A. Polhemus (formerly BIMc), J. T. Polhemus (JTPC), R. Schuh (AмNh), J. van Tol (RMNH), T. Vásárhelyi (TMBC), C. M. Yang (zRCS), and Y. Hanboonsong (KKUA). We thank L. Dembicky and P. Pacholatko (both Brno) for depositing specimens in the NHMw.

We are most grateful to S. Wongsiri, S. Leepitakrat, R. Thapa, U. Booncham (all in Chulalongkorn University, Bangkok), S. Piyapichart, Sudarak (both Naresuan University, Phitsanulok), T. Jamjanya, Y. Hanboonsong, N. Sangpradub, Dun, Wirote, Nutcharee, Jum (all in Khon Kaen University), Virode Naknan (Nam Nao NP), and P. Schwendinger (Innsbruck and Chiang Mai) for their company and help during our field work in Thailand.

The junior author is deeply indebted to Maryati Mohamed (UMSM) and W. Hödl (University of Vienna) who enabled his field trip to Sabah. Further, his thanks are due to Homathevi R. (UMSM), G. Gunsalem (sPCM) and the staff of the Danum Valley Field Centre for the hospitality during his stay in the research station. He highly appreciated the help of the Wawa students group (G. Grabenweger, E. Grünberger, and G. Schindler) who assisted him in the Danum Valley. Further, the junior author wants to express his special thanks to J. Recuenco-Adorada, V. P. Gupta, and A. C. Sumalde (all in UPLB) as well as his many other Philippine friends who supported his field work in the Philippines.

We are deeply indebted to J. T. Polhemus for a scientific and linguistic review of the manuscript, to I. M. Kerzhner (St. Petersburg) and N. Nieser for discussing the manuscript and the geographic distribution patterns, and to Ch. Hecher (Vienna) for mapping numerous distributional data.

The study was enabled by the stay of the first author in Vienna, which was financially supported by the Österreichischer Austausch-Dienst (ÖAD).

\section{TAXONOMY}

\section{Genus Ventidius Distant}

Ventidius Distant, 1910: 149-150. Type-species by monotypy: Ventidius aquarius Distant, 1910.

Ventidius Distant; Bergroth 1911: 186 (synonymized Ventidius with Metrocoris Mayr); Esaki 1928: 509-511 (descr., new species); Esaki, 1929: 417 (confirmed as valid genus); Esaki 1930: 18; Hungerford \& Matsuda 1960: 323-343 (descr., illustr., key, new species, new subgenus); Matsuda 1960: 313-316 (morphological descr., syst., illustr.); Cheng 1965: 153-163 (key to species of Malay Peninsula, descr., illustr., new species); Gupta 1981: $97-$ 99 (descr., illustr., key to subgenera, new species); Kovac \& Yang 1989: 285 (list, in Pahang, Malaysia); Chen \& Nieser 1992: 156-159 (descr., illustr., new species); Yang \& Kovac 1995: 293 (list, Perak, Malaysia); Zettel \& Chen 1996: 152, 180 (list, Viet Nam).

Nomenclatorial notes. - The genus Ventidius was established by Distant (1910) for the new species $V$. aquarius, known from both apterous and macropter- 


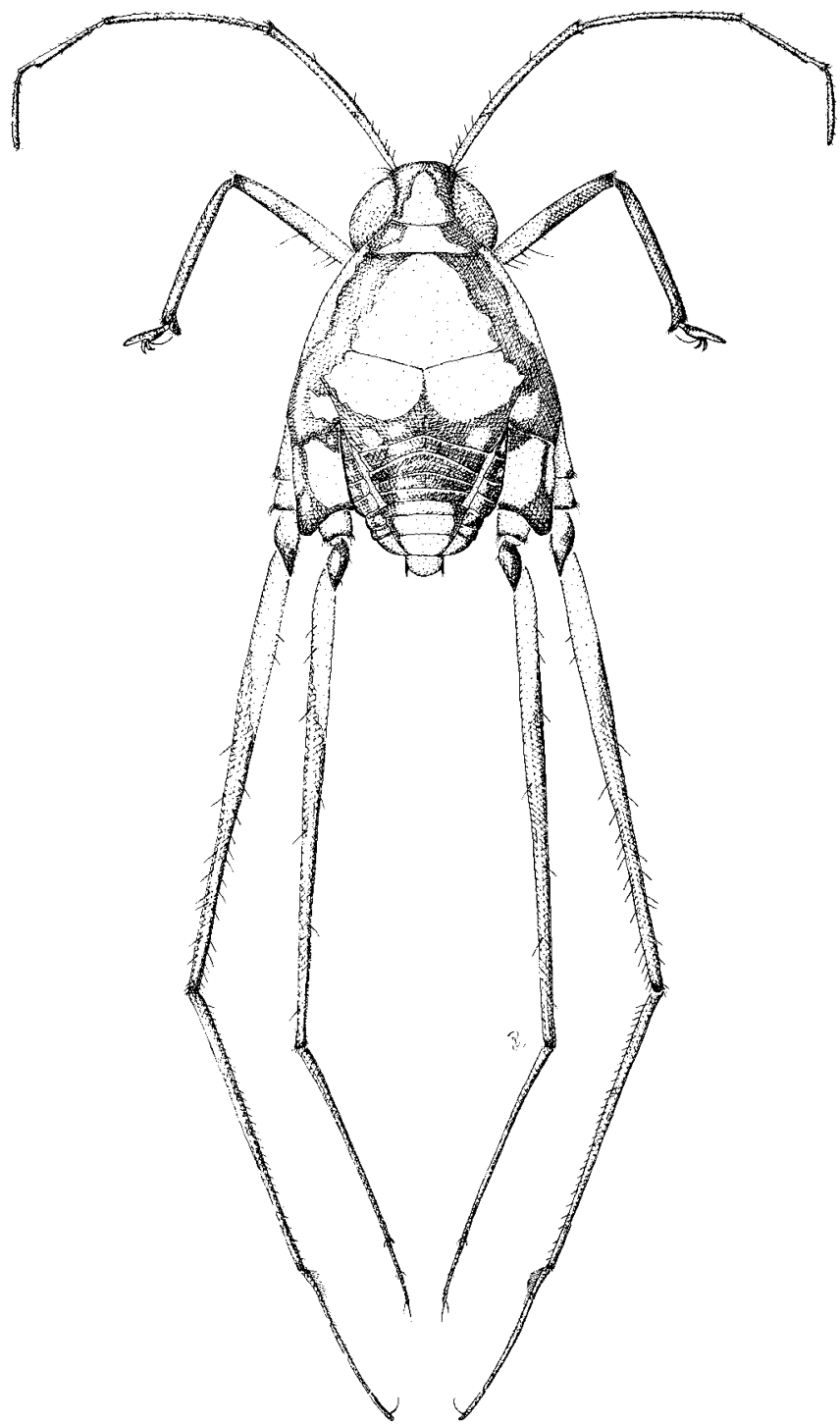

Fig. 6. Ventidius (s. str.) usingeri, apterous male, length $3.65 \mathrm{~mm}$.

ous forms. Bergroth (1911) considered the genus Ventidius Distant identical with Metrocoris Mayr, stating that the distinguishing characters given by Distant (1910) were only specific characters, and that therefore, Ventidius could not be generally separated from Metrocoris. Esaki (1929) pointed out that Ventidius was wrongly synonymized by Bergroth (1911), and insisted that Ventidius is a very distinct genus. Since then, no more confusion has been created on the generic status, which has been accepted by all recent authors.

\section{Redescription}

Dimensions. - Males smaller than females, length of body usually 2.37-4.60 (ठ) , 2.50-4.40 ( 9 ); maximal width of body usually 1.60-3.10 (ઠ) ; 1.74-2.96 ( 9 ); width of head across eyes 1.01-1.65 (ठ̋), 1.04$1.61($ ㅇ)

Colour. - General colouration yellowish to light brown, overlain with complex black patterning. Several small brownish marks or one big dark mark present on interocular space of head, in some species too vague to see. Inner margin of eyes usually with brownish 
stripes. Eyes varying from greyish to black. Base of rostrum dark. Antennae dark except basal part of first segment; in two species segments 3 and 4 with yellowish bands. Anteclypeus, labrum and apical part of labium dark. Pronotum of apterous form with lateral dark stripes or a T-shaped dark mark, in some species totally dark. Pronotum of macropterous form mainly dark with two yellowish marks (fig. 9). Mesonotum with lateral dark stripes, but showing broad variation, often forming a pale triangular area between the pale stripes (fig. 6). Metanotum either totally pale or with lateral dark marks or stripes, posterior margin with a triangular dark mark, which is confluent with dark abdominal tergite 1 . In some species the pale marks on metanotum confluent with the pale marks on mesonotum and together forming a big mushroom-shaped or pear-shaped pale mark (figs. 54, 183). Propleura yellowish, in some species with a dark mark; a dark stripe usually running through the length of mesopleura; metacetabula yellowish, usually dark at protruding posterior angle, in some species more darkened and with a long yellowish mark in the central part. Narrow dark mark on anterior half of ventral metacetabula. Fore femur yellowish to light at basal third or half; fore tibia either totally dark or pale at base of external surface; fore tarsi totally dark. Middle and hind legs totally dark, in some species the middle legs yellowish basally. Fore wings dark brown with dark veins (fig. 155). Abdomen mainly dark dorsally, with pale marks. Ventral surface of body yellowish.

Structural characters. - Body triangular or subtriangular in dorsal outline, only moderately dorso-ventrally flattened; body clothed with short fine pubescence. Head bluntly projecting anteriorly of eyes, with broadly rounded anterior margin; head length in apterous form about 1.5 times as long as pronotum along median line. Eyes relatively large, narrower than the width of interoculus; posterior margin in lateral view covering propleura and anterior part of mesopleura. Vertex along inner margin of eyes bearing 5-6 stiff setae, interocular with 4 pairs of trichobothria at vertex, the third pair shorter than the other pairs and extending externally, the others pointing upwards (fig. 134). Antennae slender, in males usually stouter than in females; inner surface of antennae usually with fine erect pubescence through apical half of segment 1 to segment (3 or) 4 (except in $V$. aquarius-group with very long antennae in males, longer setae on internal surface and segment 3 of males modified by an apical indentation). Anterior margin of pronotum in apterous form slightly sinuated or concave, posterior margin sinuated. Pronotum of macropterous form large, forming an acute posterio-medial angle. Lateral suture of metanotum not reaching the meso-metanotal suture anteriorly. Pleura clothed with fine pubescence, which in some species is longer and more conspicuous. Mesosternal 'groove' conspicuous, in most species represented by a translucent internal ridge. Centre of mesosternum in some species with a tuft of tiny bristles, which in certain cases extends towards the anterior margin of the mesosternum. Metasternum reduced to a small triangular sclerite, in some species swollen to a tubercle. Abdomen with some golden pubescence dorsally; caudal margin of posterior abdominal tergites and genital segments with longer pilosity in male. Male abdominal sternite 7 much longer than sternite 6 , broadly concave on apical margin. Female abdominal sternite 7 strongly developed and not modified distinctively. Laterotergites usually broad. Legs slender, usually not modified. Fore femur of males slightly stronger than in females, its ventral surface usually smooth, but modified in subgenus Ventidioides: in $V$. kuiterti-group with a tooth halfway along its inner surface length (figs. 148-154); in V. xiphibion-group sometimes with a broad tubercle (figs. 198-202); fore femur usually bearing a number of long setae, its inner surface sometimes with dense short dark hair fringe. Inner surface of fore tibia in both sexes straight, but in two species (V. kurtokalami and $V$. nieseri) with an indentation at $2 / 5$ of its length in male, the remaining $3 / 5$ with distinct dark hair fringe; its apical finger-like projection with a grasping comb in male, which is composed by varied number of bristles and dense pilosity. Inner surface of tarsi with a row of modified hairs, which vary according to species. Middle and hind legs long, middle femur usually slightly shorter than hind femur; middle and hind femora with a number of long spines, and on dorsal surface with one or two long trichobothria-like setae basally.

Male genital segments usually relatively large. They comprise the following structures: the cylindrical segment 8 (s8); the boat-shaped pygophore (fig. 3, py, segment 9); the plate-shaped proctiger (pr, segment $10+11)$; the parameres (pa), which are varied in size, symmetrical and small in subgenus Ventidius, but asymmetrical and longer in subgenus Ventidioides, and of high diagnostic importance; and the phallus (ph). The distal section of the phallus is the endoso$\mathrm{ma}$, which is armed with a number of sclerites. In the descriptions, the endosoma sclerites and other structures are named as follows (figs. 4, 5): dorsal sclerites $(\mathrm{ds})$, apical accessory sclerites (as), lateral sclerites (ls, paired), ventral sclerites (vs, paired); a second pair of lateral sclerites occurs in all species, a third pair in some species (lp); the ductus seminis (se) is supported by the ventral sclerites.

In females so far only a few useful diagnostic characters have been found, which are usually found also in males (e.g. some group characters, colour pattern, body shape, pilosity). There are no distinct differ- 
ences in female terminalia, except in the subgenus $V e$ tidiopsis. Within species groups not all females can be identified to species level.

Comparative notes. - Ventidius seems to be most closely related to the genus Esakia. Main differences are: thorax anteriorly widened and conspicuously flat in Esakia, but anteriorly constricted and (usually) domed in Ventidius; antennal segment 3 dilated in males of Esakia, but usually rounded in Ventidius (slightly flattened in subgenus Ventidiopsis); in Esakia fore wing venation reduced, with closed cells in basal half only, but more developed in Ventidius, with closed cells reaching distal half; metanotum with an antero-lateral separation represented by a longitudinal ridge in Esakia, but fused with metapleura in Ventidius.

Distribution (maps 1-6). - Endemic to the Oriental region, from Sri Lanka to the Philippines and Indonesia (eastward to Sulawesi and Sumba).

\section{Key to the subgenera of Ventidius}

1. Posterolateral angle of metacetabula truncate or slightly bilobate in caudal view (figs. 29-38, 7587), parameres symmetrical, pronotum yellow with dark lateral stripes and/or triangular dark mark in middle of hind margin (except: black in $V$. henryi) Ventidius s. str.

- Posterolateral angle of metacetabula distinctly bilobate in dorsal view (figs. 157-166, 203-212), parameres asymmetrical, pronotum usually black

2. Tergites 3 and 4 fused in apterous morphs; 9 (apterous): metacetabula and metacoxae each with a stout, medially directed and hairy processus (figs. 240-242), metanotum and anterior tergites concave, meso-metanotal suture with or without two tufts of hairs; $\hat{\delta}$ : antenna very stout, segment 1 thicker than fore tibia, segments 2 and 3 slightly flattened (figs. 249, 252) ... Ventidiopsis

- Tergites 3 and 4 not fused; $q$ : without medially directed processes on metacetabula and metacoxae, metanotum and anterior tergites slightly convex to flat, rarely slightly concave (in $V$. nieseri sp. n.), meso-metanotal suture without tufts of hairs; of: antenna slender, segment 1 thinner than fore tibia, segments 2 and 3 not flattened (fig. 142, $143,145,147)$ Ventidioides

\section{Subgenus Ventidius (s. str.) Distant, 1910}

Diagnosis. - Colouration comparatively lighter than in the subgenus Ventidioides (except in $V$. hen$r y i)$. Antennal segment 1 distinctly shorter than segments 2-4 together. In some species the subdistal part of segment 3 modified. Posterolateral angle of metacetabula not bilobate or only slightly bilobate. Ventral surface of male fore femur not modified without a tooth or tubercle. Mesosternum without tubercle or row of setae. Parameres symmetrical, small.

Distribution (maps 1-3). - Widely distributed throughout the Oriental region, from Sri Lanka to the Philippines, Borneo and Sumba. Highest species diversity in Malaya.

Identifications. - Nearly all characters used in the following key for apterous males are also present in macropterous males (which are unknown in some species) except pronotum not completely black in macropterous $V$. henryi. Females are very difficult to identify, but species-groups can be easily separated by the legs. The middle and hind femora are very stout in females (and males) of the species of $V$. aquariusgroup, but comparatively slender in species of the $V$. modulatus-group. As species of the $V$. aquarius-group are mostly allopatric, females may be provisionally identified after their provenance; only $V$. malayensis and $V$. harrisoni are known to occur in the same areas, but females of these species can be separated by the length of the fore tarsus (table 1). Furthermore, there may be an overlapping zone between the ranges of $V$. malayensis and $V$. longitarsus sp. n. As we could not find reliable characters to differentiate between females of these species, identifications of single females from Indochina are doubtful. Females of the V. modulatus-group are indistinguishable, except $V$. henryi with the typical black pronotum, and $V$. hungerfordi with a much flatter body than in $V$. modulatus. Ventidius modulatus is also distinguishable by the shorter pilosity of the mesopleura, but this character is difficult to observe and variable. Other species are allopatrically distributed, but because of the occurrence of $V$. modulatus in Borneo, females of $V$. polhemorum sp. n. or $V$. modulatus from this island can only be identified by the slightly longer pilosity of the first species.

\section{Key to apterous males of the subgenus Ventidius}

1. Antennal segments very long and slender; length of segment 1 shorter or subequal to segments 2 and 3 together, usually more than $1.2 \mathrm{~mm}$, at least with 8 long setae which are evenly scattered all over its length; segments 2 and 3 with erect, rather long dark hairs; segment 3 with more or less distinct subapical indentation (figs. 18-22); middle and hind femora very stout (fig. 6, 53); segment 8 with conspicuous deep ventral emargination and lateral tufts of black bristles caudoventrally (figs. 39-42); parameres very small, straight or cucumber-shaped (figs. 43-47) ( $V$. aquarius-group) .................................................

- Antennal segments shorter and less slender; length of segment 1 longer or subequal to segments 2 and 3 together, usually less than $1.2 \mathrm{~mm}$, and usually 

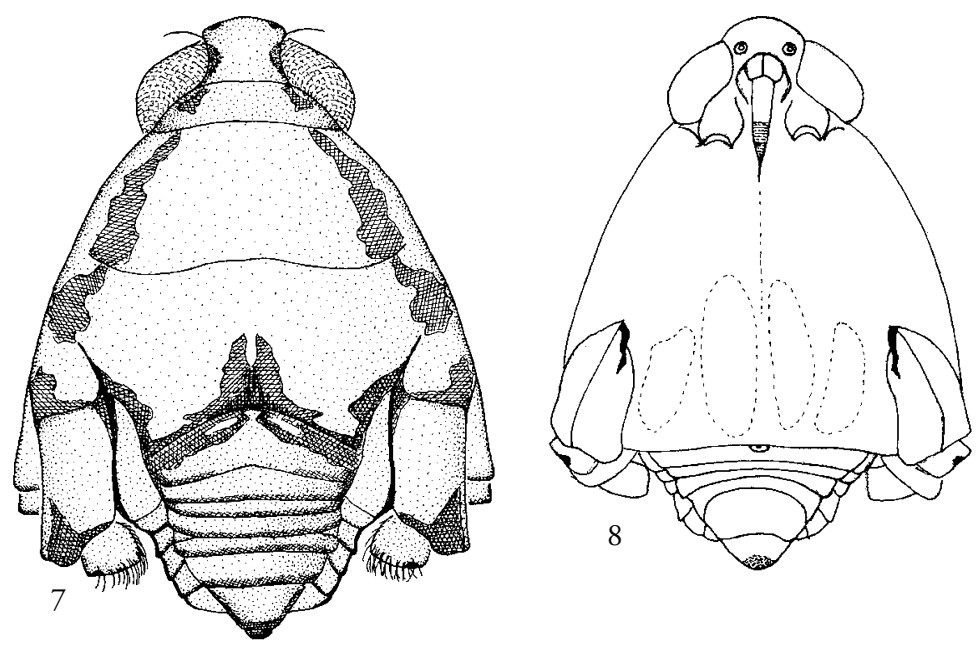

Figs. 7-9.

Ventidius aquarius (female, antennae and legs removed, length 3,60 mm). - 7, dorsal view (holotype); 8, ventral view (holotype, egg shells visible); 9, pronotum of macropterous form.

Figs. 10-11.

Ventidius malayensis (male, antennae and legs removed, length XX mm). - 10, pronotum of macropterous form; 11 , dorsal view of apterous male.

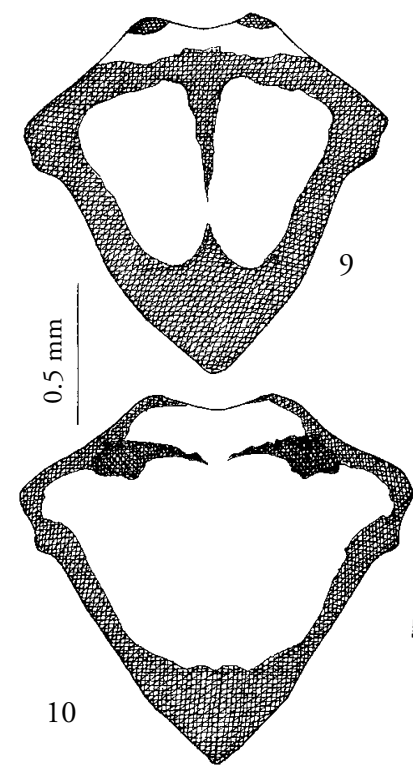

with less than 8 setae, most of them in a subbasal row; segments 2 and 3 with dense erect silvery pilosity; segment 3 without subapical indentation (figs. 60-66); middle and hind femora normal, slender (fig. 123); segment 8 without distinct ventral emargination and without lateral tufts of black bristles; parameres slightly longer, in most species apically widened (figs. 97-101), except in $V$. henryi (see fig. 96) ( $V$. modulatus-group) .....6

2. Segment 2 of fore tarsus only moderately long, surpassing the claws only slightly, fore tibia internally with a row of stout spinules (fig. 23, 25, 26), hairs on apical portion of antennal segment 3 only slightly longer than the normal erect hairs all over the length of the segment and shorter than width of segment at this location (figs. 18, 19) ..3

- Segment 2 of fore tarsus very long, surpassing the claws by more than their length (figs. 27, 28), fore tibia internally without a row of stout spinules, antennal segment 3 apically with conspicuous long hairs which are longer than width of segment at this location (fig. 22)

3. Antennal segment 3 about 0.6 times as long as segment 2, straight and with a sharp indentation subapically, spinules on internal face of fore tibia distinctly increasing in length from base to tip and becoming hair-like in distal third, segment 8 

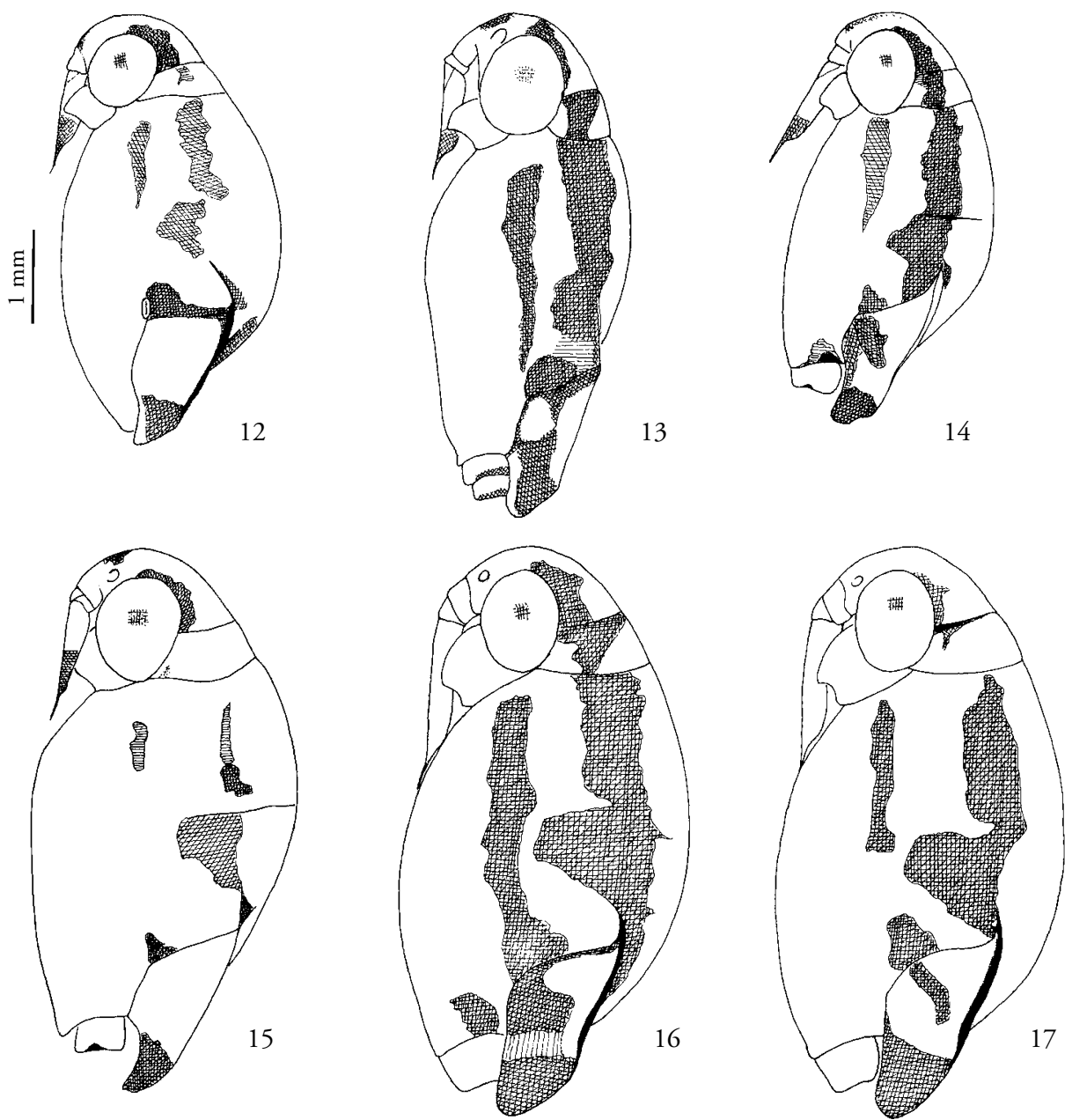

Figs. 12-17. Lateral view of apterous form, showing colour pattern of pleura. - 12, Ventidius aquarius (holotype); 13, V. usingeri; 14, V. harrisoni (paratype); 15, V. malayensis; 16-17, V. longitarsus (types).

with broader tuft of hairs ventrocaudally ...........

- Antennal segment 3 about 0.8 times as long as segment 2 , with a very shallow indentation subapically (fig. 20); spinules on internal face of fore tibia only sligthly increasing in length from base to tip and becoming only slightly thinner towards apex of tibia (fig. 26), segment 8 with narrow tufts of hairs ventrocaudally (fig. 41) (Malaya, Borneo) V. harrisoni

4. Mesopleural stripe ending at or at short distance from the second spiracle, ventral incision of segment 8 broad and less deep (fig. 40), parameres more straight and with numerous small hairs ventrally (fig. 44) (Philippines) V. usingeri
- Mesopleural stripe ending in middle of mesopleura in long distance from the second spiracle, ventral incision of segment 8 narrower and deeper (fig. 39), parameres more curved and without small hairs ventrally (fig. 43) (Sri Lanka, South India) $V$. aquarius

5. Segment 2 of fore tarsus very long (fig. 28), antennal segments 2-4 slightly thicker than in the following species, colouration variable (Viet Nam) $V$. longitarsus

- Segment 2 of fore tarsus slightly shorter (fig. 27), antennal segments 2-4 extremely thin, colouration always bright (Thailand, Malaya, Borneo) .. V. malayensis 

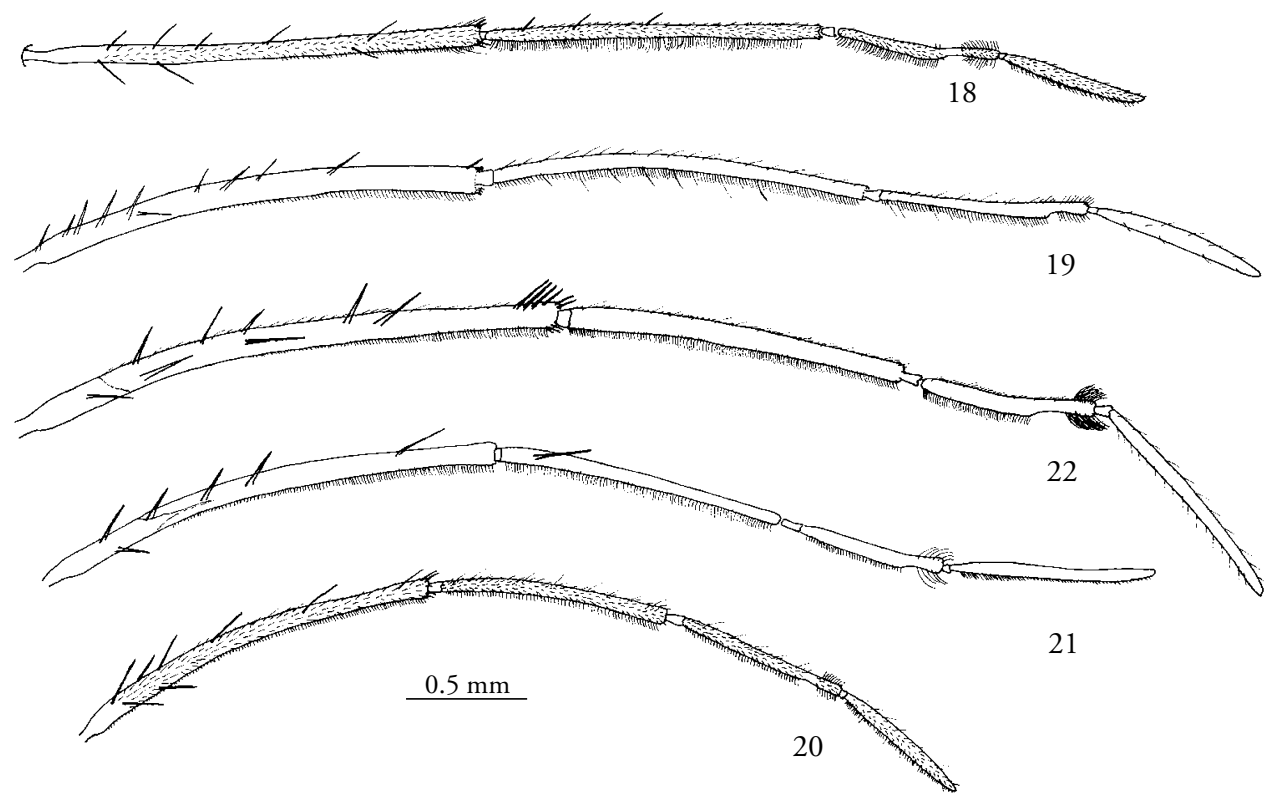

Figs. 18-22. Dorsal view of male right antennae. - 18, Ventidius aquarius; 19, V. usingeri; 20, V. harrisoni (paratype); $21 . V$. malayensis; 22, V. longitarsus (holotype).

6. Pronotum completely black (fig. 54); distal part of parameres parallel-sided (fig. 96); thorax clothed with dense, long pubescence and fore femur slightly flattened (Sri Lanka, South India) .. V. henryi

- Pronotum completely or mainly yellowish, or at least with a large yellowish mark in middle; distal part of parameres club-shaped or at least slightly dilated apically (figs. 102-113); either thorax without dense, long pubescence or fore femur not slightly flattened

....7

7. Antennal segment 1 very slender, 12.5-15 times as long as maximum width; thorax with less dense pubescence, sometimes relatively dense in dorsal part, but length of hairs on middle part of mesopleura short, distinctly shorter than that of the dark lateral band (which is sometimes lacking) (this character is not valid in a population from Viet Nam); paramere in distal part strongly widened and with a distinct tubercle (figs. 102113); fore femur slightly flattened, at least basally (Sri Lanka, India, Thailand, Viet Nam, Malaya, Borneo, Sumatra, Java) $V$. modulatus

- Antennal segment 1 usually stouter and thickened in middle of its length, 9.5-11.5 times as long as maximum width in $V$. hungerfordi and $V$. polhemorum, 10.5-12.5 times as long as maximum width in $V$. werneri and $V$. pilosus. (but these species out of distribution of $V$. modulatus) thorax clothed with dense, long pubescence, length of hairs on mesopleura long, in its middle (in yellowish part) nearly of same length than that of dark lateral band which is always developed; parameres varied; fore femur not flattened ........8

8. Parameres distally strongly widened and with a distinct tubercle in most specimens (fig. 97), body depressed (Thailand, Malaya)

.. V. hungerfordi

- Parameres distally only slightly widened, without or with a faint indication of a tubercle, body depressed or not ...9

9. Paramere in middle part broad, about 0.7 times as broad as width of apical part, usually without a dimple at base of apical part (fig. 98), body more depressed, on average first antennal segment stouter (Borneo: Sabah, Sarawak)

V. polhemorum

- Paramere in middle part very slender, about half as broad as width of apical part, in most specimens with a very faint dimple at base of apical part, body less depressed, first antennal segment usually less thickened .....................................10

10. Paramere slightly twisted (fig. 100) (Indonesia: Sumba, Sumbawa) ............................... V. pilosus

- Paramere straight, not twisted (fig. 99) (Philippines: Palawan Province) 


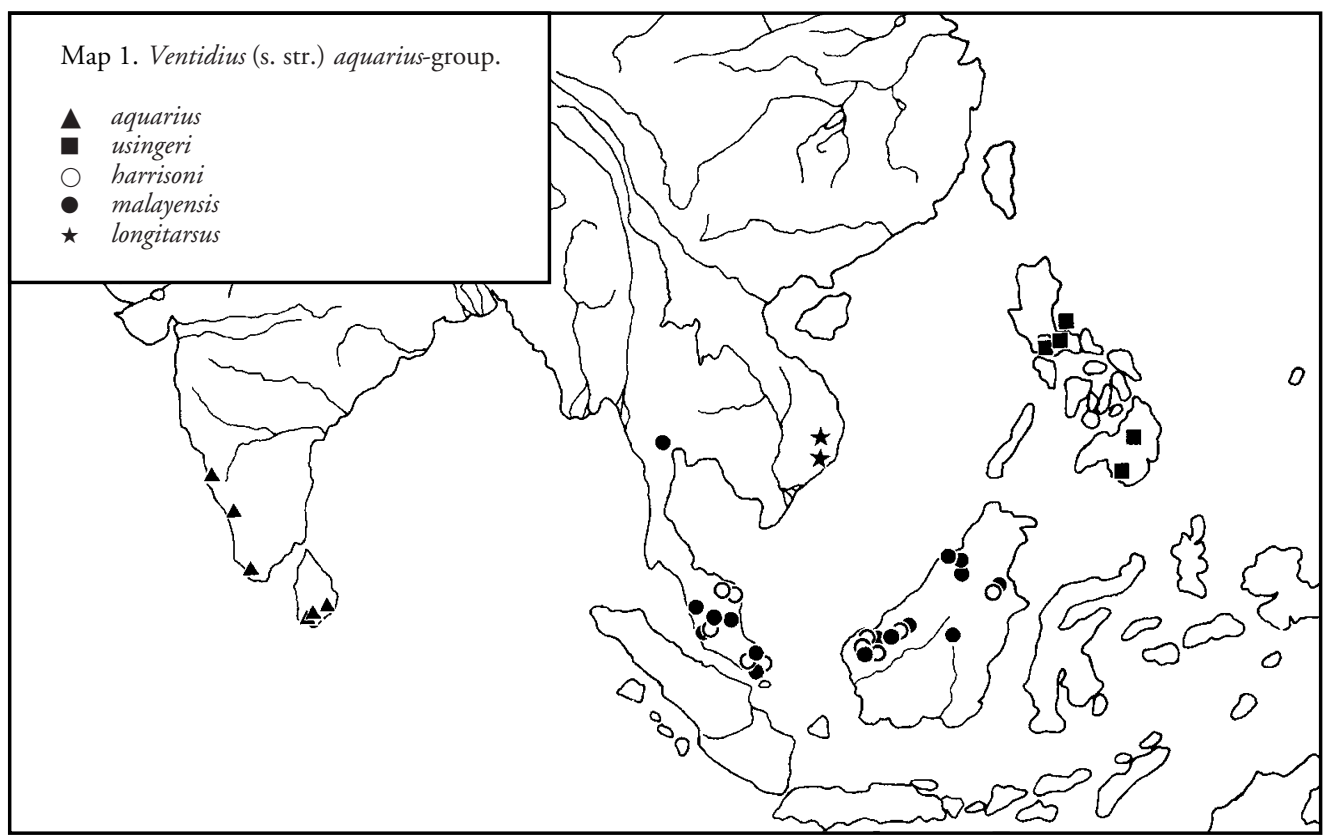

* We were not able to check the type material of $V$. distanti and $V$. sushmae. Therefore, they are absent from the key. But according to the original descriptions and the illustrations, they both key out with $V$. modulatus.

\section{The Ventidius aquarius-group}

Diagnosis. - Comparatively larger size, length 3.38-4.60 (o) ), 3.20-4.40 ( + ); width 2.32-3.10 (o) ), 2.30-2.96 ( + ); with distinctively long and slender antennae; segment 1 shorter or subequal to segments 2 and 3 together, usually more than $1.20 \mathrm{~mm}$; segment 2 in male usually much longer than segment 3 (except in $V$. harrisoni); antennal segment 1 with more than 8 long setae, in males segments 2 and 3 with dense erect hairs and segment 3 with a more or less distinct indentation near apex, which in some species is surrounded by a number of long thin setae apically; inner surface of fore tibia with dense and long setae, in distal part with a row of stout spinules forming an Sshaped comb, and in some species with a long row of stout spinules nearly all over its length; middle and hind legs distinctively stout and shining, with scattered long spines on femora and tibiae; segment 8 (s8) of male with a tuft of dark setae at each posterior angle, parameres small and symmetrical, straight or cucumber-shaped, never dilated apically; in three species endosoma with a third pair of lateral sclerites, which are very broad but with their distal parts slender and recurved backwards.
Distribution (map 1). - Widely distributed, from Sri Lanka to the Philippines and Borneo, not reaching Wallacea. Five species with allopatric distribution except $V$. malayensis and $V$. harrisoni which both inhabit the Southeast Asian mainland and Borneo.

\section{Ventidius (s. str.) aquarius Distant}

(figs. 7-9, 12, 18, 23, 24, 29, 30, 39, 43, 48, map 1)

Ventidius aquarius Distant, 1910a: 150 (descr. of genus);

Distant 1910b: 157-158 (descr., illustr. of species). Hungerford \& Matsuda 1960: 324-325, 337 (descr., illustr., key). Thirumalai 1986: 10, 28-30 (list, descr., illustr.).

Type locality. - s. INDIA: Travancore.

Type material examined. - Holotype + , apt., 's. INDIA: Travancore, Pallode, 20 miles N.E. of Trivandrum (Annandale)', 'on road side jungle stream (N. Annandale)' (вмNн).

Other material examined. - INDIA (South): $60 \hat{0} 15 q$ apt., 205 macr., Karnataka, Gersoppa, Jog Falls, 600 m, 19. 24.xi.1977, Zool. Mus. Copenhagen Exped. (zMuc, NHMw); 20 , 2 ㅇ apt., Karnataka, Mudigere area, ca. 900 m, 2.-10.xi.1977, Zool. Mus. Copenhagen Exped. (zMUC,

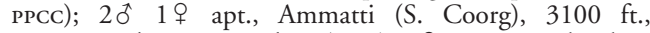
10.v.1951, leg. P.S. Nathan (JTPC); 1 apt., same locality, II.1952 (JTPC); 2 † 5 क apt., 2 के macr. Kerala, $15 \mathrm{~km} \mathrm{SW}$ Munnar, Kallar Valley, 1250 m, 1.-9.v.1997, 1002’N 7658'E, leg. Dembicky \& Pacholatko (NHMw, PPCC). SRI LANKA: 20 apt., Ratnapura, 20.ii.1961, leg. K.L.A. Perera (SEMC); 7 đ 3 ㅇ apt., 2 larvae, Ambagaspihya, 1.ii.1961, leg.

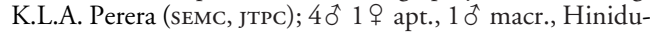
ma, Ela, 29.i.1958, leg. K.L.A. Perera (sEmc); 1010 우 apt., 
South Prov., Udugama, N of Galle, 50 m, 22.x.1974, leg. N.M. Andersen (ZMUC, NHMw); 50 t 2 apt., 2 q macr., South Prov., Homadola, Udugama, Kan-eliya, from river pools, leg. P.B. Karunaratne (JTPC, NHMw); 1 m macr., Uva Prov., Helagama, Meemina Hela-Large, pool at forest of hill, 500 ft., 7.-8.xii.1967, leg. P.B. Karunaratne (JTPC).

\section{Redescription}

Dimensions. - Apterous form, length 3.48 (む), 3.62 ( + ), width 2.40 (ठ), 2.55 ( + ), width of head 1.31 (ઠ), 1.31 (ㅇ).

Colour (fig. 7). - Whole body prominently pale, with distinct dark stripes and marks. Eyes mainly dark brown to black, their inner margin brownish. Interoculus pale and its dark marks faint, along inner margin of eye with broad dark stripes reaching the posterior margin of vertex. Antennal segments dark, except basal $1 / 5$ of segment 1 . Pronotum yellowish, its anterior margin dark and with dark lateral marks. Mesonotum with dark lateral stripes. Posterior margin of metanotum dark and with a small triangular dark mark basomedially which is confluent with the dark mark of tergites, and with two more or less square dark lateral marks which are confluent with the dark strip of mesonotum; a transverse dark stripe along anterior margin of acetabula which broadens at external angle of mesonotum. Mesopleura yellowish with a broad longitudinal stripe running through its length, not reaching its anterior margin (fig. 12). Anterior margin and external angle of metacetabula dark (fig. 29, 30). Fore leg dark, femur with basal $1 / 2$ yellowish (fig. 23). Middle and hind leg dark. Tergite 1 with two yellowish marks laterally, tergites 2-3 dark with a triangle-shaped yellowish mark in the centre, 4-8 yellowish with posterior margin dark. Laterotergites yellowish with dark posterior margins. Connexiva dark. Venter yellowish.

Pilosity. - Around antennal segment 1 scattered 12-14 long spinules, and with 7-8 distal short spinules, segment 2 with 6 spinules along its length, segment 3 with one distal spinule in female and a tuft of longer setae around the distal part in male, in distal part of segment 1 and all over the length of segments 2 and 3 ventrally with short erect dark hairs (fig. 18). Dorsum and pleura bearing dark pubescence, which is especially prominent on head. About 15 long setae along inner surface of fore femur, their lengths decreasing from basal to distal part. Fore tibia clothed by dense dark setae which form the whole tibia as a brush, but especially dense in distal part, and there with an S-shaped comb (fig. 23), in male along internal face with a row of stout spinules which are increasing in length and becoming more slender towards distal part. Long stiff spines scattered along middle and hind legs, tibiae with short stiff spinules. Basal part of middle and hind femora each with two very long trichobothria-like setae on dorsal surface, the external one shorter than internal one. The trichobothria-like setae were lost in most specimens we have seen. Venter clothed by golden pubescence, on abdominal segments the pilosity longer and denser, ventral face of segment 8 of male with tufts of broader ranged (comparing with that in $V$. harrisoni) dark setae at each posterior angle (fig. 39).

Structural characters. - Interoculus narrower than width of an eye, $0.45: 0.42$ in males, $0.48: 0.41$ in females. Antennae distinctly long and slender, especially the second segment in male much longer than in most species (measurements see table 1); segment 3 modified at subdistal part, near apex with a deep indentation (fig. 18). Mesonotum swollen, its lateral width 1.52 (ð), 1.70 ( 9 ). Intersegmental suture between meso- and metanotum distinct. Metanotum somewhat declivent. Lower half of hind margin of metacetabula rounded (slightly bilobate in caudal view), broad and nearly transverse in dorsal view (figs. 29, 30). Metasternal tubercle prominent in male. Anterior margin of abdominal tergite 1 visible; anterior margin of tergite 2 faint and obliterated strongly at medium part; anterior margin of tergite 3 arched forwards. Abdominal sternite 7 as long as the preceding abdominal sternites together in both sexes.

Male terminalia. - Parameres (fig. 43) small, symmetrical, more or less straight, cucumber-shaped, not extending beyond genital segments, with blunt apex. Endosoma (fig. 48): dorsal sclerite long and recurved proximally, ventral sclerite long, lateral sclerite straight, broadened at two ends, second lateral sclerites distinct, apical sclerite indistinct.

Female terminalia. - Abdominal sternite 7 large elevated medially, posterior margin concave forward.

Macropterous form. - Same as above with the following exceptions: apex of pronotum pointed (measurements see table 3); length of fore wings from humeri to apex 4.12. Yellowish mark of pronotum see figure 9 .

Distribution (map 1). - S. India: Kerala. Sri Lanka: Sabaragamuwa (Ratnapura), Southern (Hiniduma), Prov.? (Ambagaspihya).

Comparative notes. - According to the relatively short segment 2 of fore tarsus, the row of stiff spines on fore tibia of males, and the shorter apical setae on segment 3 of antenna of males, $V$. aquarius is closely related to $V$. harrisoni and $V$. usingeri. The other two species of the group, $V$. malayensis and $V$. longitarsus sp. n., are easily distinguished by the long fore tarsi in both sexes. Ventidius aquarius shares the deep indentation in male segment 3 of antenna with $V$. usingeri, but differences are found in colour, in the deep semicircular incision ventrally on segment 8 of males, and in the shape and absence of pubescence on the parameres. 


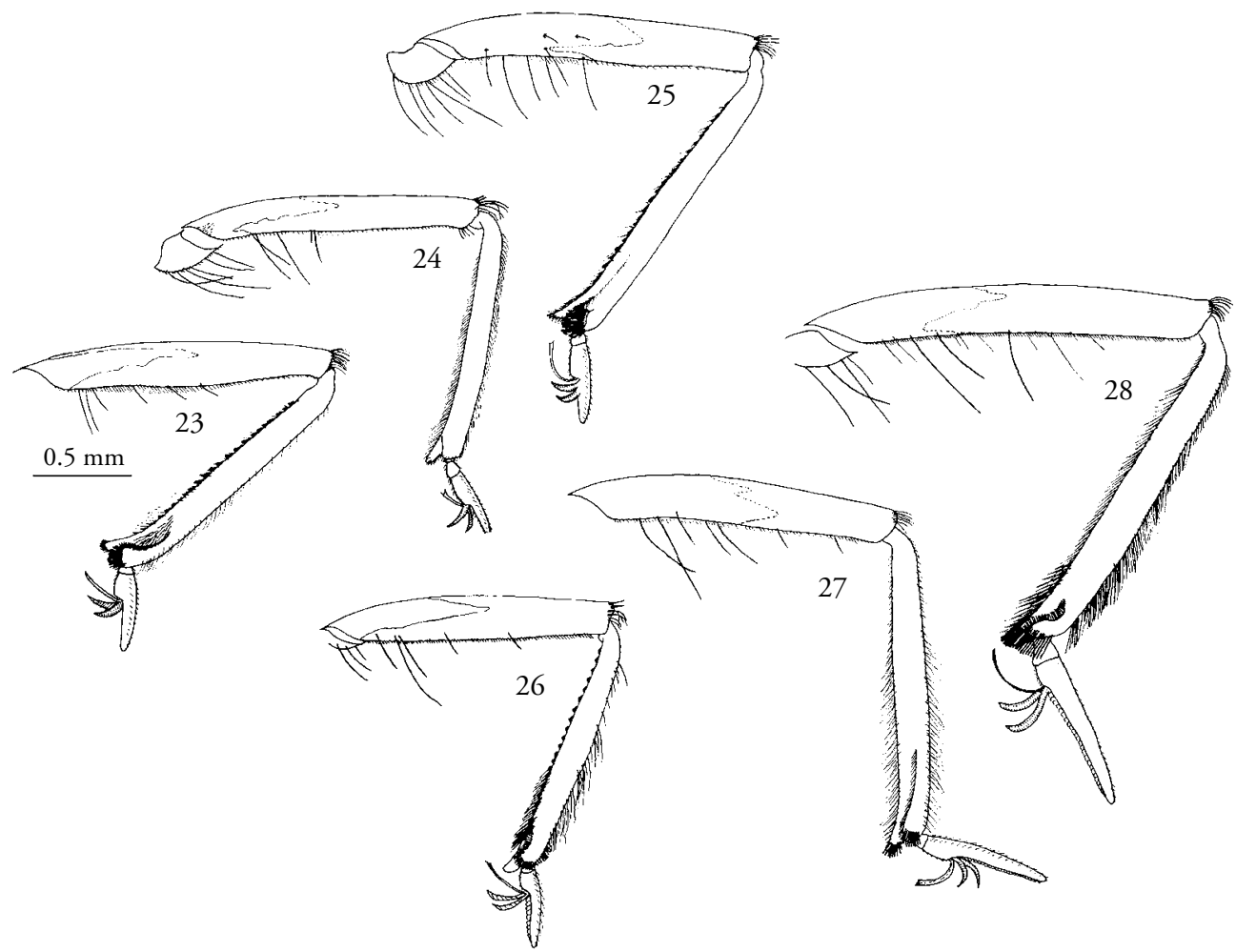

Figs. 23-28. Dorsal view of right fore legs. - 23, Ventidius aquarius (male); 24, same species (female); 25, V. usingeri (male); 26, V. harrisoni (male, paratype); 27, V. malayensis (male); 28, V. longitarsus (male, holotype).

2. Ventidius (s. str.) usingeri Hungerford \& Matsuda (figs. 6, 13, 19, 25, 31, 32, 40, 44, 49, map 1)

Ventidius usingeri Hungerford \& Matsuda, 1960: 326-327 (descr., illustr., key).

Type locality. - PHiLıppınes: Los Baños (Luzon).

Type material examined. - PHILIPPINEs: holotype $\widehat{\delta}$, macr., 'Los Baños, P.i., 17.vii.1936', 'R.L. Usinger collector', formerly belonged to Usinger collection (CNHM); allotype + , macr., 'CNHM-Philippines Zool., Exped. (19461947)', 'Borungkot, Upi, Cotabato Province, Mindanao $1500 \mathrm{ft}$. '47', and 'stream through original forest' (CNHM).

Other material examined. - PHILIPPINES: 1107 apt., $2 \delta^{\dagger}$ 2 o macr., Quezon Province, W. Atimonan, Quezon NP, Old Zigzag Road, 12.ii.1996, leg. H. Zettel (zCWA, GCLB, NHMw,

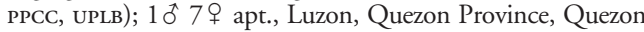
N.P., stream at entrance house, CL 1969, 10.vii.1985, leg. J.T. \& D.A. Polhemus (JTPC, PPCC); 101 to apt., $10 \hat{1} 19$ macr. Luzon, Quezon Province, Quezon N.P., Nalubog Creek, CL 1971, 10.vii.1985, leg. J.T. \& D.A. Polhemus (JTPC); 1 q apt., Polillo Island, leg. Baker (FMHF); $30 \hat{~} 49$ apt., 10 macr., Mindanao, Bukidnon Prov., Malaybalay, Kaamulan Site, 650 m, 12.11.1996, leg. H. Zettel (90d) (NHMw, Uplb, PPCC); 1 ㅇ macr., Bukidnon Prov., Malaybalay, Kaamulan Site, 650 m, 6.-7.11.1996, leg. H. Zettel (90c) (NHMw).

\section{Redescription}

Dimensions. - Body length 3.65 (ङ), 3.79 ( $\%$ ),

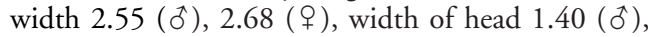
$1.40($ ( ) .

Colour (fig. 6). - Whole body prominently yellowish, dorsal ground colour yellowish with distinct dark marks. Eye dark brown with grey lines. Interoculus pale, with a crescent dark mark along inner margin of eye in male, prominently smokey darkened in female, and the outline of dark mark rather obscure. Antennal segments black to brownish, except basal $3 / 4$ of segment 1 yellowish. Pronotum and mesonotum yellowish with dark lateral stripes. Metanotum dark at basal half and with a median triangular dark mark. Mesopleura with a brownish stripe running through its length, not reaching its anterior margin but connected with anteroexternal angle of metacetabula (fig. 13). Metacetabula with two yellowish marks (figs. 31, 32). Fore leg with yellowish fore femur, but apical $2 / 5$ more or less dark (fig. 25); tibia and tarsi dark. Middle and hind femora in male brownish, yellowish basally. Abdominal tergites and laterotergites in some specimens prominently yellowish; in some specimens 
mainly dark. Connexiva 1-3 dark, the rest yellowish. Venter yellowish.

Pilosity. - Trichobothria on vertex conspicuous. Around antennal segment 1 with 10-12 long stiff dark spines; inner surface of segments 2-4 with dark short erect hairs (fig. 19). The hair around the constriction of male antennal segment 3 not specially modified. Pronotum and fore wing bearing dark pilosity. Pleura clothed with dark pubescence. Venter clothed by golden pubescence. Inner surface of male fore femur with 5-7 stiff spines except the long trichobothria-like pilosity; fore tibia clothed by dense dark setae which form the whole tibia as a brush, its inner surface in males with a dense row of dark spinules which short and stout at base and gradually becoming longer and thinner towards apex of tibia. Dark stiff spines scattered along middle and hind legs. Abdominal segment 8 of males with a tuft of dark setae at each corner of hind margin ventrally (fig. 40).

Structural characters. - Interoculus subequal to width of an eye, $0.51: 0.48$ in male, $0.47: 0.46$ in female. Antennae long, segment 2 much longer than 3 in male, slightly longer than 3 in female; subdistal part of the segment 3 constricted (fig. 19) in male (measurements see table 1). Pronotum more or less triangular (measurements see table 3). Lateral width of body 1.45 (ठ) , 1.66 (q). Lower part of metacetabula obtusely triangular in caudal view (figs. 31,

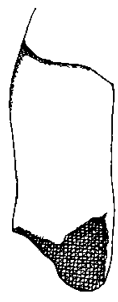

29

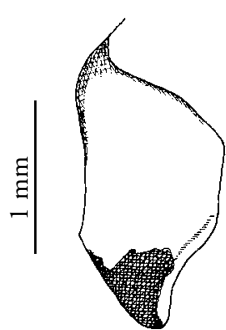

30
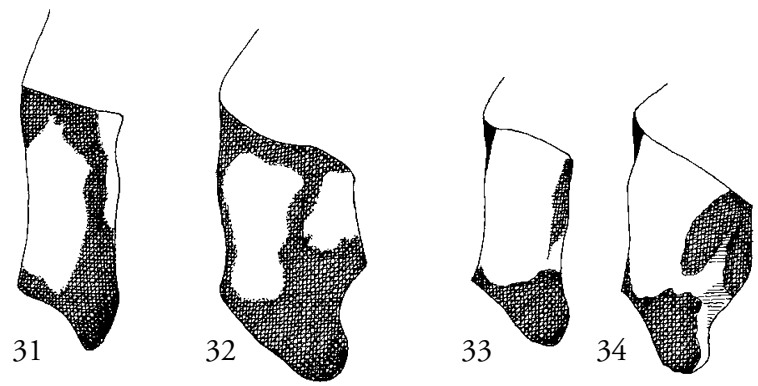

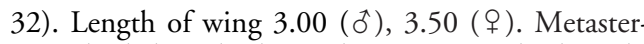
num keel-shaped, distinctly projecting backwards. Fore femur slender and not modified, claws rising from $1 / 3$ of second tarsal segment. Anterior margin of tergite 1 indistinct, anterior margin of tergite 2 faint and obliterated strongly at medium part, anterior margin of tergites 3 arched forwards. Abdominal sternite 7 as long as the preceding abdominal sternites together in both sexes.

Male terminalia. - Parameres (fig. 44) very small, symmetrical, both bar-shaped, with blunt apex; not extending beyond genital segments. Endosoma (fig. 49): dorsal sclerite long and recurved proximally, ventral sclerite long, lateral sclerite more or less straight, broadened and curved at two ends, second lateral sclerites long and thin, third lateral sclerites irregularly shaped, apical sclerite not visible.

Macropterous form. - Same as above with the following exceptions: apex of pronotum pointed (measurements see table 3 ); length of fore wings from humeri to apex 3.00 (ㅎ) 3.40 (우). Pronotum yellowish with two dark marks at anterior margin and one thick transverse band between humeral angles which is interrupted at median line, lower part of pronotum with dark margins.

Distribution (map 1). - Philippines: Luzon (Laguna, Quezon), Polillo Island, Mindanao (Cotabato South, Bukidnon).
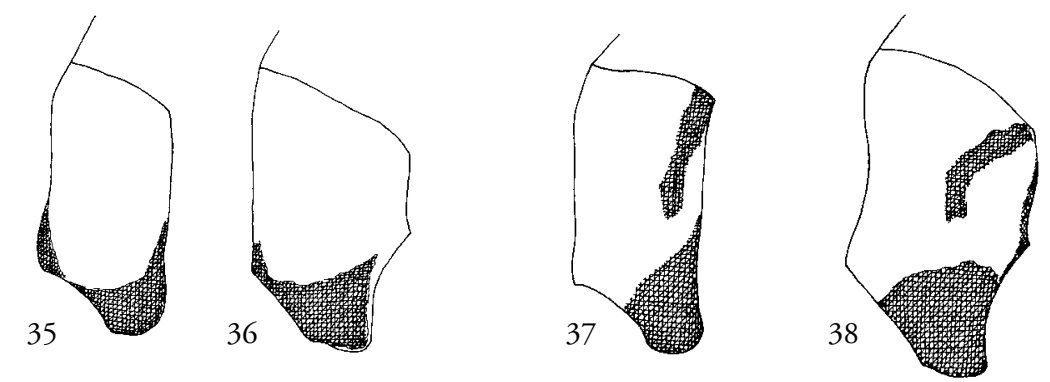

Figs. 29-38. Right metacetabula of female; odd numbers: dorsal view, even numbers: dorsolateral view. -29 , 30, V. aquarius; 31, 32, V. usingeri; 33, 34, V. harrisoni (paratype); 35, 36, V. malayensis; 37, 38, V. longitarsus. 


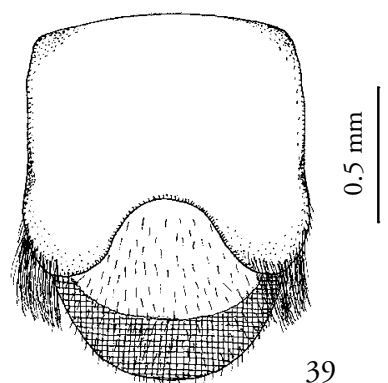

39

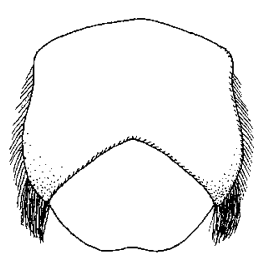

40

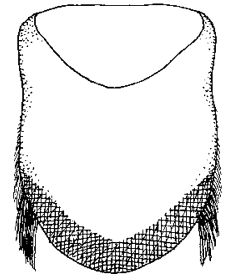

41

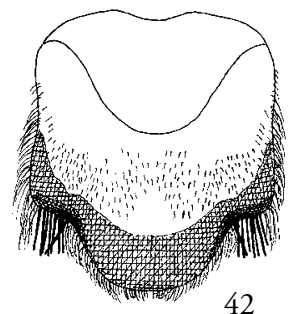

42
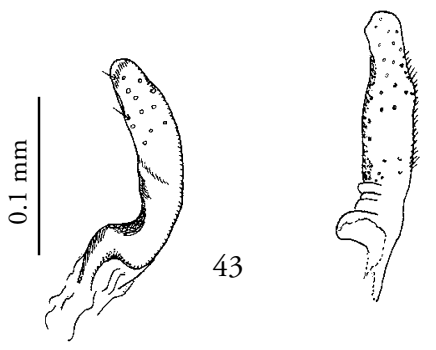

44

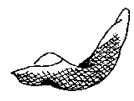

45
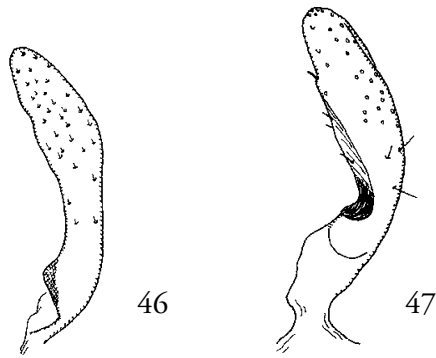

Figs. 39-47. - 39-42, Ventral view of male abdominal sternites VIII, showing the pilosity; 43-46. External view of left paramere. - 39, 43, Ventidius aquarius; 40, 44, V. usingeri; 41, 45, V. harrisoni (paratype); 42, 46, V. malayensis, 47, V. longitarsus (paratype).

Comparative notes. - This species is very similar to V. aquarius (from South India and Sri Lanka), for differences see under the comparative notes for that species.

\section{Ventidius (s. str.) harrisoni Cheng}

(figs. 14, 20, 26, 33, 34, 41, 45, 50, map 1)

Ventidius harrisoni Cheng, 1965: 155-158, 163 (descr., illustr., key); Kovac \& Yang 1989: 285 (rec.).

Type locality. - SINGAPORE.

Type material examined. - Holotype $₫$, apt., SINGAPORE: Seletar River (Sungai Seletar) (1²4’N., 10347’50’ E.), 10.iv.1964 (вмNн). Paratypes, 50 59 , apt., same locality data as holotype (BMNH, ZRCS).

Other material examined. - SINGAPORE: $11 \delta 9+$ apt., 46 larvae, Lower Peirce, forest stream, J, Dhm Phy, 6.xi.1991, coll. C.M. Yang (ZRCS, PPCC, NHMw); $10{ }^{\star} 15$ apt., Mac Ritchie, up stream, 17.vi.1994, NS161A (zRCS, PPCC, NHmw); 1 to 6 ㅇ apt., 3 larvae, Nee Soon, Swamp forest,

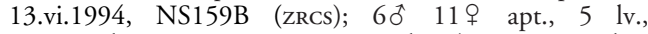
MacRitschie Reservoir, SICC nr. plot 4, 28.v.1993, leg. C.M. Yang et al., NS104 (zRCS, NHMw); 10 क 13 o apt., Nee Soon swamp forest and drain, 13.x.1986, CL 2214, leg. J.T. \& D.A. Polhemus (JTPC, NHMw); 19 apt., Chestnut Drive, 5.v.1994, NS128A (ZRCS); MALAYSIA: $60^{\circ} 79$ apt.,
North Selangor, Peat Swamp Forest, stream at $0.2 \mathrm{~km}$ from $45 \mathrm{~km}$ mark road to Sungei Bosar., 17.vi.1991, 152 (ZRCS, PPCC); $60 \hat{4} 49$ apt., 1 larva, North Selangor, Peat Swamp, Forest stream, at $50 \mathrm{~km}$ mark to Tanjong Malim, 18.vi.1991, 156, leg. H.K. Lua, Mala (ZRCs, NHMw); $1 \delta^{\widehat{ }}$ 2 q apt., 4 larvae, Selangor, Sabak Bernam, $43 \mathrm{~km}$ to sg. Besar fm. Tg. Malim, coll. T.R. Lim (zrcs); 3016 ㅇ apt., 13 larvae, Selangor, peat swamp forest, 25.iii.1994, leg. K.L. Yeo (zRCs, NHMw); $3 \hat{\sigma} 7$ apt., Johor, Gunong Panti, track 270, 22.i.1991, Y734, Leg. K.L. Yeo (ZRcs, NHMw); $1 \%$ apt., Johor, Sg. Temetang, between Kota Tinggi and Jemelung, 28.4.1993, Y828, leg. C.M: Yang (zRCs); 2 đ apt., Johor, Tg. Sedili, Sg. Selangi, muddy water, sandy bottom, up to 1.5 feet water, Coll. K.L. Yeo \& Chia Yi

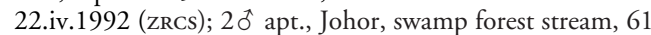
$\mathrm{km} \mathrm{NE}$ of Johor Bharu on Mersing road, 16.x.1986, CL 2220, J.T. \& D.A. Polhemus (JTPC); $1 \delta^{\star} 19$ apt., Johor, swamp forest stream, $15 \mathrm{~km}$ W of Sedili Besar, $20 \mathrm{~m}$, 16.x.1986, CL 2218, leg. J.T. \& D.A. Polhemus (JTPC); 10 1 ㅇ apt., Johor, Sg. Mupoh, 14.x.1964, leg. L. Cheng, ZRCS\&.6471-6472 (zRCS); 1 đ̂ apt., 788L, Johor, S. Bong, 5.iv.1992, leg. K.L. Yeo (zrCs); 1 ô 1 q , apt., Terengganu, north of Ayer Puteh, about $121 \mathrm{~km}$ on road from Kuantan to Kuala Terengganu, 19.iii.1992, L181, leg. H.K. Lua (zrCs); $60 \hat{0}, 3$ ㅇ apt., Kelantan, waterfall $10 \mathrm{~km} \mathrm{NW}$ of Pasir Puteh, CL 2084, 21.viii.1985, leg. J.T. \& D.A. Polhemus

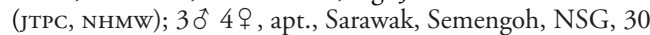
km S. Kuching, 17.ii.1993, leg. H. Zettel (2) (NHMw, PPCC); 1 đo 3 ㅇ apt., Sarawak (Borneo), Rumah Kabau anak 
muggot, Ng sebong Baleh, 25 km E. Kapit, III.1994, leg. J.

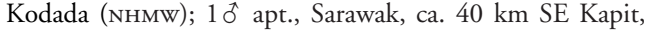
Rumah Ugap Ng, marating bena Kapit, III.1994, leg. J. Kodada (NHMw); 10 apt., Sarawak (Borneo), Tapah Riv., 16 km NW of Bau, CL 2052, 10.viii.1985, leg. J.T. \& D.A. Polhemus (JTPC); 20 49 apt., Sarawak (Borneo), $4 \mathrm{~km} \mathrm{~S}$ Tebakang, 19.viii.1985, CL 2044, leg. J.T. \& D.A. Polhemus (JTPC, PPCC); 1 tิ apt., Sarawak (Borneo), Kampong Pueh, Lundu District, 690-1500 m, 6.-12.vi.1958, leg. T.C. Маa (вIмс); 1 q apt., Sarawak, Kapit District, Merirai V., 30-300 m, 1.-6.viii.1958, secondary forest, leg. T.C. Maa (вімс); $10^{\hat{\alpha}}$ apt., Sarawak (Borneo), $8 \mathrm{~km} \mathrm{~S}$ of Tebakang, stream dissappearing into cave, CL 2046, 9.viii.1985, leg.

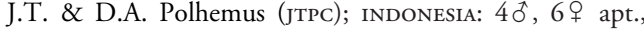
Kalimantan Timur, Long Bagun Ulu, 14.i.1995, leg. Seyfert \& Graindl (9) (NHMw, PPCC).

\section{Redescription}

Dimensions. - apterous form, length $3.38(\widehat{0})$, 3.20 ( + ), width $2.32(\hat{O}), 2.30$ (q), width of head 1.30 (하), 1.26 (우).

Colour. - Whole body prominently pale, with distinct dark stripes and marks. Eyes dark brown, their inner margin blackish. Interoculus pale, along inner margin of eye with dark stripe reaching the posterior margin of vertex. Antennal segments dark, except basal 1/5 of segment 1 . Pronotum yellowish, its anterior margin dark and with lateral dark marks. Mesonotum with lateral dark stripes. Posterior margin of metanotum dark and with a triangular dark mark basomedially which is confluent with the dark mark of abdominal tergites. Mesopleura yellowish with a broad longitudinal stripe running through its length (fig. 14). Dark mark of metacetabula see figs. 33,34 . Fore leg dark, femur with basal $2 / 3$ yellowish (fig. 26). Middle and hind leg dark. All tergites and laterotergites yellowish with posterior margin dark in female, male tergite 8 totally dark. Connexiva 1-4 dark. Venter yellowish.

Pilosity. - Around antennal segment 1 12-14 scattered long spines and with 7-8 distal short spines, segment 2 with 3 spines, segment 3 with one distal spinule in female and a tuft of longer setae around the distal part in male, all antennal segments with dense dark short erect hairs (fig. 20). Dorsum and pleura bearing dark pubescence, which is especially prominent on head. More than 10 long setae along inner surface of fore femur, their lengths decrease from basal to distal part; fore tibia clothed by dense dark setae which form the whole tibia as a brush, its distal part with an S-shaped comb (fig. 20), internal face in males with a dense row of short and stout spinules which are only slightly increasing in length towards apex. Long stiff spines scattered along middle and hind legs, tibiae with short stiff spinules. Venter clothed by golden pubescence, on abdominal sternites the pilosity longer and denser, ventral face of segment 8 of male with a narrow tuft of dark setae at each posterior angle (fig. 41).
Structural characters. - Interoculus equal to width of an eye, 0.44 and 0.44 in males, 0.42 and 0.42 in females. Antennae distinctly long and slender, especially the second segment in male much longer than usual (measurements see table 1); segment 3 modified at distal part, near apex with a shallow indentation (fig. 20). Mesonotum swollen, its lateral width 1.47 (ઠ)), 1.60 ( 9 ). Intersegmental suture between meso- and metanotum distinct and marked by a brown line. Metanotum somewhat declivent. Lower half of hind margin of metacetabula slightly bilobate, broad and nearly transverse from dorsal view (figs. 33, 34). Metasternal tubercle prominent in male. Anterior margin of abdominal tergite 1 visible; anterior margin of tergite 2 clear and obliterated strongly at medium; anterior margin of tergite 3 arched forwards. Abdominal sternite 7 as long as the preceding abdominal sternites together in both sexes. Laterotergites broad.

Male terminalia. - Parameres (fig. 45) small, symmetrical, slightly hooked, slightly curved upwards, not extending beyond genital segments, with blunt apex. Endosoma (fig. 50): dorsal sclerite long and recurved proximally, ventral sclerite long, lateral sclerite straight, broadened at two ends.

Female terminalia. - Abdominal sternite 7 large, elevated medially, posterior margin concave forward.

Macropterous form. - Unknown.

Distribution (map 1). - Malaysia: Selangor, Johor, Trenganu, Kelantan, Sarawak; Singapore; Indonesia: Kalimantan Timur.

Comparative notes. - Ventidius harrisoni is closely related to $V$. aquarius and $V$. usingeri by the characters mentioned under the comparative notes of $V$. aquarius. Differences to these species are found in males: the antennal segment 3 which has only a very shallow indentation subapically, the spines of the clasping comb on fore tibia which are only slightly increasing in length from base to tip and becoming only slightly thinner towards apex of tibia, and the segment 8 with a small tuft of hairs laterally. In some samples we found $V$. harrisoni mixed with $V$. malayensis, from which it differs in length of fore tarsi in both sexes.

4. Ventidius (s.str.) malayensis Hungerford \& Matsuda (figs. 10, 11, 15, 21, 27, 35, 36, 42, 46, 51, map 1)

Ventidius malayensis Hungerford \& Matsuda, 1960: 325326, 336 (descr., illustr., key); Kovac \& Yang 1989: 285 (rec.).

Type locality. - MALAYSIA: Selangor.

Type material examined. - Holotype $\hat{\delta}$ and allotype $q$, Malaya, Selangor, F.M.S., Sungai Ampang, 15.Aug.1926, C. Dover, Ex. Coll. F.M.S: Museum (вмNн). The holotype also labelled 'Ventidius aquarius Dist., det. Teiso Esaki', the allotype bears the label 'Metrocoris aquarius Dist., det. Dover 26'. 

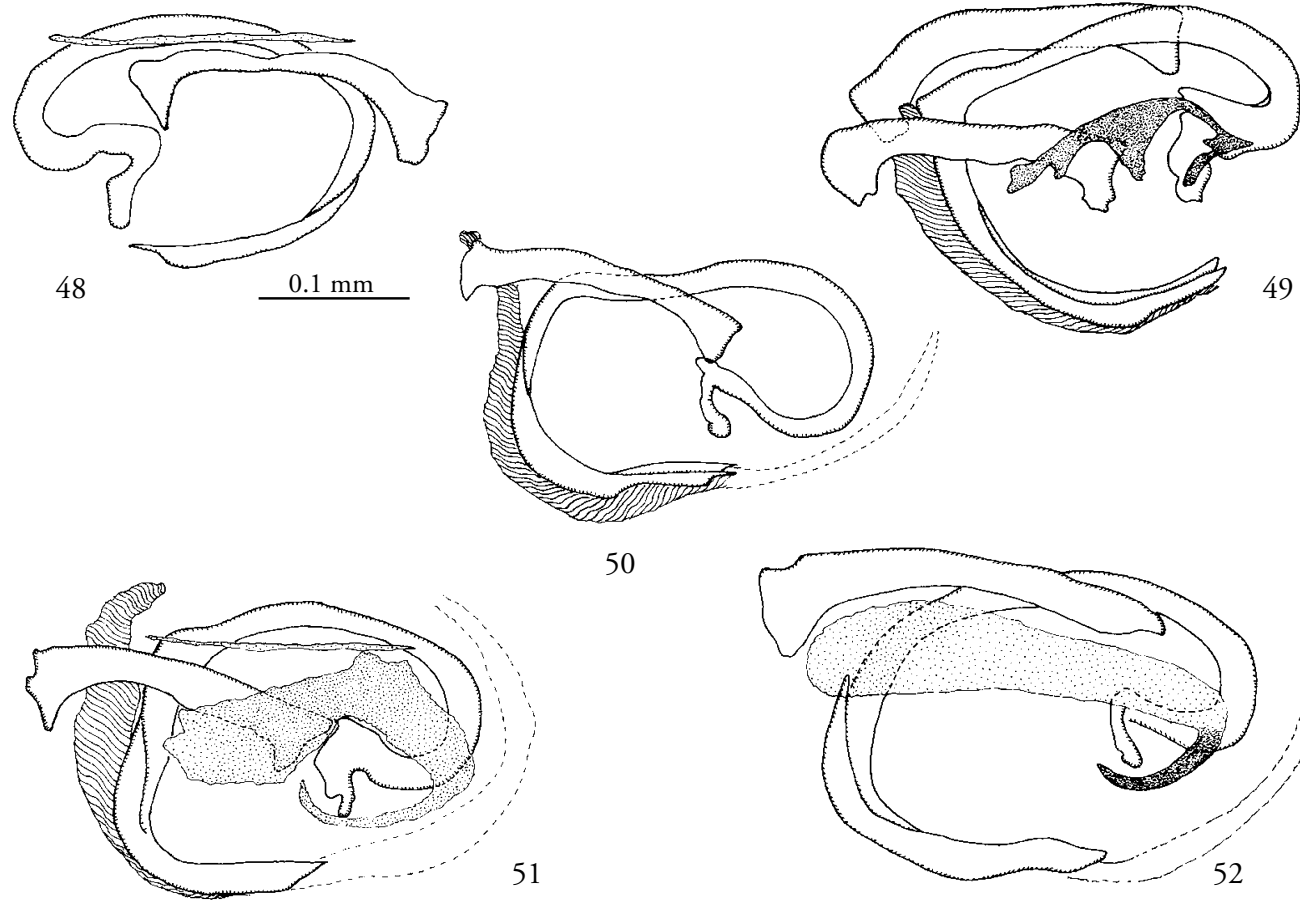

50

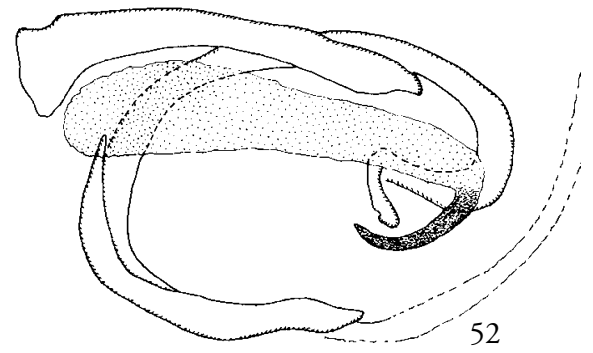

Figs. 48-52. Lateral view of endosoma sclerites. - 48, Ventidius aquarius; 49, V. usingeri; 50, V. harrisoni (paratype); 51, V. malayensis; 52, V. longitarsus (paratype).

Other material examined. - THAILAND: $1 \delta 1 \%$ apt., Kanchanaburi, Sai Yok waterfall, river Kwai, VIII.1979, leg. B. Petersen (ZMUC); 49 apt., Kanchanaburi, Sai Yok, waterfall, 21.-22.xii.1981, leg. N.M. Andersen (ZMUC); SINGAPORE: 4 đ 1 ㅇ apt., 16,5 miles Mersing, Mersing Kluang Rd., 4.viii.1963, leg. L. Cheng (вмNн); 1 apt., Nea Soon, swamp forest, 13.vi.1994, NS159B (ZRCS); MALAYSIA: $30^{\star}$ 7 , lv, Pahang, S. Seladang, 13. and 19.vii.1989, leg. K.L. Yeo \& E. Koh, zRCS 6.2619-2632 (zRCS, NHMw); 2 apt., Pahang, S. Kernam, 19.vii.1989, leg. K.L. Yeo, zRCS 6.2634-2635 (zRCS); 1 a apt., Pahang, S. Kinchin, 13.vi.1989, leg. C.M. Yang (ZRCS); $1 \sigma^{\star}$ apt., Johor, Taku, 19.vii.1989, leg. K.L. Yeo, zRCS 6.2633 (zRCS); 1 to apt., 5lv, Johor, S. Marong, 5.iv.1992, 788M, leg. K.L. Yeo (zRCS); $1 \delta^{\text {T }} 4$ 우 apt., 788L, Johor, S. Bong, 5.iv.1992, leg. K.L. Yeo (zrcs, NHMw); 101 apt., Johor, stream 12 km $\mathrm{N}$ of Labis, CL 2087, 22.viii.1985, leg. J.T. \& D.A. Polhemus (JTPC); 60 , 99 apt., Johor, $27 \mathrm{~km} \mathrm{~S}$ of Mersing, slow shaded stream, CL 2058, 14.viii.1985, leg. J.T. \& D.A. Polhemus (JTPC, PPCC); 4 ㅇ apt., Johor, Endau, Sg. Anak Jasin, 4.iv.1992, L186, leg. H.K. Lua (zRCs); 10 3 \% apt. 5 lv., Johor, S. Anak, Jasin, Y788D2, leg. K.L. Yeo, 4.iv.1992 (zRCS); $5 \hat{0}, 5 q$ apt, $1 \hat{0}$ macr., Perak, stream $58 \mathrm{~km} \mathrm{~S}$ of Grik, CL 2077, 19.viii.1985, leg. J.T. \& D.A. Polhemus (JTPC, NHMw); 2 apt., Upper Perak, Longgong, surface of irrigation channel, fast water, 22.x.-5.xi.1926 (BMNH); 2 운 apt., Sarawak (12), Kelabit Highland, $5 \mathrm{~km}$ E Bareo, Pa Ukat 1000 m, 27.ii.1993 (a) mäandrierender ca 6 m breiter
Fluß, leg. H.Zettel (Nнmw); 2 apt., Sarawak, Mulu N.P., 3-5.iii.1993, leg. H. Zettel (14), (e) rechter Zufluß des Tutoh River bei Long Iman, ca. $8 \mathrm{~m}$ breit, 4.3. (NHMw); $10^{\widehat{0}}$ 1 ㅇ apt., Sarawak, Nanga Pelagus nr. Kapit, 180-585 m, 717.viii.1958, T.C. Maa Collector (BIMC); 1 ㅇ apt., Sarawak, Sadong, Kampong Tapuh 300-450 m, 10.vii.1958, T.C.

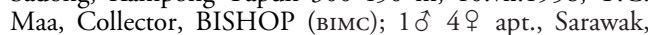
Kapit Dist., Merirai V., 30-300 m, 1-6.viii.1958, Secondary Forest, T.C. Maa Collector, No. MB164 (BIMC, SEMC); 40 apt., Sarawak, Sameran River, $2 \mathrm{~km} \mathrm{~W}$ of Tubeh, CL 2047 , 19.viii.1985, leg. J.T. \& D.A. Polhemus (JTPC); 90 t 10 우 apt., Sarawak (Borneo), Tapah Riv., $16 \mathrm{~km} \mathrm{NW}$ of Bau, CL 2052, 10.viii.1985, leg. J.T. \& D.A. Polhemus (JTPC, NHмw, PpCC); 19 apt., Sabah, Tibow Estate, slow flow stream, MB42, 25.5.1996, leg. T.B. Lim (zRCs); BRUNEI: $10 \hat{~ a p t ., ~ T e m b u r o n g, ~ B e l a l o n g ~ F i e l d ~ R e s . ~ C e n t r e, ~ S u n g a i ~}$ Belalong, 60 m, 2-8.v.1995, leg. E. Heiss (zCWA); INDONESIA: $90^{\circ} 23 q$ apt., 4079 macr., Kalimantan Timur Province, Borneo, waterfall and stream, $11 \mathrm{~km} \mathrm{NE}$ of Samarinda, CL 2091, 27.viii.1985, leg. J.T. \& D.A. Polhemus (JтPC, NHмw, PрCC); 101 i apt., C. Borneo, Sg. Birang, leg. Mjöberg 1925, Coll. Dr. D. MacGillavry (ZMAC).

\section{Redescription}

Dimensions. - Apterous form, length $4.02(\delta)$ $4.26(q)$, width $2.90($ ( ), $2.93(q)$, width of head $1.60($ ( $), 1.55$ (우). 
Colour. - Whole body prominently pale, with distinct dark stripes and marks (fig. 11). Eyes mainly dark brown to blackish, their margins greyish. Interoculus pale with three obscure long dots, which are not connected with margin of vertex, along inner margin of eye dark which is confluent with the dark mark of pronotum. Antennal segments dark, except basal $2 / 5$ of segment 1 . Pronotum yellowish with lateral dark marks which are more prominent anteriorly. Mesonotum with lateral dark stripes. Metanotum with a large triangle-shaped dark mark basomedially which is confluent with the dark mark of tergites, and with two irregular lateral dark marks which are confluent with the dark stripes of mesonotum. Mesopleura yellowish with a broad longitudinal stripe running through its length (fig. 15); external angle of metacetabula dark (fig. 35, 36). Fore leg dark, femur with basal $1 / 2$ of fore femur yellowish (fig. 27). Middle and hind legs dark. Tergite 1 along anterior margin yellowish, the triangle-shaped dark mark confluent with a dark mark of metanotum; tergites 2-8 dark laterally with a median yellowish mark which varies individually. Laterotergites yellowish. Connexiva either black or 1-4 blackish, 5-7 brownish. Venter yellowish.

Pilosity. - Around antennal segment 1 7-8 scattered long spinules, and with 5-6 distal short spinules, segment 2 with one subbasal spinule, segment 3 with a tuft of longer setae around the distal part, all antennal segments with silvery fine hair fringe. Dorsum and pleura bearing dark pubescence, especially prominent on head. Circa 20 long setae along inner surface of fore femur, their length decreasing from base to apex; fore tibia clothed by dense dark setae which form the whole tibia as a brush, its distal part with an S-shaped comb (fig. 27). Long stiff spines scattered along middle and hind legs, tibia with shorter stiff spinules. Basal part of middle and hind femora with two very long trichobothria-like setae on dorsal surface respectively, external one shorter than internal one. Venter clothed by golden pubescence, on genital segments the pilosity slightly longer and denser, ventral face of segment 8 of male with a tuft of broader range (compared with the case in $V$. harrisoni) dark setae at each posterior angle from ventral view (fig. 42).

Structural characters. - Interoculus subequal to width of an eye, $0.55: 0.50$ in males, $0.51: 0.56$ in females. Antennae distinctly long and slender, especially segment 2 in male much longer than usually (measurements see table 1); segment 3 modified at distal half, near apex with a shallow indentation (fig. 21). Thorax bulbous, mesonotum swollen, its lateral width 1.93 (ठ)), 1.96 (ㅇ). Intersegmental suture between meso- and metanotum faint but visible. Metanotum somewhat declivent. Lower half of hind margin of metacetabula slightly bilobate, broad and nearly transverse from dorsal view (figs. 35, 36). Metasternal tubercle prominent in male. Anterior margin of abdominal tergite 1 visible; anterior margins of tergites 2 and 3 faint, obliterated medially and protruding forward; abdominal sternite 7 as long as the preceding abdominal sternites together in both sexes. Laterotergites broad.

Male terminalia. - Parameres (fig. 46) small, symmetrical, more or less straight, slightly curved upwards, not extending beyond genital segments, with blunt apex. Endosoma (fig. 51): dorsal sclerite long and recurved proximally; ventral sclerite long; first lateral sclerites straight, broadened and curved at two ends; second lateral sclerites slender and long; third lateral sclerite broad, distal part slender and recurved backwards; apical sclerite indistinct.

Female terminalia. - Abdominal sternite 7 large, elevated medially, sometimes keel-like, posterior margin concave forward.

Macropterous form. - As apterous form with the following exceptions: apex of pronotum bluntly pointed (measurements see table 3 ); length of fore wings from humeri to apex 3.30. Dark mark of pronotum see fig. 10.

Variations. - Specimens from Borneo show small differences in relative lengths of antennal segments and colour of pronotum; the Bornean population is regarded as of infrasubspecific rank.

Distribution (map 1). - Thailand: Kanchanaburi; Malaysia: Selangor, Pahang, Johor, Perak, Sarawak, Sabah; Singapore; Brunei; Indonesia: Kalimantan Timur.

Comparative notes. - This species is very closely related to $V$. longitarsus sp. n. It differs from the other species of the group ( $V$. aquarius, $V$. harrisoni, and $V$. usingeri) by longer fore tarsi, by lacking a row of stiff spines on male fore tibia, and by long hairs apically on segment 3 of males. For differences between $V$. malayensis and $V$. longitarsus sp. n. see comparative notes of that species.

\section{Ventidius (s. str.) longitarsus sp. $\mathrm{n}$.} (figs. 16, 17, 22, 28, 37, 38, 47, 52, 53, map 1)

Ventidius (s. str.) sp.: Zettel \& Chen 1996: 152, 180 (list, rec.).

Type locality. - viET NAM: : Da Lat Province, Mdrak, E of Ban Me Thuot.

Type material. - Holotype: $\hat{0}$, apt., vIET NAM: : [Da Lak Province] Mdrak E. of Ban Me Thuot, 4$600 \mathrm{~m}, 8-19 . x i i .1960$, C.M. Yoshimoto collector (BIMC). - Paratypes: $10 \hat{~} 2 \%$ apt., same locality data as holotype (BIмC, NHмw); 20 , 5 ㅇ apt., Gia Lai-Kon-

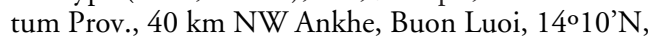
108³0'E, 620-750 m, 28.iii.-12.iv.1995, leg. Pacholatko \& Dembicky (NHMw, PPCC). 


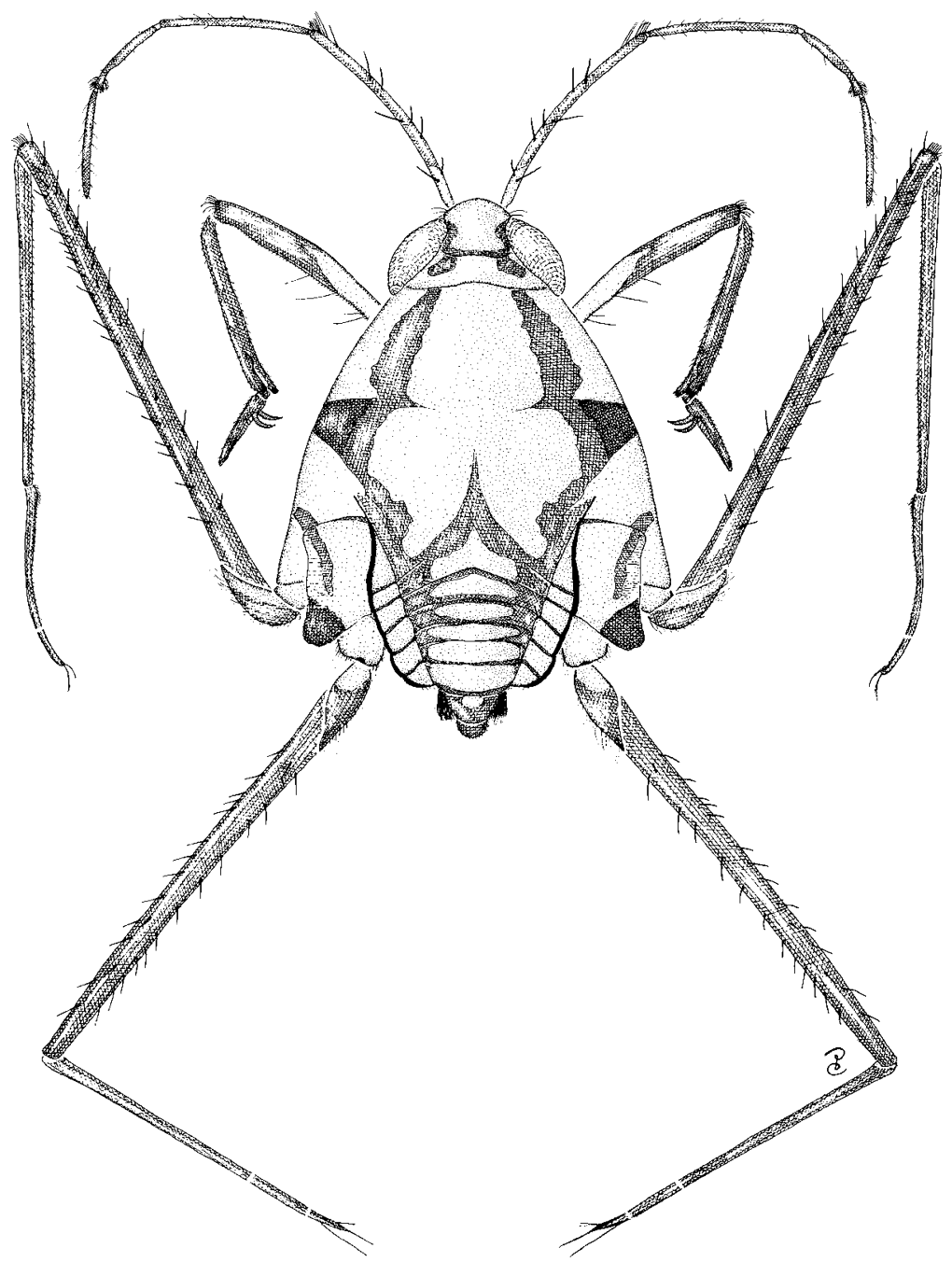

Fig. 53. Ventidius (s. str.) longitarsus, holotype, apterous male, length $4.60 \mathrm{~mm}$.

Etymology. - This species is named after the long fore tarsus of male.

\section{Description}

Dimensions. - apterous form, length 4.60 ( $\widehat{0})$, 4.40 () , width 3.10 (क)), 2.96 (ㅇ), width of head $1.65($ (ో) $), 1.61($ ( $)$.

Colour (fig. 53). - Whole body prominently pale, with distinct dark stripes and marks. Eyes mainly dark brown to blackish, their margins greyish. Interoculus pale with three obscure long dots, not connected with margin of vertex, along inner margin of eye dark posteriorly which is confluent with the dark mark of pronotum. Antennal segments dark, except basal 2/5 of segment 1 . Pronotum yellowish with dark lateral mark which is more prominent anteriorly. Mesonotum with dark lateral mark. Metanotum with a triangle-shaped dark mark basomedially which is confluent with the dark mark of tergites, and with two irregular-shaped dark lateral marks which are confluent with the dark strip of mesonotum. Mesopleura yellowish with a broad longitudinal stripe running through its length (figs. 16, 17); external angle of metacetabula dark (figs. 37, 38). Fore leg dark, femur with basal $1 / 2$ yellowish (fig. 28). Middle and hind legs dark. Tergite 1 along anterior margin yellowish, the triangle-shaped dark mark confluent with dark mark of metanotum; tergites 2-8 dark laterally 
with a median yellowish mark which varies individually. Laterotergites yellowish. Connexiva either totally black or 1-4 brownish and 5-7 yellowish. Venter yellowish.

Pilosity. - Around antennal segment 1 7-8 scattered long spinules, and with 5-6 distal short spinules, segment 2 with one subbasal and one subdistal spinules, segment 3 with a tuft of longer setae around the distal part, all antennal segments with silvery fine hair fringe (fig. 22). Dorsum and pleura bearing dark pubescence, which is especially prominent on head. Circa 20 long setae along inner surface of fore femur, their lengths decrease from basal to distal part; fore tibia clothed by dense dark setae which form the whole tibia as a brush, its distal part with an S-shaped comb (fig. 22). Long stiff spines scattered along middle and hind legs, tibia with shorter stiff spinules. Basal part of middle and hind femora with two very long trichobothria-like setae on dorsal surface respectively, the external one shorter than internal one. Venter clothed by golden pubescence, on genital segments the pilosity slightly longer and denser, ventral face of segment 8 of male with a tuft of broader ranged (compared with the case in $V$. harrisoni) dark setae at each posterior angle from ventral view.

Structural characters. - Interoculus broader than width of an eye, 0.63 and 0.52 in males, 0.58 and 0.51 in females respectively. Antennae distinctly long and slender, especially segment 2 in male much longer than usual (measurements see table 1); segment 3 modified at distal half, near apex with an indentation (fig. 22). Thorax bulbous, mesonotum swollen, its lateral width 1.95 (ô), 2.00 ( + ). Intersegmental suture between meso- and metanotum faint but visible. Metanotum somewhat declivent. Lower half of hind margin of metacetabula slightly bilobate, broad and nearly transverse from dorsal view (figs. 37, 38). Metasternal tubercle prominent in male. Anterior margin of abdominal tergite 1 visible; anterior margins of tergites 2 and 3 faint, obliterated medially and protruding forward; abdominal sternite 7 as long as the preceding abdominal sternites together in both sexes. Lateral tergite plate broad.

Male terminalia. - Parameres (fig. 47) small, symmetrical, more or less straight, inner surface with indentation at basal half, not extending beyond genital segments, with blunt apex. Endosoma (fig. 52): dorsal sclerite long and recurved proximally, ventral sclerite long, lateral sclerite straight, broadened at proximal end, second lateral sclerite long oblique and distinct, the third lateral sclerite broad, darkened and curved at distal part, apical sclerite indistinct.

Female terminalia. - Abdominal sternite 7 large, elevated medially, posterior margin concave forward.

Macropterous form. - Unknown.

Distribution (map 1). - Viet Nam: Da Lak, Gia

\section{Lai-Kontum.}

Comparative notes. - This species is very similar to $V$. malayensis Distant, but has larger size and darker colouration. Main difference is the very long segment 2 of male fore tarsus (see table 2), with claws arising from basal $1 / 6$ of the segment.

\section{The Ventidius modulatus-group}

Diagnosis. - Comparatively smaller size, length

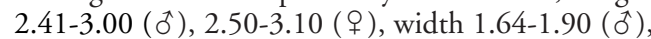
1.74-2.20 ( + ); length of antennae intermediate; segment 1 longer or subequal to segments 2 and 3 together, usually less than $1.20 \mathrm{~mm}$; length of segment 2 in male not or slightly longer than segment 3 (up to 1.4 times); antennal segment 1 usually with less than 8 long setae, in males segments $2-4$ with dense erect silvery pubescence and segment 3 without indentation near apex; inner surface of fore tibia with dense setae, in distal part with a row of stout spinules forming an S-shaped comb, never with a long row of stout spinules; middle and hind legs distinctly more slender than in the $V$. aquarius-group; segment 8 (s8) of male without tufts of dark setae at each posterior angle, parameres small and symmetrical, usually distinctly dilated apically (except in $V$. henryi); in three species endosoma with a third pair of lateral sclerites, which are very broad only at distal part slender and recurved backwards.

Distribution (maps 2, 3). - Widely distributed in Oriental region, from Sri Lanka to Philippines (Palawan region) and Borneo, in the east reaching the Wallacea (Sumbawa and Sumba), but unknown from $\mathrm{Su}$ lawesi.

\section{Ventidius (s. str.) henryi Esaki} (figs. 54, 55, 60, 67-69, 75, 76, 88, 96, 114, map 2)

Ventidius henryi Esaki, 1928: 509-511 (descr., illustr.); Lundblad 1933: 372 (list); Hungerford \& Matsuda 1960: 327-329 (descr., illustr., key).

Type locality. - SRI LANKA: Sabaragabuwa.

Type material examined. - Holotype, $\widehat{\delta}$ apt., SRI LANKA: Sabaragabuwa Prov., Kitulgala, 12.iv.1927,. leg. G.M. Henry (вмNн). Paratypes, $3 q$ apt., same locality data as holotype (BMNH).

Other material examined. - SRI LANKA: 30 t $2 q$ apt., Sabaragabuwa Prov., Kitulgayala, Dec., 1934 (sEmc); 407 3 q apt., Sabaragabuwa Prov., 57th mi. Kitulgayala, 23.vii.1966, leg. Karunaratne (JTPC); 3 ô 3 ㅇ Central Prov., 6.-7.viii.1966, leg. P.B. Karunaratne (JTPC, NHMw); 203 우 apt., 1 larva, Central Prov., Noari Estate, Noari, 10.vi.1966, leg. D.N. Bartholomaeusz (JTPC, PPCC); $70 \hat{~} 6 q$ apt., 19 macr., Southern Prov., Homadola, Udugama, 2.vi.1966, leg. Karunaratne (semc, NHMw, JTPC); (Prov.?): 201 1 \% apt., Pitamba, Ela., 26.i.1958, leg. K.L.A. Perera (semc). 


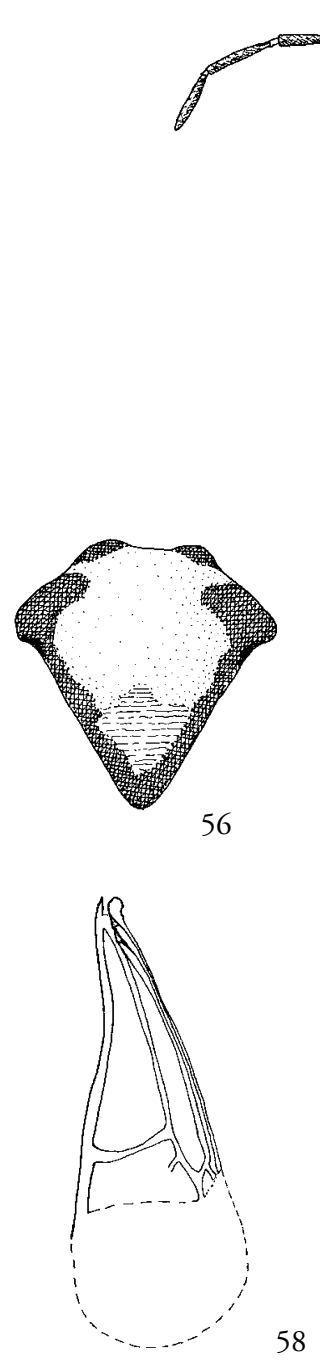

58

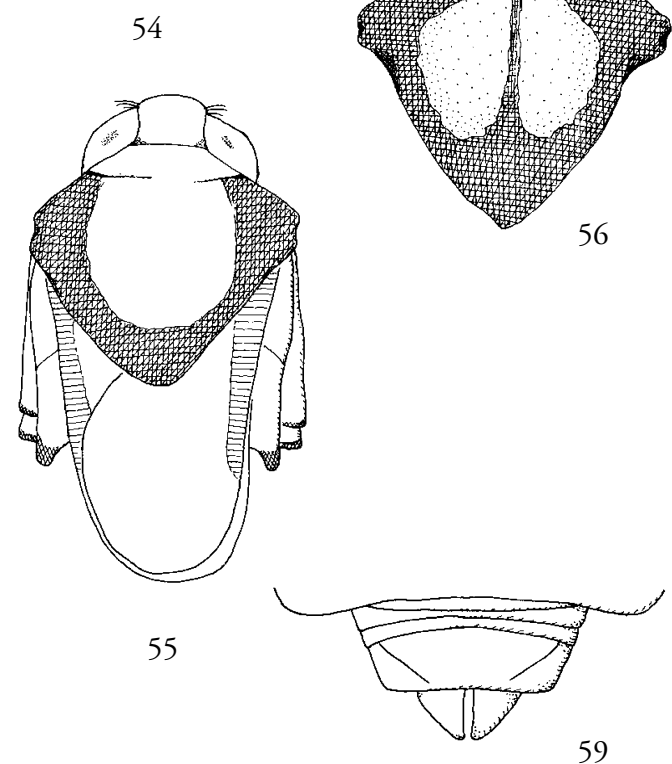

Figs. 54-59.

54, Ventidius henryi, holotype, dorsal view of apterous male (legs removed), length $2.44 \mathrm{~mm}$. - 55, Ventidius henryi dorsal view of macropterous female (appendages removed). - 56, 57, Macropterous pronotum. $-56, \mathrm{~V}$. polhemorum; 57, $V$. werneri. $-58, V$. hungerfordi, dorsal view of right fore wing (after Lansbury 1990). - 59, $V$. modulatus (female), ventral view of abdominal segments.

\section{Redescription}

Dimensions. - Apterous form, length 2.46 (ઠ)), 2.70 ( + ), width 1.64 (o), $1.84(q)$, width of head 1.04 (ठํ), 1.08 (ㅇ).

Colour (fig. 54). - Whole body predominantly dark dorsally, with yellowish marks. Eyes blackish. Interoculus dark from dorsal view, with a thick Mshaped yellowish mark at its posterior margin, along inner margin of eye with a dark stripe which is connected with anterior margin of pronotum. Male antennal segments blackish except at basal $1 / 3$ of segment 1. Pronotum blackish, posterolateral angle with a very small and indistinct yellowish mark. Mesonotum with broad dark lateral stripes, which are confluent with the lateral black stripe of metanotum. Metan- otum dark laterally and a triangular dark mark basomedially which reaches its anterior margin. Mesopleura yellowish with a longitudinal stripe at anterior half (figs. 67-69); posterior margin of metapleura dark; metacetabula black with central yellowish mark (figs. 75, 76). Fore leg totally black (fig. 88). Middle and hind legs dark. Tergites 1-3 blackish, 4 blackish with a small obscure yellowish mark in the middle, 56 yellowish, 7-8 dark. Laterotergites and connexiva 14 blackish, 5-7 yellowish in male, predominantly yellowish with dark margins in female. Venter yellowish, male segment 8 ventrally darker.

Pilosity. - Inner surface of antennal segment 1 with 4 subbasal, and 1 subdistal long spines, along ventral surface of segments 2-4 clothed with usual pubes- 
cence and longer setae; from distal half of segment 1 , through all segments with dark fine hair fringe. Dorsum and pleura bearing dark and golden pubescence. Long stiff bristles scattered along middle and hind legs, tibiae with shorter stiff bristles. Venter clothed by golden pubescence, on genital segments the pilosity slightly longer and denser.

Structural characters. - Interoculus broader than width of an eye, $0.42: 0.34$ in males, $0.45: 0.36$ in females. Antennae moderately strong in male, segment 2 roughly of same length as segment 3 in male, shorter than segment 3 in females (measurements see table 1) (fig. 60). Pronotum not bulbous, mesonotum swollen dorsally, its lateral width 1.08 (ठ) , 1.30 ( + ). Intersegmental suture between meso- and metanotum faint to obscure. Metanotum somewhat declivent. Lower half of hind margin of metacetabula obtusely triangular (figs. 75, 76). Metasternal tubercle not prominent in male. Anterior margin of abdominal tergite 1 obscure; anterior margins of tergites 2 and 3 faint, obliterated medially and protruding forward; abdominal sternite 7 as long as the preceding abdominal sternites together in both sexes.

Male terminalia. - Parameres (fig. 96) symmetrical, straight, bar-shaped with blunt apex; slightly extending beyond genital segments. Endosoma (fig. 114): dorsal sclerite long and recurved proximally, ventral sclerites long, lateral sclerites straight, hooked at apical end and broadened at distal end, second lateral sclerites long and thin, third lateral sclerites curved.

Female terminalia. - Abdominal sternite 7 large, broadly elevated medially, posterior margin slightly concave forward.

Macropterous form. - As apterous form except the apex of pronotum pointed (measurements see table 3); length of fore wings from humeri to apex 2.00. colour pattern of pronotum (fig. 55) black with two small roundish yellowish blotches. Wings anteriorly black with fine pubescence and with dense longer black hairs. Posterior membranous part of wings dark brown.

Distribution (map 2). - Sri Lanka: Sabaragabuwa, Central Prov., Southern Prov., Pitamba (Prov.?).

Comparative notes. - Ventidius henryi differs from all other species of the $V$. modulatus-group by much darker colouration (e.g. the black pronotum and completely black fore leg) and very different shape of paramere which is bar-shaped and not broadened in distal part.

\section{Ventidius (s. str.) hungerfordi Cheng}

(figs. 58, 61, 62, 77-80, 89, 90, 97, 115, 123, 124, map 2)

Ventidius hungerfordi Cheng, 1965:158-159, 163 (descr., illustr. \& key); Kovac \& Yang 1989: 285 (rec.).

Type locality. - MALAYsia: Johor.

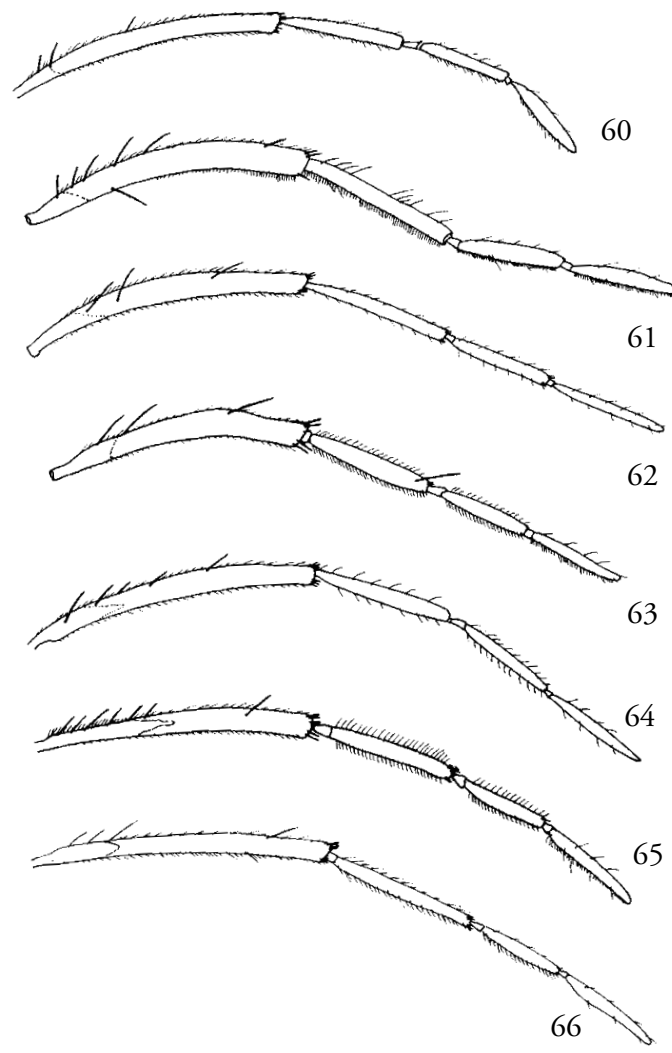

Figs. 60-66. Dorsal view of male right antennae. - 60, Ventidius henryi; 61, V. hungerfordi, apterous; 62, same species, macropterous; 63, V. polhemorum; 64, V. werneri; 65, V. pilosus; 66, V. modulatus.

Ventidius wallacei Lansbury, 1988: 61-65 (synonym, descr., illustr.). Syn. n.

Type locality. - MALAYsia: Selangor, Johor.

Type material examined. - Ventidius hungerfordi: Holotype $\hat{\sigma}$, apt., Malaysia: Selangor, Ampang, Sungai Kongsi Lapan (310' N., 10146’30'E.), 2000 ft., 13.iii.1964, leg. L. Cheng (вмNн); Paratypes: $1 \delta^{\dagger}$ apt., same locality data, ZRCS 6.998 (zRCS); $1 \delta^{\pi}$ apt., Johor, stream at 48th mile, Mersing-Kluang Road, leg. C.H. Fernando, zRCs 6.997 (zRCS); 1 \& apt., Johor, Sungai Kayu Ara, 5.x.1964, leg. L. Cheng (BMNH).

Ventidius wallacei: Holotype $\widehat{\jmath}$, macr., Malaysia: Mt. Ophir [= Gunong Ledang, Johor; Yang, pers. comm.] (A.R. Wallace) Westwood Coll. Oxford (OUMC).

Other material examined. - THAILAND: 204 apt., Kanchanaburi, Khao Phang waterfall, 70 km NW Kanchanaburi, 10.ix.1991, leg. P. Nielsen (ZMUC, NHMw); 1 ㅇ apt., Kanchanaburi, Sai Yok, waterfall, 21-22.xii.1981, leg. N.M. Andersen (ZMUC); w. MALAYSIA: $7 \hat{0} 69$ apt., 19 macr., Johor, Panti, stream, 20.ix.1990, leg. C.M. Yang \& H.K. Lua, Y29b (zRCS, NHMw); 3 ô 7 o apt., Johor, same locality data, Y29e 


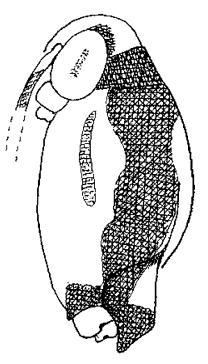

67

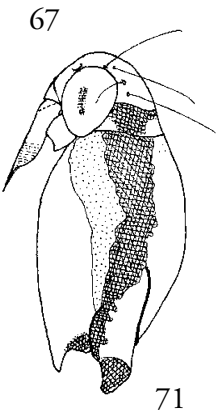

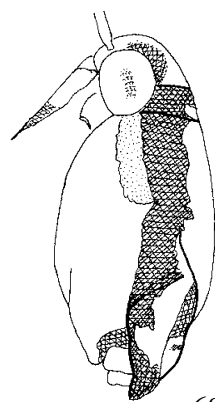

68
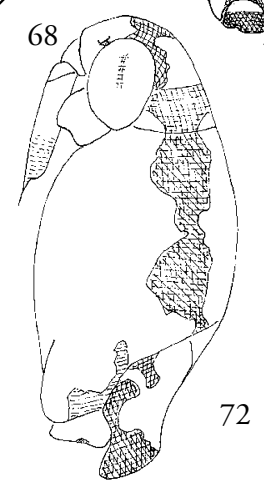

72
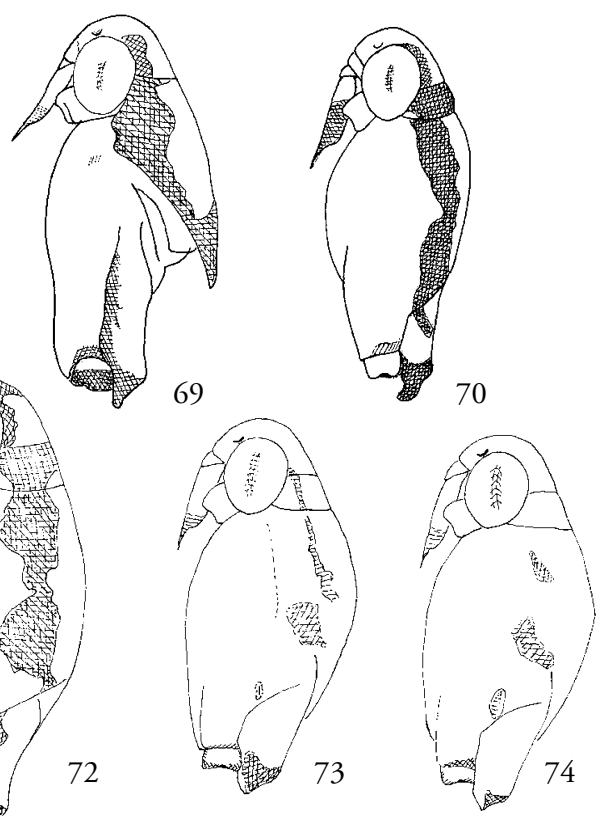

Figs. 67-74. Lateral view of apterous male, showing the colour pattern of pleura. - 67, 68, Ventidius henryi, apterous; 69, same species, macropterous; 70, V. polhemorum; 71, V. werneri; 72, V. pilosus; 73-74, V. modulatus (lectotype).

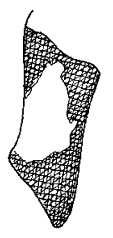

75

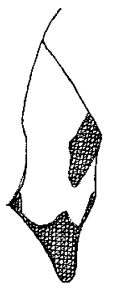

81

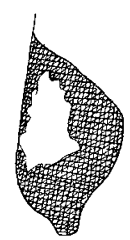

76

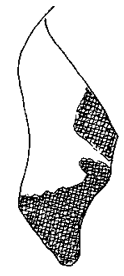

77

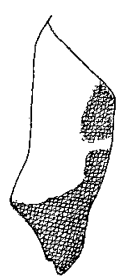

78
79

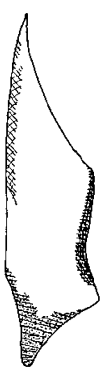

80

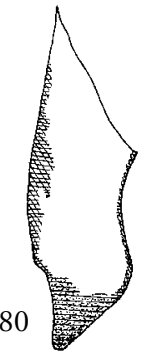

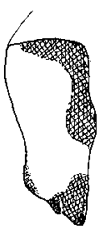

83

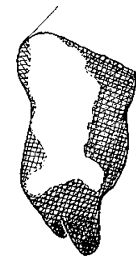

84

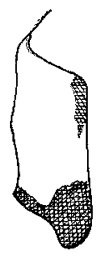

85

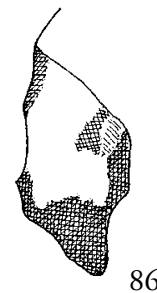

86

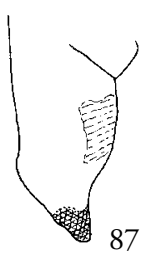

Figs. 75-87. Right metacetabula of male; odd numbers (except 87): dorsal view, even numbers and 87: dorsolateral view. 75, 76, Ventidius henryi; 77, 78, V. hungerfordi; 79, 80, same species, macropterous; 81, 82, V. polhemorum; 83, 84, V. werneri; 85, 86, V. pilosus; 87, V. modulatus (lectotype). 


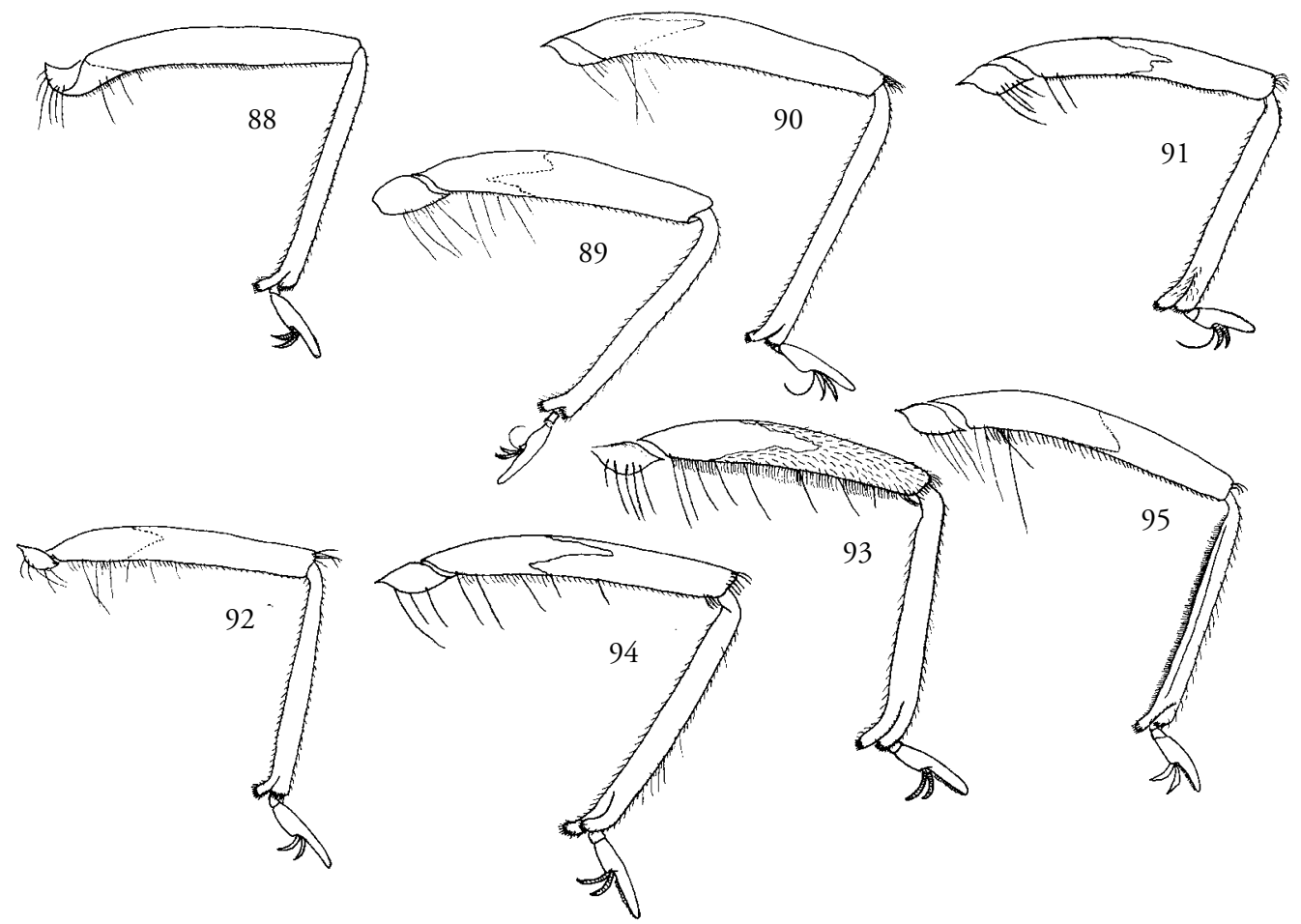

Figs. 88-95. Dorsal view of male right fore legs. - 88, Ventidius henryi; 89, V. hungerfordi; 90, same species, macropterous; 91, V. polhemorum; 92, V. werneri; 93, V. pilosus (male); 94, same species, female; 95, V. modulatus (lectotype).
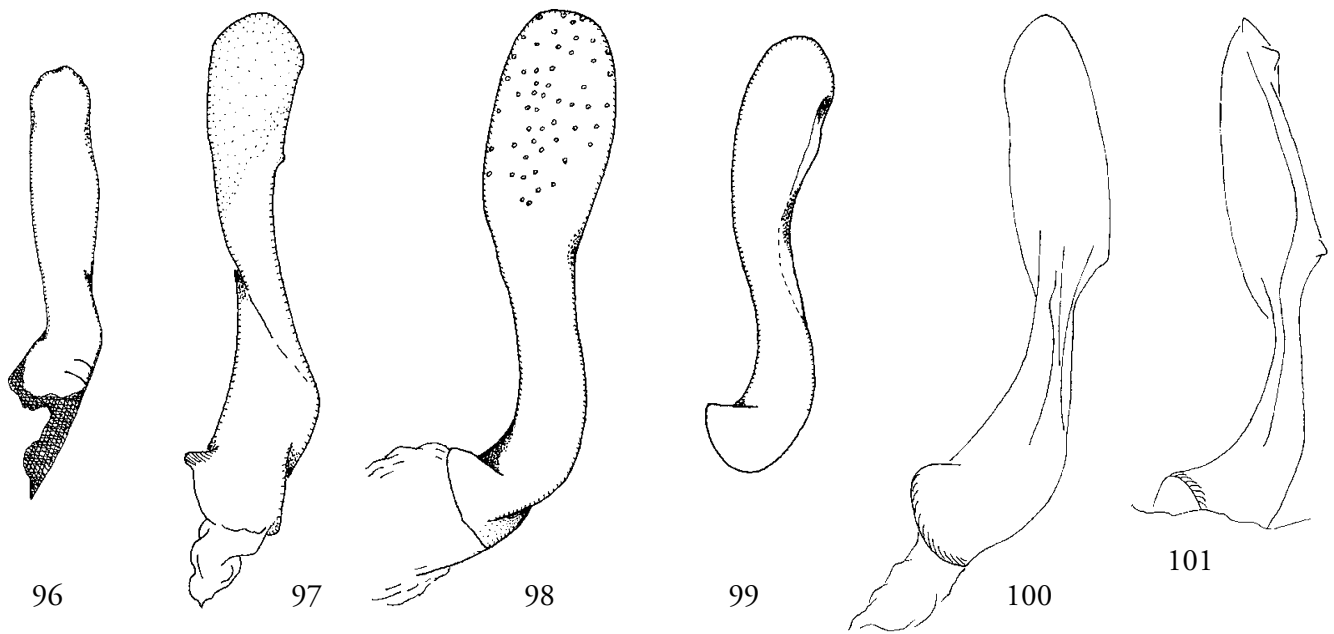

Figs. 96-100. External view of left paramere. - 96, Ventidius henryi; 97, V. hungerfordi; 98, V. polhemorum; 99, V. werneri; 100, V. pilosus, 101, V. pilosus, laterointernal view of right paramere. 


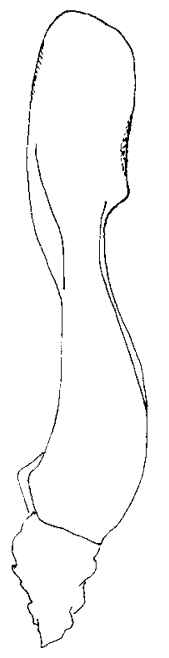

102

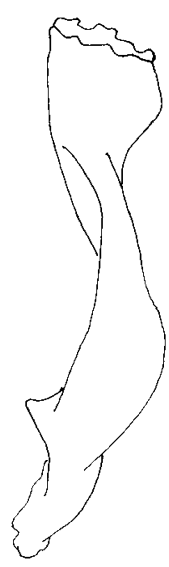

103

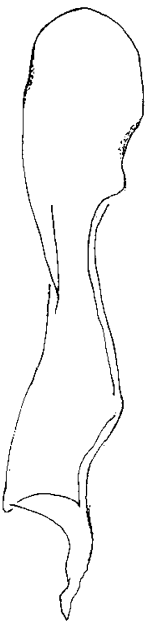

104

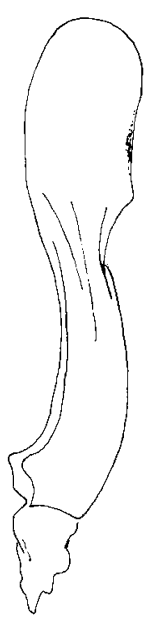

105

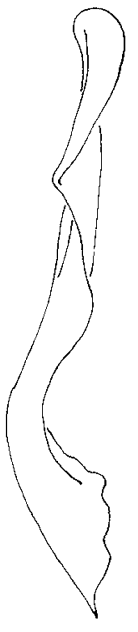

106

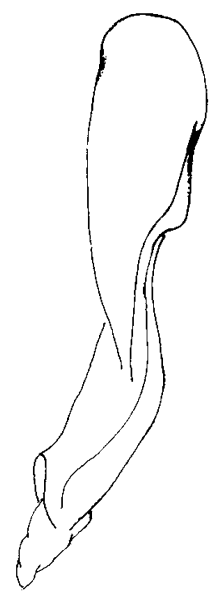

107

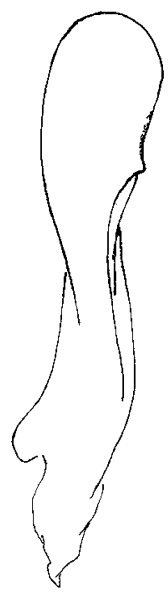

108

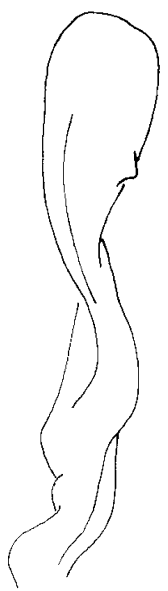

109

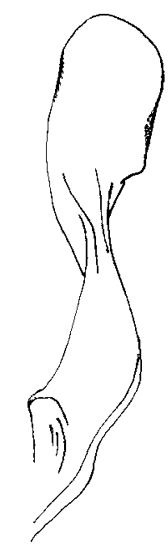

110

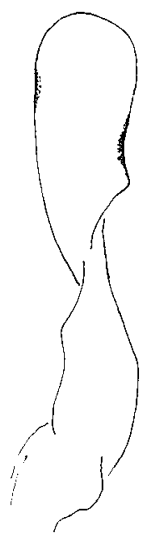

111

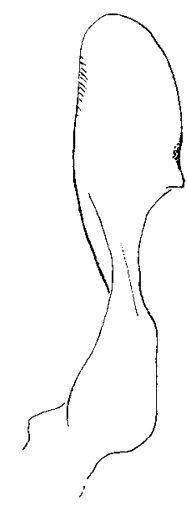

112

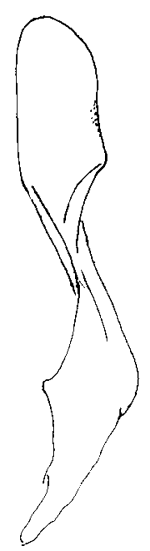

113

Figs. 102-113. - Ventidius modulatus, variation in parameres: external view of left paramere and dorsal view of right paramere (106). - 102, lectotype (Java); 103, holotype of $V$. chinai (Selangor); 104, paratype of $V$. pubescens (Johor); 105, from Sumatra; 106, from Sumatra; 107-113, from Thailand: 107, Chiang Mai (Doi Inthanon); 108, Ubon; 109, Chiang Rai (Fang); 110, Kanchanaburi; 111, Khon Kaen; 112, Chiang Mai (Hui Hong Krei); 113, Petchabun.

(ZRCS, PPCC); 204 , Johor, Kota Tinggi waterfall, $16 \mathrm{~km} \mathrm{~N}$ of Kota Tinggi, 60 m, 15.x.1986, CL 2217, leg. J.T. \& D.A. Polhemus (JTPC, NHMw); 19 apt., Johor, Kota Tinggi, waterfall, 25.ix.1993, Y838, leg. K.L. Yeo (zRCs); 101 to apt., Johor, S. Bong, 5.iv.1992, Y788L, leg. K.L. Yeo (zRCs); 10 1 ㅇ apt., Johor, S. Anak, Jasin, 4.iv.1992, Y788, leg. K.L. Yeo (zRCS); 1 to macr., Perak, Inah Hill, stream nr. reservoir, 11.iii.1927, coll. Dover (вмNн); $10 \uparrow$ apt., Kelantan, waterfall $10 \mathrm{~km} \mathrm{NW}$ of Pasir Puteh, CL 2084, 21.viii.1985, leg.
J.T. \& D.A. Polhemus (JTPC, NHмw); 19 apt., Gua Sungei, Baling Kedah, ex megaderma spasma medium Gerrid (6324), 2.v.1935 (FOG23280) (вIMC).

\section{Redescription}

Dimensions. - Body length 2.77 (ठ), 2.60 ( $(9)$ width $1.75(\widehat{\delta}), 1.80(q)$, width of head $1.01(\widehat{\delta})$, $1.10($ ( ) $)$. 


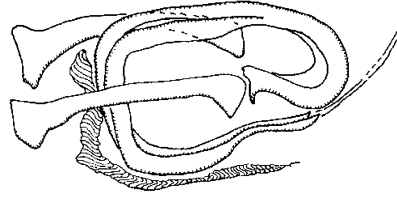

114

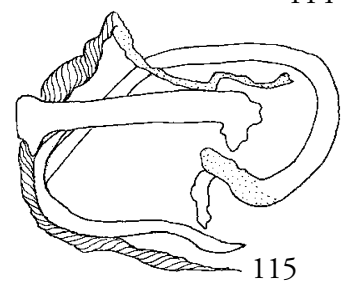

……

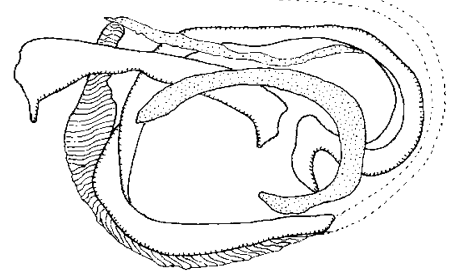

116

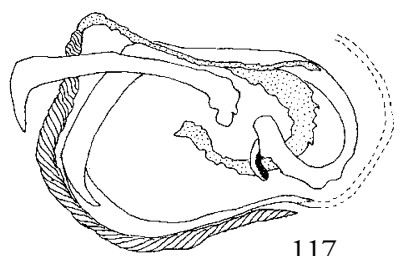

117
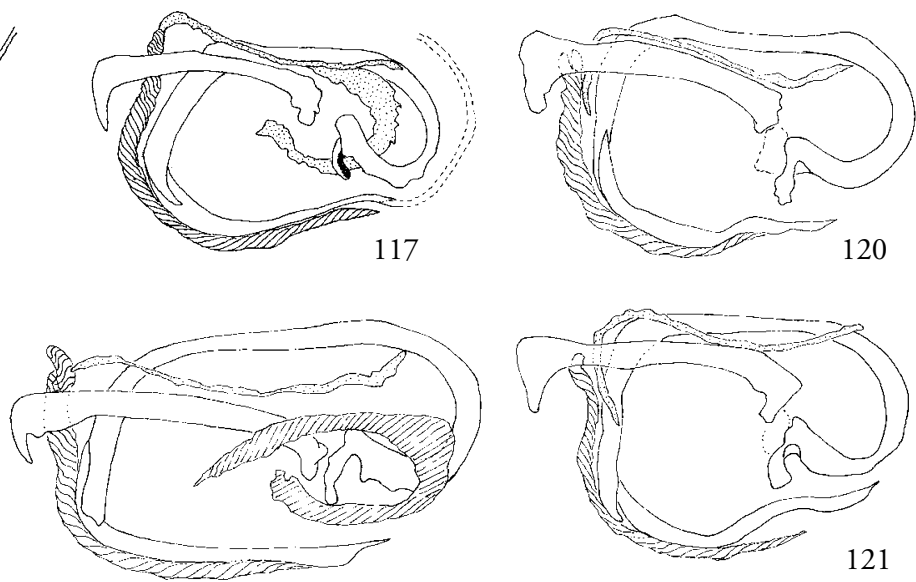

118

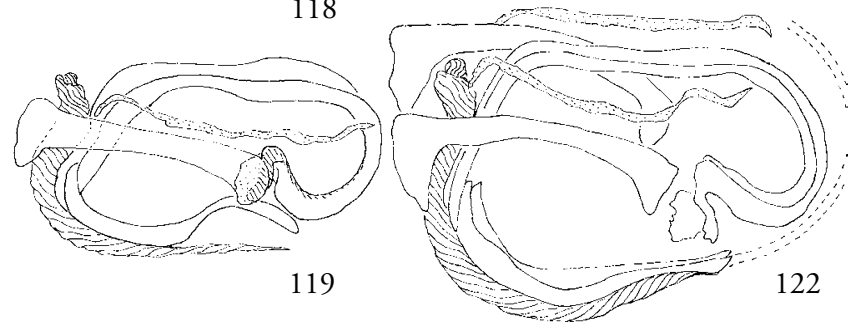

119

Figs. 114-122. Lateral view of endosoma sclerites. - 114, Ventidius henryi; 115, V. hungerfordi; $116, V$. polhemorum; $117, V$. werneri; 118, V. pilosus; 119-122. V. modulatus: 119, lectotype (Java); 120, paratype of V. pubescens; 121, From Thailand (Doi Inthanon); 122, holotype of $V$. chinai.

Colour (fig. 123). - Whole body prominently yellowish, dorsal ground colour yellowish with distinct dark marks. Eye dark brown. Interoculus pale, without distinct dark mark. Dark mark along inner margin of eye broad and reaching posterior margin of vertex. Antennal segments dark, except basal $1 / 4$ of segment 1 . Pronotum blackish with a triangular yellowish mark medioposteriorly. Mesonotum yellowish dorsally, with dark lateral stripes. Metanotum yellowish with a small triangular black mark medioposteriorly. Mesopleura with a broad brownish stripe running through its length, lower part of metacetabula dark (figs. 77, 78). Fore leg dark with basal $1 / 3$ yellowish (figs. 89, 90). Middle and hind legs dark. Tergites 1-2 completely black, 3 prominently dark with a small faint yellowish spot in the middle, 4-6 yellowish but black laterally, 7 yellowish with dark posterior margin, posterior half of tergite 8 black. Laterotergites 1-2 completely black, 3 dark with small yellowish spot, 4-5 yellowish with dark margin, 6 yellowish. Connexiva 1-3 dark, the rest yellowish. Venter yellowish. Metasternum tubercle yellowish.

Pilosity. - Trichobothria on vertex conspicuous. Inner surface of antennal segment 1 with 4 subbasal, and 1 subapical long spines; segments 2-4 with scattered dark short setae (fig. 61). Dorsum and pleura bearing longer dark setae. Pleura covered with blackish depressed longer silvery hairs. Venter clothed by golden pubescence. Stiff spines scattered along middle and hind legs.

Structural characters. - Interoculus longer than width of an eye, $(0.41: 0.36)$ in male, equal $(0.40$ : $0.40)$ in female. Antennae not modified, segment 2 longer than 3 in males (fig. 61), roughly of same length in females (measurements see table 1). Thorax not bulbous, mesonotum somewhat swollen, its lateral width 1.10 in both sexes. Intersegmental suture between meso- and metanotum weak but visible. Metanotum declivent. Lower part of metacetabulum obtusely triangular, but bilobate, the internal lobe smaller than external lobe and curved towards its body, therefore easily ignored (figs. 77, 78). Fore femur slender and not modified, claw rising from $1 / 3$ of segment 2 of fore tarsus. Anterior margin of abdominal tergite 1 distinct; anterior margins of tergites 2 and 3 obliterated medially and protruding forward; abdominal sternite 7 as long as the preceding abdominal sternites together in both sexes. 


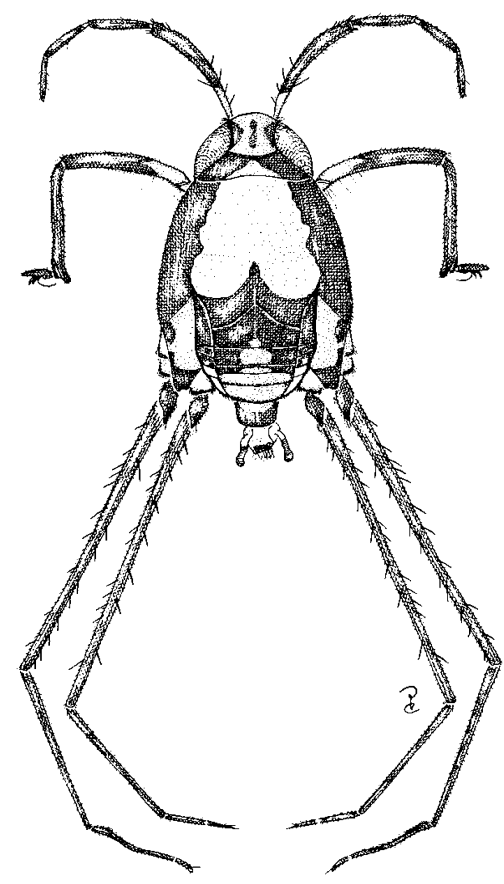

Fig. 123. Ventidius (s. str.) hungerfordi, holotype, apterous male, length $2.77 \mathrm{~mm}$.

Male terminalia. - Parameres (fig. 97) symmetrical, slender and twisted in middle part, distinctly widened in apical part, usually with distinct small tubercle on external side of ventral margin, with rounded apex, extending beyond genital segments; Endosoma (fig. 115): dorsal sclerite long and recurved proximally, ventral sclerites long, lateral sclerites straight, proximal parts broadened and hooked, second lateral sclerites thin, apical sclerite indistinct.

Macropterous form. - We present a redescription of the macropterous holotype of $V$. wallacei:

Dimensions. - Body length 2.70, including wing 3.00 , width 1.45 , width of head 1.09 .

Colour (fig. 124). - Whole body prominently yellowish, dorsal ground colour yellowish brown with distinct dark marks. Eye dark brown. Interoculus pale, without distinct dark mark. Dark mark along inner margin of eye reaching posterior margin of vertex. Antennal segments dark, except basal 1/5 of segment 1 . Pronotum with blackish margins and with a large central irregularly shaped yellowish spot. Metanotum dark. Mesopleura yellowish, external angle of metacetabula dark. Fore leg dark with basal $1 / 3$ yellowish. Middle and hind legs dark. Wings damaged, remnants dark rich brown, venation slightly darker, remnants of membranous part not differently coloured from fore wings. Tergite 1 completely yellowish, tergite 2 dark, tergites 3-7 yellowish, posterior half of tergite 8 dark. Laterotergites yellowish. Connexiva 1-4 dark, 6-7 yellowish. Venter yellowish. Metasternum tubercle brownish.

Pilosity. - Inner surface of antennal segment 1 with 3 subbasal, and 1 subapical long spines; segments 2-4 with scattered dark short setae. Dorsum and pleura bearing dark pubescence. Pleura covered with blackish depressed hairs. Venter clothed by golden pubescence, especially on genital segments with longer pilosity. Stiff spines scattered along middle and hind legs. Basal part of middle and hind femur with two very long trichobothria-like setae on dorsal surface.

Structural characters. - Interoculus broader than width of an eye, 0.40 and 0.32 respectively. Antennae not modified, second segment longer than the third in males (fig. 62), measurements see table 1. Thorax not bulbous, lateral width of mesonotum 1.10. Mesosternal ridge almost reaching an imaginary line through faint brown spots anterior of lateral mesosternal ridges. Distal ridge slightly raised; lower part of metacetabula obtusely triangular (figs. 79, 80). Metasternal tubercle slightly prominent in male. Fore femur slender and not modified, claw rising from $1 / 3$ of segment 2 of fore tarsus. Wing venation see figure 58. Anterior margin of abdominal tergite 1 distinct; anterior margins of tergites 2 and 3 obliterated medially and protruding forward; abdominal sternite 7 as long as the preceding abdominal sternites together in both sexes. Lateral tergite plate broad.

Male terminalia. - Parameres symmetrical, both pulpboard-shaped, with blunt apex; both extending beyond genital segments, internal side near lower margin with a very small but visible tooth-like tubercle, very easily ignored. Endosoma: dorsal sclerite long and recurved proximally, ventral sclerites long, lateral sclerites straight, proximal parts broadened and hooked, second lateral sclerites thin, apical sclerite indistinct.

Distribution (map 2). - Thailand: Kanchanaburi; Malaysia: Selangor, Johor, Kelantan, Perak.

Remarks. - Ventidius wallacei was described after a single macropterous male. The dense long pilosity of mesopleura and the thick antennal segment 1 remind immediately of $V$. hungerfordi. Lansbury (1988) compared $V$. wallacei with $V$. hungerfordi and states differences in colouration and parameres ('dark brownblack pigmentation of wallacei is much more extensive than that of hungerfordi; the paramere of the latter has a small tubercle on the rear margin, wallacei has the margins evenly rounded'). We cannot follow this opinion: The dark colouration corresponds well with a macropterous male of $V$. hungerfordi from Perak. After dissection of the paramere of the holotype of $V$. wallacei, we could detect a faint indication of a tu- 


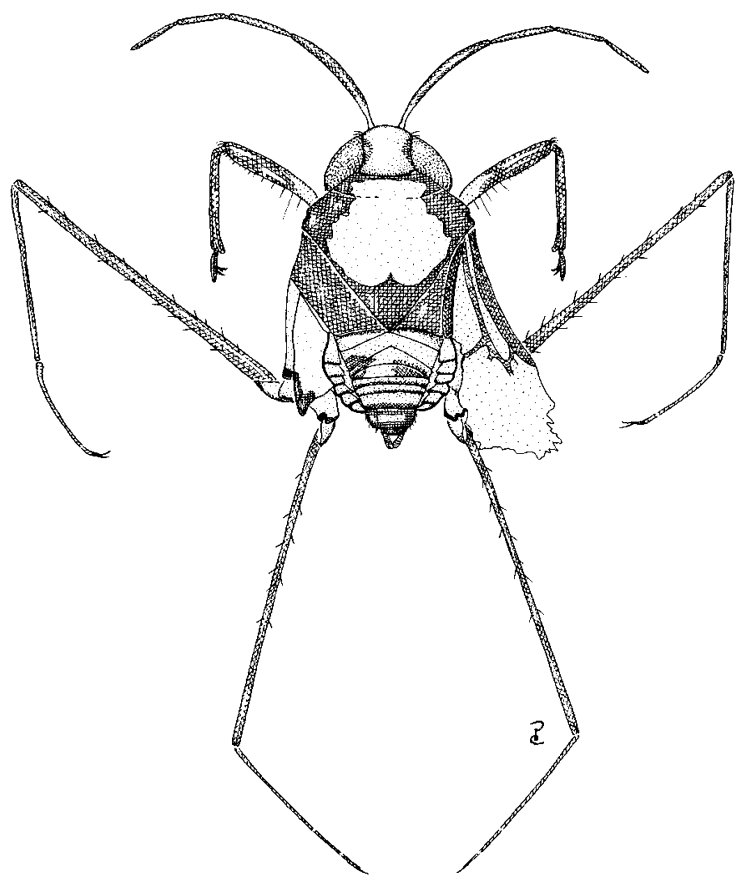

Fig. 124. Ventidius (s. str.) hungerfordi, macropterous male, length $3.0 \mathrm{~mm}(=V$. wallace $i$ Lansbury).

bercle on paramere from a certain direction of view; the tubercle is also weakly developed in $V$. hungerfordi (compared with $V$. modulatus). Although the paramere of $V$. wallacei is slightly more slender than is usual in $V$. hungerfordi, we regard this character as an individual variation and subsequently $V$. wallace $i$ as a synonym of $V$. hungerfordi.

Comparative notes. - Ventidius hungerfordi seems to be closely related to the following three species $(V$. polhemorum sp. n., $V$. werneri, $V$. pilosus sp. n.) on the basis of the long pilosity on mesopleura and by a more or less enlarged antennal segment 1 in males (compared with that in $V$. modulatus). It can be separated from all of these species by the more distinct tubercle on the ventral external face of the paramere, which is lacking or very reduced in the other three species. Ventidius hungerfordi can be separated from $V$. modulatus (which is the only sympatric species of this group) also by a flatter body in both sexes.

\section{Ventidius (s. str.) polhemorum sp. n.}

(figs. 56, 63, 70, 81, 82, 91, 98, 116, 125, map 2)

Type locality. - malaysia: Sabah.

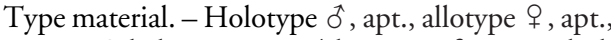
MALAYSIA: Sabah, Borneo, $34 \mathrm{~km}$ NE of Kota Belud, CL 2033, 5. VIII.1985, leg. J.T. \& D.A. Polhemus (JTPC). - Paratypes: $90 \hat{~} 26$ apt., $2 \hat{0} 49$ macr., same locality data as holotype (JTPC, NHMW, PPCC); 240 52 apt., $203 \%$ macr., Sabah, Borneo, $40 \mathrm{~km} \mathrm{NE}$ of Kota Belud, CL 2032, 5.viii.1985, leg. J.T. \& D.A. Polhemus (Jтpc, NHмw, pPCC); 301 t apt., Sabah, Borneo, stream $5 \mathrm{~km} \mathrm{~S}$ of Poring Hot Springs, CL 2024, 2.viii.1985, leg. J.T. \& D.A. Polhemus (JTPC); 10 apt., Sabah, (North Borneo, SE), Forest Camp, 19 $\mathrm{km} \mathrm{N}$ of Kalabakan, 12.xi.1962, light trap [?], leg. Y. Hiyashima (BIMC); 19 macr., same locality data, 13.xi.1962 (вIMC); 4 ㅇ apt., Sabah, Danum Valley, Sapat Kalisan, 12.2.1997, leg. H. Zettel (15) (UMSM, NHмw); $103 q$ apt., Sabah, Danum Valley, Palum Tambun, 12.2.1997, leg. Zettel et al. (P83 \& P90) (UMSM, NHMW, SPCM); 30 $3 q$ apt., 19 macr., Sarawak (Borneo), $8 \mathrm{~km} \mathrm{~S}$ of Tebakang, stream disappearing into cave, CL 2046, 9.viii.1985, leg. J.T. \& D.A. Polhemus (JTPC, NHMw); 10 apt. Sarawak, Sameran River, $2 \mathrm{~km} \mathrm{~W}$ of Tubeh, CL 2047, 19.viii.1985, leg. J.T. \& D.A. Polhemus (JTPC); 10 2 아. 19 macr., Sarawak (Borneo), $4 \mathrm{~km} \mathrm{~S}$ Tebakang, 19.viii.1985, CL 2044, leg. J.T. \& D.A. Polhemus (JTPC).

Etymology. - The species is named after Dr. J.T. Polhemus (Englewood) and Dr. D.A. Polhemus (Washington), for their distinguished achievements in the aquatic and semiaquatic Hemiptera fauna of the world, and for their generous offering of material deposited in the JTPC and BIMC collections for our study. 


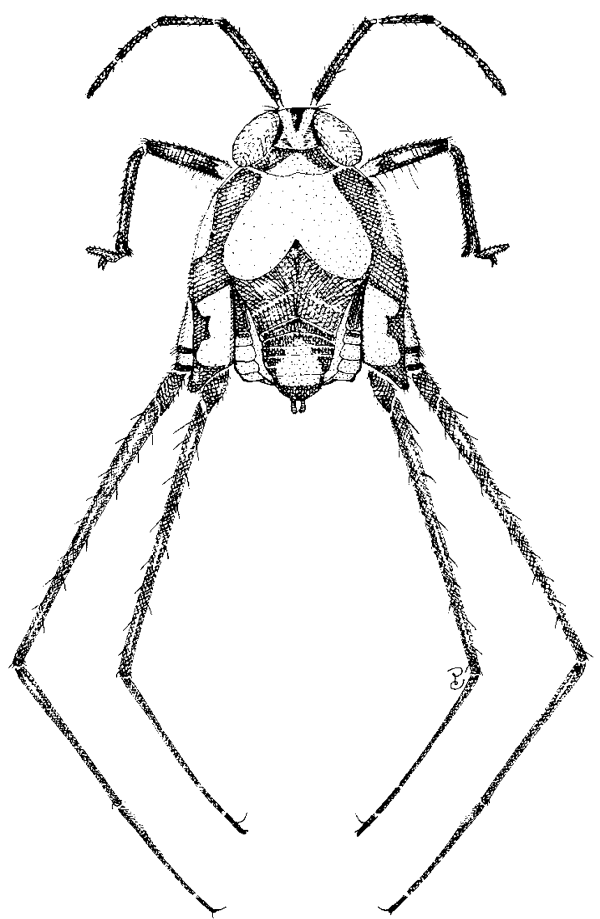

Fig. 125. Ventidius (s. str.) polhemorum, paratype, apterous male, length $2.78 \mathrm{~mm}$.

\section{Description}

Dimensions. - Body length 2.78 (बै), 2.89 ( $(+)$,

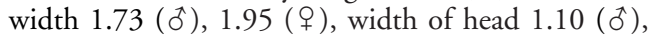
$1.10($ ( ) $)$.

Colour (fig. 125). - Whole body prominently yellowish, dorsal ground colour yellowish with distinct dark marks. Eye dark brown. Interoculus pale, central part with darker pilosity. Dark mark along inner margin of eye broad and reaching posterior margin of vertex. Antennal segments dark, except basal 1/4 of segment 1. Pronotum yellowish with dark lateral mark. Mesonotum yellowish dorsally, with dark lateral stripe. Metanotum yellowish with a small triangular black mark medioposteriorly and dark lateral stripes. Mesopleura yellowish, lower part and external margin of metacetabula dark (fig. 70). Fore leg dark with basal half yellowish (fig. 91). Middle and hind legs dark. Tergites 1-2 completely black, 3 prominently dark with a small faint yellowish spot in the middle, 4 black with a big yellowish mark in the middle, 5-6 yellowish but black laterally, tergite 7 yellowish with dark posterior margin, posterior half of tergite 8 black. Laterotergites 1-2 completely black, 3-7 yellowish. Connexiva slightly darkened. Venter yellowish. Metasternum tubercle yellowish.

Pilosity. - As a whole, body with long, more promi- nent pilosity. Inner surface of antennal segment 1 with 4 subbasal and 1 subapical spine, and 2-3 long spines scattered; segments 2-4 with scattered dark short setae, and especially inner surface of segments $2-4$ with fine hair fringe (fig. 63). Dorsum and pleura bearing dark setae, more conspicuous on pleura and metacetabula. Venter clothed by pale pubescence. Genital segments with longer and darker setae. Stiff spines scattered along middle and hind legs.

Structural characters. - Interoculus broader than width of an eye $(0.46: 0.39)$ in male, equal $(0.40$ : $0.40)$ in female. Antennae not modified, segment 2 longer than 3 in males (fig. 63), shorter than in females (measurements see table 1). Thorax not bulbous, mesonotum somewhat swollen, its lateral width 1.20 (ઠ), 1.23 (). Intersegmental suture between meso- and metanotum weak but visible, and marked with a fine brownish line laterally. Metanotum declivent. Lower part of metacetabula obtusely triangular, but bilobate in caudal view, the internal lobe much smaller than external lobe and slightly curved mediad (figs. 81, 82). Metasternal tubercle darkened. Fore femur slender and not modified, claw rising from $1 / 3$ of segment 2 of fore tarsus. Anterior margin of abdominal tergite 1 faint; anterior margins of tergites 2 and 3 obliterated medially and protruding forward; abdominal sternite 7 as long as the preceding abdominal sternites together in both sexes.

Male terminalia. - Parameres (fig. 98) symmetrical, curved, broad in middle part, slightly widened apically, usually without any tubercle, in some specimens with a faint indication of a dimple, with rounded apex; extending beyond genital segments. Endosoma (fig. 116): dorsal sclerite long and recurved proximally, ventral sclerites long, lateral sclerite straight, broadened and hooked at two ends, second lateral sclerite thin, apical sclerite indistinct.

Macropterous form. - $1.40 \mathrm{~mm}$ long, maximum width $1.51 \mathrm{~mm}$. colour pattern (fig. 56) of pronotum yellowish anteriorly and in the central area with two yellowish blotches, lateral and posterior margin blackish. Wings anteriorly blackish with fine pubescence and with scattered longer black hairs. Posterior membranous part of wings dark brown. The other morphological characters as apterous form except the apex of pronotum pointed (measurements see table 3); length of fore wings from humeri to apex $2.40 \mathrm{~mm}$.

Distribution (map 2). - East Malaysia: Sabah, Sarawak.

Comparative notes. - This species is very similar to $V$. hungerfordi (Malaya), $V$. werneri (Philippines: Palawan), and $V$. pilosus sp. n. (Indonesia: Sumba) by colour pattern, conspicuous pilosity, and slightly bilobate lower structure of metacetabula. Ventidius werneri and $V$. pilosus sp. n. differ in males by a distinctly more slender antennal segment 1 and by differ- 


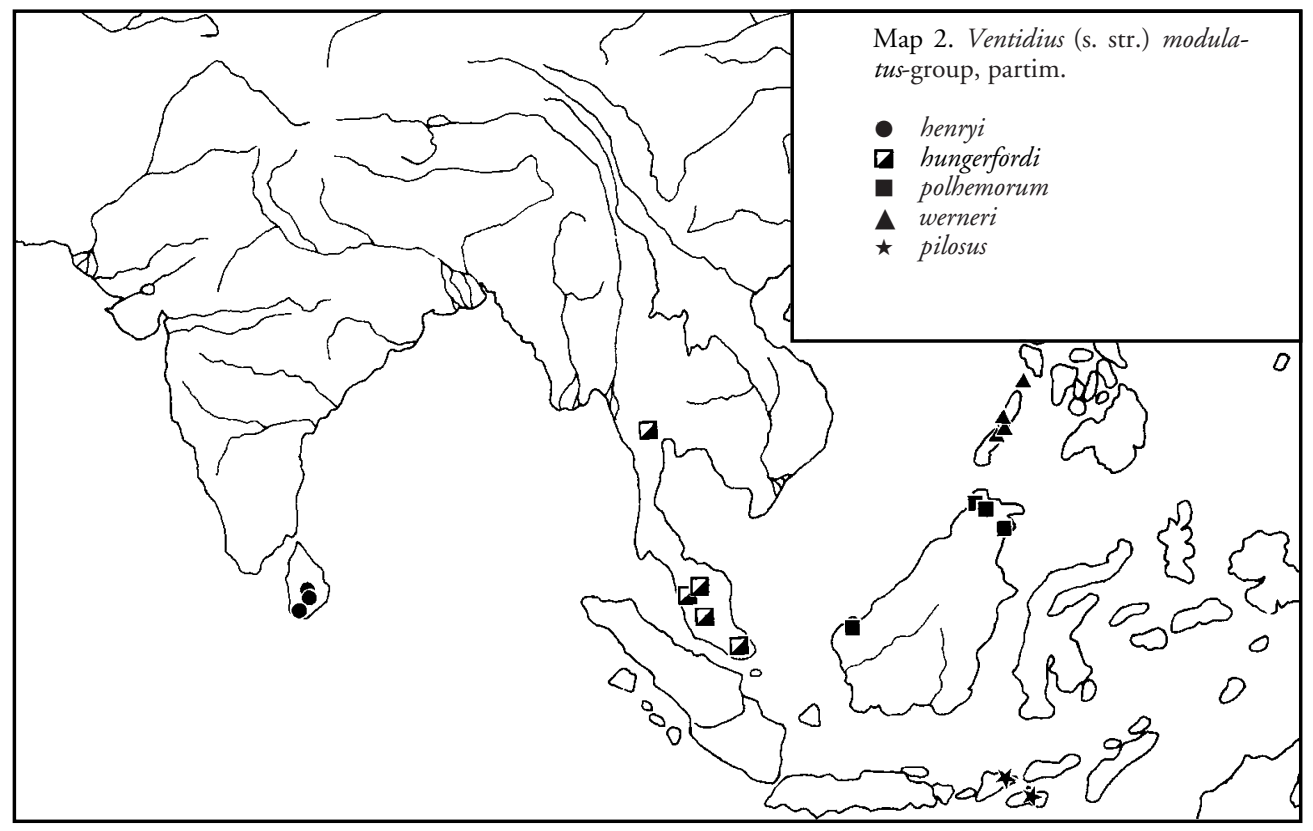

ent shapes of parameres. Ventidius hungerfordi, which is similar in most characters can be distinguished by the paramere which in $V$. hungerfordi is strongly widened apically and usually with a distinct tubercle on the ventral external face, but in $V$. polhemorum sp. $\mathrm{n}$. is less widened (because of the wide middle part) and usually without any tubercle.

9. Ventidius (s. str.) werneri Hungerford \& Matsuda (figs. 57, 64, 71, 83, 84, 92, 99, 117, 126, map 2)

Ventidius werneri Hungerford \& Matsuda 1960: 330-331 (descr., illustr., key).

Type locality. - PHILIPpines: Palawan.

Type material examined. - Holotype ${ }^{\dagger}$ apt., and allotype $q$ apt., Philippines: Palawan 'CNHM Philippines Zool. Exped. (1946-47). F.G. Werner, Puerto Princesa, Palawan Is. Sea Level, March (1947)' (CNHM).

Other material examined. $-5 \hat{0} 15 \%$, all apt., PHILIPPINEs: Palawan, Sabang, 0-30 m, 27.iii.1994, leg. Zettel (52b) (NHмw, PPCC); 10 t1 1 apt., 10 macr., Palawan, 9 $\mathrm{km}$ W Puerto, Princese, lwahig, Balsahan riv., leg. Zettel, 24.iii.1994 (48, 60) (NHMw, PPCC); 2 apt., Palawan, Bacungan Creek, $18 \mathrm{~km} \mathrm{NW}$ of Puerto Princesa, CL 2019, 28.vii.1985, leg. J.T. \& D.A. Polhemus (JTPC); $120^{\star} 169$ apt., Palawan, Apoapo Arawan River, $76 \mathrm{~km} \mathrm{~S}$ of Puerto Princesa, CL 2005, 25.vii.1985, leg. J.T. \& D.A. Polhemus (JTPC, NHMw, PPCC); 6011 우 apt., Palawan, Taritien River, at Trident Mine, $7 \mathrm{~km} \mathrm{NW}$ of Narra, CL 2011, 27.vii.1985, leg. J.T. \& D.A. Polhemus (JTPC, NHMw); 6018 apt., 1 우 macr., Palawan, Balsahan Riv., 20 km SW of Puerto Prince- sa, CL 2014, 27.vii.1985, leg. J.T. \& D.A. Polhemus (JTPC); $60 \hat{10} 10$ apt., Palawan Pr., Busuanga Is., 13 rd.km WNW Coron, Balulu Falls, 24.2.1996, leg. H.Zettel (81) (zcwA, GCLB, UPLB); 201 o macr., Palawan Pr., Busuanga Is., $5 \mathrm{~km}$ NW Coron, Mabintangen Riv., 25.-29.2.1996, leg. H. Zettel (82) (ZCWA).

\section{Redescription}

Dimensions. - apterous form, length $2.41(\hat{0})$, 2.50 ( $(+)$, width 1.66 (ठ), 1.74 ( + ), width of head $1.06($ 太), $1.04($ q $)$.

Colour (fig. 126). - Whole body prominently yellowish, with distinct dark marks. Eye dark brown or blackish. Interoculus pale, with one large more or less round dark mark, which stretches backwards into a short stripe at each external corner, in most cases very difficult to recognize as a clear shape; dark mark along inner margin of eye reaching posterior margin of vertex. Antennal segments black except basal $1 / 4$ of segment 1 . Pronotum with very broad dark stripes so usually looking prominently dark, with a yellowish transverse band along posterior margin and one small yellowish spot at each latero-posterior angle. Mesonotum yellowish with dark lateral stripes. Metanotum yellowish with a triangular black mark at medio-posterior margin. Mesopleura with a broad brownish stripe, external angles of metacetabula dark (figs. 71). Fore leg dark with less than basal half yellowish (fig. 92). Middle and hind legs dark. Tergites 1-3 completely dark, 4-5 dark, with trace of central light mark, 6-7 prominently yellowish, 8 prominently 


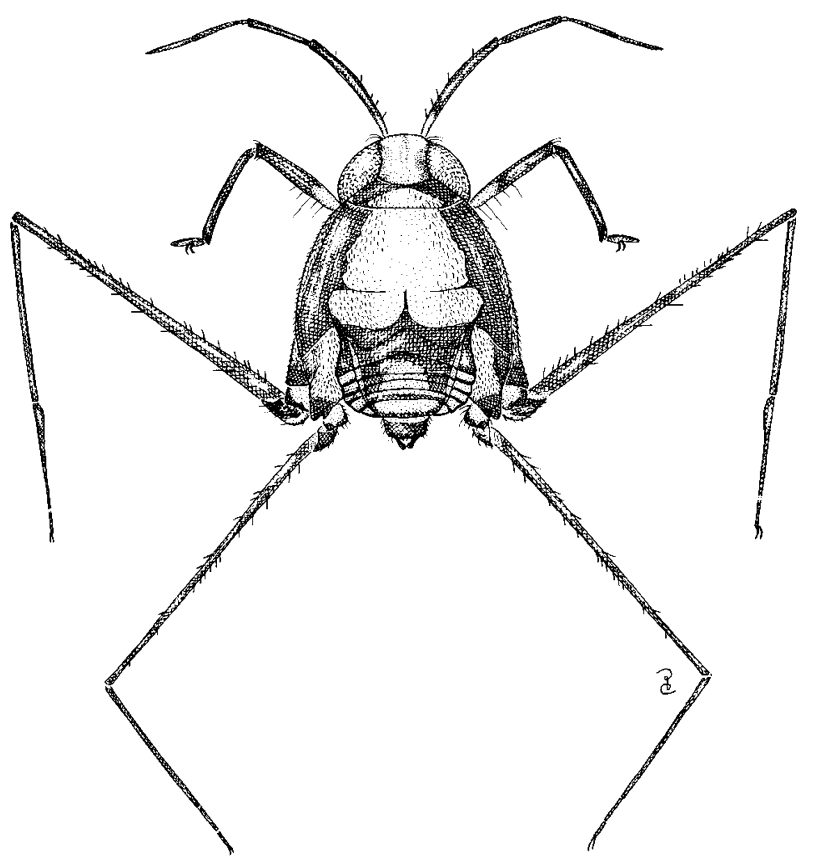

Fig. 126.

Ventidius (s. str.) werneri, apterous male, length $2.40 \mathrm{~mm}$.

dark. Laterotergites 1-2 dark, 3-7 yellowish. Connexiva 1-5 dark, 6-7 yellowish. Venter yellowish.

Pilosity. - As a whole, body with longer, more prominent pilosity. Trichobothria on vertex conspicuous. Inner surface of antennal segment 1 with 4 subbasal and 1 subapical long spines, dorsal surface with 1 subbasal spine; through basal half of segment 1 to apical half of segment 4 with fine hair fringe, especially segments 2-3 more distinct, segments 2-4 with scattered dark short setae (fig. 64). Dorsum and pleura bearing long, dark pubescence, more distinct than usually. Venter clothed by golden pubescence, especially on mesosternum denser. Fore trochanter and femur with dark longer trichobothria setae; Inner surface of fore femur and tibia with dark fine hair fringe. Longer stiff spines scattered along middle and hind legs. Basal part of middle and hind femora with a very long trichobothria-like seta on dorsal surface.

Structural characters. - Interoculus broader than width of an eye, $0.40: 0.38$ in male, $0.41: 0.37$ in female. Antennae not modified, segment 2 longer than 3 in males (fig. 64), shorter than 3 in females (measurements see table 1). Thorax bulbous, mesonotum somewhat swollen, its lateral width $0.91(\widehat{o}), 0.95$ ( ( ). Intersegmental suture between meso- and metanotum weak but visible. Metanotum strongly declivent. Lower part of metacetabula obtusely triangular, but bilobate in caudal view, internal lobe smaller than external lobe and curved towards its body, therefore easily ignored (figs. 83, 84). Metasternal tubercle slightly prominent in male. Fore femur slender and not modified, claw rising from $1 / 3$ of segment 2 of fore tarsus. Anterior margin of abdominal tergite 1 distinct; anterior margins of tergites 2 and 3 obliterated medially and protruding forward; abdominal sternite 7 as long as the preceding abdominal sternites together in both sexes.

Male terminalia. - Parameres (fig. 99) symmetrical, slightly curved, not twisted halfway its length, very slender in middle of its length, apically distinctly widened, without or with a very faint indication of a tubercle, with rounded apex; extending beyond genital segments. Endosoma (fig. 117): dorsal sclerite long and recurved proximally, ventral sclerite long, lateral sclerites straight, hooked at two ends, second lateral sclerites thin, apical sclerite indistinct.

Female terminalia. - Abdominal sternite 7 large, posterior margin smooth, concave forwards.

Macropterous form. - As apterous form except the apex of pronotum pointed (measurements see table 3); length of fore wings from humeri to apex 2.45 . colour pattern of pronotum (fig. 57) black with two irregular yellowish blotches. Wings anteriorly black with fine pubescence and with scattered longer black hairs. Posterior membranous part of wings dark brown.

Distribution (map 2). - The Philippines: Palawan Prov.: Palawan Island, Busuanga Island.

Comparative notes. - This species is very similar to $V$. hungerfordi, $V$. polhemorum sp. n., and $V$. pilosus sp. n. For distinguishing characters see under the comparative notes of these species. 
10. Ventidius (s. str.) pilosus sp. n.

(figs. 65, 72, 85, 86, 93, 94, 100, 101, 118, 127, map 2)

Type locality. - INDONEsIa: Sumba.

Type material. - Holotype, $\widehat{\delta}$, apt., Indonesia: Sumba, Nusa Tenggara Timur Prov., Patawang, 55 $\mathrm{km}$ E of Waingapu, 15.ix.1991, CL 2603, leg. D.A. \& J.T. Polhemus (JTPC). - Paratypes, 23 đิ 20 \% , apt., 10 to macr., same locality data as holotype (JTPC,

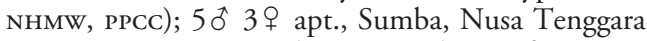
Timur Prov., spring and stream $10 \mathrm{~km} \mathrm{~S}$ of Waingapu, 180 m, 13.ix.1991, CL 2597, leg. D.A. \& J.T. Polhemus (JTPC); $53 \delta^{\star} 101$ a apt., Sumba, Nusa Tenggara Timur Prov., Mata River, $49 \mathrm{~km} \mathrm{E}$ of Waingapu, 15 m, 15.ix.1991, CL 2604, leg. D.A. \& J.T. Polhemus (JTPC, PPCC, NHMw); 410 đo 43 apt., Sumbawa, Nusa Tenggara Barat Prov., Bela River, 28 km SW Bima, 100 m, CL 2172, 19.x.1985, leg. J.T. \& D.A. Polhemus (JTPC, PPCC, NHMw).

Etymology. - Species name refers to the conspicuous pilosity of its body, especially the longer hair fringe on the ventral surface of fore femur in both sexes.

\section{Description}

Dimensions. - Apterous form, length 2.60 (ङ) , 3.06 ( $q$ ), width 1.82 (o), 2.20 ( + ), width of head 1.15 (đ), 1.26 (

Colour (fig. 127). - Whole body prominently yellowish, with distinct dark marks. Eye dark brown or blackish. Interoculus pale, with three longitudinal brownish marks, one in middle and two along inner margin of eyes which stretch backwards to the hind margin of vertex. Antennal segments black except basal 2/5 of segment 1 . Pronotum with very broad dark stripes so usually appearing prominently dark, with a yellowish triangular mark along posterior margin and one small yellowish spot at each latero-posterior angle. Mesonotum yellowish with dark lateral stripes. Metanotum yellowish with a small triangular black mark at medio-posterior margin and two large square dark marks laterally. Mesopleura totally yellowish (fig. 72). Metacetabula with posterior external angles dark and brownish in anterior external part (figs. 85, 86). Fore leg dark with basal half of fore femur yellowish (fig. 93). Middle and hind legs dark. Tergite 1 completely dark or with two vague yellowish marks laterally, 2-5 dark with triangular central yellowish marks, 6-7 yellowish, 8 dark. Laterotergites in some specimens totally yellowish, in some specimens tergites 1-3 dark, 4 prominently dark with central yellowish mark, 5-7 yellowish. Connexiva 1-5 dark, 6-7 yellowish. Venter yellowish.

Pilosity. - As a whole, the body with more prominently pilosity. Trichobothria on vertex conspicuous. Inner surface of antennal segment 1 with 6 subbasal,

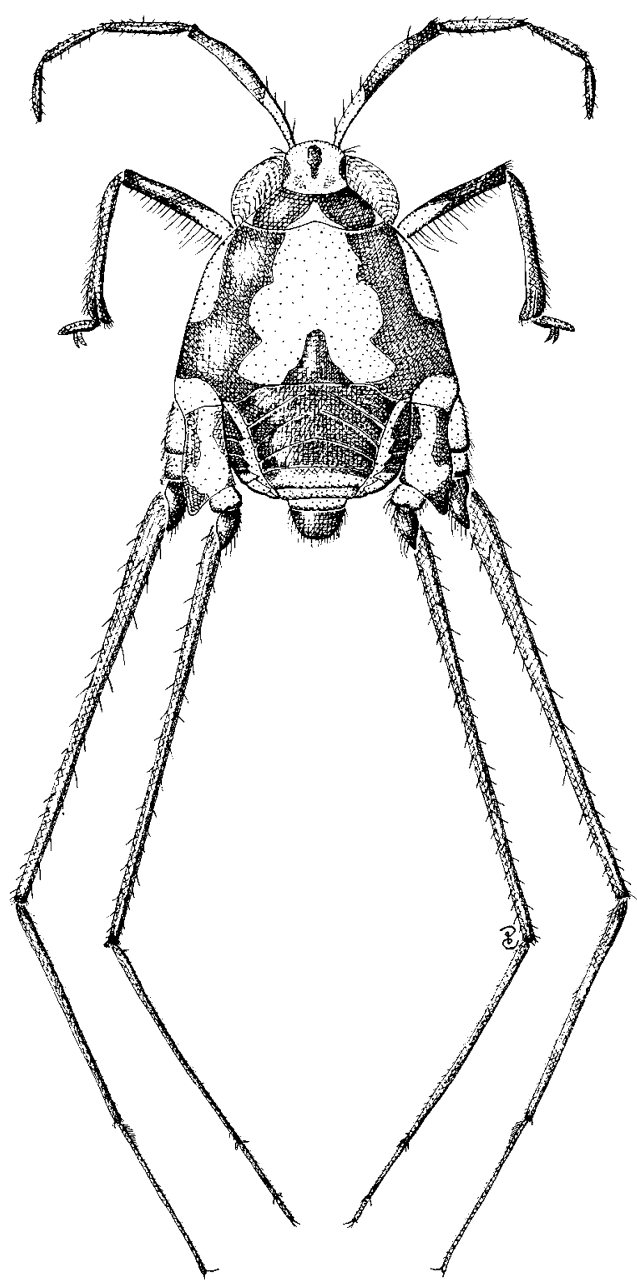

Fig. 127. Ventidius (s. str.) pilosus, holotype, apterous male, length $2.60 \mathrm{~mm}$.

and 1 subapical long spines; through basal half of segment 1 to apical half of segment 4 with dark fine hair fringe, and with scattered dark short setae (fig. 65). Dorsum and pleura bearing dark pubescence, more conspicuous than usually in the genus. Venter clothed by golden pubescence. Ventral face of fore trochanter and femur with dark long trichobothrial setae; in both sexes ventral surface of fore femur with dark long hair fringe. Longer stiff spines scattered along middle and hind legs.

Structural characters. - Interoculus broader than width of an eye, $0.49: 0.40$ in both sexes. Antennal segment 1 stout but not as broad as in $V$. hungerfordi, segment 2 longer than segment 3 in both sexes (fig. 
65), segment 3 shorter than 4 in male (measurements see table 1). Mesonotum somewhat swollen, its lateral width 1.11 (ઠ), 1.27 ( $\%)$. Intersegmental suture between meso- and metanotum weak but visible. Metanotum declivent. Posterior part of metacetabula obtusely triangular. (figs. 85, 86). Fore femur slender and not modified, claw rising from $1 / 3$ of segment 2 of fore tarsus (figs. 93, 94). Anterior margin of abdominal tergite 1 distinct; anterior margins of tergites 2 and 3 obliterated medially and protruding forward; abdominal sternite 7 as long as the preceding abdominal sternites together in both sexes.

Male terminalia. - Parameres (fig. 100, 101) symmetrical, slightly curved, distinctly twisted halfway its length, with slender middle part, apical part distinctly widened, with a faint indication of a tubercle on ventral external face, apex rounded, extending beyond genital segments. Endosoma (fig. 118): dorsal sclerite long and recurved proximally, ventral sclerite long, lateral sclerite straight, hooked at two ends, second lateral sclerites thin, with third lateral sclerites, apical sclerite indistinct.

Female terminalia. - Abdominal sternite 7 large, posterior margin smooth, slightly concave anteriorly.

Macropterous form. - As apterous form except the apex of pronotum pointed (measurements see table 3); colour pattern of pronotum: black with yellowish median line and two irregular yellowish blotches. Wings anteriorly black with fine pubescence. Posterior membranous part of wings dark brown. length of fore wings from humeri to apex $2.45 \mathrm{~mm}$.

Distribution (map 2). - Indonesia: Nusa Tenggara Timur Prov. (Sumba Isl.), Nusa Tenggara Barat Prov. (Sumbawa Isl.).

Comparative notes. - This species is very similar to $V$. hungerfordi, $V$. polhemorum sp. n., and $V$. werneri, but $V$. hungerfordi and $V$. polhemorum sp. n. are easy to distinguish by the stouter antennal segment 1 of males and by the shapes of parameres. The most similar species is $V$. werneri from Philippines (Palawan), which has a similar slender antennal segment 1 and slender parameres, but the paramere of $V$. pilosus sp. n. is more twisted, whereas that of $V$. werneri is nearly straight; further $V$. pilosus sp. n. is larger in body size and length of middle and hind femora (comp. table 2), has a denser pilosity of fore femora in both sexes and a longer antennal segment 2 (compared with segment 3, see Tab. 1), and differs in colouration of the abdomen.

\section{Ventidius (s. str.) modulatus Lundblad}

(figs. 59, 66, 73, 74, 87, 95, 102-113, 119-122, 128, map 3)

Ventidius modulatus Lundblad, 1933: 339-401 (descr., illustr.); Hungerford \& Matsuda 1960: 329 (descr., illustr., key); Cheng 1965: 162-163 (descr., illustr., key); Kovac
\& Yang 1989: 285 (rec.); Yang \& Kovac 1995: 293 (rec.); Zettel \& Chen 1996: 152, 180 (list, rec.); Hanboonsong et al. 1996: 24 (rec.).

Ventidius chinai Hungerford \& Matsuda, 1960: 331-332, 336 (descr., illustr., key) Syn. n.

Ventidius pubescens Cheng, 1965: 160-161, 163 (descr., illustr., key) Syn. n.

Type locality. - INDONESIA: Western Java.

Type material examined. - Ventidius modulatus: Lectotype (present designation) ô apt., InDONESIA: 'Westjava, Stausee Tjigombong, South of Buitenzorg, $500 \mathrm{~m}$ above see level, 17.ix.1928' (sMNH); paralectotypes: 2 of apt., from the same locality (SMNH).

Ventidius chinai: Holotype $\hat{\sigma}$ apt., Malaysia: 'Malay Peninsula, Selangore, F.M.S. Kajang Sungei Lang, Feb. 12, 1927', 'C. Dover Coll., F.M.S. Museum' (antennal segments 3-4 and parts of legs missing) (вмNH); allotype + apt., and paratypes $1 \delta 1 \%$ apt from the same locality (genitalia of male missing) (вмNн).

Ventidius pubescens: Holotype $\delta$ apt., and allotype $q$ apt., MALAYSIA: Johor, Sungai Muar at Rompin, 14.iii.1963, leg. L. Cheng (вмNH); paratypes: $8 \delta^{\star} 3 q$ apt., same locality (BMNH, ZRCS).

Other material examined. - SRI LANKA: 19 apt., 10 macr., Northern Prov., 28 mi. Pullian- kulam Nedunkerni Rd., 1.-5.v.1966, slow stream, shady corners, leg. P.B. Karunaratne (JTPC); $20 \hat{2} 2$ apt., Northern Prov., $127 \mathrm{mi}$ Madu Rd., 14.iv.1968, leg. P.B. Karunaratne (JTPC, NHMw); 201 o macr., North Western Prov., Giriulla 13.x.1957, leg. C.H. Fernando. (semc); $20 \hat{~} 2$ ㅇ Central Prov., Aruppola, Kandy, 25.vi.1966, edge of river Mahuveli,

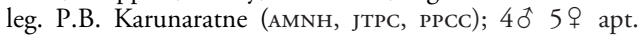
Central Prov., Katagastota, Kalugala, Pinga , Oya, 30.vii.1966, leg. P.B. Karunaratne (JTPC, NHMw); 19 apt., 2 o macr., Uva Prov., Helagama, 500 ft., 7.-8.xii.1967, Okkampitiya, from Kumbukkan Oya, leg. P.B. Karunaratne (JTPC); 303 apt., Uva Prov., Aluthnuwara, 29.viii.1967, leg. P.B. Karunaratne (JTPC, NHMw); 202 웅 apt., Uva Prov., Helagama, 500 ft., 7.-8.xii.1967, Meeminna, Hela Pool, at foot of hill, leg. P.B. Karunaratne (JTPC, PPCC); Thailand: $90 \hat{~} 15 \%$ apt., Chiang Mai Prov., Doi Inthanon N.P., Mae Klang Falls, 4.xi.1995, leg. H. Zettel (6) (NHMw, PPCC, NCTN); 19 đ 24 ㅇ apt., Chiang Mai Prov., Huai Hong Khrai, $30 \mathrm{~km} \mathrm{~N}$. Chiang Mai, stream, 500 m, 31.xi.1994, leg. P.P. Chen \& S. Wongsiri (ppCC, NCtn, NHmw); $22 \delta^{\pi} 14$ ㅇ apt., Chiang Mai Prov., Fang Horticultural Station, ponds, 15.xi.1985, CL 2201, leg. J.T \& D.A. Polhemus (JTPC, PPCC, NHMw); 201 macr., Chiang Mai Prov., $7 \mathrm{~km} \mathrm{NW}$ of Fang, Horticultural Experimental Station, 30.x.-2.xi.1979, Zool. Mus. Copenhagen

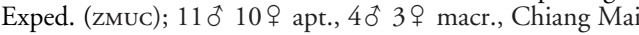
Prov., stream $10 \mathrm{~km} \mathrm{NW}$ of Mae Rim, 19.xi.1985, CL 2204, leg. J.T. \& D.A. Polhemus (JTPC, NHMw); 10 5 ㅇ apt., Lampang Prov., Nam Mae Tha, 300 m, loc. 67, shallow river, 4.iii.1989, leg. M. Andersen \& H. Read (zMUc); 1 apt., Lampang, 7 km SW Sop Drop, Mae Nam Wang, 23.iii.1994, A-1041, leg. W.D. Shepard (Nнмw); 1 t 4 \% macr., Tak Prov., Sam Ngao, at. Bhumiphol Dam, 6. 8.xi.1979, Zool. Mus. Copenhagen Exped. (ZMUC); 1 đo 2 우 Phitsanulok Prov., Subdiv. of Tung Saleangluang N.P., waterfall of Kaek riv., 17.xi.1994, leg. Chen \& Piyapichart (PPCC); 10 apt., Phitsanulok Prov., Boi Waterfall, nr. Mae Nam, Khek River, 300 m, loc. 60, 2.iii.1989, leg. Mich. Andersen \& H. Read (zMUc); $3 \hat{\sigma} 3 q$ apt. Ubon Ratchan- 


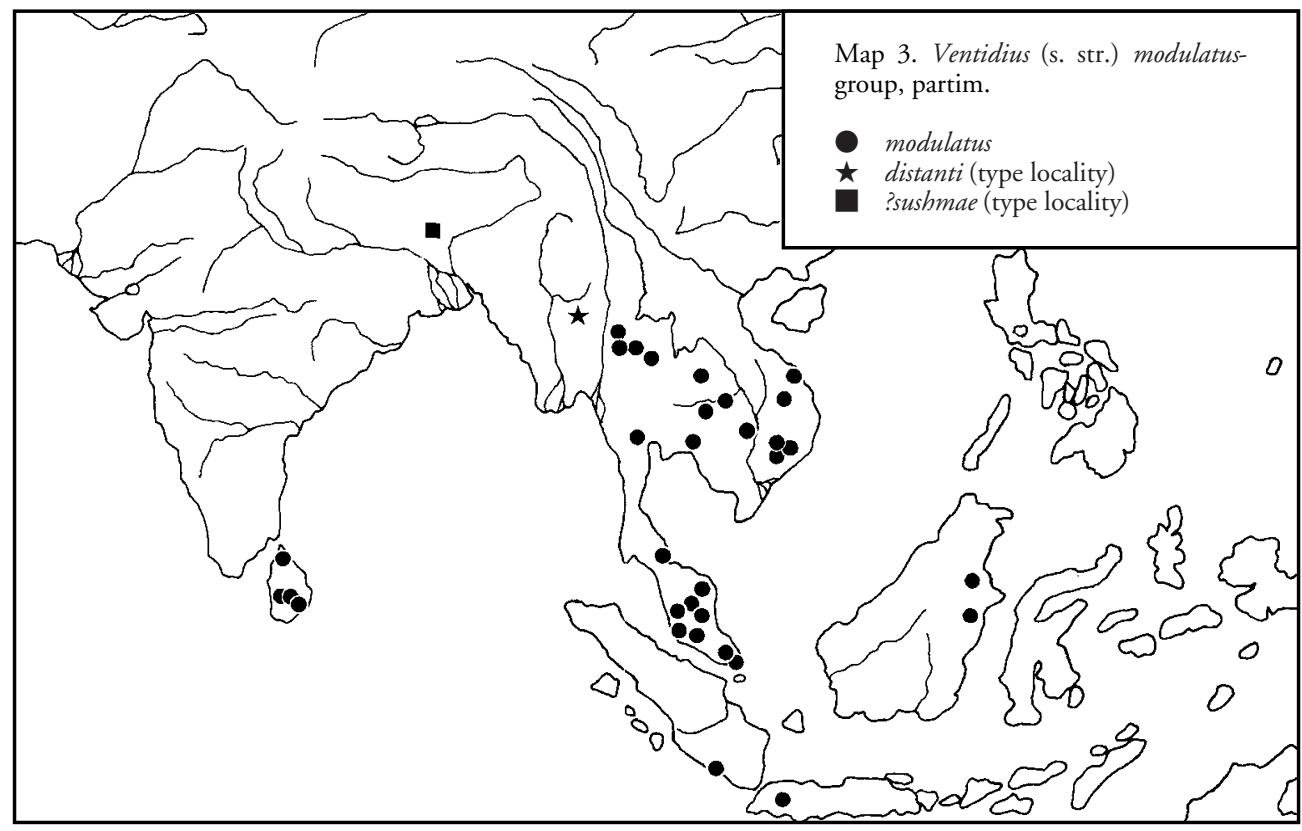

thani, Ban Tasala, Maekong River, 17. Nov. 1995, leg. Yupa Hanboonsong (NHMw); 10 apt., Ubon Ratchanthani, Sirinton, 16.iii.1996, leg. Yupa Hanboonsong (13) (NHMw); 2 đ 2 ㅇ apt., Ubon Ratchanthani, Tasala, 16.iii.1996, leg. Yupa Hanboonsong (13) (KKUA, NHMw); $30 \hat{~} 4$ 우 apt., same locality data, 7.vii.1996 (18) (KKUA, NHMW); 19 apt., Ubon Ratchanthani, Muang, Han Phudua, 16.iii.1996, leg. Yupa Hanboonsong (14) (KKUA); $30^{*} 3$, all apt., Khon Kaen Prov., Phu Phan Kham N.P., Ban Noon Huan Chang, Huai sam Caen, (upper stream of Nam Phong River), N9521, N9523, 21.xi.1995, leg N. Nieser, (NCTN, PPCC); 1508 우 apt., same locality, leg. H. Zettel (20a) (NHMw, PPCC); 50 3 a apt., same locality, leg. H. Zettel (20b) (NHMw); $3 \hat{\sigma}$ 1 , all apt., Kanchanaburi, River Kwai, 20.xii.1981, leg. N. M. Andersen (zMuc); 10 5 ㅇ apt., Chantaburi Prov., Horticulture Research Centre, Dept. of Agriculture, $15 \mathrm{~km}$ E of Chantaburi city, stream, 29.i.1995, leg. P.P. Chen (PPCC, NHMw); $10^{\pi} 1$ ㅇ apt., Surin Prov., Surin, $150 \mathrm{~m}$, 5.10.12.1995, leg. P. Schwendinger (NHMw); 90 , 29 apt., Songkhla Prov., Hat Yai, SW of Songkhla, 21.xi.1979, leg. P. Nielsen (zMUC, NHMw); viet NAM: : 403 Q Quang Tri, 1 mi. N of Quang Tri, 9.v., 15.v., and 9.vi.1970, leg. A.R. Gillogly (JтPC, NHмw); 507 웅., Gia Lai-Kontum, 20 $\mathrm{km} \mathrm{N}$ of Pleiku, $650 \mathrm{~m}$, 9.v.1960, leg. S. Quate (BIMC, JTPC, NHмw); 207 ㅇ apt., Gia Lai-Kontum, Pleiku, 700 m, 8.14.v.1960, leg. S. Quate (вIMC); 1 ㅇ apt, Gia Lai-Kontum, $25 \mathrm{~km} \mathrm{SW}$ of Pleiku, $400 \mathrm{~m}, 12 . v .1960$, leg. S. Quate, (вIMC); Lam Dong, 45 km E of Da Lat, 850 m, 5.v.1960, leg. S. Quate, 2 oे (a) (BIMC); $5 \hat{0} 89$ apt., $2 \hat{0} 4$ ㅇ macr., Song Be: Nam Cat Tien NP, 1.-15.5.1994, leg. Pacholátko \& Dembicky (NHMw, PPCC); MALAYSIA: $120^{\hat{\gamma}} 13 q$ apt., Pahang, pond $54 \mathrm{~km} \mathrm{SW}$ of Kuantan, CL 2085, 22.viii.1985, leg. J.T. \& D.A. Polhemus (JтPC, NHмw); $32 \widehat{\widehat{0}} 50$ 우 apt., Pahang, river $65 \mathrm{~km}$ NE of Segamet, CL 2086, 22.viii.1985, leg. J.T. \& D.A. Polhemus (JTPC, NHMw, PPCC); 2 apt.,
Pahang, King Geo. V. Nat. Park, Kuala Tahan, 12. 15.xii.1958, leg. T.C. Маa (вIмC); 19 apt., Pahang, S. Kinchin, 13.vi.1989, leg. C.M. Yang, zRCs2617 (zRCs); 1 ơ 1 ㅇ apt., Johor, swamp forest stream, $15 \mathrm{~km} \mathrm{~W}$ of Sedili Besar, 20 m, 16.x.1986, CL 2218, leg. J.T. \& D.A. Polhemus (JTPC); $1 \hat{\delta}, 1$ ㅇ apt., $2 \hat{\sigma}$ macr., Johor, $27 \mathrm{~km} \mathrm{~S}$ of Mersing, slow shaded stream, CL 2058, 14.viii.1985, leg. J.T. \& D.A. Polhemus (JTPC); 104 우 apt., Johor, blackwater river $2 \mathrm{~km}$ W of Sedili Besar, 0-50 m, 16.x.1986, CL 2219, leg. J.T. \&

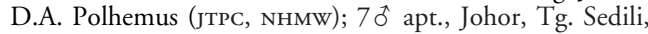
Sg. Selang, muddy water, sandy bottom, up to 1.5 feet wa-

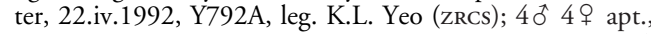
Johor, S. Bong, 5.iv.1992, Y788L, leg. K.L. Yeo (zRCs); 80 $5+$ apt., Johor, S. Endau, nr. base camp (partly night collecting), 3.-5.iv.1992, Y788A, Y788B, and Y788J, leg. K.L. Yeo (ZRCS, NHmw); 1 đิ 4 ㅇ apt., Johor, Endau, Sungai Jasin, 3.iv.1992, L185, leg. H.K. Lua (ZRCs); 10 1 우 apt., Johor, S. Jenahang, 4.viii.1963 (zRCS); 1 q macr., Negeri Sembilan, $10 \mathrm{~km} \mathrm{~S}$ of Seramban, CL 2059, 14.viii.1985, leg. J.T. \& D.A. Polhemus (JTPC); $203 q$ apt., Negeri Sembilan, 9 km S Simpang Pertang, Serting River, 10.iv.1994, A-1062, leg. W.D. Shepard (Css, NHMw, PPCC); $280^{\dagger} 26$ 우 apt., Negeri Sembilan, 14 km NW Kota, unnamed stream, 9.iv.1994, A-1056, leg. W.D. Shepard (CSs, NHMw, PPCC); 1 ㅇ apt., Negeri Sembilan, Ulu Bahau, Rubber Estate, 17.iii.1964, zRCS6.6481 (zRCS); 1 to apt., Negeri Sembilan, S. Jelai, 1.xi.1963 (zRCs); 20 apt., Selangor, Dusun Jua, 17 miles from Diteh, 26.viii.1926, coll. Dover (вмNн); 4 ㅊ 2 우 apt., Selangor, North Selangor Peat swamp-forest stream at $43 \mathrm{~km}$ mark on road to Sg. Besar, 19.vi.1991, leg. H.K. Lua \& Mala, LHK159 (ZRCS, NHMw); 15 apt., Selangor, Ampang, nr. Sg. Kongsi Laban, 500, small pond, 13.iii.1964, leg. L. Cheng, zRCs6.6456-6470 (zRCs); 2 ㅇ apt., Upper Perak, Longgong, surface of irrigation channel, fast water,

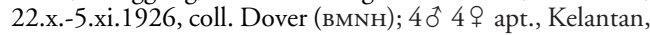


Sg. Sat, 11.xii.1964, leg. A. Jothy (JTPC, NHMw); 10 apt., Kelantan, Sungai Hulu Besut, 6 km (W?) after Kampang Keruah, on road to hydroelectric station, 20.iii.1992, L184, leg. H.K. Lua (zrcs); $40 \hat{0} 4$ apt., P. Tioman, tributary of Sg. Paya, brackish water, 25.vi.1996, leg. C.M. Yang, 'Yii7

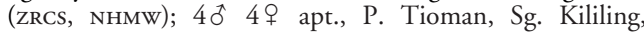
27.vi.1996, leg. H.K. Lua, Y136 (zRCs); 101 apt., Terengganu, Sg. Terengganu tributary, Sekayu, 16.v.1995, leg. Bruce Tan \& Sumita, TG6 (zrcs); 40 apt. Prov.?, Sungai Kingsi, Laban, leg. L. Cheng (JTPC); 303 a apt., Prov.? Sg. Belat, 26 km from Kuantan, 15.v.1995, leg. Bruce Tan \& Sumita, TG3 (zRCS, NHMw); SINGAPORE: 2 ㅇ apt., 16.5 mls. from Mersing, Mersing-Kluang Rd., 4.viii.1963, leg. L. Cheng (вмNн); 60 5 ㅇ apt., pond nr. MacRitchie Reservoir, 11.5.1993, NS25 (ZRCS, NHMw); 69 apt, Botanical Gardens pond, 6.iv.1990, leg. C.M. Yang \& H.K. Lua (zRCS); 40 apt., Bukit Batok Nature Park, 10.7.1995, leg. H.K. Lua, LHK282 (zRCs); 4 ô 3 ㅇ, stream at Lower Pierce, 21.vii.1990, Y21B (zrcs); 2 9 apt., Stream H, Sime Road, 5.vi.1995, leg. H.K. Lua et al. NS181 (zRCS); INDONESIA: 27 ઈิ 18 ㅇ apt., 1 t 1 ㅇ macr., Sumatra, Bengkulu Prov., Bantiring River, 7 km E of Bengkulu, 30 m, 6.ix.1991, CL 2580, leg. D.A. \& J.T. Polhemus (JTPC, NHMw, PPCC); 10 apt., (Borneo), Kalimantan Timur Prov., waterfall $4 \mathrm{~km} \mathrm{~S}$ of Kota Bangun, 29.viii.1985, CL 2095, leg. J.T. \& D.A. Polhemus (JTPC); 10 apt., 1 ㅇ macr., Kalimantan Timur Prov., Borneo, waterfall and stream, $11 \mathrm{~km} \mathrm{NE}$ of Samarinda, CL 2091, 27.viii.1985, leg. J.T. \& D.A. Polhemus (JTPC); 50 7 apt., 1 ㅇ macr., 8 larvae, Kalimantan Timur Prov., Kedang R., $12 \mathrm{~km}$ above Maura Kedang, 0.6º , $116.2^{\circ} \mathrm{E}$, leg. M.S. Christensen (JTPC, PPCC, NHMw). 10 males macr. Myanmar (Burma): Bago Division, $33 \mathrm{~km} \mathrm{~W}$ of Oktwin, Bago Yoma, Sein Yai Forest Camp, Selnyay River, 170 m, 29.x.1998, leg. H. Schillhammer (NMw, PPCC).

\section{Redescription}

Dimensions. - Apterous form. Length 2.54 ( $\left.\sigma^{\star}\right)$,

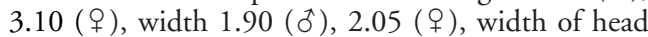
$1.10($ đ), 1.10 ( 9 ).

Colour (fig. 128). - Whole body prominently yellowish, with distinct dark marks. Eye blackish. Interoculus pale, with one large dark mark, dark mark along inner margin of eye reaching posterior margin of vertex, but in the case of paralectotypes indistinct. Antennal segments dark, except basal 1/3-1/4 of segment 1 . Pronotum usually yellowish with two lateral dark marks. Mesonotum yellowish with dark lateral stripes. Metanotum with square lateral dark mark. Mesopleura yellowish, its anterior half with a dark stripe; external angle of metacetabula dark (figs. 73, 74). Fore leg dark with basal $1 / 3$ of fore femur yellowish (fig. 95). Middle and hind legs dark. Tergite 1 completely dark, 2-5 dark, with central light mark, 6-8 yellowish. Laterotergites 1-2 dark along the edge, 5-7 yellowish, Connexiva 1-5 dark, 6-7 yellowish. Venter yellowish.

Pilosity. - Inner surface of antennal segment 1 with 3 subbasal, and 1 subapical long spines; through basal half of segment 1 to apical half of segment 4 with silvery fine hair fringe; segments 2-4 with scattered dark short setae (fig. 66). Dorsum and pleura bearing dark pubescence. Venter clothed by golden pubescence, especially on genital segments, the pilosity very long and dense. Fore femur and tibia with silvery fine hair fringe. Longer stiff spines scattered along middle and hind legs. Basal part of middle and hind femur with a very long trichobothria-like seta on dorsal surface.

Structural characters. - Interoculus broader than width of an eye, $0.42: 0.31$ in male. Antennae not modified, segment 2 longer than 3 in males (fig. 66), roughly of same length in females (measurements see table 1). Thorax not bulbous, mesonotum somewhat swollen, its lateral width 1.02. Intersegmental suture between meso- and metanotum distinct. Metanotum somewhat declivent. Lower part of metacetabula truncate (fig. 87). Metasternal tubercle slightly prominent in male. Fore femur slender and not modified, claw rising from $1 / 3$ of segment 2 of fore tarsus. Anterior margin of abdominal tergite 1 distinct; anterior margins of tergites 2 and 3 obliterated medially and protruding forward; abdominal sternite 7 as long as the preceding abdominal sternites together in both sexes.

Male terminalia. - Parameres (figs. 102-113) symmetrical, twisted in middle part, apically strongly widened, with distinct tubercle, with rounded apex, extending beyond genital segments. Endosoma (fig. 119-122): dorsal sclerite long and recurved proximally, ventral sclerites long, lateral sclerites straight, proximal parts broadened and hooked, second lateral sclerites thin, apical sclerite indistinct.

Female terminalia. - Abdominal sternite 7 large, posterior margin smooth, slightly concave anteriorly (fig. 59)

Macropterous form. - (After specimens from Sri Lanka). Colouration: pronotum black with a large round yellowish central blotch. Wings anteriorly black with fine pubescence and with scattered longer black hairs. Posterior membranous part of wings dark brown. The other morphological characters as in apterous form except the apex of pronotum pointed (measurements see table 3); length of fore wings from humeri to apex 2.02.

Variability. - In contrast to most other species of Ventidius, $V$. modulatus shows a surprising variability in dorsal colour pattern and size, but specimens from the same sample are usually similar in these characters. Bright yellowish specimens are mainly found in Malaysia, where dark-coloured populations are also found. In a large sample from Negeri Sembilan (A1056, leg. Shepard) all specimens have a completely yellowish thorax. Specimens from Sri Lanka always have dark lateral stripes on mesonotum, specimens from Thailand mostly so; there are only a few samples with differently coloured specimens, e.g. that from Udon Thani Prov., Thailand. Pubescence of thorax is also similar between specimens of the same sample.

We include within $V$. modulatus also a darkcoloured population from Viet Nam (Gia Lai-Kon- 


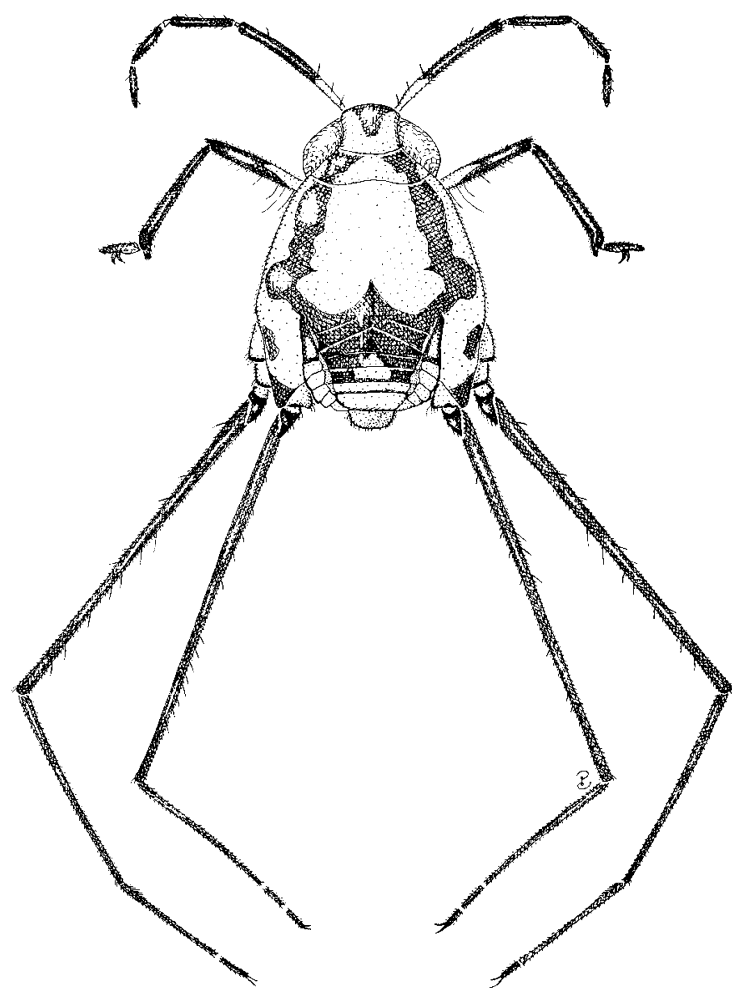

Fig. 128. Ventidius (s. str.) modulatus, lectotype, apterous male, length $2.54 \mathrm{~mm}$.

tum), which shows a slightly thickened antennal segment 1 in males (length : width $=12.5-13.5$ ), denser and longer pilosity and a more flattened body than in other populations within the large area of $V$. modulatus. These specimens resemble somewhat $V$. hungerfordi, but, beside genitalia structures, the antennal segment 1 of males is distinctly less stout (9.5-11.5 in $V$. hungerfordi) and the pleural colour pattern is different. We have also seen intermediate $V$. modulatus specimens from Northeast Thailand, so that we are sure that the Viet Nam population is no more than a geographic, infrasubspecific form of $V$. modulatus.

Distribution (map 3). - Sri Lanka: Northern Prov., North Western Prov., Central Prov., Uva Prov.; India: West Bengal State; Thailand: Chiang Mai, Lampang, Tak, Phitsanulok, Khon Kaen, Ubon Ratchanthani, Kanchanaburi, Chantaburi, Surin, Songkhla; Viet Nam: Quang Tri, Gia Lai-Kontum, Lam Dong, Song Be; Malaysia: Selangor, Johor, Perak, Pahang, Negeri Sembilan; Singapore; Indonesia: Sumatra, Java, Kalimantan.

Comparative notes. - This species is similar to the four preceding species ( $V$. hungerfordi, $V$. polhemo- rum sp. n., V. werneri, and $V$. pilosus sp. n.), and differs mainly in the slender antennal segment 1 of males (much thicker in $V$. hungerfordi and $V$. polhemorum, slightly thicker in $V$. werneri and $V$. pilosus), and a shorter pubescence on metapleura. The paramere is especially similar to that of $V$. hungerfordi, but differs from that of the other species by having a distinct tubercle.

Remarks. - As the synonymies of the taxa $V$. modulatus, $V$. chinai, and $V$. pubescens are problematical, we feel obliged to give a detailed analysis of the type specimens:

We have studied three of the four male syntypes of $V$. modulatus Lundblad 1933, from West Java, which are deposited in the SMNH. One of them bears the label 'Typus' and is presently designated and labelled as lectotype, the other two with the label 'Paratypus' as paralectotypes.

Ventidius chinai was based on two males and two females from Selangor in Malaya. In the comparative notes by Hungerford \& Matsuda (1960) it is compared with $V$. aquarius, but this species is not closely related. In the key by Hungerford \& Matsuda (1960) $V$. china $i$ is compared with $V$. werneri and $V$. henryi by colouration; due to a mistake (paragraph 6'. is missing) the comparison with $V$. modulatus is not clear, but mainly based on the shape of parameres and more (in $V$. modulatus) or less (in $V$. chinai) developed sutures between the meso- and metanotum and the metanotum and tergite 1 . The description of the paramere of $V$. china $i$ is based on the incomplete paramere of the holotype (apical part lacking) and therefore useless for a comparison; strangely enough we have seen two males from Selangor (also from the Dover collection) with similarly broken parameres. We could not find any proper differences in the development of thoracic sutures between $V$. china $i$ and $V$. modulatus. Differences mentioned by Hungerford \& Matsuda (1960) may be due to the figure of Lundblad (1933: pl. xii) which shows very pronounced sutures; in fact the sutures are faint but partly dark-coloured in one type specimen investigated. The dark colour pattern is extremely reduced in the types of $V$. chinai. The thoracic hairs are partly rubbed off, so that an investigation is difficult. In the centre of the mesopleura the hairs are short as in the types of $V$. modulatus.

Ventidius pubescens was based on numerous specimens from Johor in Malaya (Cheng 1965). We have studied the holotype and several paratypes, which have a uniformly reduced dark colour pattern. Cheng (1965) re-described V. modulatus after 'a mating pair' from Pahang, Malaysia, but compared $V$. pubescens with $V$. chinai on the assumption that " $\mathrm{t}]$ he colour pattern is also quite a constant character' (Cheng 1965: 153). The main difference between $V$. pubescens and V. chinai is, according to Cheng (1965), the dif- 
ferent shape of parameres. As this is based on the broken paramere of $V$. chinai, this character is useless. Furthermore, Cheng (1965) stated: ' $V$. pubescens also differs from the latter species $[=V$. chinai $]$ in the possession of the mesosternal groove, densely haired body and differently proportioned antennal and leg segments.' The 'mesosternal groove' mainly consists of an internal ridge medianly on the mesosternum and can be more or less seen through the cuticula; it is more easily visible in specimens preserved in alcohol ( $V . p u-$ bescens paratypes) than in dried specimens (as type specimens of $V$. chinai). We could not find any important differences in ratios of the antennal and leg segment of the type specimens of $V$. chinai and $V$. pubescens for these parts which are still present in the types of $V$. chinai. Indeed there is a difference in the pubescence of $V$. pubescens and $V$. chinai (and V. modulatus), not so much in the general dorsal appearance (which we think is due to the bad condition of the type specimens of $V$. chinai), but more in a longer pubescence in the middle part of mesopleura of $V$.pubescens. This character can be seen only under high magnifications and is the only character we found to distinguish $V$. pubescens from $V$. modulatus and $V$. chinai. Body pubescence has been shown to be important for protection against UV-radiation in different genera of Gerridae (Cheng et al. 1978, Andersen 1990); therefore it could be variable under different microhabitat conditions. As the types of $V$. pubescens correspond in all other characters either with $V$. modulatus and/or with $V$. chinai, we regard it as synonymous with $V$. modulatus. Although there may be some doubts about the synonymy of $V$. pubescens and $V$. modulatus, we regard it presently more practical to treat them as one species than to separate them only by the difference in pubescence which is very difficult to observe. Recently, a sample including only macropterous specimens was collected at Bago Yoma, Burma (c. $\left.18^{\circ} 47^{\prime} \mathrm{N}, 96^{\circ} 21^{\prime} \mathrm{E}\right)$, whcih is close to the type locality of $V$. distanti (c. $20^{\circ} 35^{\prime} \mathrm{N}, 96^{\circ} 58^{\prime} \mathrm{E}$ ). The paramere shows the typical shape of the $V$. modulatus-group. We suspect that these macropterous specimens from Bago Yoma are $V$. distanti. In that case, further study of $V$. distanti and $V$. modulatus will be needed (see also under $V$. distanti).

\section{Ventidius (s. str.) distanti Paiva}

(fig. 129, map 3)

Ventidius distanti Paiva, 1918: 25, pl. VIII, fig. 4 (descr., illustr.); Esaki 1928: 511 (comparative notes); Dover 1929: 69 (misidentif.); Esaki 1930: 18 (considers as valid species, misidentif.); Lundblad 1933: 372 (list, comp. with modulatus); Hungerford \& Matsuda 1960: 332 (discussion, key).

Type locality. - MYANMAR (BURMA): Yawnghwe State.
Types [not examined]. - 'Described from several specimens in alcohol, from the top of gorge of the He-Ho River, Yawnghwe State, ca. 3,500 ft., 7-iii-1917’ (Paiva 1918).

\section{Description}

Since we have no material either from the type series or other specimens from the type locality, we adopt the main description points given by Paiva (1918) which are based mainly on colour characters.

Dimensions. - Apterous form. Length 3.00.

Colour and structural characters. - 'Head black with a large patch at base, and a transverse fascia at apex of face yellowish ochraceous; eyes silvery grey, with a black patch on the disk; antennae black, basal half of first joint yellowish. Pronotum very short, black, a narrow ochraceous weaved fascia at basal margin, anterior margin slightly concave, posterior margin almost straight. Mesonotum large, about as long as its greatest breadth (Esaki (1930) pointed out that ' $\mathrm{h}]$ is 'mesonotum' evidently includes a part of the metanotum'), covered with decumbent hairs, disk obliquely striate on anterior area, ochraceous, with two broad lateral black fasciae curved inwards anteriorly and meeting narrowly on anterior margin, each extended posteriorly to meet a curved fascia on the intermediate acetabula; a large subtriangular patch at centre of posterior margin; the posterior lateral angles narrowly dull black. Metanotum dull black with a small ochraceous spot near each basal angle. Abdomen above dull white, the basal segment, a spot at lateral margin of each segment and the apical segment black. Underside pale ochraceous; legs black, base of anterior femora ochraceous.'

Distribution (map 3). - Myanmar: Yawnghwe.

Remarks. - The type material of this species was deposited in the collection of the Zoological Survey of India (type No. 7152/H.i.), but is so far not available for study. We quote here the notes from the revisionary paper of Hungerford \& Matsuda (1960): 'Dr. P. Kapur of the Calcutta Museum is now unable to find this type in their museum and it may have been lost by high water in the temporary quarters in 1943 . This is most unfortunate since only a re-examination or the type of a study of a series of specimens from the type locality the identity of Ventidius distanti can be established.'

Judging from the drawing (fig. 129) and the description given by Paiva (1918) we consider $V$. distan$t i$ as belonging to the $V$. modulatus-group; the specimen figured is probably a female. Species of the subgenus Ventidioides usually have the pronotum completely black (never with a yellow mark medially on hind margin as figured by Paiva). Species of the $V$. aquarius-group are larger in size (Paiva states $3 \mathrm{~mm}$ for $V$. distanti) and have longer antennae and stouter middle and hind femora than figured by Paiva (1918). Re- 


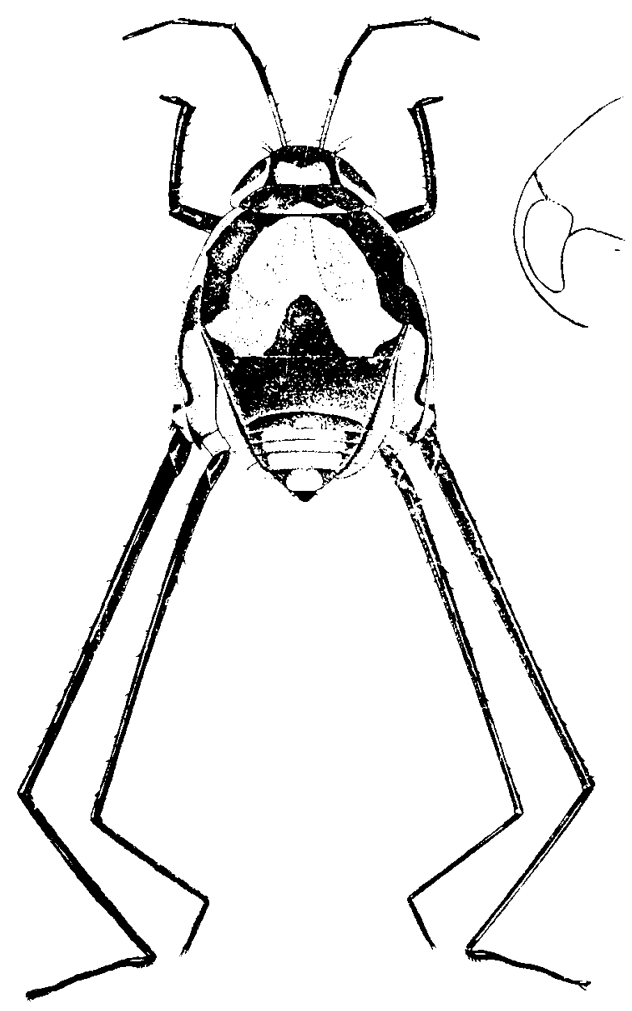

Fig. 129. Ventidius (s. str.) distanti, apterous male, reproduced from Paiva's drawing (1918).

cently we have obtained records of $V$. modulatus from India and Sri Lanka, which shows that this species is widely distributed and probably also occurs in Myanmar (although we have no records from this country).

As the description given by Paiva (1918) is not sufficient, there was a confusion about the species named $V$. distanti during the following decades. Dover (1929) recorded it from Malaya (Selangor) and added to the confusion; his material was considered as belonging to two different species (see Hungerford \& Matsuda 1960). One of them was established as a new species, $V$. malayensis, by Hungerford and Matsuda (1960), while the other smaller specimen-which was identified as $V$. distanti also by Esaki and China-is a Ventidioides sp. We agree with Hungerford \& Matsu$\mathrm{da}(1960)$ that the morphological characteristics show clearly that this specimen belongs to the subgenus Ventidioides, and reject the conspecific status of this specimen with $V$. distanti. The only Ventidioides species presently known from Malaya (and from Selangor) is $V$. pulai.

Lundblad (1933) stated that his new species, $V$. modulatus, was similar to $V$. distanti, but differed in the length of the antennal segments: segment 3 was longer than segment 2 in $V$. distanti, but shorter than segment 2 in $V$. modulatus. In this case-because he had only four males at hand-Lundblad (1933) walked right into a deep trap: he could not know that in this species complex ( $V$. modulatus-group) usually the ratio between lengths of antennal segment 2 and 3 is completely different in males and females. If we are right that Paiva (1918) figured a female, indeed there is no obvious difference between $V$. distanti and $V$. modulatus. Furthermore, Lundblad (1933) trusted the paper of Esaki (1930): Esaki had a male at hand of which the antennal segment 2 is also shorter than segment 3; but this specimen even belongs to another subgenus (see above).

A recent sample from Burma (see also under $V$. modulatus) including only macropterous specimens, was collected at Bago Yoma (c. $18^{\circ} 47^{\prime} \mathrm{N}, 9^{\circ} 21^{\prime} \mathrm{E}$ ), which is close to the type locality of $V$. distanti (c. $\left.20^{\circ} 35^{\prime} \mathrm{N}, 9^{\circ} 58^{\prime} \mathrm{E}\right)$. It is quite possible that these macropterous specimens from Bago Yoma are $V$. distanti. A definitive conclusion is difficult to draw without checking the type material.

Finally, we are of the opinion that $V$. distanti should be a valid species of the genus Ventidius within the $V$. modulatus-group. It cannot be $V$. henryi because of the colour pattern figured by Paiva (1918) (see fig. 129), and probably not $V$. hungerfordi which has a thick antennal segment 1 and is so far only known from Southeast Asia. But until material from the type locality is available, we consider it premature to make $V$. distanti a senior synonym of one of the known sibling species in this group.

\section{Ventidius (s. str.) sushmae Gupta nomen inquirendum}

Ventidius sushmae Gupta, 1981: 99-102, figs.1-12 (descr., illustr.).

Type locality. - INDIA: West Bengal, Darjeeling, Sukna.

Types [not available for examination]. - 'The type specimens are for the time being retained in the department of Zoology, B.S.A. College, Mathura (U.P.) but subsequently would be deposited in the National Collection of Zoological Survey of India, Calcutta' (Gupta, 1981). The type serie includes 10 apterous males and 8 females, and 6 macropterous males and 4 females.

\section{Description}

We were not able to study type material of $V$. sushmae. We adopt the description given by Gupta (1981) as below:

Dimension. - Apterous form, length 2.40 (ङ̋), 2.60 (ㅇ), width 1.85 (ङ), 2.10 (ㅇ), width of head 1.05 ( đ), 0.95 ( ㅇ).

Colour. - Dorsal surface yellowish-brown in 
ground colour with black markings. Head yellowishbrown, a median somewhat triangular and a pair of lateral black stripes, confluent anteriorly. Pronotum yellowish-brown with lateral longitudinal black stripes. Mesonotum yellowish-brown with a pair of lateral longitudinal black stripes. Metanotum yellowish-brown with black stripes on fifth, sixth and seventh tergites. Venter light brown. Connexivum yellowish-brown laterally. Antennae and legs brown.

Pilosity. - Fore femur of male not clothed with long hairs on inner margin.

Structural characters. - (The measurement of antennnae and legs were given by Gupta for both apterous and macropterous form. As the scale was not in millimetres, his data are excluded from the tables in this paper). Head including eyes much wider than long. Eyes exserted, rounded on outer margin, strongly emarginate on inner half margin, covering entire lateral margin of pronotum and anterior angle of mesonotum. Antenniferous tubercles not developed. Proportional length of antennal segments see table 1. Clypeus with balsa margin lost. mandibular and maxillary plates well demarcated from each other. Rostrum short, clearly surpassing hind margin of prosternum, third segment about three times longer than last segment [7.2: $2.4(\widehat{O})$, and 7.5: $2.5($ ( $)$ ] Pronotum short, transverse, lateral margin rounded, both anterior and posterior margins concave. Intersegmental suture between mesonotum and metanotum poorly defined dorsally, obliterated laterally in front of metathoracic spiracle. mesosternum without a small tubercle on median longitudinal axis. Metanotum without median longitudinal sulcus, lateral longitudinal suture not meeting intersegmental suture. Metacetabular suture clearly reaching anterolateral angle of first abdominal tergite dorsally. Metacetabulum broad, with posterolateral angle simple. Metasternum highly reduced, represented by a small transverse subtriangular plate. Omphalium highly reduced, located closer to posterior margin than to anterior margin of metasternum. Omphalial groove absent. Fore leg relatively long, femur slender, simple, without a tubercle in male; tibia with a conspicuous narrow apical processus; tarsus with first segment much shorter than second segment. Claws arising from about middle of second segment. Abdomen broad and short. First tergite nearly straight on anterior margin. Anterior margin of second and third tergites produced anteriorly, obliterated medially. Abdominal spiracles hidden beneath metacetabula and hind legs, situated about in the middle between both the margins of each segment. Ventral longitudinal suture of connexivum not retained. Median ventral longitudinal carina absent. Seventh ventrite a little shorter than all preceding ventrites together, deeply concave on apical margin.
Male terminalia. - Eighth segment with dorsal posterior margin broadly rounded, ventrally concave on apical margin. Ninth segment with suranal plate simple; pygophore with apical margin simply rounded; parameres well developed, symmetrical. Endosoma with definitive dorsal plate curved back along apical margin of endosoma; simple at apex; ventral plate indistinguishably fused with dorsal plate, supported by basal plate; lateral plates simple, elongated, weakly sclerotized, with small downward projection apically. A V-shaped sclerite lying over dorsal plate.

Female terminalia. - Seventh segment ventrally distinctly longer than all preceding segments together, nearly straight on hind margin, narrowly rounded apically; intervalvular membrane with its apical margin broadly concave, valva large totally membranous.

Macropterous form. - Length 3.58 (ठే), 3.72 ( $($ ), width $1.90(\delta), 1.92(q)$, width of head $1.10(\widehat{)})$, 1.14 ( 9 ).

Wing venation: Hemelytra with distinct embolium. $\mathrm{R}+\mathrm{M}+\mathrm{Cu}$ vein divided into two veins, $\mathrm{R}+\mathrm{M}$ and $\mathrm{Cu}$ at basal third of the wing; two apical cells are formed, lower cell is relatively longer than vein A joined at its extremity. Vein also joined with rear margin of wing at about middle by a short cross vein.

Distribution (map 3). - India: West Bengal.

Remarks. - Gupta (1981) correctly put this species in subgenus Ventidius (s. str.). He discussed and keyed the difference of the two subgenera: Ventidius (s. str.) and Ventidius (Ventidioides). The comparative notes of this species with other species of $V$. modulatus-group were not given. But he mentioned that he has compared this species with $V$. aquarius Distant, although he wrote: 'Unfortunately, the type specimen (of V. aquarius Distant at Z.S. I., Calcutta) is poorly mounted on a slide and is damaged.' The illustration given by him is reasonable and shows great similarity to $V$. modulatus Lundblad. The original description and drawings, especially the lateral view of paramere, fit very well with $V$. modulatus. Further, we have studied specimens of $V$. modulatus from Sri Lanka. Although we suspect strongly its status as a good species, until checking the type material we treat here this species as a valid species in the $V$. modulatusgroup of the subgenus Ventidius.

\section{Ventidius (Ventidioides) Hungerford \& Matsuda}

Ventidius (Ventidioides) Hungerford \& Matsuda, 1960: 335-336. Type species by monotypy: Ventidius (Ventidioides) kuiterti Hungerford \& Matsuda.

Diagnosis. - Dorsal dark colouration more prominent and not varying as much as in Ventidius s. str.; antennae stouter than in Ventidiuss. str., in males the length of antennal segment 1 approximately as long 
as segments 2-4 together, from basal half of segment 1 to segment 3 or 4 with a fine pubescence of erect hairs ventrally; posterolateral angle of metacetabula bilobate; mesosternum of male with a small, in some species very prominent, tubercle at the end of the median groove, either with a row of dark setae anteriorly of the tubercle, or the tubercle more or less covered with a tiny tuft of setae; surface of male fore femur in middle of its length with a small tooth, a broad tubercle or simple; parameres asymmetrical, left paramere stronger than right one.

Distribution (maps 4, 5). - Widely distributed in the Oriental region (in the Southeast Asian mainland from Myanmar to Malaysia, and in Borneo) and reaching the Wallacea (Sulawesi). Unknown from the Indian region.

Identifications. - The following key for apterous males may be also used for macropterous males in most characters, but as the thickening of fore femur and fore tibia is less developed in this morph, this character can not be used to distinguish $V$. kurtokala$m i$ and $V$. nieseri sp. n. Females are very difficult to distinguish in most species, but females of the $V$. kuiterti-group differ partly in colour and length of antennal segments, body length and colouration. The Sulawesian species of the $V$. xiphibion-group ( $V$. xiphibion and $V$. xyele) also show a different colour pattern in females, which is not very reliable, because both species show some variations. The same is true for the Bornean species $V$. kurtokalami and $V$. nieseri sp. n. The female of $V$. heissi sp. n. is unknown.

\section{Key to apterous males of the subgenus Ventidioides}

1. Ventral surface of fore femur with a small, sharp tooth in middle of its length (fig. 148); mesosternum without a row of dark setae anterior of tubercle, but the tubercle may be more or less covered by dark setae (fig. 132); endosoma with two pairs of lateral sclerites (fig. 4) (V. kuiterti-group; species from the Southeast Asian mainland) .......2

- Ventral surface of fore femur without a sharp tooth, but sometimes in middle of its length with a blunt tubercle or thickening (figs. 198-202); mesosternum with a row of black setae anterior of tubercle (fig. 215); endosoma with three pairs of lateral sclerites (fig. 5) ( $V$. xiphibion-group; species from Borneo and Sulawesi)

2. Antennal segment 3 shorter than segment 4 , segment 3 and 4 partly yellowish

- Antennal segment 3 subequal to segment 4, segments 3 and 4 uniformly brown ....................... 4

3. Body length less than $2.6 \mathrm{~mm}$; yellowish marks of meso- and metanotum separated by a black stripe (fig. 130); antennal segment 4 slightly longer than segment 3; yellowish mark on antennal seg-

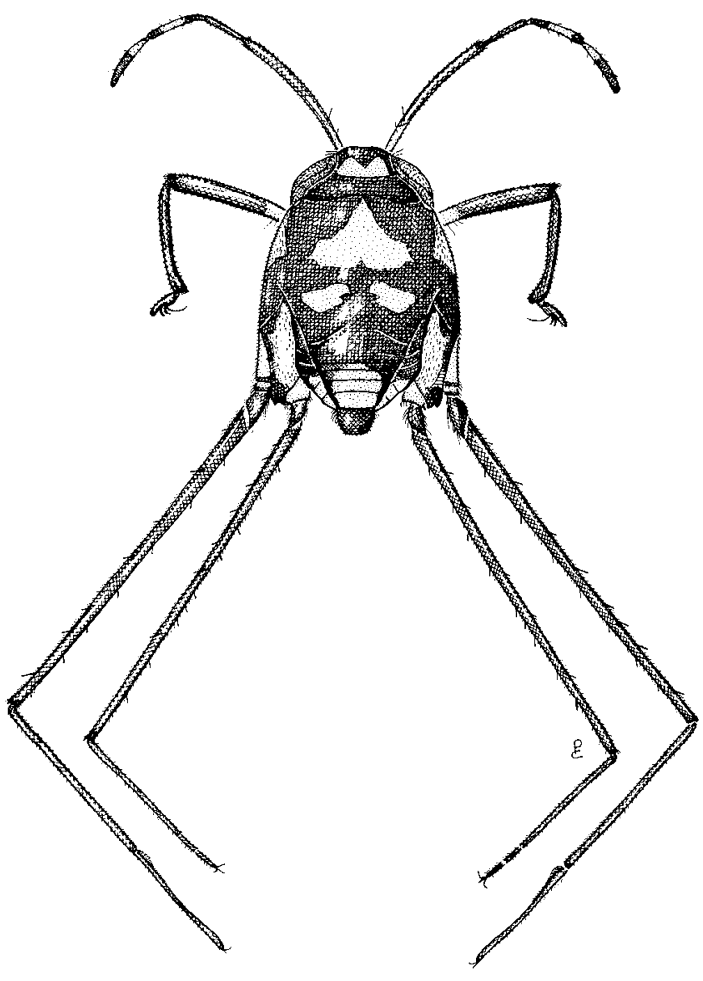

Fig. 130. Ventidius (Ventidioides) kuiterti, paratype, apterous male, length $2.46 \mathrm{~mm}$.

ment 4 less distinct; parameres as in figs. 167, 168 (Myanmar, NE India) V. kuiterti

- Body length more than $2.6 \mathrm{~mm}$; yellowish marks of meso- and metanotum partly confluent (fig. 183); antennal segment 4 distinctly longer than segment 3; yellowish mark on antennal segment 4 very distinct; parameres as in figs. 169, 170 (Thailand, Vietnam) ............................. V. karen

4. Left paramere in distal part long and slender, not twisted (fig. 176); right paramere small and rather slender (fig. 175); segment 8 with densely developed long dark pilosity (fig. 182) (Thailand)

..V. lundbladi

- Left paramere in distal part plate-like, apically twisted (figs. 172, 174); right paramere slightly broader (fig. 171, 173); pilosity of segment 8 less developed (Thailand, Laos, Malaya) .......V. pulai

5. Fore trochanter without a tuft of black setae; left and right parameres hooked upward halfway their length, with slender base (figs. 223, 224, 227, 228) (Bornean species)

- Fore trochanter with a distinct tuft of black setae (fig. 213); inner surface of fore femur and fore 
Figs. 131-132.

Ventidius karen. - 131, dorsal view of macropterous male (appendages removed, after Lansbury); 132, ventral view of apterous male (genital segments removed, after Lansbury).

Fig. 133.

V. pulai, pronotum of macropterous form.

Fig. 134.

$V$. lundbladi, lateral view of head, showing the trichobothria of interoculus.

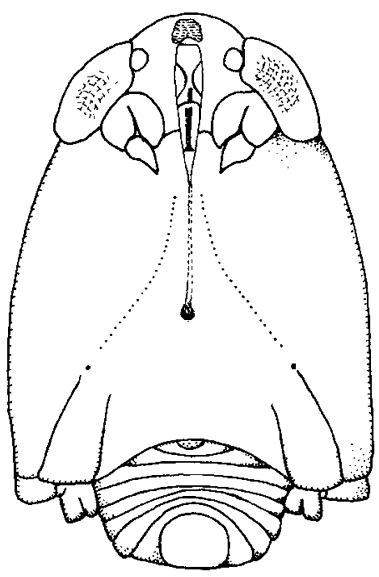

132

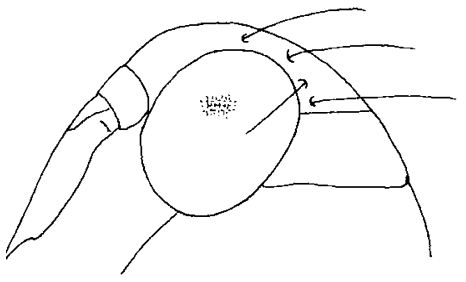

134

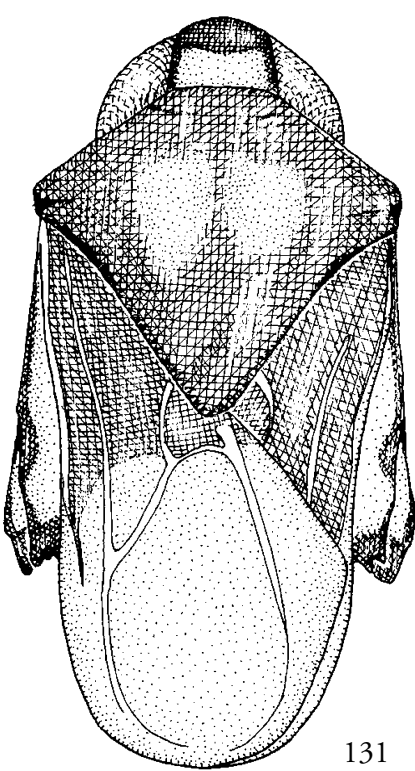

133

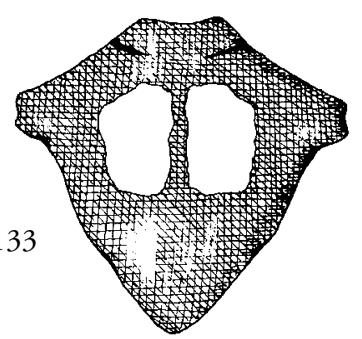

tibia without a swelling halfway its length, but slightly broadened (figs. 198, 199); left and right parameres hooked upward close to the strongly enlarged base, left paramere distinctly broader than right one (figs. 219-222) (Sulawesian species)

6. Inner surface of fore femur and fore tibia with a more or less prominent swelling halfway its length (figs. 200, 201); row of black setae on mesosternum long; left and right parameres slender and pointed apically 7

- Inner surface of fore femur and fore tibia without distinct swelling halfway their length (fig. 202); row of black setae on mesosternum less developed; both parameres thick, left paramere curved apically, right paramere blunt (figs. 225, 226) ....

$V$. heissi

7. Brighter species, yellowish marks on metanotum large, metacetabulum with two separated black marks (figs. 207, 208); thickening of fore tibia stronger developed; along mesosternal groove with a row of short dark setae; endosomal apical accessory sclerite indistinct (fig. 232)

V. kurtokalami

- Darker species, yellowish marks on metanotum small (fig. 236), metacetabulum in most specimens with confluent black marks (figs. 209, 210); thickening of fore tibia mainly by erect pilosity; along mesosternal groove with a row of long black setae (fig. 215); endosomal apical accessory sclerite distinct (fig. 233) $V$. nieseri

8. colouration darker, yellowish marks on metanotum usually separated from that of mesonotum; mesopleura with a dark long stripe running through its length; left and right parameres with elongate tips, right paramere not much shorter than left one (figs. 221, 222); endosomal apical accessory sclerite indistinct (fig. 231) ......V. xyele

- colouration brighter, yellowish marks on metanotum usually not separated from that of mesonotum; mesopleura with a small dark mark anteriorly, Left paramere with acute, but not elongate 
tip (fig. 219), right paramere with less slender tip and much shorter than left one (fig. 220), endosomal apical accessory sclerite distinct (fig. 230) . V. xiphibion

\section{The Ventidius kuiterti-group}

Diagnosis. - Male fore femur in middle of its length with a small distinct ventral tooth; at the end of median mesosternal groove with a small prominent tubercle covered with short setae; parameres with blunt apex (except left paramere of $V$. lundbladi); endosoma without apical accessory sclerite, usually without third pair of lateral sclerites (but in $V$. karen with a thin third pair); in $V$. kuiterti and $V$. karen with yellowish bands on antennal segments 3-4 in both sexes, but sometimes in heavily pigmented females totally dark.

Distribution (map 4). - Endemic to the Southeast Asian mainland.

14. Ventidius (Ventidioides) kuiterti Hungerford \& Matsuda

(figs. 130, 135-137, 142, 148, 157, 158, 167, 168, 177, map 4)

Ventidius (Ventidioides) kuiterti Hungerford \& Matsuda,
1960: 333-336 (desc., illustr., key).

Type locality. - MYANMAR: Shingbwiyang.

Type material examined. - Paratypes: MYANMAR [Bur-

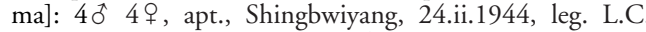
Kuitert (sEMC, JTPC, NHMw); 10 apt. Tingkawk, V.1944, leg. L.C. Kuitert (JTPC).

Other material examined. - MYANMAR: $10 \hat{4} q 9$ apt., Shingbwiyang, 22.ii.1944, leg. L.C. Kuitert (sEMC, NHMw); 1 to 1 우 apt., Tingkawk, V.1944, leg. L.C. Kuitert (sEMc).

\section{Redescription}

Dimensions. - Apterous form: length 2.46 (đ)), 2.60 ( $q$ ), width $1.60(\delta), 1.90(q)$, width of head 1.10 (o), 1.20 (ㅇ).

Colour (fig. 130). - Whole body prominently dark, with distinct yellowish marks. Eye blackish. Interoculus blackish, with one large M-shaped yellowish mark at posterior margin. First antennal segments dark except basal 1/6; second segment dark; segment 3 mostly yellowish, fourth segment brownish or yellowish at basal half. Pronotum dark, in some specimens with two small yellowish marks at the lateroposterior margin. Mesonotum yellowish with broad dark lateral stripe which confluent with the dark mark on metanotum. Metanotum with two triangular yellowish marks laterally. Mesopleura with variable colour pat-

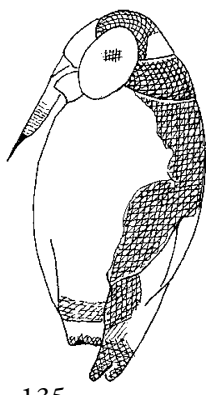

135
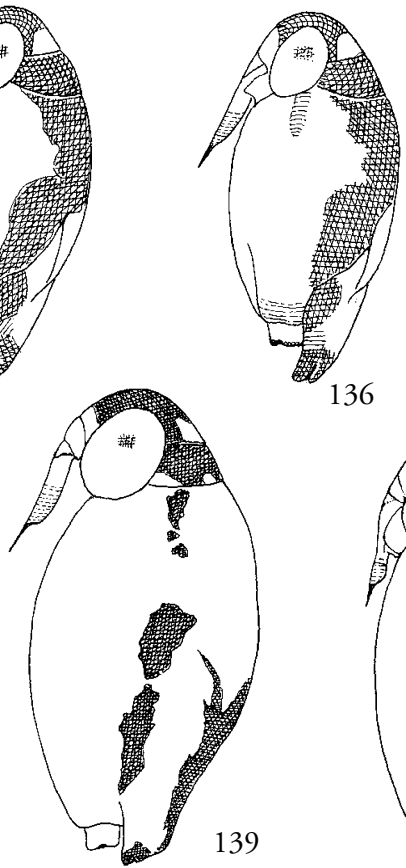
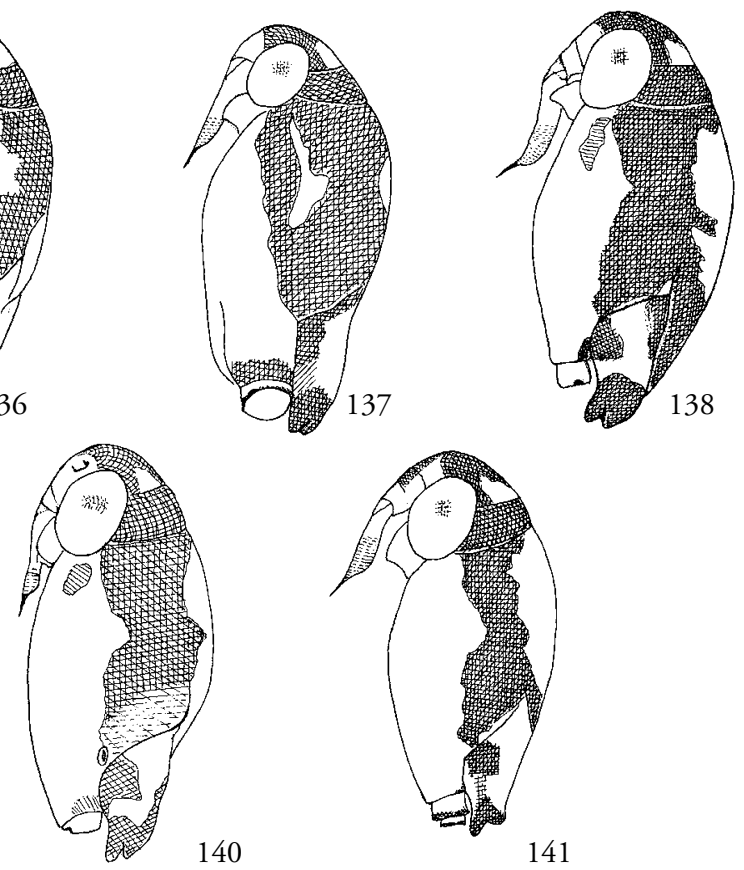

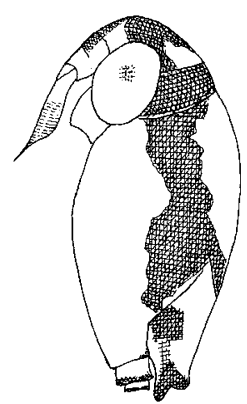

141

Figs. 135-141. Lateral view of apterous males, showing the colour patterns of pleura. - 135-137, Ventidius kuiterti; 138, V. karen; 139, V. sp. from Viet Nam; 140, V. pulai, 141, V. lundbladi. 

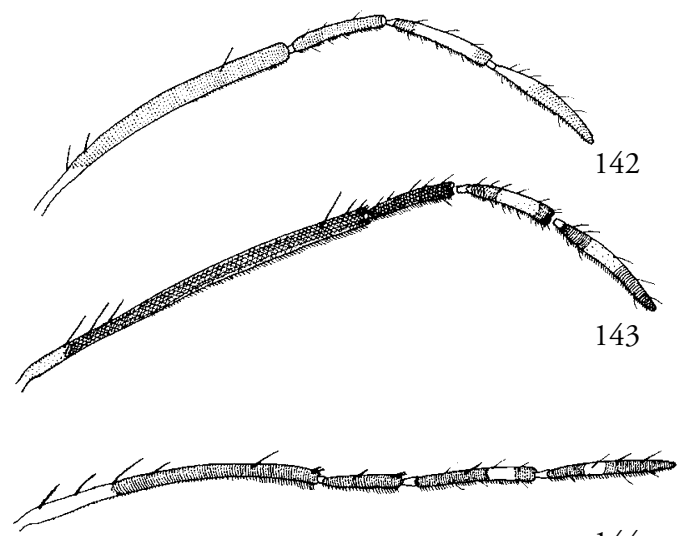

144
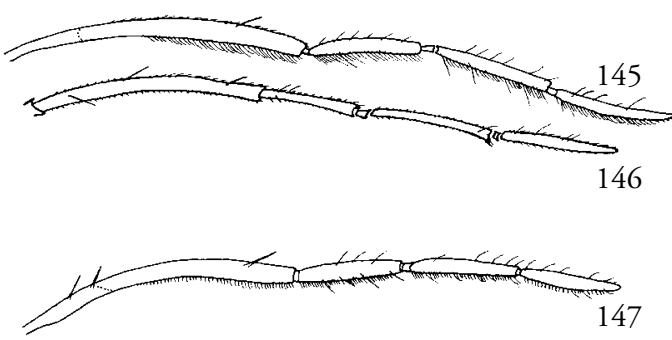

Figs. 142-147. Dorsal view of male right antennae. - 142, V. kuiterti; 143, V. karen; 144, V. sp., female, from Viet Nam; 145, V. pulai, male; 146, same species, female; $147, V$. lundbladi. tern; one apterous paratype male with totally yellowish mesopleura (fig. 135); one apterous paratype male with a small brownish mark near the anterior margin of mesopleura (fig. 136); one apterous paratype female with broad dark stripe running through the length of mesopleura (fig. 137). Distal margin of metapleura brownish. External part and lower part of metacetabula blackish (figs. 157, 158). Fore leg dark with basal $1 / 3$ yellowish (fig. 148). Middle and hind legs dark. Tergites 1-3 completely dark, 4 blackish with a triangular yellowish mark in the middle, 5-6 yellowish but dark laterally, 7 yellowish, 8 dark. In males: laterotergites 1-4 blackish, 5 dark with a small pale mark, 6-7 yellowish; connexiva 1-5 dark, 6-7 yellowish. In females: laterotergites and connexiva yellowish. Venter yellowish. Metasternum yellowish.

Pilosity. - Inner surface of antennal segment 1 with 3 subbasal and 1 subapical spines, in male through basal half of segment 1 to segment 4 with dark fine hair fringe; segments 2-4 with scattered brownish short setae (fig. 142). Dorsum, pleura and metacetabula bearing dark pubescence. Venter clothed by golden pubescence, especially on genital segments, the pilosity longer and denser. In male at the end of mesosternal groove with a small tubercle, which is covered by short dark setae. Long stiff spines scattered along middle and hind legs.

Figs. 148-154. Dorsal view of right fore leg. - 148, $V$. kuiterti; 149, V. karen; 150, V. sp. female, from Viet Nam; 151, V. pulai, male; 152, V. pulai, female; 153-154, V. lundbladi; 153, dorsal view; 154, posteroventral view of fore femur, showing the tooth.
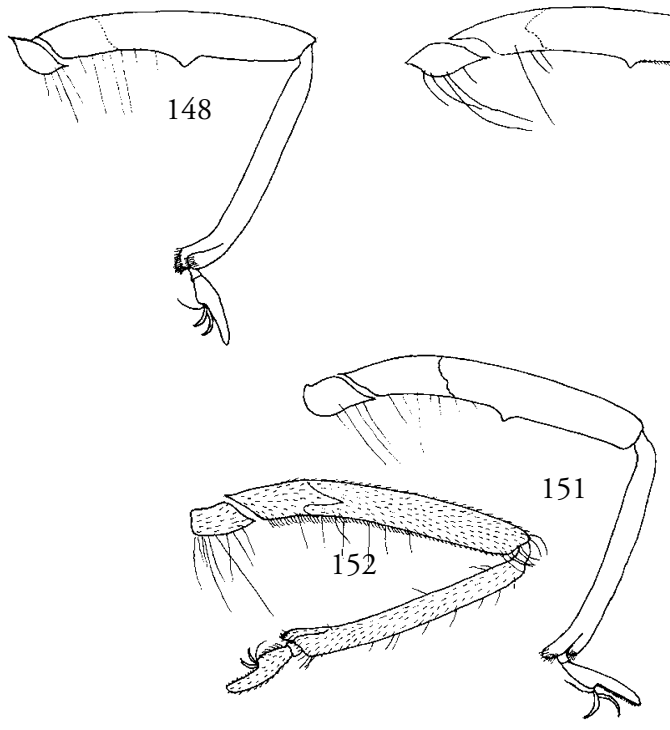
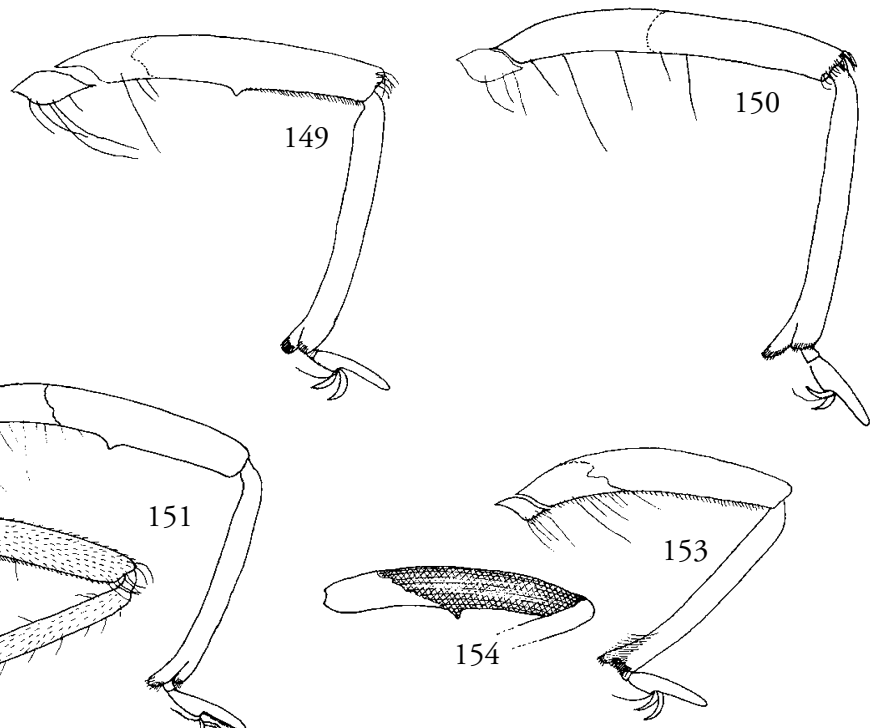
Structural characters. - Interoculus subequal to width of an eye, $0.40: 0.40$ in male, $0.45: 0.40$ in female, respectively. Antennae not modified, measurements see table 1. Thorax not bulbous, mesonotum somewhat swollen, its lateral width 0.90 (ङ), 1.30 (ㅇ). Intersegmental suture between meso- and matenota obscure. Metanotum somewhat declivent. Lower part of metacetabula bilobate (figs. 157, 158). Metasternum not prominent. Fore femur of male slightly incrassate, halfway its inner surface with a small tooth (fig. 148), claw rising from $2 / 5$ of segment 2 of fore tarsus. Anterior margin of abdominal tergite 1 obscure, anterior margins of tergites 2 and 3 obscure but eventually obliterated medially and protruding forward; abdominal sternite 7 as long as the preceding abdominal sternites together in both sexes. Laterotergites broad.

Male terminalia. - Parameres (figs. 167, 168) asymmetrical, both hooked subbasally, left paramere larger than the right one, with blunt apex, extending beyond genital segments. Endosoma (fig. 177): dorsal sclerite long and recurved proximally, ventral sclerite long, lateral sclerites straight, hooked distally and broadened proximally, second lateral sclerite long and thin.

Female terminalia. - Abdominal sternite 7 large, posterior margin smooth, anteriorly concave.

Macropterous form. - Unknown.

Distribution (map 4). - Myanmar: Shingbwayang. India: Arunachal Pradesh.

Comparative notes. - This species is most similar to $V$. karen, for differences see under comparative notes of that species.

\section{Ventidius (Ventidioides) karen Lansbury}

(figs. 131, 132, 138, 143, 149, 159, 160, 169, 170, $178,181,183$, map 4)

Ventidius karen Lansbury, 1988: 61-66 (descr., illustr.); Zettel \& Chen, 1996: 152, 181 (list, rec.).

Type locality. - THAILAND: Nakhon Ratchasima.

Type material examined. - Holotype, $\widehat{0}$, apt., THAILAND: [Nakhon Ratchasima], Khao Yai National Park, Pha Kuai Mai Waterfall, 6.xi.1987, leg. C. Deelman (оuмc). Paratype $\hat{\delta}$, apt., same data as holotype (oumc).

Other material examined. - THAILAND: 3099 all apt., 17lv., Phetchabun Prov., Huai Nam Phang, S. Ban Nam Nao, 25.xi.1995, leg. H. Zettel; ca. 31 km NW der Abzweigung von der Straße Lom Sak-Chumpae, ca. 5-6 m breiter Fluß, sehr stief, sehr schlammig (NHMw, PPCC); $503 \%$ all apt., Petchabun Prov., Nam Nao N.P., Huai Phrom Laeng, 2-3 m breiter Bach, 24.xi.1995, leg. H. Zettel (22) (NHMw);

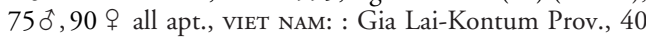
km NW An Khe, Buon Luoi, 14¹0’ N., 108³0' E., 620750 m, 28.iii.-12.iv.1995, leg. Pacholatko \& Dembicky (NHMW, NCTN, PPCC, BMNH, ZRCS).

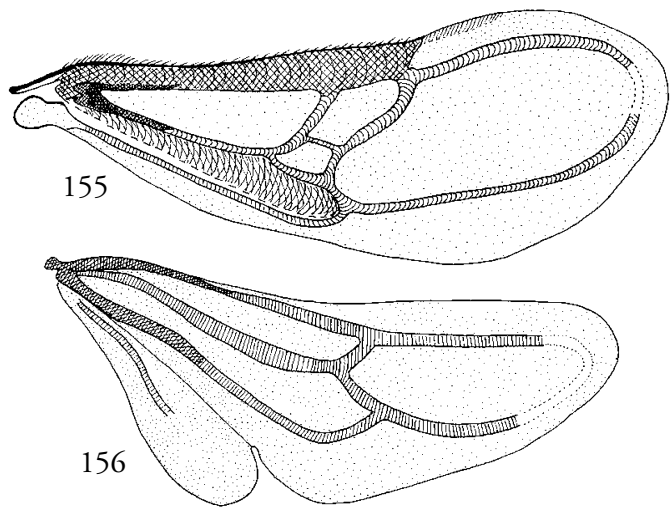

Figs. 155-156. V. pulai. - 155, dorsal view of fore wing (after Cheng); 156, dorsal view of hind wing (after Cheng).

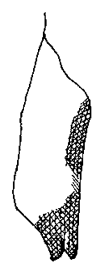

157

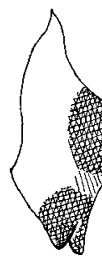

158

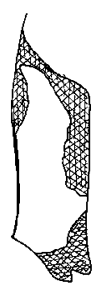

163

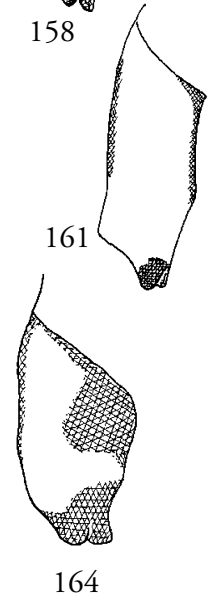

164

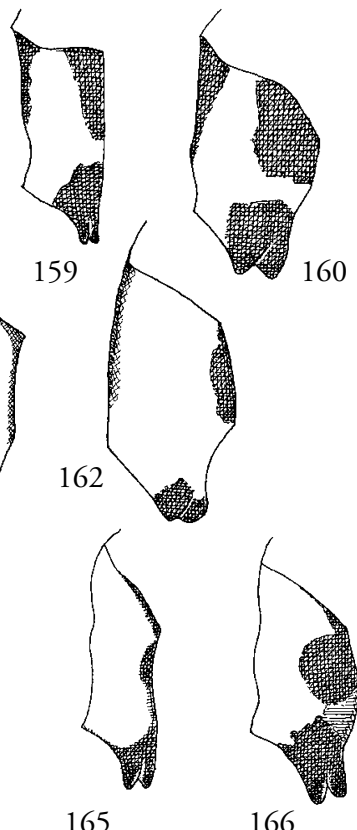

165
166
Figs. 157-166. Male right metacetabula: odd numbers: dorsal view; even numbers: dorsolateral view. $-157,158$, Ventidius kuiterti; 159, 160, V. karen; 161, 162. V. sp., male, from Viet Nam; 163, 164, V. pulai; 165, 166, V. lundbladi. 

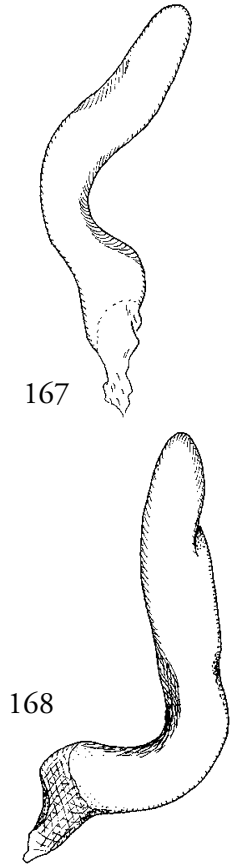

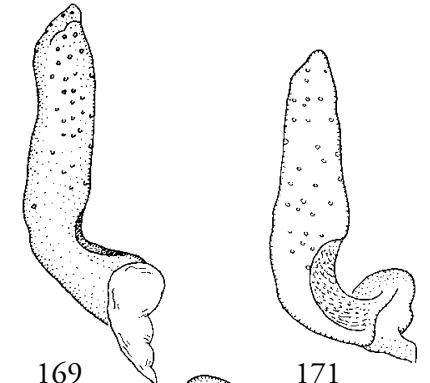

171
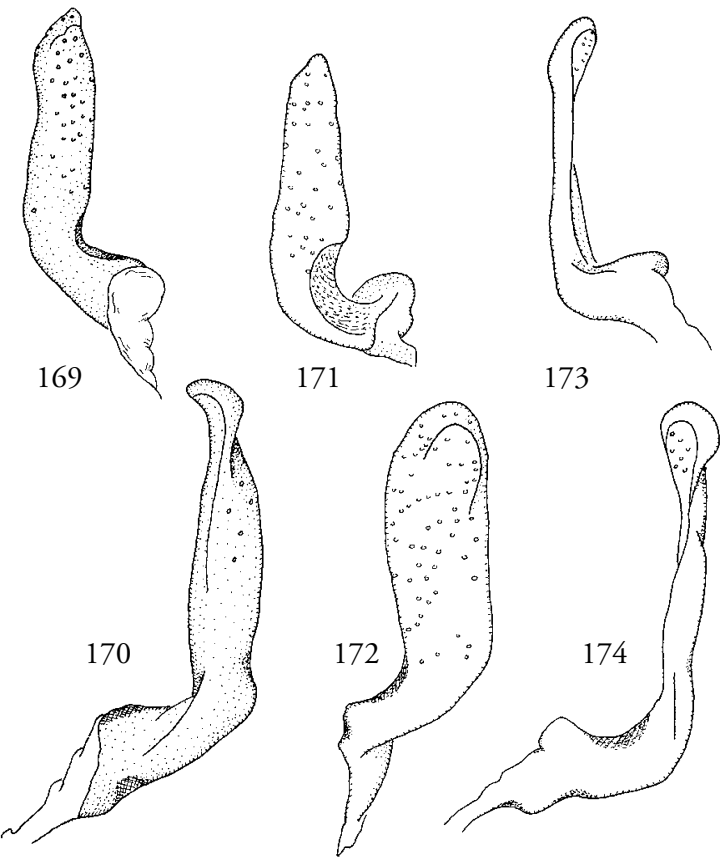

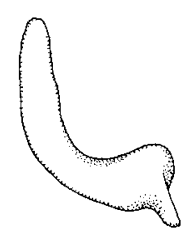

175

175

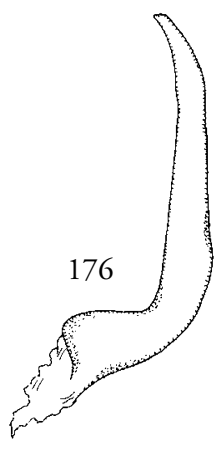

Figs. 167-176. External view of parameres, odd numbers: right paramere (except 173: internal view), even numbers: left paramere (except 174: posterior view of right paramere). - 167, 168, Ventidius kuiterti; 169, 170, V. karen; 171-174, V. pulai; 175, 176, V. lundbladi.

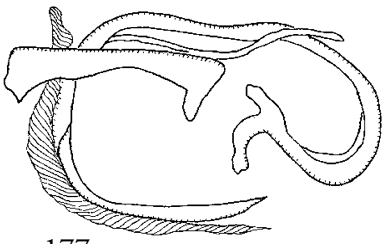

177

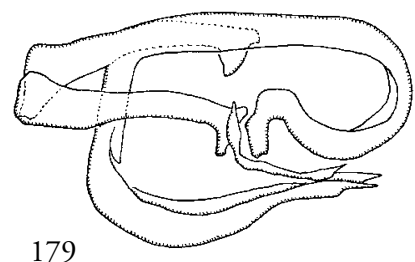

179

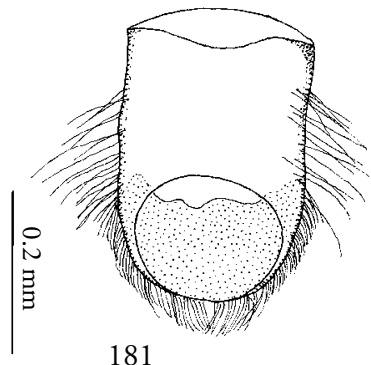

181

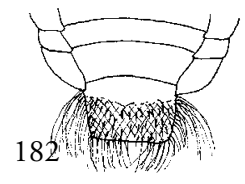

178
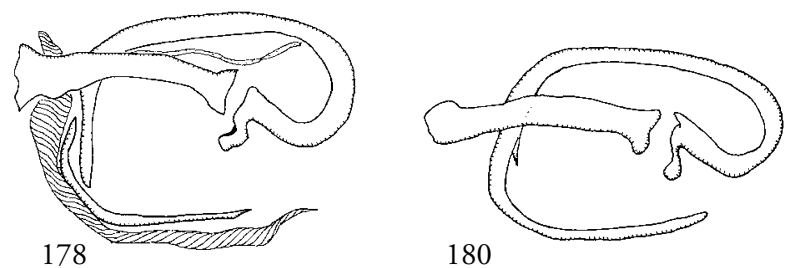

Figs. 177-180. Lateral view of endosoma sclerites. - 177, Ventidius kuiterti; 178, V. karen; 179, V. pulai; 180, V. lundbladi. -Fig. 181. V. karen, ventral view of male 8th abdominal segment. - Fig. 182. V. lundbladi, dorsal view of male 7 th abdominal tergite, showing the pilosity. 


\section{Redescription}

Dimensions. - Apterous form, length 2.66 ( $\overline{0})$,

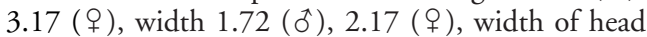
1.15 (ô), 1.30 (우).

Colour (fig.183). - Whole body predominantly yellowish dorsally, with dark marks. Eyes mainly dark brown to blackish, with brownish margins. Interoculus dark from dorsal view, with a thick M-shaped yellowish mark at its posterior margin, along inner margin of eye with a dark stripe. Antennal segments mainly blackish, but yellowish at basal $1 / 3$ of segment 1 , most part of the segment 3 and middle part of fourth segment; in female sometimes all antennal segments blackish except basal $1 / 3$ of first segment yellowish. Pronotum blackish, lateroposterior angle with a very small yellowish mark. Mesonotum with broad lateral dark stripes, which are confluent with the lateral triangular blackish mark on metanotum. Metanotum also with a large triangular dark mark basomedially which is close to the anterior margin. Mesopleura yellowish without longitudinal stripe at anterior half (fig.138); posterior margin of metapleura dark; upper external half and lower external half of metacetabula dark (figs. 159, 160). Fore leg dark, femur with basal 2/5 yellowish (fig.149). Middle and hind legs dark. Tergites 1-2 blackish, 3-4 blackish with obscure yellowish mark in the middle, 5-6 dark laterally with a median yellowish mark, 7 yellowish, with posterior margin dark, 8 dark. Laterotergites and connexiva 1-5 blackish, 6-7 yellowish in male, predominantly yellowish with dark margins in female. Venter yellowish, male segment 8 ventrally dark (fig. 132).

Pilosity. - Inner surface of antennal segment 1 with 4 subbasal and 1 subdistal long spine, around segments 2-4 clothed with usual pubescence, also with longer setae and spinules. In male from distal half of segment 1 , through all antennal segments with fine silvery hair fringe. Dorsum and pleura bearing dark pubescence. Long stiff spines scattered along middle and hind legs, tibia with shorter stiff spinules, inner surface of tarsal segment 1 of middle leg with a fringe of hairs (fig.149). Basal part of middle and hind femora with two very long trichobothria-like seta on dorsal surface respectively, the external one shorter than the internal one. Ventrally clothed by golden pubescence, on genital segments the pilosity slightly longer and denser.

Structural characters. - Interoculus subequal to width of an eye, $0.39: 0.36$ in male, $0.46: 0.42$ in female, respectively. Antennae slender, segment 2 shorter than segment 3 (Measurements see table 1); segment 3 in male not modified at distal half (fig.143). Pronotum not bulbous, mesonotum strongly swollen dorsally, its lateral width 1.04 (ठ)), 1.36 (\$). Mesosternal groove conspicuous, distally terminated by a small tubercle covered by short brown setae. Intersegmental su-

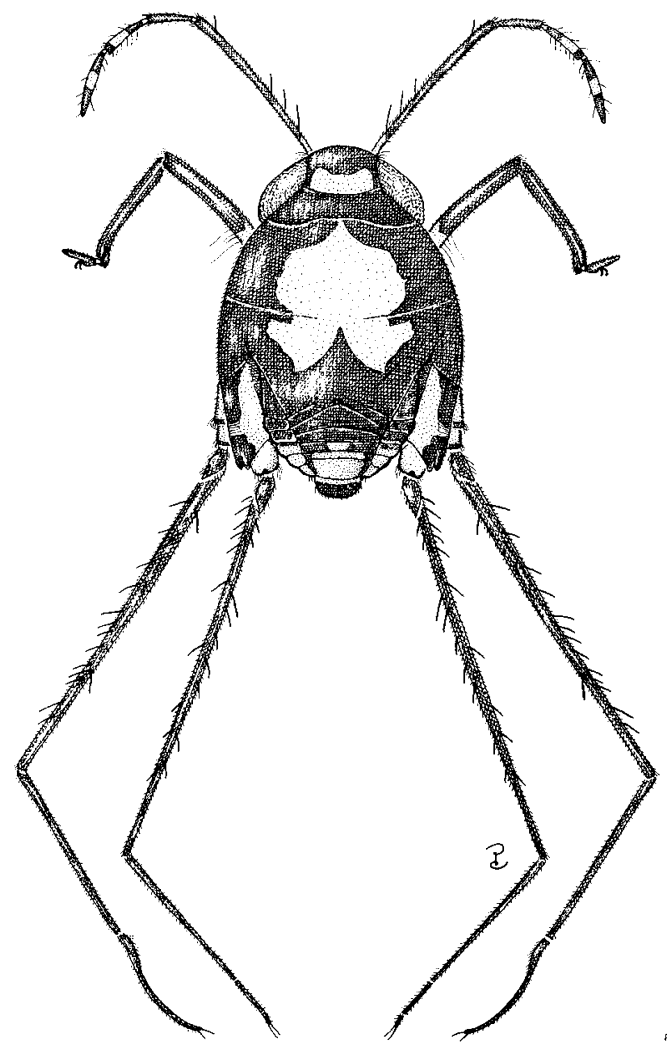

Fig. 183. Ventidius (Ventidioides) karen, paratype, apterous male, length $2.66 \mathrm{~mm}$.

ture between meso- and metanotum faint but visible. Metanotum somewhat declivent. Lower half of hind margin of metacetabula bilobate (figs. 159, 160). Metasternal tubercle not prominent in male. Fore femur slightly curved, ventral surface with a small tooth (fig. 149). Anterior margin of abdominal tergite 1 visible; anterior margins of tergites 2 and 3 faint, obliterated medially and protruding forward; abdominal sternite 7 as long as the preceding abdominal sternites together in both sexes. Laterotergites broad.

Male terminalia. - Parameres (figs. 171, 172) asymmetrical, both hooked at subbasal part, left paramere larger than right one, its apex twisted and blunt; right paramere bar-shaped with blunt apex; not extending beyond genital segments. Endosoma (figs.178, 181): dorsal sclerite long and recurved proximally, ventral sclerite long, lateral sclerite straight, hooked at distal and broadened at proximal parts, second lateral sclerite long and thin, third lateral sclerites curved, apical sclerite indistinct.

Female terminalia. - Abdominal sternite 7 large, 
broadly elevated medially, posterior margin slightly concave forward.

Macropterous form. - (According to Lansbury, pers. comm.) $3.60 \mathrm{~mm}$ long, maximum width 1.90 mm. colour pattern (fig. 131) pronotum black with two irregular yellowish blotches. Wings anteriorly black with fine pubescence and with scattered longer black hairs. Posterior membranous part of wings dark brown. The other morphological characters as in apterous form except the apex of pronotum pointed (measurements see table 3); length of fore wing from humeri to apex 2.60.

Distribution (map 4). - Thailand: Nakhon Ratchasima, Petchabun; Viet Nam: Gia Lai-Kontum.

Comparative notes. - Ventidius karen shares most characters with $V$. kuiterti, especially the short antennal segment 3 , the yellowish bands on antennal segments 3 and 4, and the mesosternal groove ending with a small tubercle which is covered by dark setae. Main differences between these species are found in body length ( $V$. kuiterti smaller than $V$. karen), in dorsal colour patterns of meso- and metanotum (in $V$. kuiterti darker than in $V$. karen), in relative lengths of antennal segment 3 and 4 (segment 4 longer in $V$. karen), and in male parameres (see figs. 169, 170). Furthermore, V. karen is the only species within the $V$. kuiterti-group, which has a third pair of endosoma lateral sclerites (see fig.178).

Remarks. - One apterous female (figs. 139, 144, 150, 161, 162, 184) was collected from Viet Nam: : Prenn, $900 \mathrm{~m}, 15 \mathrm{~km} \mathrm{~S}$ of Da Lat, No. 294, 15.x.1988, leg. Vasarhehj (тмвC). This specimen has been listed as a Ventidius (Ventidioides) sp. by Zettel \& Chen (1996: 152, 181). As male specimens are lacking, it is difficult to decide its specific status. According to its aberrant appearance, we present the description below:

Dimensions. - apterous female: length 3.30, width 2.35, width of head 1.38 .

Colour (fig.184). - Whole body predominantly yellowish, with dark marks. Eyes mainly greyish. Interoculus yellowish with a broad blackish transversal mark, along inner margin of eye with a dark stripe. Antennal segments mainly blackish, but yellowish at basal $1 / 3$ of the segment 1 , distal half of the segment 3 and middle part of the segment 4 with a yellowish band respectively. Pronotum blackish, lateroposterior angle with a small yellowish mark, posterior margin with two small yellowish marks. Mesonotum yellowish without dark stripes. Metanotum with a triangular dark mark basomedially. Mesopleura yellowish with interrupted dark stripe (fig.139). Anterior external half and posterior external angle of metacetabula dark (figs. 161, 162). Fore leg dark, femur with basal 2/5 yellowish (fig.150). Middle and hind legs dark. Tergite 1 black in the middle, and yellowish laterally,

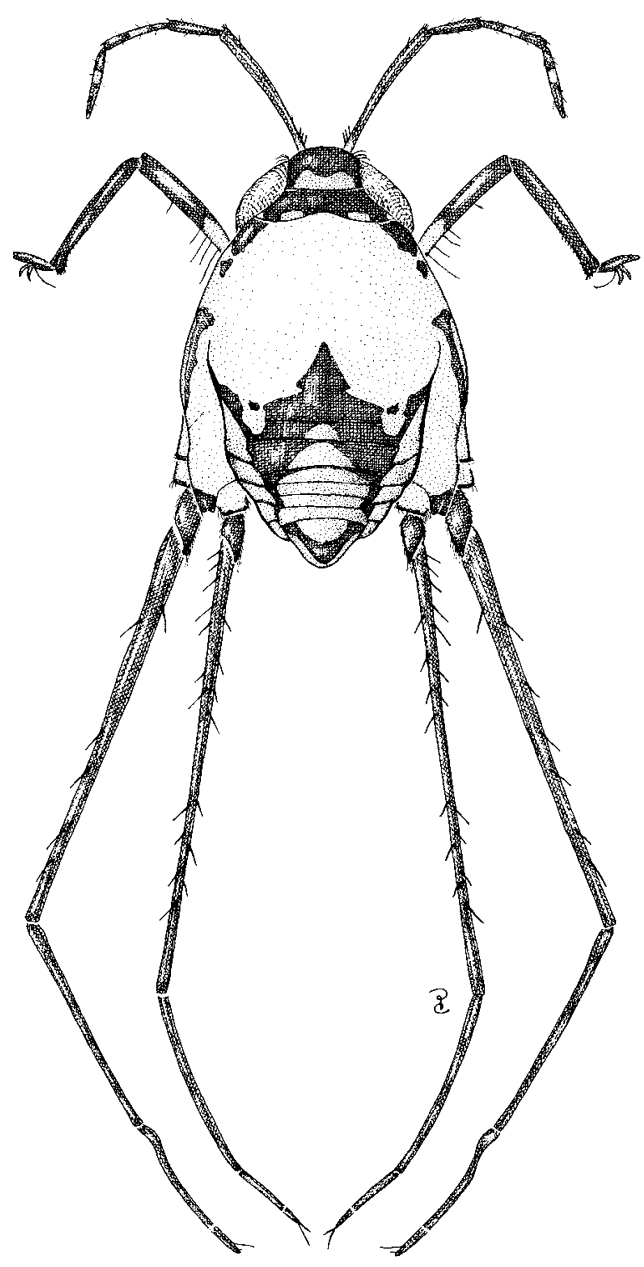

Fig. 184. Ventidius (Ventidioides) sp. from Viet Nam, apterous female, length $3.25 \mathrm{~mm}$.

2-3 blackish with triangular yellowish mark in the middle, 4 yellowish with dark lateral and anterior margins, 5-6 and 8 yellowish with dark lateral margins, 7 completely yellowish. Laterotergites completely yellowish and connexiva 2-4 blackish, 5-7 yellowish. Venter yellowish.

Pilosity. - Inner surface of antennal segment 1 with 4 subbasal and 1 subapical long spines, around segments 2-4 clothed with usual pubescence, also with longer setae, especially on segment 4. Dorsum and pleura bearing dark pubescence. Long stiff spines scattered along middle and hind legs. Tibia with shorter stiff spinules.

Structural characters. - Interoculus broader than width of an eye, $0.52: 0.42$. Antennae slender, seg- 


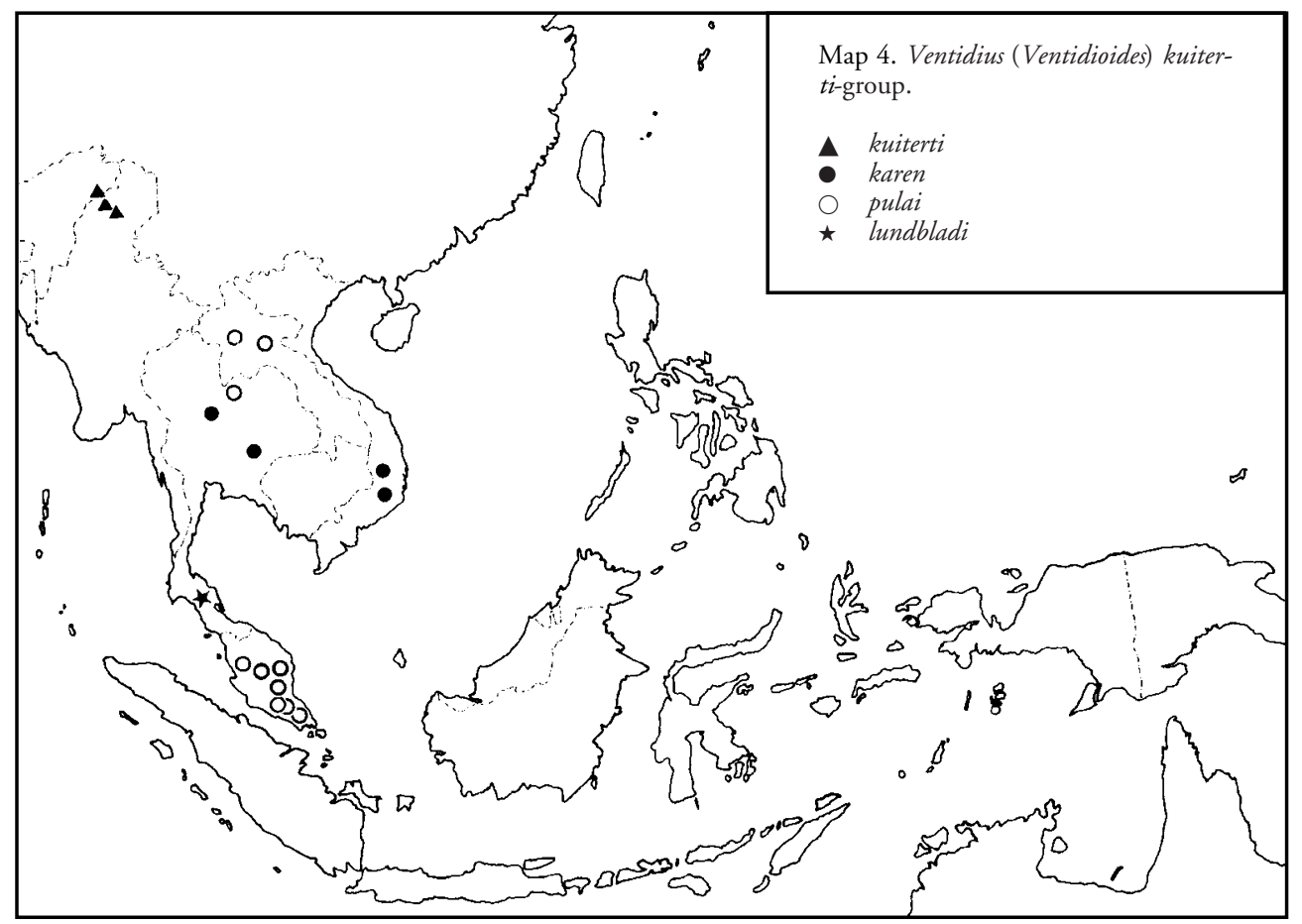

ment 2 shorter than segment 3 (fig.144) (measurements see table 1). Pronotum not bulbous, mesonotum strongly swollen dorsally, lateral width of mesothorax 1.40 ( $q$ ). Intersegmental suture between meso- and metanotum not visible. Metanotum somewhat declivent. Lower half of hind margin of metacetabula bilobate (figs. 161, 162). Fore femur slightly curved, ventral surface not modified (fig.150). Anterior margins of abdominal tergite 1-3 not visible.

Female terminalia. - Abdominal sternite 7 large, as long as the preceding abdominal sternites together, broadly elevated medially, posterior margin slightly concave forward.

Comparative notes. - This specimen is similar to $V$. karen in most characters. But differences are found in colour of pronotum, mesonotum, and abdominal tergites, which are much darker in $V$. karen. The thorax is much more bulbous than in $V$. karen. It is difficult to decide until the male specimen will be available. Although the specimen represents most likely a further species of the V. kuiterti-group, it is not impossible that it is a very aberrant female of $V$. karen.

\section{Ventidius pulai Cheng}

(figs. 133, 140, 145, 146, 151, 152, 155, 156, 163, $164,171-174,179,185$, map 4)
Ventidius pulai Cheng, 1965: 153-155, 163 (descr., illustr., key); Kovac \& Yang 1989: 285 (rec.); Yang \& Kovac 1995: 293 (rec.).

Type locality. - MALAYSIA: Johor.

Type material examined. - Holotype $\widehat{\delta}$, apt., allotype $q$, apt., and paratypes ( $3 \hat{\delta} 1 \uparrow$ apt.): MALAYSIA: Johor, stream at Gunung Pulai, $500 \mathrm{~m}, 17$. .iii.1963, leg. L. Cheng (BMNH, ZRCS).

Other material examined. - MALAYSIA: $15 \hat{0}, 25 q$ apt., 30 , 2 ㅇ macr., Perak, stream $58 \mathrm{~km} \mathrm{~S}$. of Grik, CL 2077 , 19.viii.1985, J.T. \& D.A. Polhemus (JTPC, NHMw); MALAYSIA: 19 apt., Perak, Kerunai River, $9 \mathrm{~km} \mathrm{~N}$ of Grik at bridge, CL 2078, 19.viii.1985, J.T. \& D.A. Polhemus (JTPC); 1 đo 2 apt., 2 macr., Perak, Ipah Hill, stream nr. reservoir, 4.iii.1927 (BMNH, NHMw); 10 1 apt., 1 ㅇ macr., Perak, Sungai Batang Padang, nr. for. camp, 13.iii.1927, coll. Dover (вмNH); 3 우 apt., Selangor, Klang River, near Klang Gates, 21.viii.1926, coll. Dover (BмNH); 40 apt., Selangor, Ampang, waterworks, 5.ix.1926, coll. Dover (BMNH, ZMUC); 1 t apt., same locality, 30.ii.1927 (вмNH); 204 ㅇ Selangor, Sungai Ampang, 5.ix.1926, coll. Dover (BMNH, NHMw, ZMUC); 6080 apt., same locality, 15.viii.1926, coll. Dover (BMNH, PPCC); $1 \hat{\sigma}$ apt., same lo-

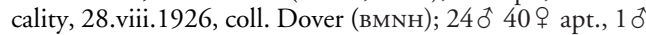
1 \% macr., Selangor, Templer Park, CL 2070, 17.viii.1985, leg. J.T. \& D.A. Polhemus (JTPC, NHMw, PPCC); 10 , 3 우 macr., Johor, Gunong Pulai, 26.ii.1961, leg. C.H. Fernando (SEMC); 7 apt., Johor, Endau, Sg. Anak Jasin, 4.iv.1992, L186, leg. H.K. Lua (zRCS, NHMw); $20 \hat{~} 2$ apt., same locality data, leg. K.L. Yeo (zrcs); $5 q$ apt., Johor, S Taku, 


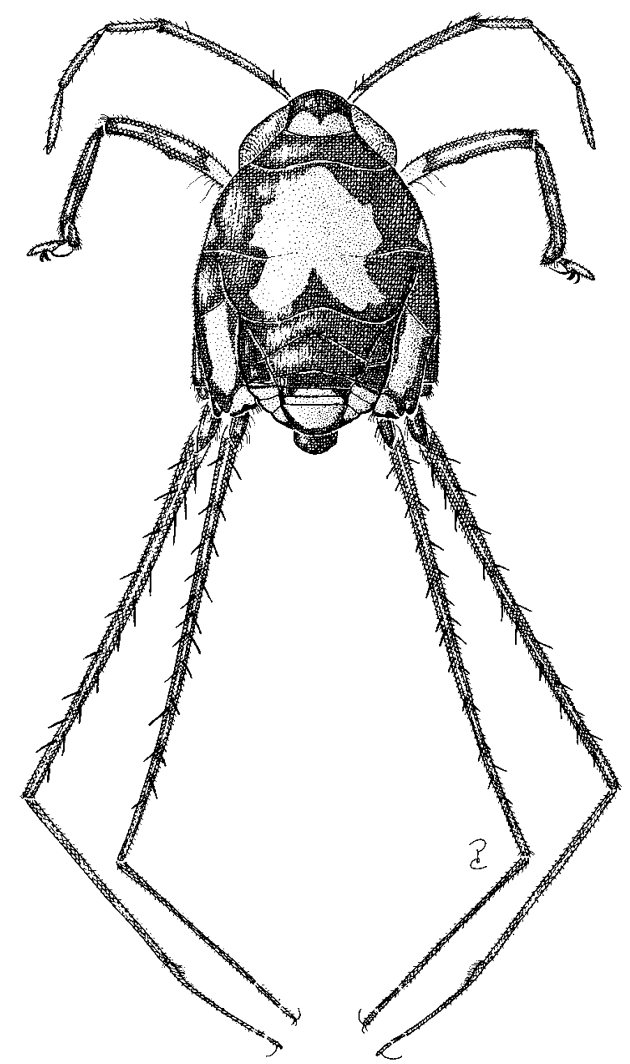

Fig. 185. Ventidius (Ventidioides) pulai, paratype, apterous male, length $2.63 \mathrm{~mm}$.

18.vii.1989, K.L. Yeo (zrcs); 19 apt., Johor, S Taku, 15.vi.1989, leg. C.M. Yang et al. (zrcs); 1 ㅇ macr., Negeri Sembilan, $10 \mathrm{~km} \mathrm{~N}$ Simpang Pertang, unnamed stream, 10.iv.1994,A-1063, leg. W.D. Shepard (NHMw); 1 क 1 우 macr., Terengganu, Sg. Terengganu tributary, Sekayu, 16.v.1995, leg. Bruce Tan \& Sumita, TG6 (zRCs); 1 ㅇ apt., Kelantan, Sungai Hulu Besut, 6 km (W?) after Kampang Keruah, on road to hydroelectric station, 20.iii.1992, L184, leg. H.K. Lua (ZRCs); 2 5 9 apt., $1+$ macr., Pahang, S. Kinchin, 19.vii.1989, leg. K.L. Yeo \& K.H. Lua (zrcs, NHмw); 1 đo 3 q apt., Pahang, S. Kernam, 19.vii.1989, K.L. Yeo (zRCs); 30 4 apt., 19 macr., Pahang, S. Kinchin, 13.vi.1989, leg. C.M. Yang et al. (zRCs, PPCC); 303 우 apt., 2 ㅇ macr., Pahang, S. Seladang, 19.vii.1989, leg. K.L. Yeo (zRCS, NHMw); 203 apt., 8 larvae, Prov.?, H.T. Pagden, BM 1959-236 (вмNH); LAOS: 1 तิ 4 오, (Indo-China), Luang prabang, Pak Lueng, 5.iii.1920, leg. R.v. de Salvaza, 1920-280 (вмnн, NHмw); 19 apt., Xieng Khouang, Sala Hat Sampong, 17.xi.1917, leg. R.v. de Salvaza (BMNH);

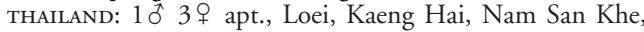
9.iii.1994, A-1035, leg. W.D. Shepard (css, NHMw). 10 1 , apt. Chiang Mai, c. $10 \mathrm{~km}$ E Samoeng (18051'N, 98²'E), river, leg. W.G. Ullrich (Ullrich collection, NHMW)

\section{Redescription}

Dimensions. - Apterous form: length $2.63(\hat{0})$, 2.92 () , width $1.75(\delta), 2.00$ ( $(+)$, width of head $1.20($ đ) $), 1.50$ (

Colour (fig.185). - Whole body prominently dark, with distinct yellowish marks. Eye blackish. Interoculus blackish, with one large M-shaped yellowish mark at posterior margin. Antennal segments dark, except basal $1 / 5$ of segment 1 . Pronotum totally dark. Mesonotum dark with central triangular yellowish mark which is confluent with the yellowish mark of metanotum. Metanotum with a triangular dark mark basomedially and two oblique yellowish stripes laterally. Mesopleura yellowish, with a small dark mark anteriorly; anterior, external margin and lower part of metacetabula blackish (fig. 140). Metasternum dark. Fore leg dark with basal 1/5 yellowish (figs. 151, 152). Middle and hind legs dark. Tergites 1-4 completely dark, 5-6 blackish with a yellowish mark in the middle, 7 yellowish but dark laterally, 8 dark. Laterotergites 1 4 blackish, 5 dark with a fine yellowish mark, 6-7 yellowish. Connexiva 1-5 dark, 6-7 yellowish. Sternite 7 dark laterally, segment 8 ventrally dark in male.

Pilosity. - Inner surface of antennal segment 1 with 4 subbasal and 1 subapical spines, in males through basal half of segment 1 to segment 4 with silvery fine hair fringe; segments 2-4 with scattered brownish short setae (figs. 145, 146). Dorsal side, pleura, and acetabula clothed with dark pubescence. Dark setae prominent at subdistal part along inner surface of fore tibia. Venter clothed by golden pubescence, especially on genital segments the pilosity longer and denser. Venter yellowish, the setae on mesosternal tubercle dark brown. Long stiff spines scattered along middle and hind legs, denser than usual in the genus.

Structural characters. - Interoculus broader than width of an eye, $0.44: 0.41$ in male, $0.50: 0.41$ in female. Antennal segment 3 subequal to segment 4 (measurements see table 1) (fig. 145, 146). Thorax not bulbous, mesonotum somewhat swollen, its lateral width $1.10($ đ $), 1.45$ (ㅇ). Intersegmental suture between meso- and matanotum obscure. Metanotum somewhat declivent. Lower part of metacetabula bilobate (figs. 163, 164). Fore femur slightly incrassate, halfway its inner surface with a small tooth (fig. 151), claw rising from $2 / 5$ of segment 2 of fore tarsus. Fore leg of female see fig. 152. Anterior margin of abdominal tergite 1 obscure, anterior margins of tergites 2 and 3 obscure but eventually obliterated medially and protruding forward; abdominal sternite 7 as long as the preceding abdominal sternites together in both sexes. Laterotergites broad.

Male terminalia. - Parameres (figs. 171-174) asymmetrical, stout, curved at basal part, left paramere distinctly longer than right one, its apical part curved upwards, with blunt apex; apical part of right paramere 


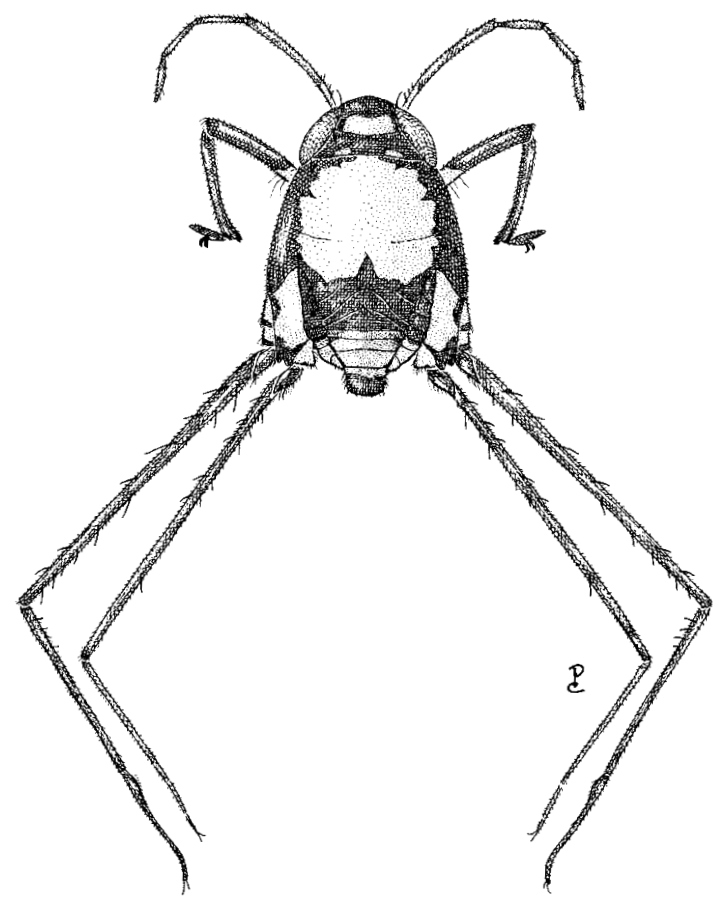

Fig. 186. Ventidius (Ventidioides) lundbladi, apterous male, length $2.37 \mathrm{~mm}$.

straight and pointed upwards, with blunt apex; the left paramere extending beyond genital segments. Endosoma (fig. 179): dorsal sclerite long and recurved proximally, ventral sclerite long, lateral sclerites straight, broadened at two ends, second lateral sclerites thin and weak.

Female terminalia. - Abdominal sternite 7 large, posterior margin smooth, concave forwards.

Macropterous form. - Maximum width $1.66 \mathrm{~mm}$. colour pattern: Pronotum black with two regular yellowish marks (fig. 133); wings black anteriorly with fine pubescence and with scattered longer black hairs; posterior membranous part of wings dark brown (figs. 155, 156). Other morphological characters as in apterous form except the apex of pronotum pointed (measurements see table 3).

Distribution (map 4). - Thailand: Loei; Laos; Malaysia: Perak, Johor, Selangor, Pahang, Kelantan, Negeri Sembilan, Terengganu.

Comparative notes. - Typical member of the $V$. kuiterti-group, and easy to distinguish from $V$. kuiter$t i$ and $V$. karen by subequal and uniformly brown antennal segments 3 and 4 in the male, and a less developed blotch of dark setae on mesosternum. The left paramere is apically twisted (fig. 174) similar as in $V$. karen (fig. 170), but less curved. The shape of para- meres, a usually darker colouration, and a less developed pilosity of segment 8 of males are the main differences to $V$. lundbladi (see under comparative notes of that species).

17. Ventidius (Ventidioides) lundbladi Miyamoto (figs. 134, 141, 147, 153, 154, 165, 166, 174-176, $180,182,186$, map 4)

Ventidius lundbladi Miyamoto, 1967: 245-247 (descr., illustr.). Type locality. - THAILAND: Khao Chong.

Material examined. - THAILAND: $8 \delta 11 q$ apt., S. Banna, Nakhon, 108 m, 5-10.v.1958, leg. T.C. Maa, No. 415 (BIMC, JTPC, NHMW, PPCC).

\section{Redescription}

Dimensions. - Apterous form. Length 2.37 ( $\widehat{\delta})$, 2.60 (q), width $1.57(\hat{0}), 1.88$ (q), width of head 1.04 (す)), 1.11 (ㅇ).

Colour (fig. 186). - Whole body prominently dark, with distinct yellowish marks. Eye blackish. Interoculus pale, with one large heart-shaped dark mark, the dark mark along inner margin of eye reaching posterior margin of vertex, and connected with the heart-shaped one. Antennal segments dark, except basal $2 / 5$ of segment 1 . Pronotum usually completely dark, in some specimens with two small yellowish marks at the lateroposterior margin of pronotum. Mesonotum with lateral dark mark. Metanotum with triangular dark mark. Mesopleura yellowish (fig. 141); external angle of metacetabula dark (figs. 165, 166). Under strong light, along the intersegmental suture between metanotum and tergite 1 , the pubescence reflects with a shining greenish metallic colour. Fore leg dark with basal $1 / 3$ yellowish (figs. 153, 154). Middle and hind legs dark. Tergites 1-4 completely dark, 5 yellowish with lateral dark mark, 6-7 yellowish, 8 dark. Laterotergites 1-4 dark, 5 dark basally, 6-7 yellowish. Connexiva 1-5 dark, 67 yellowish. Venter yellowish.

Pilosity. - Trichobothria prominent (fig. 134) Inner surface of antennal segment 1 with 3 subbasal, and 1 subapical long spines; in males through basal half of segment 1 to apical half of segment 4 with silvery fine hair fringe; segments 2-4 with scattered dark short setae (fig. 147). Dorsum and pleura clothed with dark pubescence on yellowish marks, and golden pubescence on dark parts. Venter clothed by golden pubescence, especially on genital segments, the pilosity very long and dense. Long stiff spines scattered along middle and hind legs. Basal part of middle femur with a very long trichobothria-like seta on dorsal surface.

Structural characters. - Interoculus subequal to width of an eye, $0.40: 0.32$ in male, $0.40: 0.35$ in female. Antennal segment 3 subequal to segment 4 


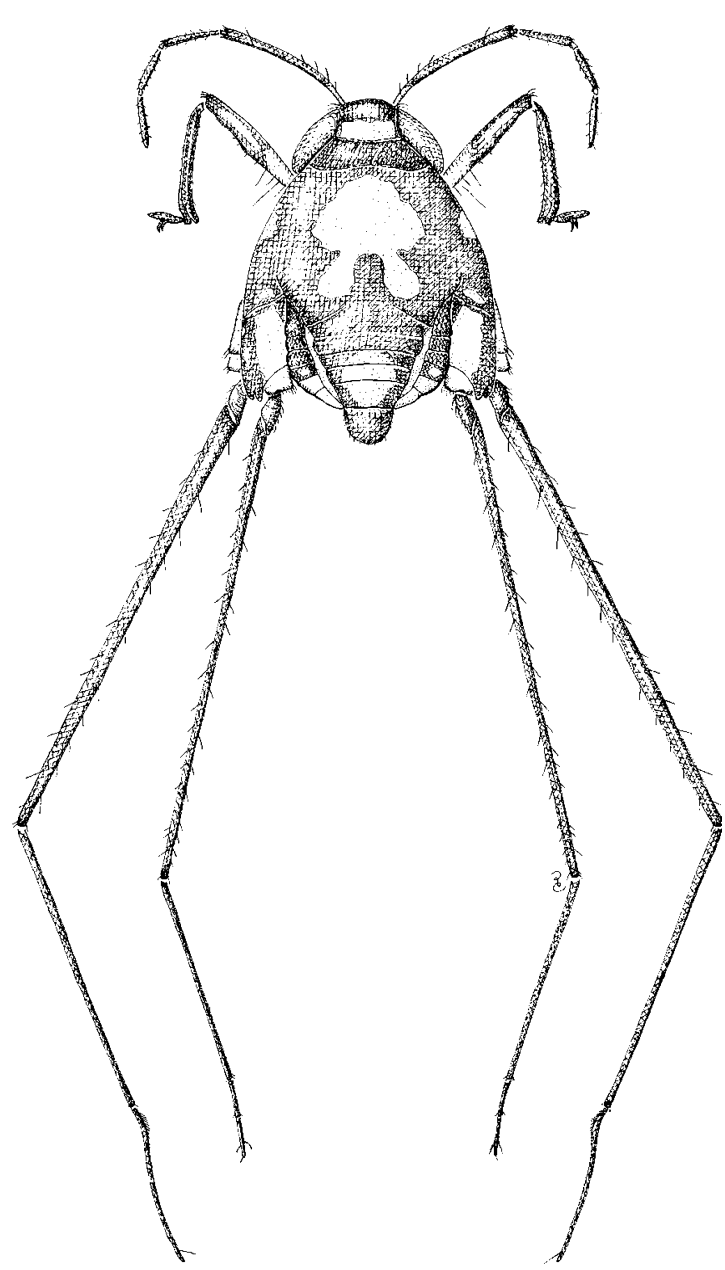

Fig. 187. Ventidius (Ventidioides) xyele, paratype, apterous male, length $2.95 \mathrm{~mm}$.

(measurements see table 1) (fig. 147). Thorax not bulbous, mesonotum somewhat swollen, its lateral width 1.00 (ठ), 1.33 ( $q$ ). Intersegmental suture between meso- and metanotum distinct. Metanotum somewhat declivent. Lower part of metacetabula bilobate (figs. 165, 166). Metasternal tubercle prominent in male. Fore femur slender and with a small tooth anterio-ventrally, claw rising from $2 / 5$ of segment 2 of fore tarsus. Anterior margin of abdominal tergite 1 distinct; anterior margins of tergites 2 and 3 obliterated medially and protruding forward; abdominal sternite 7 as long as the preceding abdominal sternites together in both sexes. Laterotergites broad.

Male terminalia. - Parameres (fig. 175, 176) asymmetrical, both hook-shaped, left paramere longer than right one, its apex sharp and pointed forward, distal part of right paramere straight upwards, with blunt apex; both parameres extending beyond genital segments. Endosoma (fig. 180): dorsal sclerite long and curved proximally, ventral sclerite long, lateral sclerite straight, broadened at distal part, second lateral sclerites thin and weak, apical sclerite indistinct.

Female terminalia. - Abdominal sternite 7 large, posterior margin smooth, concave forwards.

Macropterous form. - Unknown.

Distribution (map 4). - Thailand: S. Banna, Khao Chong.

Comparative notes. - Although the types were not available for our study, there is no doubt about this species which is characterized by the shape of parameres figured by Miyamoto (1967: figs. 73-74). It is most similar to $V$. pulai, but easily distinguishable by the shape of parameres: left paramere (fig. 174) long and slender in distal part, not plate-like and apically not twisted as in $V$. pulai; right paramere as in fig. 175. The dense developed long dark pilosity on segment 8 of male (fig. 182) richer than in $V$. pulai; Both sexes are also different in the thoracic colour pattern, which is usually much darker in $V$. pulai.

\section{The Ventidius xiphibion-group}

Diagnosis. - Prominent dark colouration; male fore femur without sharp tooth; most species with modified male fore leg, two species with a thickening on fore tibia, other species with tuft of black setae on fore trochanter, one species ( $V$. heissi sp. n.) without both of these characters; mesosternum with a patch of dark setae along median mesosternal groove; parameres protruding beyond genital segments, larger than in other Ventidius species, more or less asymmetrical; endosoma with distinct third pair of lateral sclerites, in most species with distinct apical accessory sclerite.

Notes. - This group includes five species, two from Sulawesi and three from Borneo. The Sulawesian species are characterized by a tuft of black setae on male fore trochanter and by asymmetrical parameres, which are strongly enlarged basally. Two of the Bornean species are characterized by a modified male fore tibia, which is thickened and with dense short pilosity in middle of its length, by a distinct swelling of male fore femur, and by less asymmetrical, hooked parameres. Ventidius heissi sp. n. is regarded as related to these species by the general characters of male genitalia.

Distribution (map 5). - Borneo and Indonesia:Sulawesi.

18. Ventidius (Ventidioides) xiphibion Chen \& Nieser (figs. 188, 193, 198, 203, 204, 213, 216, 219, 220, 229, 230, map 5)

Ventidius xiphibion Chen \& Nieser, 1992: 156-157 (descr., illustr.). 


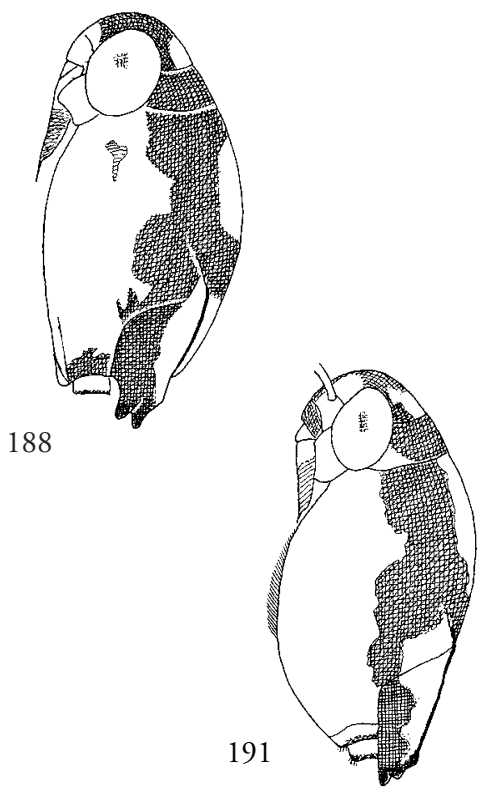

Figs. 188-192. Lateral view of apterous male, showing the colour pattern of pleura. - 188, Ventidius xiphibion; $189, \mathrm{~V}$. xyele; 190, V. kurtokalami; 191, V. nieseri; 192, V. heissi.

Figs. 193-197. Dorsal view of male right antennae. - 193, Ventidius xiphibion; 194, V. xyele; 195, V. kurtokalami; 196, V. nieseri; 197, V. heissi.

Type locality. - INDONEsia: Sulawesi.

Type material examined. - Holotype $\delta$, apt., allotype $q$ apt., INDONesia: Sulawesi Tenggara Prov., small stream 8 $\mathrm{km}$ E of Sungai Sampara along road Kendari-Wawotobi, N8911, 22.ii.1989, leg. N. Nieser (RMNH); Paratypes: 41 ठै, 64 ㅇ, apt., $10^{\widehat{T}}$ macr., same locality data as holotype (RMNH, NCTN, PPCC, NHMw); $35039 q$, apt., $1 \%$ macr., Sulawesi Tenggara Prov., P. Buton, stream just $\mathrm{N}$ of Bau-bau, N8925, 8.iii.1989, leg. N. Nieser (RMNH, NCTN, NHMw); 40 ô 17 ㅇ apt., 19 macr., Sulawesi Tenggara Prov., stream about $15 \mathrm{~km} \mathrm{E}$ of Bau-bau, N8942, 10.iii.1989, leg. N. Nieser (RMNH, NCTN).

Other material examined. $-1 \delta 1 q$ apt., Sulawesi Tengah Prov., Ampana, 31.1.1995, leg. Seyfert \& Graindl (49) (NHMW).

Locality notes. - Small to medium sized streams with turbid water due to suspended loam. The species tends to aggregate in places with little current.

\section{Redescription}

Dimensions. - Apterous form. Length 2.90 (ठ),

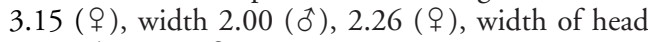
$1.28($ ( )), 1.28 (ㅇ).

Colour. - Whole body prominently dark, with distinct yellowish marks. Eye brownish. Interoculus

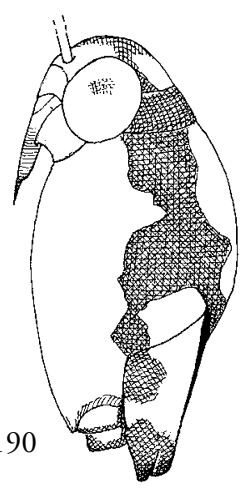

192
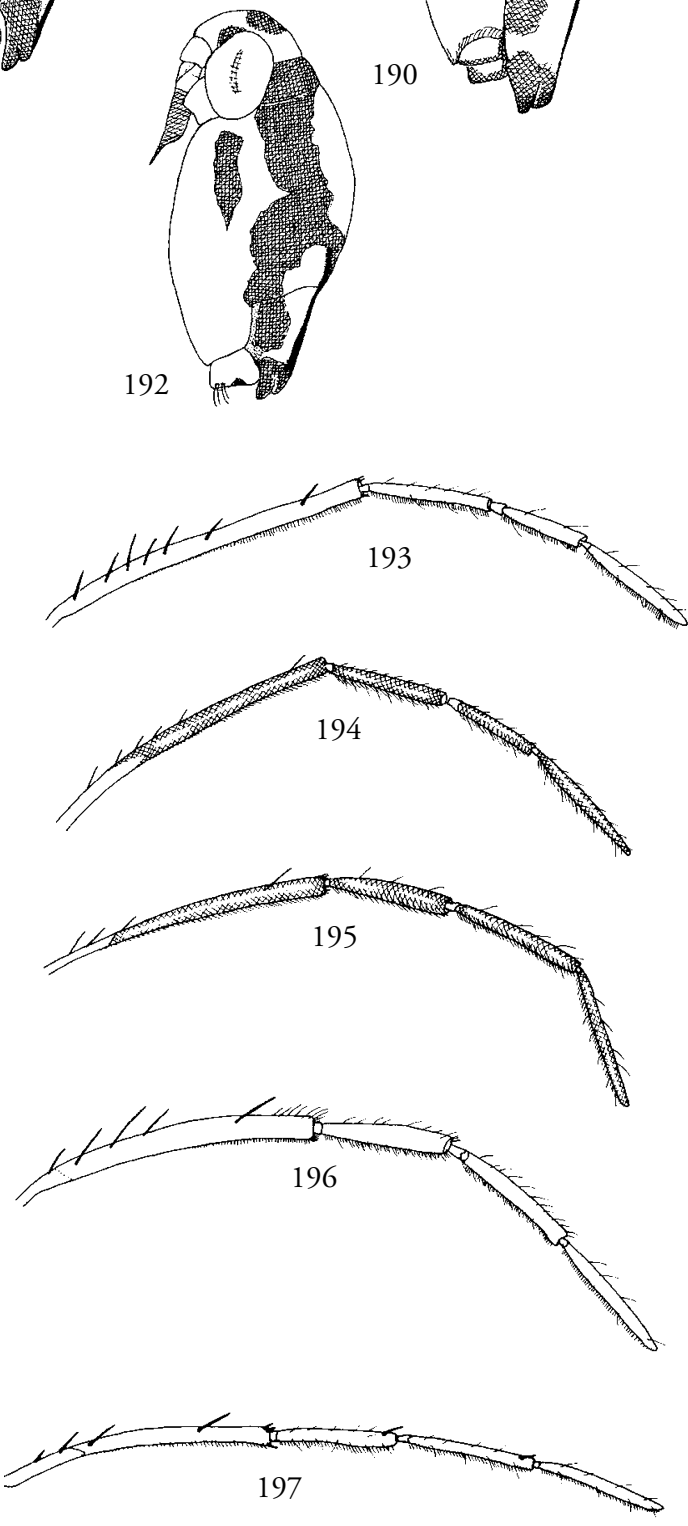


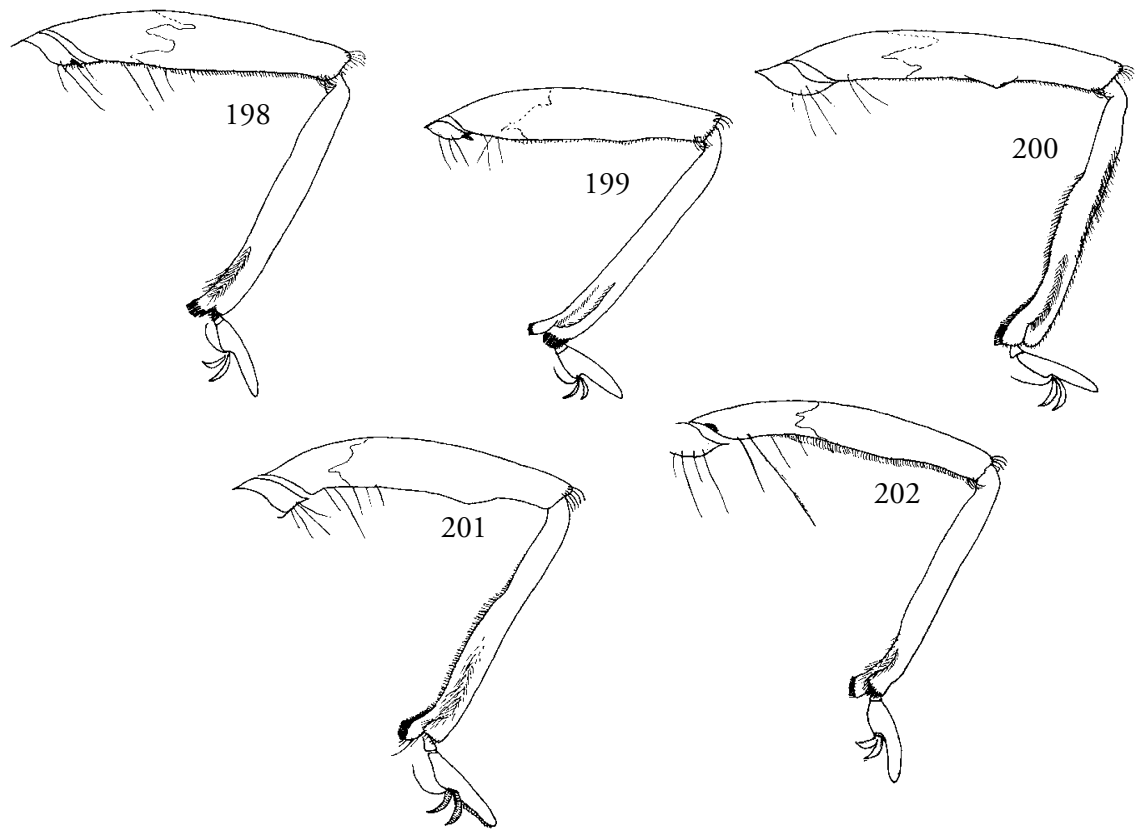

Figs. 198-202. Dorsal view of right fore leg. - 198, Ventidius xiphibion; 199, V. xyele; 200, V. kurtokalami; 201, V. nieseri; 202, V. heissi.
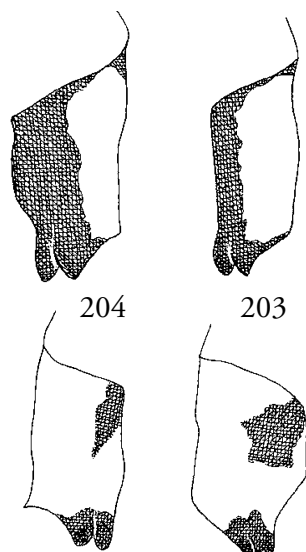

207
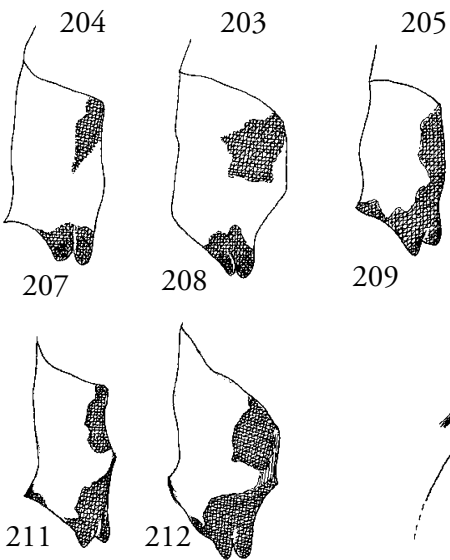

206

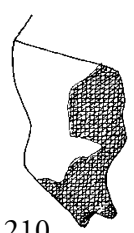

210

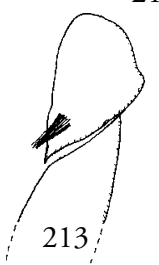

Figs. 203-212. Metacetabula, odd numbers: dorsal view,. even numbers: dorsolateral view. - 203, 204, Ventidius xiphibion; 205, 206, V.xyele; 207, 208, V. kurtokalami; 209, 210, V. nieseri; 211, 212, V. heissi. - Fig. 213. V. xyele, ventral view of fore trochanter, showing the tuft of dark setae. blackish, with one large M-shaped yellowish mark at posterior margin. Antennal segments dark, except basal $2 / 5$ of segment 1 . Pronotum dark in male, in some specimens with a small central yellowish mark; in female dark, with a central and two small yellowish marks at the lateroposterior margin, in some specimens the posterior margin with faint yellowish marks. Mesonotum yellowish with broad lateral dark stripe which is confluent with the dark mark of metanotum. Metanotum blackish with two oblique yellowish marks. Mesopleura yellowish, with a small black mark near anterior margin in male (fig. 188), with a brownish stripe running through its length in female, but in some specimens the dark marks are obscure. External half of metacetabula blackish (figs. 203, 204). Fore leg dark with basal $1 / 2$ yellowish (fig. 198). Middle and hind legs dark. Tergites 1-4 completely dark, 5 blackish with a triangular yellowish mark in the middle, 6-7 yellowish with lateral and posterior margin dark, 8 dark. Laterotergites 1-2 blackish, 3-7 yellowish. Connexiva 1-4 dark, 5-7 yellowish. In female the colouration of abdomen paler than in males. Venter yellowish.

Pilosity. - Inner surface of antennal segment 1 with 6-8 subbasal and 1 subapical spines, through basal half of segment 1 to segment 4 with fine silvery hair fringe; segments 2-4 with scattered brownish short setae (fig. 193). Dorsum, pleura and metacetabula bearing dark pubescence. Ventral surface of fore trochanter with a tuft of dark setae apically (fig. 213). 
Figs 214-218. - 214, Ventidius kurtokalami, dorsal view of macropterous female (appendages removed); 215, $V$. nieseri, ventral view of body, showing the patch of dark mesosternal setae; 216-218, dorsal view of macropterous pronotum. - 216, $V$. xiphibion; 217, $V$. nieseri; 218, V. xyele.

Figs. 219-228, External view of parameres, odd numbers: left paramere, even numbers: right paramere. - 219, 220, Ventidius xiphibion; 221, 222, V. xyele; 223, 224, V. kurtokalami; 225, 226, $V$. nieseri; 227, 228, V. heissi.
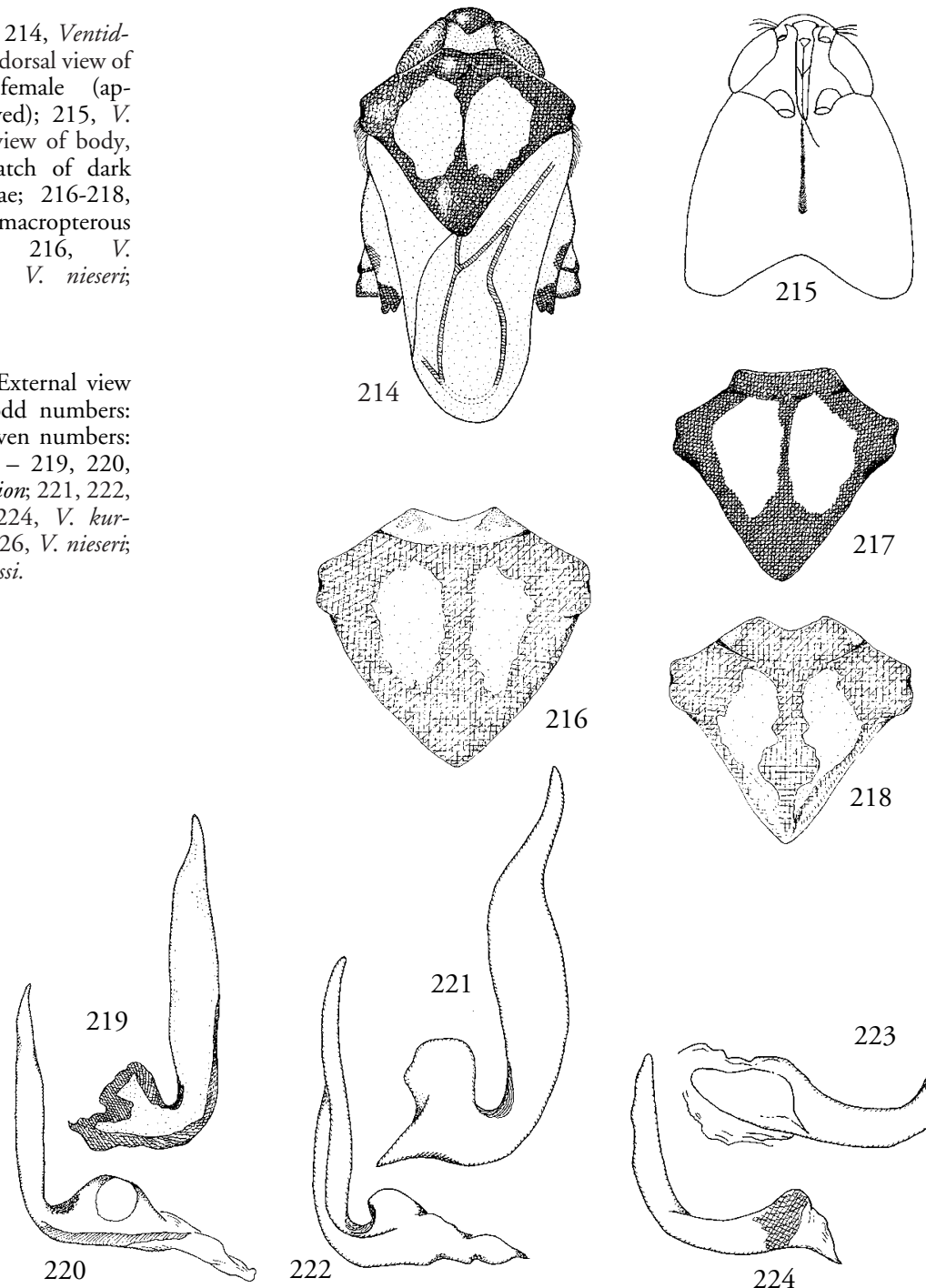

222
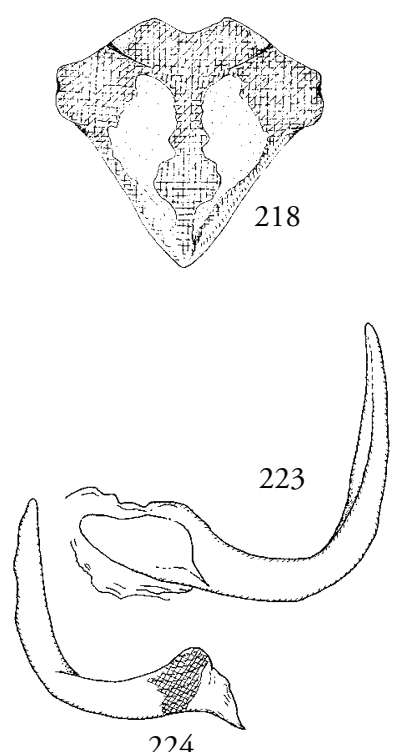

228

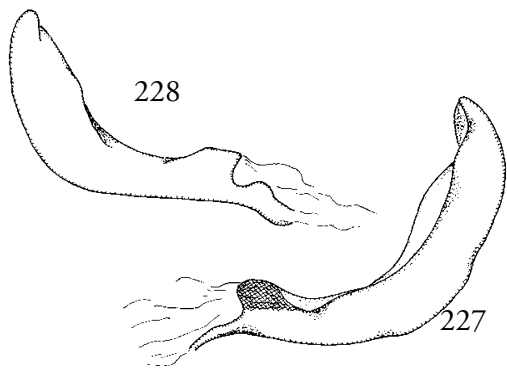


Figs. 229-234. - 229, Ventidius xiphibion, dorsal view of endosoma sclerites. - 230234. Lateral view of endosoma sclerites. - 230, $V$. xiphibion; 231, V. xyele; 232 , V. kurtokalami; 233, V. nieseri; 234, $V$. heissi
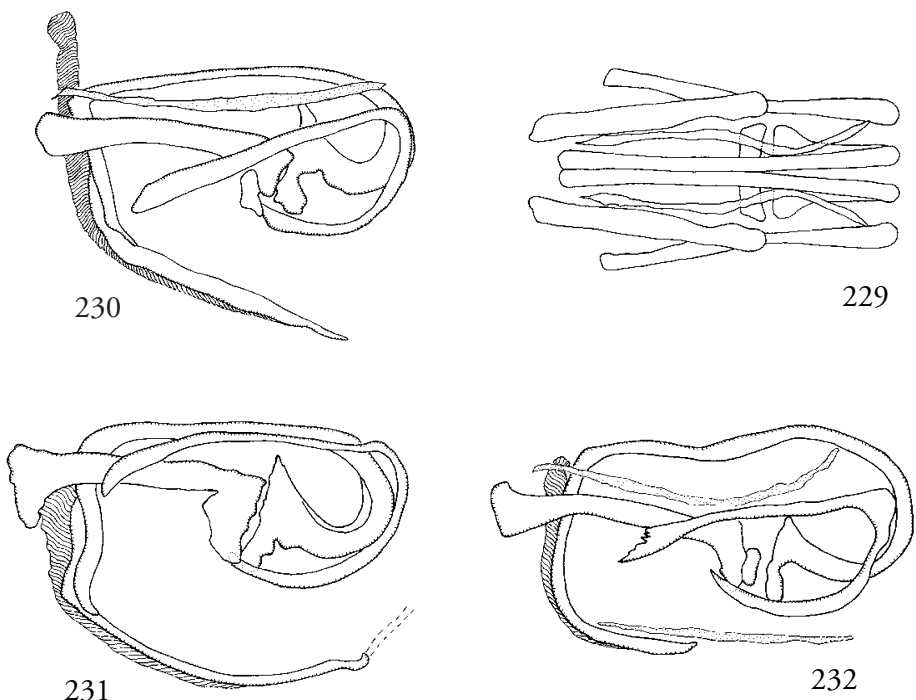

232
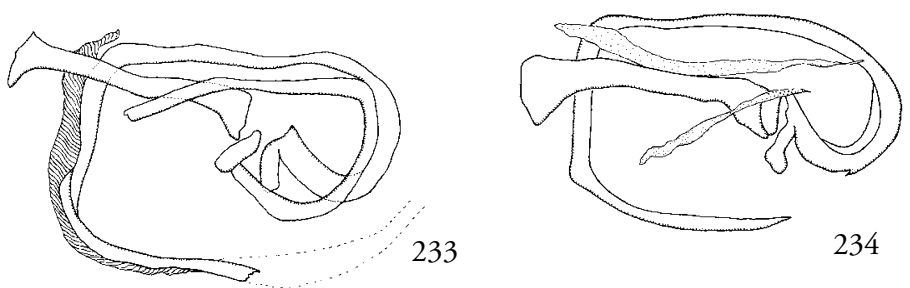

Dark setae along inner surface of fore tibia not modified (fig. 198). Venter clothed by golden pubescence, especially on genital segments the pilosity longer and denser. On half way of mesosternal groove with a blotch of dark setae which is displayed in two longitudinal lines. Stiff spines scattered along middle and hind legs.

Structural characters. - Interoculus broader than width of an eye, $0.47: 0.40$ in male, $0.47: 0.42$ in female. Antennae not modified, measurements see table 1 (fig. 193). Thorax not bulbous, mesonotum somewhat swollen, its lateral width 1.17 (đ)), 1.35 (ㅇ). Intersegmental suture between meso- and metanotum distinct. Metanotum somewhat declivent. Lower part of metacetabula bilobate (figs. 203, 204). Metasternal tubercle not prominent. Fore femur incrassate, tapering towards distal part (fig. 198), claw rising from $1 / 3$ of segment 2 of fore tarsus. Anterior margin of abdominal tergite 1 obscure but visible, anterior margins of tergites 2 and 3 obscure but eventually obliterated medially and protruding forward; abdominal sternite 7 as long as the preceding abdominal sternites together in both sexes. Laterotergites broad.
Male terminalia. - Parameres (figs. 219, 220) asymmetrical, both hooked, left paramere longer and broader than right one, knife-shaped, tapering distally, with sharp apex. Right paramere slender and with blunt apex. Endosoma (figs. 229, 230): dorsal sclerite long and recurved proximally, ventral sclerites long and weak, lateral sclerites straight, broadened at two ends, second lateral sclerites thin and weak, third lateral sclerites distinct and curved; apical accessory sclerite distinct.

Female terminalia. - Abdominal sternite 7 large, posterior margin smooth, concave forwards.

Macropterous form. - Maximum width $1.75 \mathrm{~mm}$. Colour pattern: pronotum (fig. 216) black with two regular yellowish blotches. Wings anteriorly black with fine pubescence and with scattered longer black hairs. Posterior membranous part of wings dark brown. The other morphological characters as apterous form except the apex of pronotum pointed (measurements see table 3 ); length of fore wings from humeri to apex 2.40 .

Distribution (map 5). - Indonesia: Sulawesi Tenggara Prov., Sulawesi Tengah Prov. 


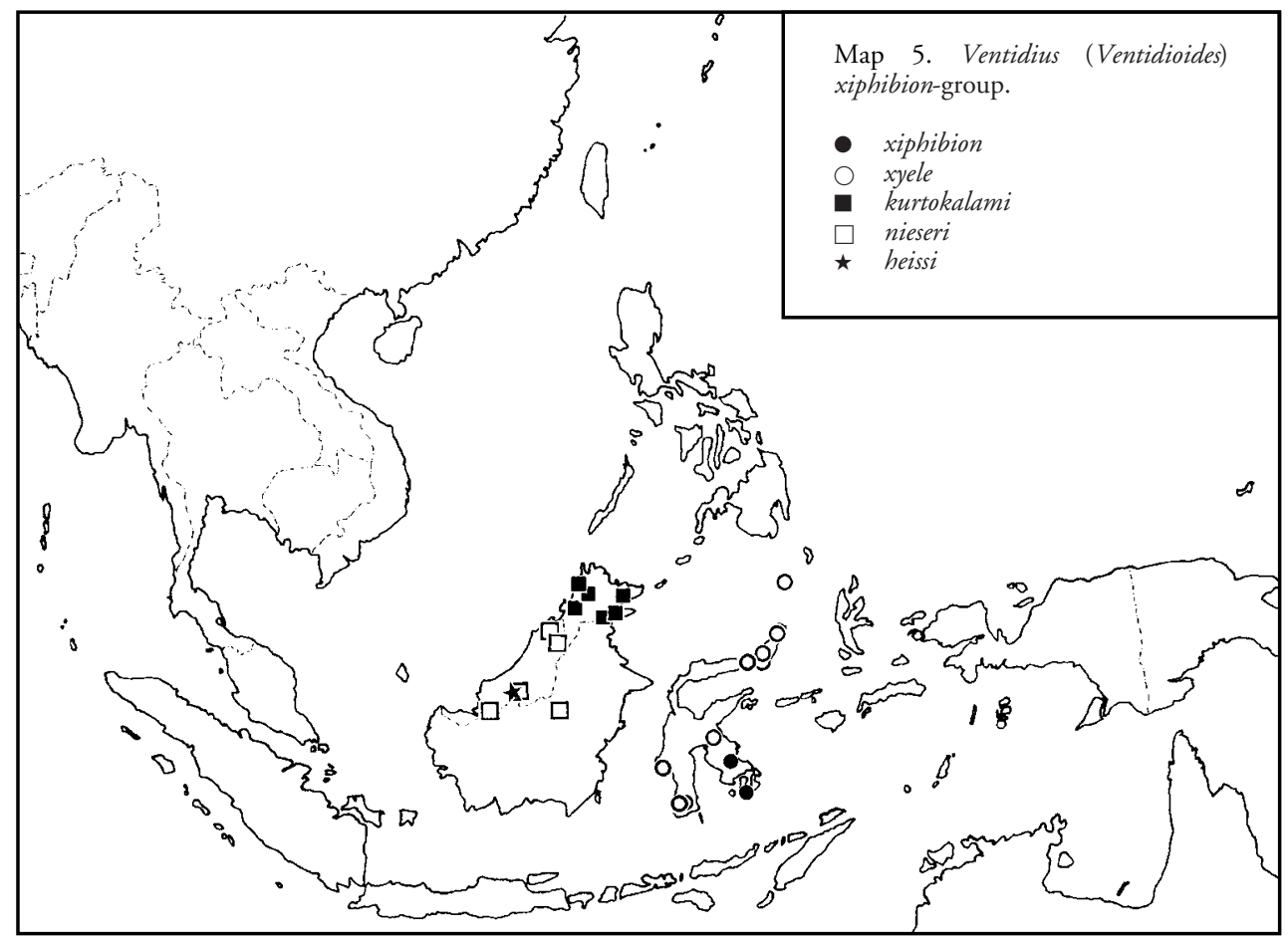

Comparative notes. - Most characters of this species are similar to that of $V$. xyele, especially the less modified male fore leg, the shape of left and right parameres which are hooked upward close to a strongly enlarged base and very asymmetrical (left paramere much broader than right one). These characters unite both Sulawesian species and separate them from the Bornean species of the $V$. xiphibion-group. Differences between V.xiphibion and V.xyele are found in the extensive yellow pattern (much darker in $V$. xyele) and different shapes of male parameres: parameres of $V$. xyele have very slender and sharp apex (fig. 221, 222), in $V$. xiphibion the apex is not so sharply constricted (fig. 219, 220). The endosoma of $V$. xiphibion has a distinct apical accessory sclerite which is less prominent in $V$. xyele, but clearly present in the Bornean species of the subgenus.

\section{Ventidius (Ventidioides) xyele Chen \& Nieser} (figs. 187, 189, 194, 199, 205, 206, 218, 221, 222, 231, map 5)

Ventidius xyele Chen \& Nieser, 1992: 157-158 (descr. \& illustr.).

Type locality. - Indonesia: Sulawesi.

Type material examined. - Holotype $\hat{\sigma}$, apt., allotype $q$ apt., Indonesia: Sulawesi Utara Prov., Dumoga Bone National Park, R. Toraut, Maze, 16.xi.1985, leg. G. Zimmermann (RMNH). Paratypes: $30 \hat{9} 9$, apt., same locality data as holotype (RMNH, ZMAC, NCTN). 1 o 1 t apt., Dumoga Bone National Park, Base camp, 16.x.1986; 1엉 Dumoga Bone River, downstream, of bridge, 22.x.1985; $8 \hat{\sigma} 9{ }^{+}$, apt. Tumpah River, Beach, 19..1985; 70 7우, apt., Tumpah River, Staustufe (low barrier), 23.x.1985; 30 apt., 201 \% macr., Malibagu Z. 8.xi.1985; 40 5 9 , apt., Südküste, Strasse, Bach (S. coast, road, rivulet), 18.xi.1985. (deposited separetely in ZCWA, NCTN, BPUH, JTPC, MBBJ, PPCC, ZMAC, ZMUC).

Other material examined. - INDONESIA: $10 \hat{0} 10 \uparrow$ apt., Sulawesi Utara Prov., P. Sangihe, Naha, Sungai Laine at last bridge upstream, N9456, 27.vi.1994 (NCTN); $12 \hat{0} 9$ 우 apt., 1 \% macr., Sulawesi Utara Prov., P. Sangihe, D. Simuang (dekat di Malahu), Sungai Simuang, N9457, 28.vi.1994, leg. N. Nieser, mountain stream water clear, hyacine, boulders, stones, stretches with sand (NCTN); $20 \hat{\text { ô } 15}$ q apt., Sulawesi Utara Prov., P. Sangihe, Desa Laine, Sungai Laine (different from N9454/56 which is on the other side of the island); pothole as water fall, 12.xi.1994, N9463, leg. N. Nieser (NCTN); $50^{\star} 12$ apt., Sulawesi Utara Prov., P. Sangihe, small stream at Kampung Lapango-Hakadele (near esa Sawaeng), 18.xi.1994, N9474, leg. N. Nieser (NCTN); $90 \hat{} 8$ ㅇ apt., Sulawesi Utara Prov., P. Sangihe, Desa Laine, Sungai Laine, near the road, 18.xi.1994, N9476, leg. N. Nieser, muddy pebbles between boulders, depth about $1 \mathrm{~m}$, quiet flow of water, except for some shallow banks with riffles (NCTN); $90 \hat{~} 6$ 9 apt., Sulawesi Utara Prov., P. Sangihe, Sungai Miulu, 20.xi.1994, N9480, leg. N. Nieser (NCTN); 27 o 39 9 apt., Sulawesi Utara Prov., P. Sangihe, desa Utaurano, Sungai Apanukang, pothole, 14.xi.1994, N9465A, 
leg. N. Nieser (NCTN); 20 4우, apt., Sulawesi Selatan Prov., E side Lake Matana, Kg. Salura: Nightjar Camp, 520 m, 13.x.1993, open water and among mangrove vegetation, 2'32'15'S. 121²8'00'E., leg. J.P. \& M.J. Duffels (zMAC); $2{ }^{\dagger} 5$ q , apt., same locality data as above, 450 m, 20.x.1993, narrow tributary to Lake Matana, 2³2'S., 121²8'E., J.P. \& M.J. Duffels (ZMAC); 1 ô 2 으, apt., SW Sulawesi Selatan Prov., Onang, Sg. Parabaya, $58 \mathrm{~km} \mathrm{~N}$ of Majene, 19.xi.1993, strongly disturbed rain forest, leg. J.P.\& M.J. Duffels (ZMAC); $4 \hat{\delta} 7$ apt., $1 \hat{0}$ macr., Sulawesi Utara Prov., cave spring and stream at Komangaan, NW Kotamobagu, CL 2120, 14.ix.1985, leg. D.A. Polhemus (JTPC, NHMw); 11 đิ $37 q$ apt., $1 q$ macr., Sulawesi Utara Prov., Tondano River tributary, S of Airmadidi, CL 2127, 20.ix.1985, leg. J.T. \& D.A. Polhemus (JTPC, NHMw); $490^{\star}$ 42 ㅇ apt., 10 macr., Sulawesi Utara Prov., tributary to Tumpah River, CL 2101, 4.ix.1985, leg. J.T. \& D.A. Polhemus (JTPC, NHMw, PPCC); 504 apt., Sulawesi Utara Prov., Pononontuna River at Tapakulintang, $200 \mathrm{~m}$, CL 2121, 15.ix.1985, leg. J.T. \& D.A. Polhemus (JTPC, NHMw); 33038 apt., Sulawesi Utara Prov., Tumpah River, Dumoga-Bone Nat. Park, 0³4'N, 1235', CL 2100, 4.ix.1985, 222 m, leg. J.T. \& D.A. Polhemus (JтPC, NHMw); $180 \hat{2} 28$ apt, $1 \uparrow$ macr., Sulawesi Utara Province, stream near Manembonembo, E of Manado, CL 2128, 20.ix.1985, leg. J.T. \& D.A. Polhemus (JтPC, NHмw); $80^{\top}$ 16 apt., 1 macr., Sulawesi Selatan Prov., Pattunuang River, $7 \mathrm{~km} \mathrm{SW}$ of Bantimurung, 0-100 m, CL 2165, 13.x.1985, leg. J.T. \& D.A. Polhemus (JтPC, NHмw); 20 5 q apt., Sulawesi Selatan Province, Marana River, nr. Camba, $50 \mathrm{~km}$ E of Maros, $450 \mathrm{~m}$, CL 2167, 14.x.1985, leg. J.T. \& D.A. Polhemus (JTPC, NHMw).

\section{Redescription}

Dimensions. - Apterous form: Length 2.95 (ठ), 3.10 ( 9 ), width $2.06(\delta), 2.26$ ( + ), width of head 1.18 (ô), 1.21 (우).

Colour (fig. 187). - Whole body prominently dark, with distinct yellowish marks. Eye blackish. Interoculus blackish, with one large M-shaped yellowish mark at posterior margin. Antennal segments dark, except basal $1 / 4$ of segment 1 . Pronotum dark in male, in female lateroposterior margin with a small yellowish mark. Mesonotum yellowish with broad dark lateral stripes which are confluent with the dark mark of metanotum. Metanotum blackish with two oblique yellowish marks. Mesopleura yellowish, with a longitudinal dark stripe in male (fig. 189), in female this dark stripe less developed. External half of metacetabula blackish (figs. 205, 206). Fore leg dark with basal $1 / 3$ (ठ) (fig. 199) or $1 / 2$ ( $($ ) of femur yellowish. Middle and hind legs dark. Tergites 1-4 completely dark, 5-7 blackish with yellowish mark in the middle. Laterotergites 1-3 blackish, 4 blackish with yellowish mark, 5-7 yellowish. Connexiva 1-4 blackish, 5-7 yellowish. Venter yellowish. Segment 8 darkened ventrolaterally.

Pilosity. - Inner surface of antennal segment 1 with 5-6 subbasal and 1 subapical spines, through basal half of segment 1 to segment 4 with fine silvery hair fringe; segments 2-4 with scattered brownish short se- tae (fig. 194). Dorsum and pleura and metacetabula bearing dark pubescence. Ventral surface of fore trochanter with a tuft of dark setae apically (fig. 213). Dark setae along inner surface of fore tibia not modified (fig. 199). Venter clothed by golden pubescence, especially on genital segments, the pilosity longer and denser. Halfway the mesosternal groove with a dark setae blotch which is displayed in two longitudinal lines. Stiff spines scattered along middle and hind legs, denser than in most other species.

Structural characters. - Interoculus broader than width of an eye, $0.49: 0.41$ in male, $0.50: 0.44$ in female. Antennae not modified, measurements see table 1 (fig. 194). Thorax not bulbous, mesonotum somewhat swollen, its lateral width 1.12 (ô), 1.27 (ㅇ). Intersegmental suture between meso- and metanotum obscure. Metanotum somewhat declivent. Lower part of metacetabula bilobate (figs. 205, 206). Metasternal tubercle not prominent. Fore femur of male incrassate, tapering towards distal part (fig. 199), Claw rising from basal $1 / 3$ of segment 2 of fore tarsus. Anterior margin of abdominal tergite 1 obscure but visible, anterior margins of tergites 2 and 3 obscure but eventually obliterated medially and protruding forward; abdominal sternite 7 as long as the preceding abdominal sternites together in both sexes. Laterotergites broad.

Male terminalia. - Parameres (figs. 221, 222) asymmetrical, both hooked, left paramere longer and broader than right one, knife-shaped, tapering distally, with sharp apex. Right paramere slender and with sharp apex. Endosoma (fig. 231): dorsal sclerite long and recurved proximally, ventral sclerites long and weak, lateral sclerites straight, broadened at both ends, second lateral sclerites thin and weak, third lateral sclerite long and curved, apical accessory sclerite small, not visible from lateral view.

Female terminalia. - Abdominal sternite 7 large, posterior margin smooth, concave forwards.

Macropterous form. - Maximum width $1.70 \mathrm{~mm}$. colour pattern: pronotum (fig. 218) black with two regular yellowish blotches. Wings anteriorly black with fine pubescence and with scattered longer black hairs. Posterior membranous part of wings dark brown. Other characters as apterous form except the apex of pronotum pointed (measurements see table 3); length of fore wings from humeri to apex 2.30.

Distribution (map 5). - Indonesia: Sulawesi Utara Prov., Sulawesi Selatan Prov.

Comparative notes. - Most closely related to $V$. xiphibion; for difference see the comparative notes under that species.

\section{Ventidius (Ventidioides) kurtokalami Chen \&} Nieser

(figs. 190, 195, 200, 214, 223, 224, 232, 235, map 5) 
Ventidius (Ventidioides) kurtokalami Chen \& Nieser, 1992: 158-159 (descrip. \& illustr.).

Type locality. - MALAysia: Sabah, Danum Valley.

Type material examined. - Holotype $\widehat{\delta}$, apt., allotype $q$, apt., E. MALAysia: Sabah, Danum Valley, $70 \mathrm{~km}$ W Lahad Datu, $4 \mathrm{~km} \mathrm{~S}$ main trail W5 nr. Sungai Segama, $150 \mathrm{~m}$, middle sized stream and waterfall, 3.xii.1989, sample Sab. 54, M.J. \& J.P. Duffels (zmac). Paratype: $1 \delta^{\top}$ apt., Sabah, Danum Valley, $70 \mathrm{~km}$ W Lahad Datu, main trail W 12, 180 m, narrow creek, 2.xii.1989, sample Sab. 52, M.J. \& J.P. Duffels (NCTN).

Other material examined. - MALAYsia: $15 \hat{\delta} 22 \%$ apt., 1 ơ macr., Sabah, Danum Valley, Palum Tambun, 2.13.2.1997, leg. H. Zettel (2) and leg. Zettel et al. (different

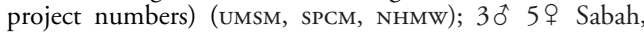
Danum Valley, Sapat Kalisan, 12.2.1997, leg. H. Zettel

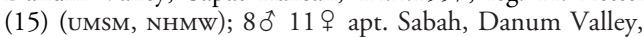
Waterfall, 3.2.1997, leg. H. Zettel (5) (uмSM, NHMw); 500 6 ㅇ apt., Sabah, Danum Valley, Water Pool, 11.2.1997, leg. H. Zettel (13) (uмsm, NHмw); 11 t 3 q apt., Sabah, North Borneo (SE), Forest Camp, $19 \mathrm{~km} \mathrm{~N}$ of Kalabakan, 12.xi.1962, leg. Y. Hirashima (BIMC, NHMw); 5010 apt., from same locality, 13.xi.1962 (вIмC, РPCC); $50 \hat{2}+$ apt., Sabah, North Borneo, Tawau, Quoin Hill, Forest Camp, 1,3-5 km WSW of Cocoa Res. Sta., 9.-20.viii.1962, leg. Y. Hirashima (вімс, Nнмw); $2 q$ apt., Sabah, North Borneo, Tawau, Quoin Hill, Cocoa Res. Sta., 26.ix.1962, leg. Y. Hirashima (BIMC); 102 우 apt., Sabah, British North Borneo, Tawau, Quoin Hill, 26.-29.vii.1962 (вIмC); 101 우 apt., Sabah, Samlang River, $7 \mathrm{~km} \mathrm{~S}$ of Ranau, CL 2026, 3.viii.1985, leg. J.T. \& D.A. Polhemus (JTPC); 5077 우 apt., 1 to 1 ? macr., Sabah, $40 \mathrm{~km}$ NE of Kota Belud, CL 2032, 5.viii.1985, leg. J.T. \& D.A. Polhemus (JтPC, NHMw); 1 apt., Sabah, trib. to Moyog River nr. km 12 on Keningau Hwy., CL 2039, 6.viii.1985, leg. J.T. \& D.A. Polhemus (JTPC); 50 3 apt., Sabah, Maliau Basin, fast flow stream, MB9a and MB10, 16.5.1996, leg. T.B. Lim (zRCs, NHMw).

\section{Redescription}

Dimensions. - Apterous form. Length $2.90(\widehat{)})$, 3.45 ( $q$ ), width 2.00 (o), 2.60 ( $q$ ), width of head 1.25 (む), 1.30 (

Colour (fig. 235). - Whole body prominently yellowish, with distinct dark marks. Eye brown to blackish. Interoculus yellowish, with one large heartshaped dark mark at middle. Antennal segments dark, except basal $1 / 6$ of segment 1 , and the colour of segment 4 paler. Pronotum dark, only with two small yellowish marks at the lateroposterior margin. Mesonotum yellowish with broad dark lateral stripes which are confluent with the dark mark of metanotum. Metanotum with a triangular dark mark medially and two transverse blackish bands laterally. Mesopleura yellowish; upper and lower external angles of metacetabula brownish (fig. 190). Fore leg dark with basal $1 / 3$ of femur yellowish. Middle and hind legs dark. Tergites 1-3 completely dark, 4 blackish with an obscure triangular yellowish mark in the middle, 5-7 yellowish but dark laterally, 8 yellowish with posterior margin dark. Laterotergites yellowish,

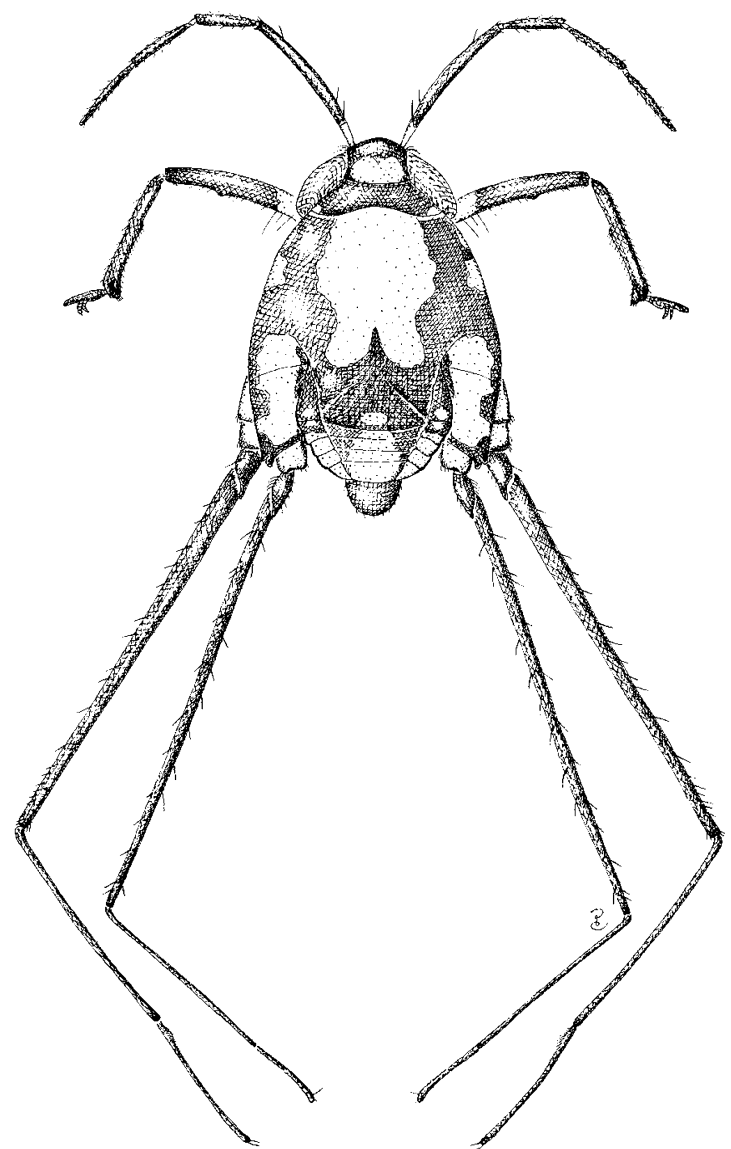

Fig. 235. Ventidius (Ventidioides) kurtokalami, paratype, apterous male, length $2.90 \mathrm{~mm}$.

3-4 more or less darkened. Connexiva 1-5 dark, 6-7 yellowish. Venter yellowish.

Pilosity. - Inner surface of antennal segment 1 with 2 subbasal and one subapical spines, through basal half of segment 1 to segment 3 with dark fine hair fringe; segments 2-4 with scattered brownish short setae (fig. 195). Dorsum and pleura clothed with dark pubescence on yellowish marks, and golden pubescence on dark part. Dark setae along both inner and external surfaces of fore tibia very prominent in male, which give the inner surface of fore tibia a wavy outline (fig. 200). Venter clothed by golden pubescence, especially on genital segments the pilosity longer and denser. Along mesosternal groove with a row of short dark bristles. Long stiff spines scattered along middle and hind legs.

Structural characters. - Interoculus subequal to width of an eye, 0.44 and 0.42 in male, 0.50 and 0.46 
in female. Antennae not modified, measurements see table 1 (fig. 195). Thorax not bulbous, mesonotum somewhat swollen, its lateral width 1.10 (ð), 1.60 (q). Intersegmental suture between meso- and metanotum obscure. Metanotum somewhat declivent. Lower part of metacetabula bilobate (figs. 207, 208). In the centre of male mesonotum with a small patch of minute black bristles which are not on a tubercle. Metasternal tubercle prominent in male. Fore femur slightly incrassate, with a blunt hump (fig. 200). Because of the prominent pilosity the fore tibia of male modified along inner and external margin, inner surface with a hump halfway its length, which is covered by erect pubescence, claw rising from 2/5 of segment 2 of fore tarsus. Anterior margin of abdominal tergite 1 obscure, anterior margins of tergites 2 and 3 obscure but eventually obliterated medially and protruding forward; abdominal sternite 7 as long as the preceding abdominal sternites together in both sexes. Laterotergites broad.

Male terminalia. - Parameres (figs. 223, 224) asymmetrical, left paramere longer than right one, hooked, apical half curved upwards, with blunt apex. Endosoma (fig. 232): dorsal sclerite long and recurved proximally, ventral sclerite long, lateral sclerite straight, broadened and hooked at two ends, third lateral sclerite recurved backwards, apical accessory sclerite distinct.

Female terminalia. - Abdominal sternite 7 large, posterior margin smooth, concave forwards.

Macropterous form. - (fig. 214). Its maximum width $1.85 \mathrm{~mm}$. Colour pattern: Pronotum black with two regular yellowish blotches separated by a thin brownish line. Wings anteriorly black with fine pubescence and with scattered longer black hairs. Posterior membranous part of wings dark brown. Other characters as in apterous form except the apex of pronotum pointed (measurements see table 3); length of fore wings from humeri to apex 2.15 .

Distribution (map 5). - East Malaysia: Sabah.

Comparative notes. - This species is very similar to $V$. nieseri sp. n., both sharing the modified fore leg in males. For differences see comparative notes of $V$. nieserisp. $\mathrm{n}$.

\section{Ventidius (Ventidioides) nieseri $\mathrm{sp} . \mathrm{n}$.}

(figs. 191, 196, 201, 209, 210, 215, 217, 225, 226, 233, 236, map 5)

Type locality. - Brunei; Malaysia: Sarawak.

Type material. - Holotype $\hat{\sigma}$, apt., allotype $q$, apt., BRUNEI: Kuala Belalong Field Research Centre, 16.iv.1993, N.9345, leg. N. Nieser (RMNH). Paratypes: $4 \hat{\jmath} 2 \%$, all apt., same locality data as holotype (RMNH, NHMw, NCTN, PPCC); 30 to apt., 1 운 macr., DARS, Temburong, Belalong FR Centre, small stream behind FRC, 16.-17.iv.1993, N9345A, leg. N. Nieser (NCTN); $3 \hat{0} 1$ 우 apt., $10 \hat{1} 1$ 우 macr., Temburong, Kuala Belalong Field Research Centre, Main river, N9344, 16.iv.1993, leg. N. Nieser, quiet edge downstream of boat \& jetty (NCTN); 20 apt., Tembrong, Kuala Belalong Field Research Centre, sungai Baki, well sized tribitary to main river, 17.iv.1993,

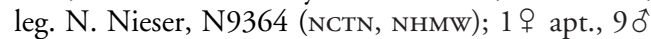
49 macr., Temburong, Belalong Field Res. Centre, Sungai Belalong, 60 m, 2-8.v.1995, leg. E. Heiss

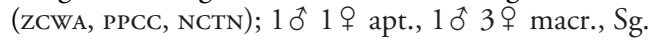
Belalong, Kuala Belalong Field Studies Centre, 16.vi.1995, leg. S.L. Goh, GSL9504 (zRCS, NHMw); 2 아 apt., $2 \delta^{\top}$ macr., same locality, 14.vi.1996, GSL9501 (zRCS); MALAYSIA: $3 \hat{0}$ apt., Sarawak, Mulu N. P., right tributary to Tutoh river, Long Iman, 4.iii.1993, leg. H. Zettel (14) (NHMw). 10 ô 14 ㅇ, apt, Sarawak, Batang Ai N.P., Engkari River, E of Bandar Sri Amman, 19-20.ii.1993, leg. H. Zettel (7) (NHмw). 20ิ, apt., Sarawak, Kapit Dist., Merirai V., 30-300 m, 1-6.viii.1958, leg. T. Maa (sEMc); 2 o 2 우 apt., Sarawak, Kapit District, Merirai V., 30-300 m, 1.-6.viii.1958, secondary forest, leg. T.C. Мaa

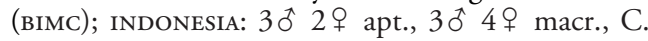
Borneo (Kalimantan), Sg. Birang, leg. Mjöberg 1925, Coll. Dr. D. Mac Gillavry (zMAC, NHMw, PPCC).

Etymology. - This species is named after our friend and colleague Dr. Nico Nieser for his devoted excellent work on aquatic and semiaquatic Heteroptera. Also for his generous offering of numerous interesting specimens from Sulawesi and Brunei, among them a large sample of this species.

Locality notes. - Small shaded river, bottom mainly pebbles, at margin and foot of waterfall.

\section{Description}

Dimensions. - Apterous form. Length 2.78 (§), $2.68($ ( ) , width $1.81(\delta), 1.93$ ( + ), width of head $1.22($ ( $), 1.25$ (우).

Colour (fig. 236). - Whole body prominently dark, with distinct yellowish marks. Eye blackish. Interoculus blackish, with one large M-shaped yellowish mark at posterior margin. Antennal segments dark, except basal 1/6 of segment 1 . Pronotum dark, only with two small yellowish marks at the lateroposterior margin of pronotum. Mesonotum yellowish with lateral dark stripe which is confluent with the dark mark of metanotum, but not reaching its anterior margin. Metanotum with a triangular dark mark medially and two transverse blackish bands laterally. Mesopleura yellowish. External margin and lower part of metacetabula blackish (fig. 191). Fore leg dark with basal $1 / 5$ of femur yellowish (fig. 201). Middle and hind legs dark. Tergites 1-3 completely dark, 4 


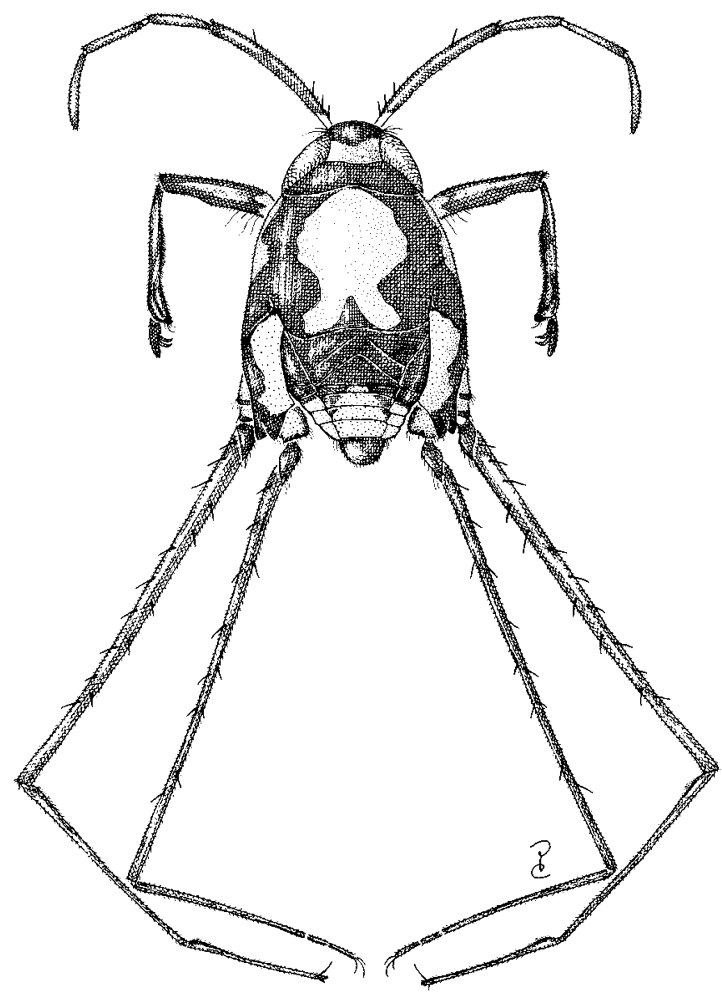

Fig. 236. Ventidius (Ventidioides) nieseri, holotype, apterous male, length $2.78 \mathrm{~mm}$.

blackish with a triangular yellowish mark in the middle, 5 yellowish but dark laterally, 6-7 yellowish with posterior margin dark, 8 dark. Laterotergites 1-4 blackish, 5-7 yellowish. Connexiva 1-5 dark, 6-7 yellowish. Venter yellowish.

Pilosity. - Inner surface of antennal segment 1 with 4 subbasal and 1 subapical long spines, through basal half of segment 1 to segment 3 with dark fine hair fringe; segments 2-4 with scattered brownish short setae (fig. 196). Dorsum and pleura bearing golden pubescence on yellowish marks, metacetabula with dark pubescence. Dark setae along inner surface of fore tibia very prominent, which gives the inner surface of fore tibia a wavy outline (fig. 201). Venter clothed by golden pubescence, especially on genital segments the pilosity longer and denser. Along medium line of mesosternum with a dark stripe composed of short setae, setae pointed upwards and gradually tapering onto the anterior margin of mesosternum (fig. 215). Long stiff spines scattered along middle and hind legs.

Structural characters. - Interoculus subequal to width of an eye, $0.46: 0.42$ in male, $0.49: 0.46$ in female. Antennae not modified, but segment 1 distinct- ly curved towards ventral side, measurements see table 1 (fig. 196). Thorax not bulbous, mesonotum somewhat swollen, its lateral width 1.43 (ङ), 1.53 (). Intersegmental suture between meso- and metanotum obscure. Metanotum somewhat declivent. Lower part of metacetabula bilobate (figs. 209, 210). Metasternal tubercle hidden under mesosternum. Fore femur of male incrassate, halfway its inner surface with a blunt swelling (fig. 201), claw rising from $2 / 5$ of segment 2 of fore tarsus. Anterior margin of abdominal tergite 1 obscure, anterior margins of tergites 2 and 3 obscure but eventually obliterated medially and protruding forward; abdominal sternite 7 as long as the preceding sternites together in both sexes. Laterotergites broad.

Male terminalia. - Parameres (fig. 225, 226) asymmetrical, left paramere longer than right one, both hooked, apex of right paramere blunt, apex of left paramere sharper than right one; paramere extending beyond genital segments. Endosoma (fig. 233): dorsal sclerite long and recurved proximally, ventral sclerite long, lateral sclerites straight, broadened at distal ends, second lateral sclerites thin and weak, third lateral sclerite curved; apical accessory sclerite distinct.

Female terminalia. - Abdominal sternite 7 large, posterior margin smooth, concave forwards.

Macropterous form. - Its maximum width 1.90 mm. Colour pattern: Pronotum (fig. 217) black with two regular yellowish blotches. Wings anteriorly black with fine pubescence and with scattered longer black hairs. Posterior membranous part of wings dark brown. Other characters as in apterous form except the apex of pronotum pointed (measurements see table 3); length of fore wings from humeri to apex 2.65.

Distribution (map 5). - Brunei; East Malaysia: Sarawak; Indonesia: Kalimantan.

Comparative notes. - Ventidius nieseri sp. n. is closely related to $V$. kurtokalami. Differences are small and mainly found in males: The thickening in the middle of fore tibia is poorly developed in $V$. nieserisp. $\mathrm{n}$. and mainly indicated by a short erect pilosity; the fore femur is more curved basally in $V$. nieseri sp. n.; the setae along mesosternal groove are more conspicuous in $V$. nieseri sp. n.; both parameres are slightly more curved and distally somewhat more slender in $V$. nieseri sp. n.; and the endosoma of $V$. nieseri sp. n. has a larger apical accessory sclerite; the species are usually also separable in colour, which is brighter in both sexes in $V$. kurtokalami, but specific variability of both species is slightly overlapping.

\section{Ventidius (Ventidioides) heissi sp. $\mathrm{n}$.}

(figs. 192, 197, 202, 211, 212, 218, 227, 228, 234, 237, map 5)

Type locality. - MALAysia: Sarawak. 


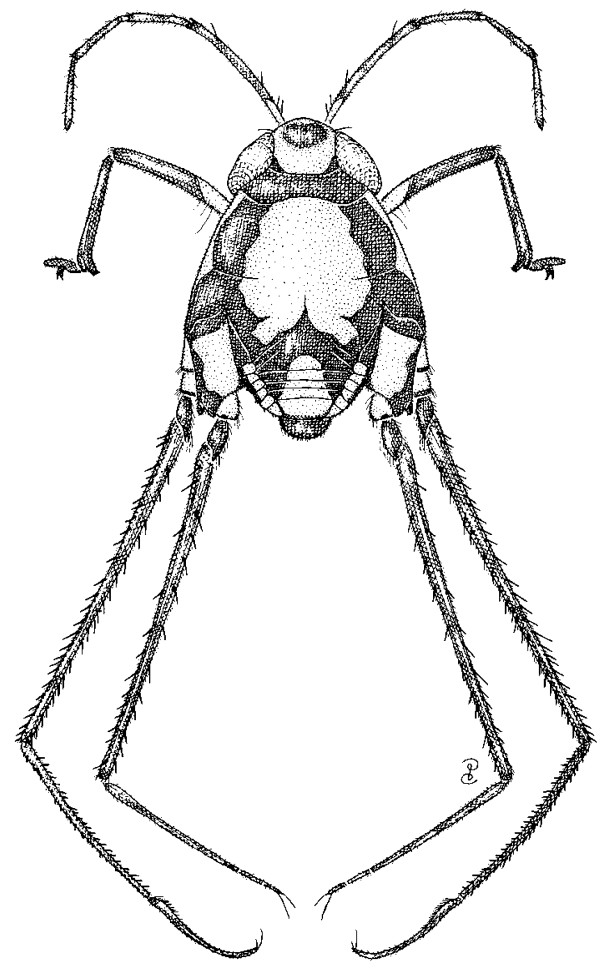

Fig. 237. Ventidius (Ventidioides) heissi, holotype, apterous male, length $2.73 \mathrm{~mm}$.

Type material. - Holotype $\hat{\sigma}$, apt, MALAYSIA: Borneo / Sarawak, Kapit Dist., Merirai Village, 30-300 m, 1-6. VIII. 1958, secondary forest, No. M.B. 164, leg. T.C. Мaа (вIMC). - Paratypes, $4 \hat{\jmath}$, apt., same locality data as holotype (BIMC, NHMW, PPCC).

Etymology. - This species is named after our friend and colleague Prof. Mag. Dr. Ernst Heiss (Innsbruck), specialist in Oriental Aradidae, who provided us with interesting specimens from Brunei.

\section{Description}

Dimensions. - Apterous male. Length $2.73(\widehat{\delta})$, width $1.85\left(\delta^{*}\right)$, width of head $1.12\left(\delta^{\circ}\right)$.

Colour (fig. 237). - Whole body prominently dark, with distinct yellowish marks. Eye blackish. Interoculus pale, with one large round dark mark. Antennal segments 1-3 dark except basal 2/5 of segment 1 , segment 4 paler. Pronotum completely dark. Mesonotum with lateral dark mark. Metanotum with triangular dark mark. Mesopleura with a thick dark stripe (fig. 192; external angle of metacetabula dark (figs. 211, 212). Under strong light, the pubescence reflects with a shining greenish metallic colour. Fore leg dark with basal $1 / 3$ yellowish (fig. 202). Middle and hind legs dark. Tergites 1 completely dark, 2-5 yellowish but dark laterally, 6 mainly yellowish, 7 yellowish, posterior margin dark, 8 dark. Laterotergites 1 dark, 2-5 dark laterally, 6-7 yellowish. Connexiva 1-5 dark, 6-7 yellowish. Venter yellowish.

Pilosity. - Inner surface of antennal segment 1 with 3 subbasal, and 1 subapical long spines; through basal half of segment 1 to apical half of segment 4 with fine hair fringe; segments 2-4 with scattered dark short setae (fig. 197). Dorsum and pleura bearing dark pubescence on yellowish marks, and golden pubescence on dark parts. Venter clothed by golden pubescence, especially on genital segments, the pilosity very long and dense. Halfway the mesosternal groove with a blotch of dark setae which is displayed in two longitudinal lines, not as obvious as in other species of this group. Dark setae and long spines scattered along middle and hind legs.

Structural characters. - Interoculus subequal to width of an eye, $0.42: 0.39$ in male. Antennae not modified, measurements see table 1 (fig. 197). Thorax not bulbous, mesonotum somewhat swollen, its lateral width $1.28(\widehat{\delta})$. Intersegmental suture between meso- and metanotum obscure. Metanotum somewhat declivent. Lower part of metacetabula bilobate (figs. 211, 212). Metasternal tubercle not prominent in male. Fore femur slender, inner surface of fore tibia not modified, claw rising from $2 / 5$ of segment 2 of fore tarsus. Anterior margin of abdominal tergite 1 indistinct; anterior margins of tergites 2 and 3 obliterated medially and protruding forward; abdominal sternite 7 as long as the preceding abdominal sternites together. Laterotergites broad.

Male terminalia. - Parameres (figs. 227, 228) asymmetrical, both hook-shaped, left paramere longer than right one, its apex more or less sharp; distal part of right paramere less pointed, with blunt apex; both parameres extending beyond genital segments. Endosoma (fig. 234): dorsal sclerite long and curved proximally; ventral sclerites long; first lateral sclerites straight, broadened at distal parts; second lateral sclerites thin and weak; third lateral sclerite oblique, thin and clear; apical accessory sclerite distinct.

Macropterous form and female. - Unknown.

Distribution (map 5). - East Malaysia: Sarawak.

Comparative notes. - This new species is similar to $V$. xiphibion and $V$. xyele in having a row of setae along mesosternal groove (although this is less prominent than in any other member of the $V$. xiphibiongroup) and the lack of a thickening or tubercle on fore femur and fore tibia in male. The lack of a tuft of setae on fore trochanter, the long antennal segment 3 , and the general shape of the parameres are characters which clearly distinguish $V$. heissi sp. n. from both 


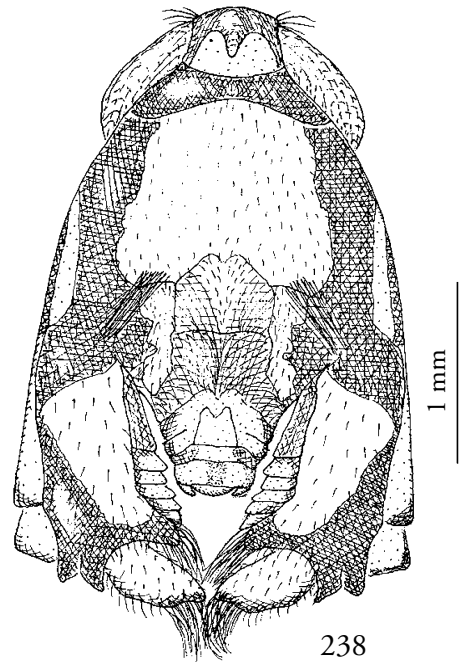

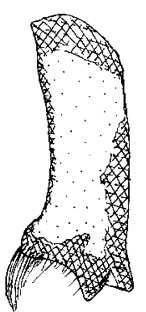

241

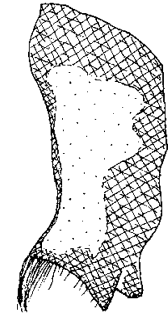

242

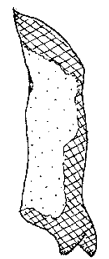

243

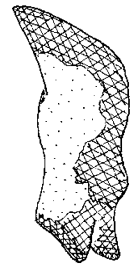

244
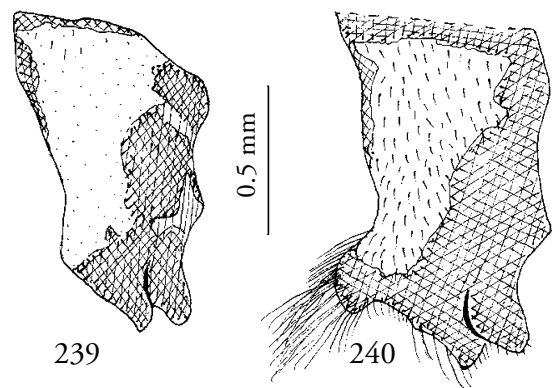

Figs 238-244. - 238, Ventidius (Ventidiopsis) imadatei Miyamoto, dorsal view of apterous female (appendages removed), length $2.90 \mathrm{~mm}$. - 239, 241, 243, dorsal view of metacetabula; 240, 242, 244, dorsolateral view of metacetabula. $-239, V$. imadatei, female; 240, male; 241, 242, V. yangae, male; 243, 244, female.

these Sulawesian species and show a closer relationship to the following two Bornean species, V. kurtokalami and $V$. nieseri sp. n. Males of $V$. heissi sp. n. are easy to distinguish from both of these species by the lack of special structures on fore femur and fore tibia (fig. 202), the less prominently developed setae along mesosternal groove, and the broad shape of the parameres: left paramere apically curved, right paramere apically blunt (figs. 227, 228).

\section{Ventidius (Ventidiopsis) Miyamoto, 1967, stat. n.}

Ventidiopsis Miyamoto, 1967: 247. Type species by monotypy: Ventidiopsis imadatei Miyamoto, 1967. Andersen 1982: 393 (classification).

Diagnosis. - Relatively dark-coloured, pronotum black; metacetabula bilobate; sexes very different: females strongly modified: thorax dorso-ventrally swollen, metacetabula with a mediad, hairy processus; metacoxa with mediad processus; abdomen shortened, most tergites fused, sternite 7 strongly modified, with two elongate lateral projections and two caudally pointed medial lobes. Males similar to the subgenus Ventidioides, but antennae much stouter, especially the long segment 1 .

Distribution (map 6). - Endemic to Borneo.

\section{Key to apterous specimens of the subgenus Ventidiopsis}

1. Female with tuft of black bristles on posterior margin of mesonotum, with acutely pointed medial processus of metacetabula (fig. 240), with longer processus of metacoxa (fig. 238), and with long lateral projections of sternite 7 (fig. 263); male with longer left paramere (fig. 258) and broader distal part of right paramere (fig. 257) (Borneo: Brunei, Sarawak) ................ . imadatei

- Female without tuft of black bristles on posterior margin of mesonotum, with rectangular medial processus of metacetabula (figs. 241, 242), with shorter processus of metacoxa (fig. 265), and with short, appressed lateral projections of sternite 7 (fig. 264); male with shorter left paramere (fig. 260) and more slender distal part of right paramere (fig. 259) (Borneo: Sabah) $V$. yangae sp. n.

\section{The Ventidius imadatei-group}

Notes. - Only two, very closely related species are known, which are so far the only representatives of the subgenus. For diagnostic characters see diagnosis of the subgenus. Macropterous morphs are unknown. 

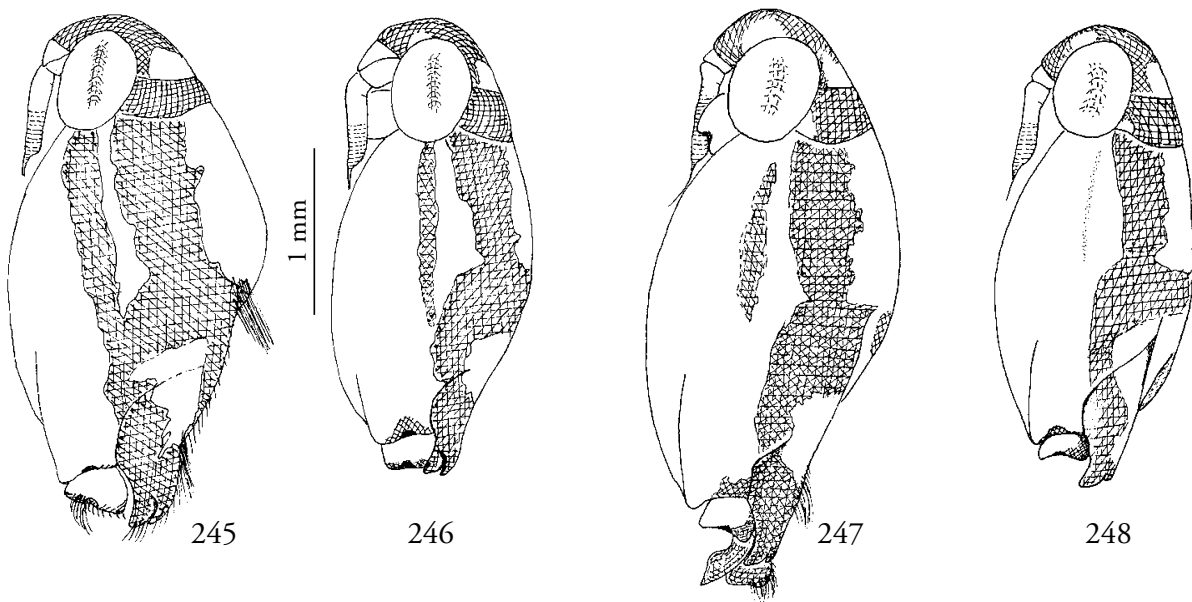

248

Figs. 245-248. Lateral view of body, showing the colour pattern of pleura. - 245, Ventidius imadatei, male; 246, female; 247 , V. yangae, male; 248 , female.

\section{Ventidius (Ventidiopsis) imadatei Miyamoto comb. n.}

(figs. 238-240, 245, 246, 249, 250, 253, 254, 257, $258,261,263$, map 6)

\footnotetext{
Ventidiopsis imadatei Miyamoto, 1967: 247-250 (gen. n., sp. n., descr., illustr.)

Type locality. - BRUNEI.
}

Material examined. $-3 \hat{\delta} 1$ ㅇ apt., BRUNEI: Temburong, Kuala Belalong Field Res. Centre, main river, N9344, 16.iv.1993, leg. N. Nieser, quiet edge downstream of boat $\&$ jetty (NCTN, PPCC); $2 \widehat{o}$ apt., Temburong, Kuala Belalong Field Research Centre, Sungai Baki, well sized tribitary to main river, 17.iv.1993, leg. N. Nieser, N9364 (RMNH, NCTN). $50^{\hat{~}}$ apt., Temburong, Belalong Field Res. Centre, Sungai Belalong, 60 m, 2-8.v.1995, leg. E. Heiss (HCiA,

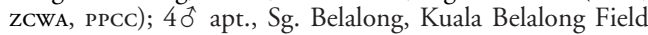
Studies Centre, 16.vi.1995, leg. S.L. Goh, GSL9504 (zRCS); $3 \widehat{t}^{2} 4$ ㅇ apt., same locality, 14.vi.1995, leg. S.L. Goh, GSL9501 (zRCS, NHMw); $10 \hat{1} 19$ apt., Sarawak, Kapit District, Merirai V., 30-300 m, 1.-6.viii.1958, secondary forest, leg. T.C. Maa (вімс), 90ิ, 6 ㅇ, apt., Sarawak, Mulu NP, 35.3.1993, leg. H. Zettel (14), (NHMw, PPCC); 1 으, apt., Sarawak, Lambir Hills NP, 25 km S Miri, 24-25.2.1993, leg H. Zettel (9), (Nhmw); Malaysia: 10 apt., Sabah, North Borneo (SE), Forest Camp, $19 \mathrm{~km} \mathrm{~N}$ of Kalabakan, 12.xi.1962, leg. Hirashima (BIMC); 19 apt., Sabah, Maliau Basin, fast flow stream, MB9a, 16.5.1996, leg. T.B. Lim (UMSM); $2 \hat{0}, 19$ apt., Sabah, Tibow Estate, slow flow stream, MB42, 25.5.1996, leg. T.B. Lim (zRCs, UMSM).

Material not examined (checked by John T. Polhemus, pers. communication). - MALAYSIA: 19 apt., Sarawak, Sameran River, $2 \mathrm{~km}$ W of Tubeh, CL 2047, 19.viii.1985, leg.

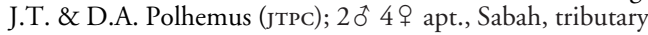
to Moyog River, near km 12 on Keningau Highway, CL 2039, 6.viii.1985, leg. J.T. \& D.A. Polhemus (JTPC).

\section{Description}

Dimensions. - Apterous form. Length 2.73 ( $\left.\delta^{\star}\right)$, $2.90(+)$, width $1.83(\delta), 1.80(q)$, width of head 1.15 (ठ), 1.23 (ㅇ).

Colour (fig. 238). - Whole body prominently dark, with distinct yellowish marks. Eye blackish. Interoculus blackish, with one large M-shaped yellowish mark at posterior margin. Antennal segments dark, except base of segment 1 . Pronotum dark, only with two small yellowish marks at the lateroposterior margin of pronotum. Mesonotum in male yellowish with lateral dark stripe which is confluent with the dark mark of metanotum and reaching its anterior margin. Mesonotum in female broadly yellowish with lateral dark stripe which is confluent with the dark mark of metacetabula. Metanotum of male with a triangular dark mark medially and two transverse blackish bands laterally. Metanotum in female blackish at anterolateral corner, inner side of lateral longitudinal elevations. Mesopleura yellowish with a dark stripe running through its length (figs. 245, 246); upper and lower external angles of metacetabula blackish (figs. 239, 240). Fore leg dark with basal $1 / 4-1 / 3$ of fore femur yellowish (figs. 253, 254). Middle and hind leg dark. In males, tergites 1-3 completely dark, tergite 4 blackish with a triangular yellowish mark in the middle, tergite 5 yellowish but dark laterally, 6-7 yellowish with posterior margin dark, tergite 8 dark. Laterotergites 1-5 blackish, lateral plates $6-7$ yellowish. Connexiva 1-5 dark, 6-7 yellowish. In females, tergites 1-3 black with broad yellowish lateral marks, tergites 4-8 yellowish with blackish lateral margins. Venter yellowish in both sexes.

Pilosity. - Inner surface of male first antennal seg- 


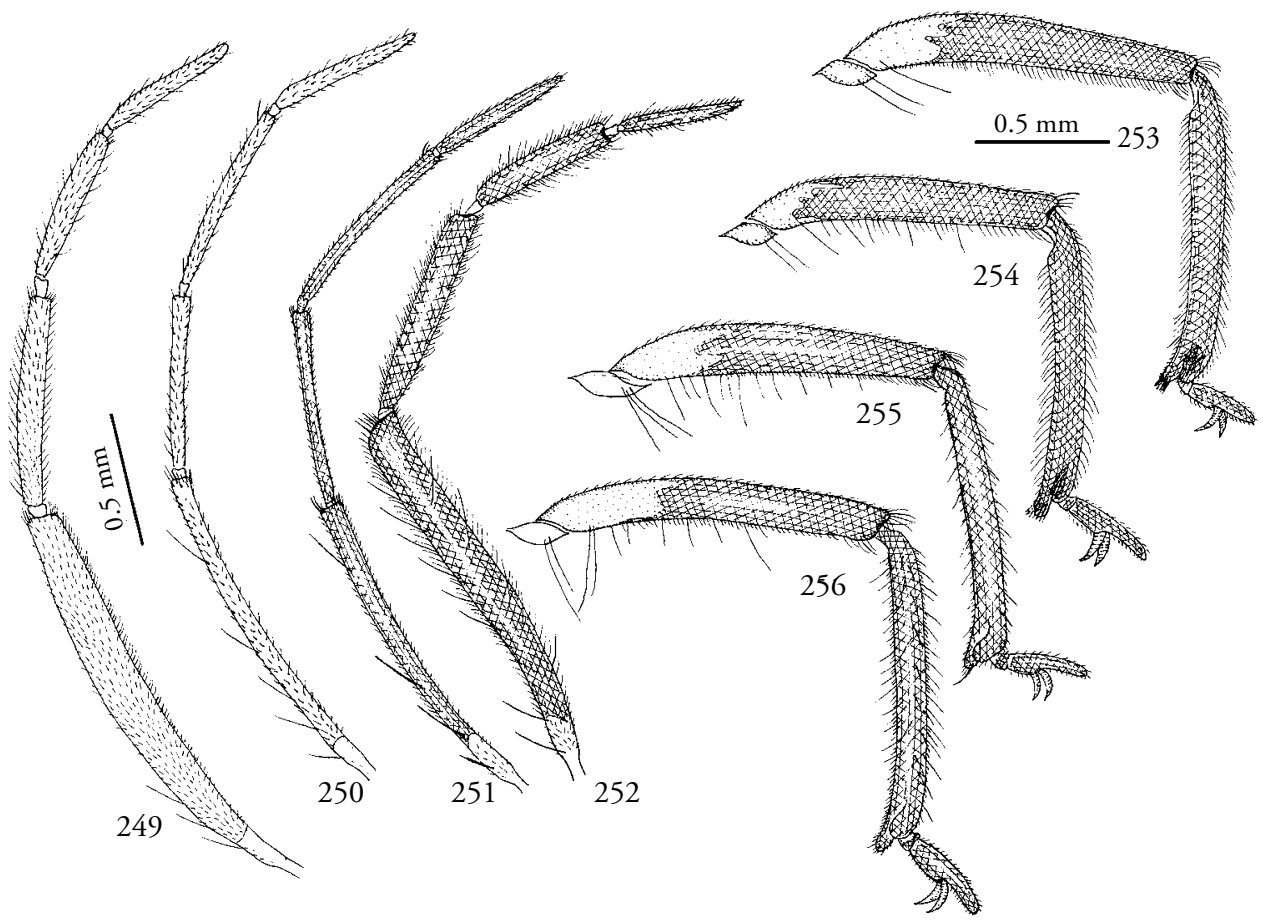

Figs. 249-252.

Dorsal view of male right antennae; 253-256. Dorsal view of right fore leg. $-249,253$, Ventidius imadatei, female; 250, 254, male; 252, 255, V. yangae, female; 251, 256, male.

Figs. 257-264.

257-260, external view of right $(257,259)$ and left $(258$, 260) parameres; 261, 262, lateral view of endosoma sclerites; 263, 264. VIIth sternite of female. - 257, 258, 261, 263, Ventidius imadatei; 259, 260, 262, 264, V. yangae.
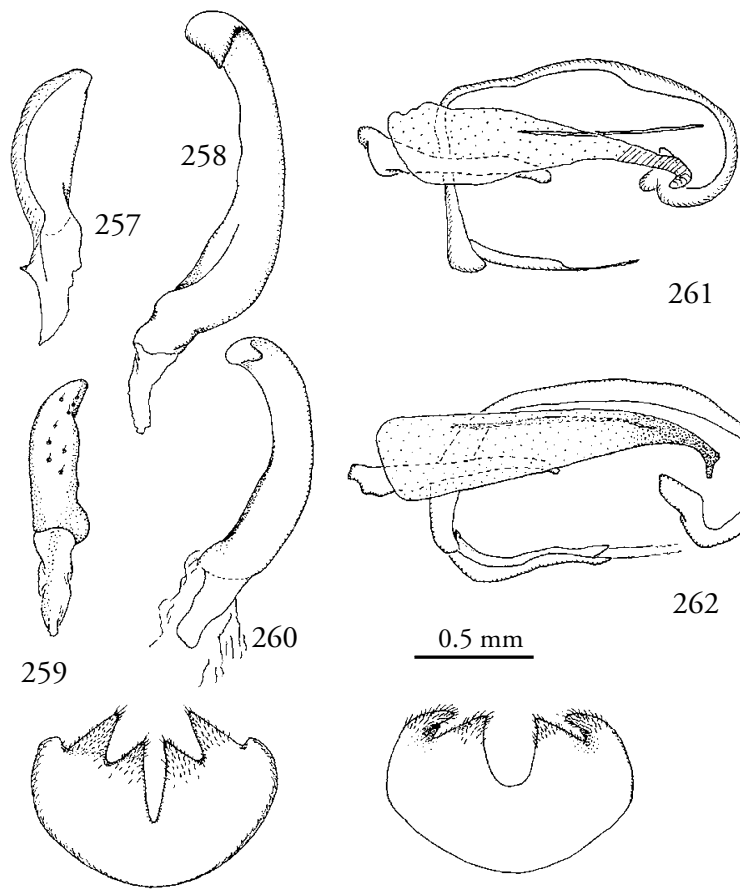

263

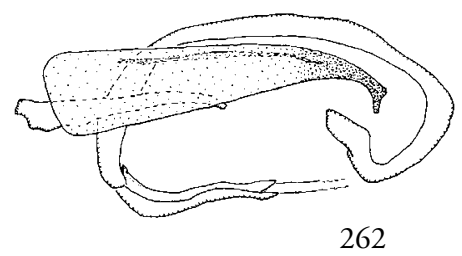

$\underline{0.5 \mathrm{~mm}}$

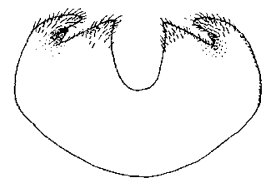

264 


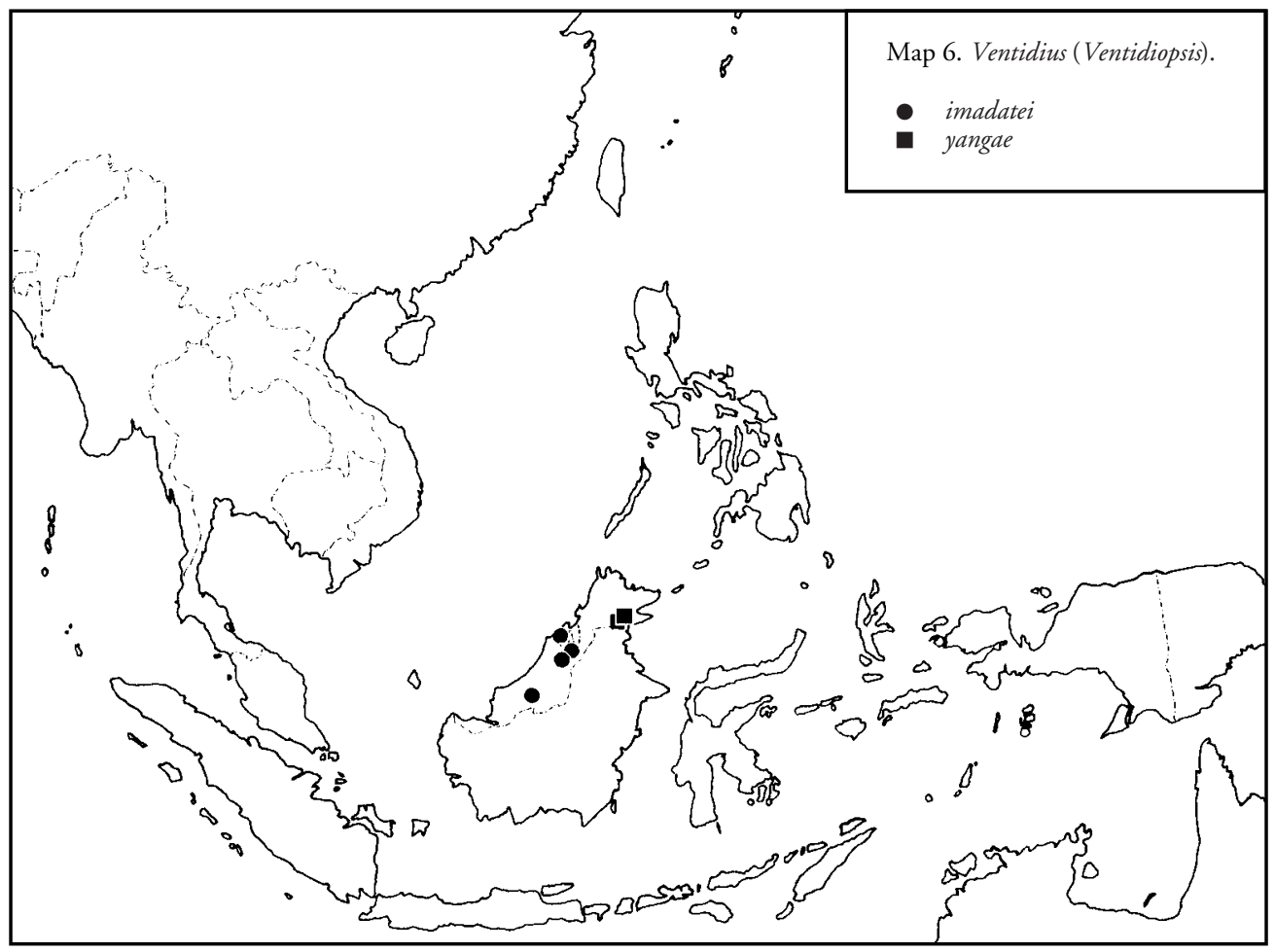

ment with 2-3 subbasal spines, but without a subapical spine as usual case in other Ventidius species (fig. 249). In females, along inner surface of first antennal segment with 5-6 long spines (fig. 250); in males, through basal half of segment 1 to segment 3 with dark fine hair fringe and segments 2-4 with scattered brownish short setae. Dorsum and pleura bearing dark pubescence on yellowish marks, and greyish pubescence on dark parts. Inner surface of fore tibia with suberect pilosity (figs. 253, 254). Females with two pairs of tufts consisting of long stiff black setae on posterior margin of mesonotum and on inner projection of metacetabula. Metacoxa of female on inner projection with numerous long black hairs. Venter clothed by dark pubescence. Long stiff spines scattered along middle and hind legs.

Structural characters. - Interoculus slightly broader than width of an eye, $0.46: 0.41$ in male, $0.43: 0.41$ in female. Male antenna thick (fig. 249), segment 1 distinctly curved towards ventral side in male, measurements see table 1. Thorax bulbous in female, mesonotum strongly swollen, which makes the female appear thick from lateral view, its lateral width 1.07 $\left(\delta^{\tau}\right), 1.40$ ( 9 ). Intersegmental suture between mesoand metanotum obscure. Metanotum declivent. Metacetabula bilobate in lower part, in female with a sharp, internally directed processus (fig. 240). Fore femur slender in both sexes, claws rising from $1 / 3$ of segment 2 of fore tarsus. In males anterior margin of abdominal tergite 1 visible, anterior margins of tergites 2 and 3 obliterated medially and protruding forward. In females abdomen shortened, sutures between tergites 1-7 obscure or only laterally visible; Abdominal sternite 7 in male shorter than the preceding abdominal sternites together, in female longer and modified. Laterotergites broad in male, narrow in female.

Male terminalia. - Parameres (fig. 257, 258) asymmetrical, left paramere twice as long as right one, extending beyond genital segments, its apical part curved upwards, with blunt, laterad curved apex; right paramere short, with pointed apex. Endosoma (fig. 261): dorsal sclerite long and recurved proximally, and broadened and homogeneous in dorsodistal half, ventral sclerites short, lateral sclerites straight, broadened at basal end, second lateral sclerites thin and weak. Third lateral sclerite curved distally and broadened at proximal half.

One male from Tibow Estate with an elongate, sharply ending right paramere seems to be an individual aberration because a second male from the same locality has a normally shaped paramere.

Female terminalia. - Apex of abdomen in dorsal 
view with distinct, mediad curved lateral projections of sternite 7; genital segments in dorsal view concealed under preceding abdominal segments. In ventral view abdominal sternite 7 large, hiding the gonocoxae completely, with two slender, strongly developed lateral projections and two large triangular, sharply pointed medial lobes (fig. 263).

Macropterous form. - Unknown.

Distribution (map 6). - Brunei; East Malaysia: Sarawak, Sabah.

Comparative notes. - Closely related to the following species, for differences see key and comparative notes of $V$. yangae sp. n.

24. Ventidius (Ventidiopsis) yangae sp. n. (figs. 241-244, 247, 248, 251, 252, 255, 256, 259, 260, 262, 264-266, map 6)

Type locality. - MaLaysia: Sabah.

Type material. - Holotype $q$, apt. and allotype 0 , apt., Sabah, Danum Valley, Palum Tambun, 7.12.2.1997, leg. Zettel et al. (P90) (UMSM). Paratypes: 10 , 1 ㅇ apt., same locality data (NHMw); 3 ô apt., Sabah, Danum Valley, Segama River, 'Beach', 4.2.1997, leg. H. Zettel (10) (UMSM, NHMw); 60 5 우 apt., Sabah, Danum Valley, Palum Tambun, 7.12.2.1997, leg. Zettel et al. (different project numbers) (Uмsм, spсм, NHмw); 19 apt., Sabah, Danum Valley, Segama River above Field Centre, 2.2.1997, leg. H. Zettel (1) (NHмw); $20 \hat{3}+$ apt., Sabah, Danum Valley, Sapat Kalisan, 12.2.1997, leg. H. Zettel (15) (NHMw).

Etymology. - Dedicated to Dr. Yang Chang Man (ZRCS) for her continuous help in making type specimens and other specimens available for this study and for her various contributions to the knowledge of Malesian water bugs.

\section{Description}

Dimensions. - Apterous form. Length 2.82 (ઠ)),

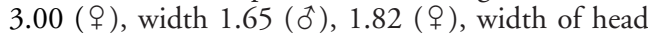
1.20 (ठ), 1.20 (ㅇ).

Colour (figs. 265, 266). - Whole body dark, with distinct yellowish marks. Eye blackish. Interoculus blackish, with one large M-shaped yellowish mark at posterior margin. Antennal segments dark, except base of segment 1. Pronotum dark, only with two small yellowish marks at the lateroposterior margin of pronotum. Mesonotum in male yellowish with lateral dark stripe which is confluent with the dark mark of metanotum and reaching its anterior margin. Mesonotum in female broadly yellowish with lateral dark stripe which is confluent with the dark mark of metacetabula. Metanotum of male with a triangular

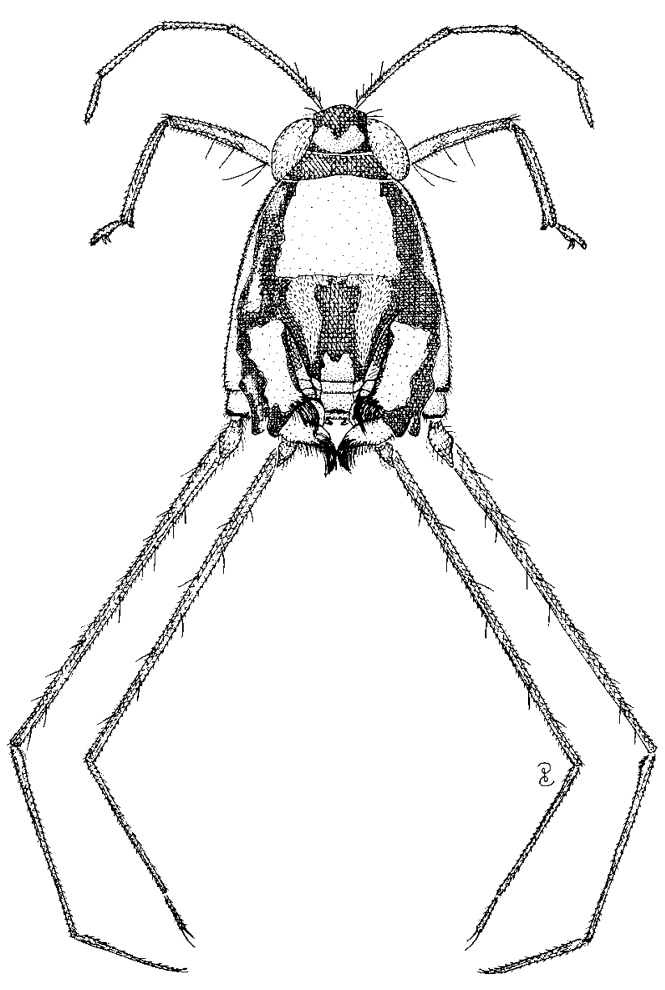

Fig. 265. Ventidius (Ventidioides) yangae, holotype, apterous female, length $2.90 \mathrm{~mm}$.

dark mark medially and two transverse blackish bands laterally. Metanotum in female blackish at anterolateral corner, inner side of lateral longitudinal elevations with an elongate dark mark medially, which is confluent laterally with abdominal dark marks. Female mesopleura yellowish with a dark stripe running through its length (fig. 247), male mesopleura totally yellowish or with thin brownish longitudinal stripe (fig. 248); upper and lower external angles of metacetabula blackish (figs. 241-244). Fore leg dark with basal $1 / 3$ of fore femur yellowish (figs. 255, 256). Middle and hind leg dark. In males, tergites 1-3 completely dark, tergite 4 blackish with a triangular yellowish mark in the middle, tergite 5 yellowish but dark laterally, 6-7 yellowish with posterior margin dark, tergite 8 dark. Laterotergites 1-5 blackish, lateral plates 6-7 yellowish. Connexiva 1-5 dark, 6-7 yellowish. In females, tergites 1 yellowish with lateral dark marks, 2-7 yellowish, tergite 8 yellowish with dark patches anteriorly. Venter yellowish in both sexes.

Pilosity. - Inner surface of male antennal segment 1 with 2-3 subbasal spines, but without a subapical spine as usual case in other Ventidius species (fig. 


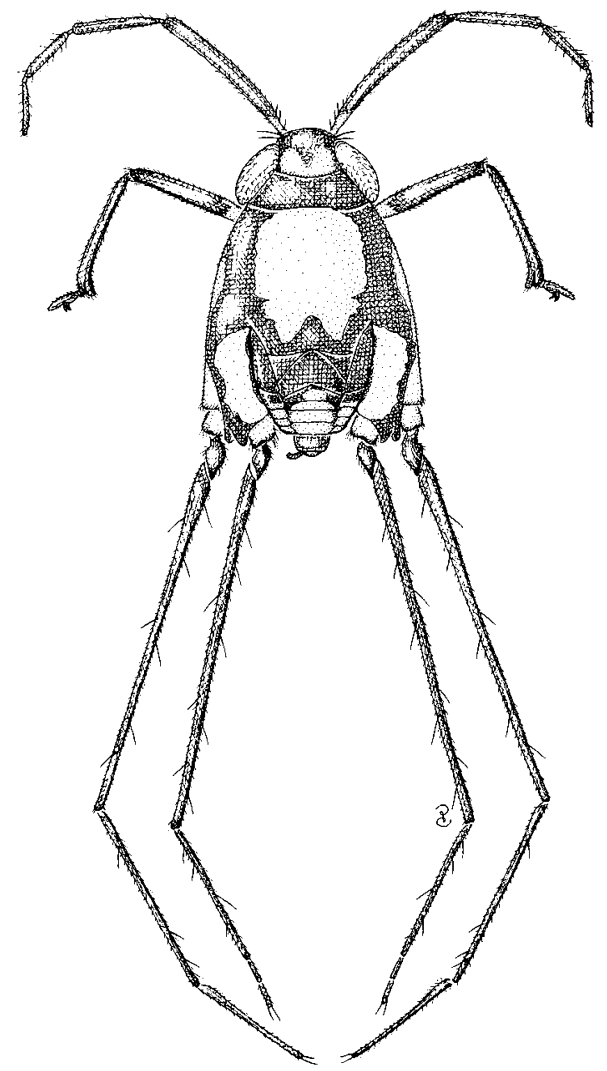

Fig. 266. Ventidius (Ventidioides) yangae, allotype, apterous male, length $2.73 \mathrm{~mm}$.

252). In females, along inner surface of antennal segment 1 with 4-5 long spines (fig. 251); in males, through basal half of segment 1 to segment 3 with dark fine hair fringe and segments 2-4 with scattered brownish short setae. Dorsum and pleura bearing dark pubescence. Inner surface of fore tibia with suberect pilosity (figs. 255, 256). Females with one pair of tufts consisting of long stiff black setae on inner projection of metacetabula (fig. 242). Metacoxa of female on inner projection with numerous long black hairs. Venter clothed by dark pubescence. Long stiff spines scattered along middle and hind legs.

Structural characters. - Interoculus slightly broader than width of an eye, $0.42: 0.40$ in male, $0.50: 0.46$ in female. Male antenna thick (fig. 252), segment 1 distinctly curved towards ventral side in male, measurements see table 1. Thorax bulbous in female, mesonotum strongly swollen, which makes the female appear thick from lateral view, its lateral width 1.05 $(\overbrace{}^{\top}), 1.35$ ( + ). Intersegmental suture between mesoand metanotum obscure. Metanotum declivent, espe- cially in females. Metacetabula bilobate in lower part, in female with a rectangular internally directed processus (figs. 241-244). Fore femur slender in both sexes, claws rising from $1 / 3$ of segment 2 of fore tarsus. In males anterior margin of abdominal tergite 1 visible, anterior margins of tergites 2 and 3 obliterated medially and protruding forward. In females abdomen shortened, sutures between tergites 1-7 obscure or only laterally visible; Abdominal sternite 7 in male shorter than the preceding abdominal sternites together, in female longer and modified. Laterotergites broad in male, narrow in female.

Male terminalia. - Parameres (fig. 259, 260) asymmetrical, left paramere one and a half times as long as right one, extending beyond genital segments, its apical part curved upwards, with blunt, laterad curved apex; right paramere short, with pointed apex. Endosoma (fig. 262): dorsal sclerite long and recurved proximally, ventral sclerites short, lateral sclerites straight, broadened proximally, second lateral sclerites thin and weak, which are covered by the third lateral sclerite, the third lateral sclerite hooked distally and broadened at proximal half.

Female terminalia. - Apex of abdomen in dorsal view without distinct projections of sternite 7; genital segments in dorsal view concealed under preceding abdominal segments. In ventral view abdominal sternite 7 (fig. 264) large, hiding the gonocoxae anteriorly, with two short angular lateral projections which are appressed to tergite 7 , and with two large triangular, pointed medial lobes, distance between the two lobes relatively broader comparing with $V$. (Ventidiopsis) imadatai.

Macropterous form. - Unknown.

Distribution (map 6). - East Malaysia: Sabah.

Comparative notes. - Closely related to $V$. imadatei. Main differences are presented in the key. In addition, the medial lobes of the female sternite 7 are of different shapes (see figs. 259-264). Differences in the endosoma are found in the distally hooked third lateral sclerite of $V$. yangae sp. n., which is less curved in $V$. imadatei.

\section{REFERENCES}

Andersen, N. M., 1982. The semiaquatic bugs (Hemiptera, Gerromorpha). Phylogeny, Adaptation, Biogeography and Classification. - Scandinavian Science Press Ltd., Copenhagen, Denmark, 455 pp.

Andersen, N. M., 1990. Genus and taxonomy of water striders, genus Aquarius Schellenberg (Insecta, Hemiptera, Gerridae), with a new species from Austria. Steenstrupia 16: 37-81.

Bergroth, E., 1911. On some recently described Hemiptera, chiefly from India. - Annales de la Société Entomologique de Belgique 55: 184-189.

Chen, P. P. \& N. Nieser, 1992. Gerridae, mainly from Su- 
lawesi and Pulau Buton (Indonesia). Notes on Malesian aquatic and semiaquatic bugs (Heteroptera), III. - Tijdschrift voor Entomologie 135: 145-162.

Cheng, L., 1965. The genus Ventidius Distant (Heteroptera: Gerridae) in Malaya, with a description of four new species. - Proceedings of the Royal entomological Society London (B) 34: 153-163.

Cheng, L., 1966. Three new species of Esakia Lundblad (Heteroptera: Gerridae) from Malaya. - Proceedings of the Royal entomological Society (B) 35: 16-22.

Distant, W. L., 1910a. Some undescribed Gerrinae. - Annals and Magazine of Natural History 5: 140-153.

Distant, W. L., 1910b. The fauna of British India, including Ceylon and Burma. Rhynchota Vol. V. Heteroptera: Appendix : 156-158

Esaki, T., 1928. New or little known Gerridae. I. Ceylonese species. - Annals and Magazine of Natural History 10: 505-513.

Esaki, T., 1929. New or little known Gerridae. II. Indian species. - Annals and Magazine of Natural History 10: 412-419.

Esaki, T., 1930. New or little known Gerridae from the Malay Peninsula. - Journal of the Federated Malay States Museums 16: 13-24.

Gupta, Y. C., 1981. A new species of Ventidius Distant (Hemiptera: Gerridae) from India. - Oriental Insects 15: 97-102.

Hanboonsong, Y., Mungkandee, P. \& H. Zettel, 1996. A preliminary list of aquatic and semiaquatic Heteroptera (Nepomorpha, Gerromorpha) from the Maekhong-ChiMun rivers area, Thailand. - Amemboa 1: 19-24.

Hungerford, H. B. \& R. Matsuda, 1958. The genus Esakia with two new species (Heteroptera, Gerridae). - Journal of the Kansas entomological Society 31: 193-197.

Hungerford, H. B. \& R. Matsuda, 1960. Concerning the genus Ventidius and five new species (Heteroptera: Gerridae). - Kansas University Science Bulletin 40: 323-343.

Kovac, D. \& C. M. Yang, 1989. A preliminary checklist of the semiaquatic and aquatic Hemiptera (Heteroptera: Gerromorpha \& Nepomorpha) of Ulu Kinchin, Pahang, Malaysia. - Malayan Nature Journal 43: 282-288.

Lansbury, I., 1990. New species of Ventidius Distant (Hem. Gerridae) from Thailand and Malaysia. - Entomologist's Monthly Magazine 126: 61-66.
Lundblad, O., 1933. Zur Kenntnis der aquatilen Hemipteren von Sumatra, Java, und Bali.. - Archiv für Hydrobiologie, Suppl. 12: 399-401.

Matsuda, R., 1960. Morphological evolution and a classification of the Gerridae (Hemiptera-Heteroptera). Kansas University Science Bulletin 41: 25-632.

Miyamoto, S., 1967. Gerridae of Thailand and North Borneo taken by the joint Thai-Japanese biological expedition 1961-62. - Nature Life in Southeast Asia 5: 217-257.

Murphy, D. H., 1990. 'Walker on water'-an account of the pleuston of Singapore. - Essay in Zoology. - In: Paper commemorating the 40th anniversary of the Department of Zoology, National University of Singapore: 153-168. Singapore.

Paiva, C. 1918. Aquatic Rhynchota from the Southern Shan States. - Records of the Indian Museum 14: 19-32, 8 plates.

Thirumalai, G., 1986. On Gerridae and Notonectidae (Heteroptera: Hemiptera: Insecta) from the Silent Valley, Kerala. - Records of the Zoological Survey of India 84: 9-33.

Thirumalai, G., 1996. A new record of the subgenus Ventidioides Hungerford \& Matsuda of the genus Ventidius Distant from India (Halobatinae: Gerridae: Heteroptera). - Arunachal Forest News, 14: 14-16.

Yang, C. M. \& D. Kovac, 1995. A collection of aquatic and semiaquatic bugs (Insecta: Hemiptera: Gerromorpha and Nepomorpha) from Temengor forest reserve, Hulu Perak, Malaysia. - Malayan Nature Journal 48: 287-295.

Zettel, H. \& P. P. Chen, 1996. Beitrag zur Taxonomie und Faunistik der Gerridae Vietnams mit Neubeschreibungen der Gattung Andersenius gen.n. aus der Unterfamilie Ptilomerinae und weiterer Arten. - Entomologische Abhandlungen des Staatliches Museum für Tierkunde Dresden 57: 149-182.

Received: 20 October 1997

Revised version accepted: 8 June 1998 
Tijdschrift voor ENTOMOLOGIE, volume 141, 1998

Table 1. Lengths of antennal segments in Ventidius species (in $\mathrm{mm}$ ).

\begin{tabular}{|c|c|c|c|c|c|}
\hline & & I & II & III & VI \\
\hline \multirow[t]{2}{*}{$V$. aquarius } & $\widehat{0}$ & 1.78 & 1.21 & 0.65 & 0.58 \\
\hline & ㅇ & 1.57 & 0.80 & 0.66 & 0.57 \\
\hline \multirow[t]{2}{*}{$V$. harrisoni } & $\delta$ & 1.50 & 0.94 & 0.75 & 0.57 \\
\hline & 우 & 1.27 & 0.61 & 0.64 & 0.52 \\
\hline \multirow[t]{2}{*}{$V$. longitarsus } & $\widehat{\sigma}$ & 2.00 & 1.32 & 0.70 & 0.88 \\
\hline & 우 & 1.80 & 0.79 & 0.65 & 0.79 \\
\hline \multirow[t]{2}{*}{$V$. malayensis } & 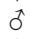 & 1.95 & 1.37 & 0.65 & 0.78 \\
\hline & q & 1.45 & 0.79 & 0.58 & 0.73 \\
\hline \multirow[t]{2}{*}{$V$. usingeri } & 0 & 1.65 & 1.32 & 0.79 & 0.61 \\
\hline & 우 & 1.43 & 0.82 & 0.72 & 0.58 \\
\hline \multirow[t]{2}{*}{$V$. hungerfordi } & $\widehat{0}$ & 1.10 & 0.67 & 0.49 & 0.44 \\
\hline & q & 1.00 & 0.42 & 0.54 & 0.42 \\
\hline \multirow[t]{2}{*}{$V \cdot$ polhemorum } & 0 & 1.07 & 0.58 & 0.49 & 0.40 \\
\hline & q & 0.90 & 0.43 & 0.51 & 0.40 \\
\hline \multirow[t]{2}{*}{$V$. werneri } & o & 1.05 & 0.50 & 0.40 & 0.41 \\
\hline & 우 & 0.90 & 0.40 & 0.47 & 0.37 \\
\hline \multirow[t]{2}{*}{$V \cdot$ pilosus } & 0 & 1.15 & 0.53 & 0.32 & 0.39 \\
\hline & 우 & 1.01 & 0.43 & 0.41 & 0.41 \\
\hline \multirow[t]{2}{*}{$V$. henryi } & 0 & 0.93 & 0.41 & 0.42 & 0.35 \\
\hline & q & 0.88 & 0.34 & 0.45 & 0.35 \\
\hline \multirow{2}{*}{ V. chinai } & o & 1.15 & 0.56 & 0.41 & 0.36 \\
\hline & q & 1.05 & 0.44 & 0.49 & 0.42 \\
\hline V. modulatus & ô & 1.20 & 0.61 & 0.48 & 0.39 \\
\hline \multirow[t]{2}{*}{$V$. kuiterti } & 0 & 1.21 & 0.39 & 0.42 & 0.45 \\
\hline & q & 1.12 & 0.32 & 0.48 & 0.50 \\
\hline \multirow[t]{2}{*}{$V$. karen } & ô & 1.40 & 0.32 & 0.35 & 0.48 \\
\hline & Q & 1.14 & 0.31 & 0.43 & 0.47 \\
\hline$V$. sp. & 우 & 1.12 & 0.36 & 0.50 & 0.52 \\
\hline \multirow{2}{*}{$V \cdot$ pulai } & 0 & 1.17 & 0.42 & 0.48 & 0.49 \\
\hline & q & 1.13 & 0.40 & 0.58 & 0.53 \\
\hline \multirow[t]{2}{*}{ V. lundbladi } & 0 & 1.18 & 0.37 & 0.41 & 0.40 \\
\hline & 우뇨 & 0.96 & 0.36 & 0.51 & 0.44 \\
\hline \multirow[t]{2}{*}{ V. xiphibion } & o & 1.29 & 0.47 & 0.38 & 0.50 \\
\hline & q & 1.25 & 0.48 & 0.50 & 0.51 \\
\hline \multirow[t]{2}{*}{ V. xyele } & 0 & 1.26 & 0.50 & 0.41 & 0.52 \\
\hline & q & 1.30 & 0.54 & 0.54 & 0.51 \\
\hline \multirow[t]{2}{*}{ V. kurtokalami } & ô & 1.22 & 0.57 & 0.55 & 0.56 \\
\hline & 우 & 1.30 & 0.50 & 0.70 & 0.60 \\
\hline \multirow[t]{2}{*}{$V$. nieseri } & $\delta$ & 1.30 & 0.51 & 0.53 & 0.50 \\
\hline & ㅇ & 1.29 & 0.50 & 0.70 & 0.60 \\
\hline$V$. heissi & 0 & 1.15 & 0.47 & 0.51 & 0.53 \\
\hline \multirow[t]{2}{*}{ V. imadatei } & ô & 1.50 & 0.77 & 0.57 & 0.51 \\
\hline & q & 1.20 & 0.55 & 0.60 & 0.48 \\
\hline \multirow[t]{2}{*}{$V$. yangae } & o & 1.50 & 0.70 & 0.52 & 0.45 \\
\hline & & 1.00 & 0.96 & 0.08 & 0.28 \\
\hline \multicolumn{2}{|l|}{ Esakia ventidioides ô } & 1.05 & 0.35 & 0.33 & 0.28 \\
\hline & q & 1.10 & 0.30 & 0.33 & 0.30 \\
\hline
\end{tabular}


Table 2. Lengths of leg segments in Ventidius species.

\begin{tabular}{|c|c|c|c|c|c|c|}
\hline & male $(c$ & & & femal & & \\
\hline species & & tibia & tarsi & femur & tibia & tarsi \\
\hline V. aquarius & & & & & & \\
\hline fore leg & 1.43 & 1.30 & 0.39 & 1.38 & 1.26 & 0.41 \\
\hline mid leg & 3.95 & 2.48 & 1.45 & 3.75 & 2.25 & 1.40 \\
\hline hind leg & 4.18 & 2.03 & 0.56 & 4.00 & 2.15 & 0.59 \\
\hline V. usingeri & & & & & & \\
\hline fore leg & 1.60 & 1.35 & 0.46 & 1.46 & 1.18 & 0.42 \\
\hline mid leg & 4.15 & 2.51 & 1.60 & 3.77 & 2.40 & 1.48 \\
\hline hind leg & 4.45 & 1.90 & 0.62 & 3.76 & 2.01 & 0.68 \\
\hline V. harrisoni & & & & & & \\
\hline fore leg & 1.42 & 1.15 & 0.39 & 1.18 & 1.05 & 0.42 \\
\hline mid leg & 3.47 & 2.04 & 1.20 & 3.00 & 1.70 & 1.07 \\
\hline hind leg & 3.50 & 1.76 & 0.53 & 3.03 & 1.54 & 0.56 \\
\hline$V$. malayensis & & & & & & \\
\hline fore leg & 1.77 & 1.45 & 0.60 & 1.50 & 1.30 & 0.60 \\
\hline mid leg & 4.50 & 2.75 & 1.65 & 4.07 & 2.46 & 1.58 \\
\hline hind leg & 4.82 & 2.50 & 0.70 & 4.17 & 2.36 & 0.75 \\
\hline$V$. longitarsus $\mathrm{sp}$ & n. (Da L & & & & & \\
\hline fore leg & 1.80 & 1.60 & 0.77 & 1.66 & 1.36 & 0.64 \\
\hline mid leg & 4.90 & 3.00 & 1.90 & 4.45 & 2.70 & 1.60 \\
\hline hind leg & 4.90 & 2.65 & 0.70 & 4.30 & 2.56 & 0.80 \\
\hline$V$. longitarsus $\mathrm{sp}$ & n. (Gia I & i-Kont & & & & \\
\hline fore leg & 1.53 & 1.55 & 0.77 & 1.51 & 1.40 & 0.62 \\
\hline mid leg & 4.53 & 2.88 & 1.70 & 4.16 & 2.60 & 1.70 \\
\hline hind leg & 4.71 & 2.57 & 0.92 & 4.00 & 4.00 & 0.88 \\
\hline$V$. hungerfordi & & & & & & \\
\hline fore leg & 1.11 & 0.93 & 0.33 & 1.10 & 0.92 & 0.32 \\
\hline Mid leg & 2.75 & 1.50 & 1.00 & 3.00 & 1.50 & 1.10 \\
\hline hind leg & 3.10 & 0.70 & 0.35 & 3.00 & 1.30 & 0.36 \\
\hline$V$. polhemorum & sp. n. & & & & & \\
\hline fore leg & 1.05 & 0.90 & 0.30 & 1.05 & 0.90 & 0.30 \\
\hline mid leg & 2.67 & 1.28 & 1.00 & 2.77 & 1.43 & 1.06 \\
\hline hind leg & 2.57 & 1.12 & 0.40 & 2.68 & 1.25 & 0.45 \\
\hline V. werneri & & & & & & \\
\hline fore leg & 1.03 & 0.86 & 0.30 & 0.95 & 0.93 & 0.28 \\
\hline mid leg & 2.66 & 1.42 & 0.95 & 2.68 & 1.41 & 0.98 \\
\hline hind leg & 2.68 & 1.11 & 0.38 & 2.61 & 1.11 & 0.35 \\
\hline$V$. pilosus sp. n. & & & & & & \\
\hline fore leg & 1.08 & 0.96 & 0.35 & 1.13 & 1.05 & 0.38 \\
\hline mid leg & 3.06 & 1.78 & 1.30 & 3.33 & 1.90 & 1.35 \\
\hline hind leg & 3.46 & 1.78 & 0.58 & 3.66 & 1.65 & 0.65 \\
\hline$V$. henryi & & & & & & \\
\hline fore leg & 1.06 & 0.95 & 0.31 & 1.05 & 0.84 & 0.31 \\
\hline mid leg & 3.03 & 1.76 & 1.07 & 3.03 & 1.80 & 1.07 \\
\hline hind leg & 3.38 & 1.30 & 0.41 & 3.40 & 1.23 & 0.41 \\
\hline V. modulatus & & & & & & \\
\hline fore leg & 1.10 & 0.96 & 0.35 & 1.11 & 0.96 & 0.34 \\
\hline mid leg & 3.00 & 1.75 & 1.11 & 3.26 & 1.80 & 1.17 \\
\hline hind leg & 3.19 & 1.37 & 0.42 & 3.40 & 1.50 & 0.50 \\
\hline V. kuiterti & & & & & & \\
\hline fore leg & 1.06 & 0.91 & 0.32 & 1.10 & 1.00 & 0.32 \\
\hline mid leg & 3.00 & 1.16 & 1.09 & 3.20 & 1.75 & 1.00 \\
\hline hind leg & 3.25 & 1.05 & 0.45 & 3.50 & 0.85 & ?? \\
\hline$V$. karen & & & & & & \\
\hline fore leg & 1.12 & 0.90 & 0.30 & 1.20 & 0.99 & 0.38 \\
\hline mid leg & 3.00 & 1.50 & 1.00 & 3.25 & 1.66 & 1.12 \\
\hline hind leg & 3.18 & 1.17 & 0.40 & 3.55 & 1.42 & 0.50 \\
\hline$V$. sp. (V. karen? & ? from Vie & Nam) & & & & \\
\hline fore leg & ?? & ?? & ?? & 1.30 & 1.04 & 0.38 \\
\hline mid leg & ?? & ?? & ?? & 3.48 & 1.90 & 1.22 \\
\hline hind leg & ?? & ?? & ?? & 3.58 & 1.58 & 0.54 \\
\hline
\end{tabular}




\begin{tabular}{|c|c|c|c|c|c|c|}
\hline \\
\hline $\begin{array}{l}V . \text { pulai } \\
\text { fore leg }\end{array}$ & 1.11 & 0.90 & 0.33 & 1.11 & 0.94 & 0.33 \\
\hline mid leg & 3.01 & 1.61 & 1.02 & 3.20 & 1.75 & 1.05 \\
\hline hind leg & 3.21 & 1.28 & 0.45 & 3.51 & 1.38 & 0.51 \\
\hline V. lundbladi & & & & & & \\
\hline fore leg & 1.10 & 0.86 & 0.28 & 1.08 & 0.90 & 0.31 \\
\hline mid leg & 2.54 & 1.51 & 1.05 & 3.00 & 1.60 & 0.94 \\
\hline hind leg & 2.76 & 1.20 & 0.52 & 2.97 & 1.28 & 0.43 \\
\hline $\begin{array}{l}\text { V. xiphibion } \\
\text { fore leg }\end{array}$ & & & & 120 & م 0 & 030 \\
\hline $\begin{array}{l}\text { fore leg } \\
\text { mid leg }\end{array}$ & $\begin{array}{l}1.10 \\
3.20\end{array}$ & $\begin{array}{l}0.90 \\
1.90\end{array}$ & $\begin{array}{l}0.35 \\
1.10\end{array}$ & $\begin{array}{l}1.20 \\
3.30\end{array}$ & $\begin{array}{l}0.90 \\
1.90\end{array}$ & $\begin{array}{l}0.30 \\
1.10\end{array}$ \\
\hline hind leg & 3.50 & 1.50 & 0.40 & 3.70 & 1.60 & 0.40 \\
\hline V. xyele & & & & & & \\
\hline fore leg & 1.20 & 1.10 & 0.40 & 1.20 & 1.00 & 0.40 \\
\hline mid leg & 3.40 & 1.90 & 1.10 & 3.50 & 1.90 & 1.10 \\
\hline hind leg & 3.90 & 1.70 & 0.50 & 3.90 & 1.80 & 0.50 \\
\hline V. kurtokalami & & & & & & \\
\hline fore leg & 1.20 & 1.05 & 0.40 & 1.40 & 1.20 & 0.40 \\
\hline mid leg & 3.30 & 1.90 & 1.20 & 3.70 & 2.15 & 1.35 \\
\hline hind leg & 3.60 & 1.65 & 0.56 & 3.70 & 1.88 & 0.52 \\
\hline$V$. nieseri sp. n. & & & & & & \\
\hline fore leg & 1.25 & 1.05 & 0.36 & 1.35 & 1.14 & 0.40 \\
\hline mid leg & 3.40 & 1.89 & 1.18 & 3.59 & 2.02 & 1.26 \\
\hline hind leg & 3.61 & 1.50 & 0.50 & 3.86 & 1.77 & 1.57 \\
\hline $\begin{array}{l}\text { V. heissisp. n. } \\
\text { fore leg }\end{array}$ & & & & & & \\
\hline $\begin{array}{l}\text { fore leg } \\
\text { mid leg }\end{array}$ & $\begin{array}{l}1.11 \\
3.20\end{array}$ & $\begin{array}{l}0.98 \\
1.73\end{array}$ & 0.37 & & & \\
\hline hind leg & 3.19 & 1.37 & 0.48 & & & \\
\hline V. imadatei & & & & & & \\
\hline fore leg & 1.30 & 1.00 & 0.34 & 1.18 & 1.10 & 0.36 \\
\hline mid leg & 3.50 & 1.94 & 1.18 & 3.48 & 1.90 & 1.28 \\
\hline hind leg & 3.69 & 1.40 & 0.43 & 3.57 & 1.36 & 0.48 \\
\hline$V$. yangae sp. n. & & & & & & \\
\hline fore leg & 1.15 & 1.02 & 0.39 & 1.00 & 0.96 & 0.36 \\
\hline mid leg & 3.20 & 1.75 & 1.12 & 2.85 & 1.58 & 1.25 \\
\hline hind leg & 3.28 & 1.30 & 0.48 & 3.30 & 1.44 & 0.44 \\
\hline Esakia ventidioic & & & & & & \\
\hline fore leg & 1.10 & 0.93 & 0.27 & 1.15 & 1.00 & 0.30 \\
\hline mid leg & 3.20 & 2.44 & 0.92 & 3.60 & 2.50 & 0.95 \\
\hline hind leg & 3.70 & 0.95 & 0.30 & 3.90 & 1.05 & 0.38 \\
\hline
\end{tabular}

Table 3. Measurements of pronotum of macropterous form of Ventidius species. For an explanation of the characters between parentheses, see fig. 2 .

Species Median humeral lateral lateral length (j) width (k) length (l) length (m)

\begin{tabular}{lllll}
\hline$V$. aquarius & 2.70 & 2.00 & 0.80 & 1.90 \\
$V$. usingeri & 1.95 & 2.00 & 0.98 & 1.58 \\
$V$. malayensis & 2.10 & 2.25 & 0.10 & 1.60 \\
$V$. henryi & 1.32 & 1.42 & 0.60 & 1.18 \\
$V$. hungerfordi & 1.40 & 1.51 & 0.64 & 1.51 \\
$V$. polhemorum & 1.40 & 1.54 & 0.70 & 1.10 \\
$V$. werneri & 1.60 & 1.70 & 0.50 & 1.30 \\
$V$. pilosus & 1.65 & 1.80 & 0.77 & 1.38 \\
$V$. modulatus & 1.61 & 1.65 & 0.71 & 1.40 \\
$V$. karen & 1.48 & 1.90 & 0.30 & 0.84 \\
$V$. pulai & 1.45 & 1.66 & 0.40 & 1.25 \\
$V$. xyele & 2.55 & 1.70 & 0.75 & 1.35 \\
$V$. xiphibion & 2.70 & 1.75 & 0.88 & 1.45 \\
$V$. kurtokalami & 1.67 & 1.73 & 0.79 & 1.38 \\
$V$. nieseri & 1.75 & 1.90 & 0.80 & 1.40 \\
\hline & & & &
\end{tabular}

